\title{
Evaluation and Testing of Eye, Nose, and Mouth Protection for Biological Hazards to Support a Consensus Standard
}

Jeremy R Gouzd

Follow this and additional works at: https://researchrepository.wvu.edu/etd

\section{Recommended Citation}

Gouzd, Jeremy R, "Evaluation and Testing of Eye, Nose, and Mouth Protection for Biological Hazards to Support a Consensus Standard" (2018). Graduate Theses, Dissertations, and Problem Reports. 7183. https://researchrepository.wvu.edu/etd/7183

This Dissertation is protected by copyright and/or related rights. It has been brought to you by the The Research Repository @ WVU with permission from the rights-holder(s). You are free to use this Dissertation in any way that is permitted by the copyright and related rights legislation that applies to your use. For other uses you must obtain permission from the rights-holder(s) directly, unless additional rights are indicated by a Creative Commons license in the record and/ or on the work itself. This Dissertation has been accepted for inclusion in WVU Graduate Theses, Dissertations, and Problem Reports collection by an authorized administrator of The Research Repository @ WVU.

For more information, please contact researchrepository@mail.wvu.edu. 
Evaluation and Testing of Eye, Nose, and Mouth Protection for Biological Hazards to Support a Consensus Standard

\author{
Jeremy R. Gouzd
}

Dissertation submitted to
College of Engineering and Mineral Resources
at West Virginia University
in partial fulfillment of the requirements
for the degree of

\title{
Doctor of Philosophy \\ In
}

Occupational Safety and Health

\author{
Gary Winn, Ph.D., Committee Chair \\ Xinjian He, Ph.D. \\ Travis Knuckles, Ph.D. \\ Kenneth Currie, Ph.D. \\ James Harris, Ph.D. \\ Ashish Nimbarte, Ph.D. \\ Department of Industrial and Management Systems Engineering
Morgantown, West Virginia
2018

Keywords: Eyewear, Eye Protection, Face Protection, PPE, Spurt, Spray

Copyright 2018 Jeremy R. Gouzd 


\title{
Abstract \\ Evaluation and Testing of Eye, Nose, and Mouth Protection for Biological Hazards to Support a Consensus Standard
}

\author{
Jeremy R. Gouzd
}

Eye protection is one of the greatest personal protective equipment items that has ever been made readily available to workers. In almost every occupation there will be some hazard that requires the worker to wear eye protection. Nearly three out of five injured workers were not wearing eye protection at the time of the accident or were wearing the wrong kind of eye protection for the job. Eye injuries alone cost more than $\$ 300$ million per year in lost production time, medical expenses and worker compensation (Matela, 2012). Eye protection should be integrated with other PPE to achieve head-to-toe protection. It should be fit to the individual worker or be adjustable so it can provide sufficient coverage. According to a BLS survey, 94 percent of the injuries to workers wearing eye protection resulted from objects or chemicals going around or under the protective device (Matela, 2012). When it comes to safety glasses, users need to know they've been rigorously tested, and held up to a set of industry standards. This knowledge allows wearers to be confident that their safety glasses will do their job, so workers can focus on the task at hand without worrying about whether their eyes are, in fact, protected. Whenever an employee or employer needs to reference standards on eye protection they generally are referred to ANSI Z87.1. Although this standard covers many occupational hazards there are still a few that are not addressed. These hazards are that of biological hazards such as blood borne pathogens. ANSI Z87.1 does not cover eye protectors for biological hazards. A committee was formed and concluded that a new standard ANSI Z87.62 standard will include a variety of testing procedures that mimic the different types of biological hazard exposures that can be experienced (spurt and spray). The most common occupations that are seen to have the highest incidence rate of these hazards projected at the workers eyes would be nurses, doctors performing procedures, dental healthcare workers, and laboratory workers in the health related research fields. A subcommittee has been formed to try and resolve this issue by creating a new standard, (ANSI Z87.62) to include a more detailed description of the proper eye and face protection that workers exposed to biological hazards should be using. A test apparatus, testing method, and standard for which eye and face protectors will be tested on, has been created in correlation to this standard to test that protectors are providing adequate worker protection. 


\section{Acknowledgments}

I would like to start by giving a special thank you to my wife, who continually reminded me to keep pushing through to the end and supported me all along this

journey. Without her, this would not have been possible. I also want to especially thank my parents; Mark and Lora Gouzd, who taught me how to be the hardest worker in the room and to strive for the greatest in every aspect of life.

I would like to thank the Centers for Disease Control and Prevention (CDC) and the National Institute for Occupational Safety and Health (NIOSH) for their generous support of my program. I would also like to especially acknowledge Dr. James Harris for his close guidance through this project.

I am also very appreciative of the expertise provided by the committee, Dr. Xinjian He, Dr. Travis Knuckles, Dr. Kenneth Currie, Dr. Ashish Nimbarte, and Dr. James Harris. A special note of appreciation goes to the chair of this committee, Dr. Gary Winn, for guiding me through the Ph.D. process and for motivating me to pursue graduate work in occupational safety and health. 


\section{Table of Contents}

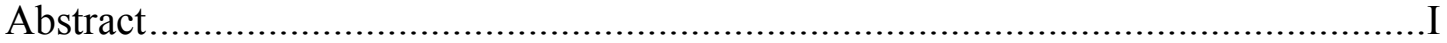

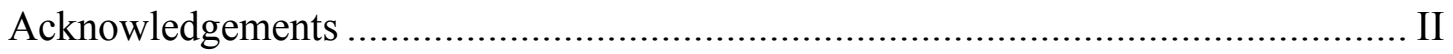

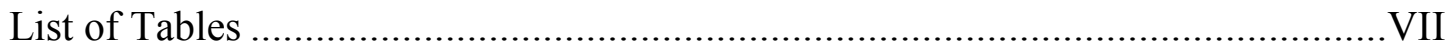

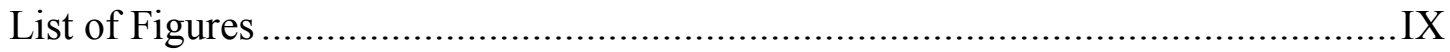

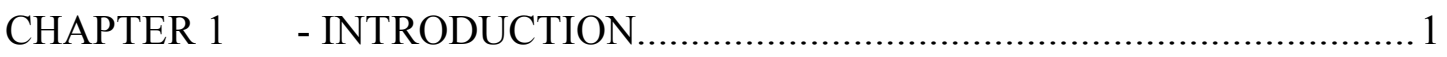

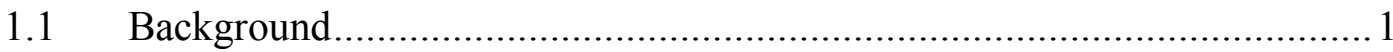

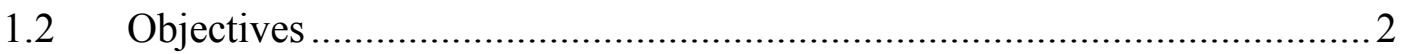

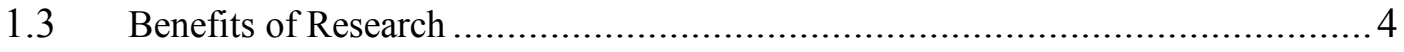

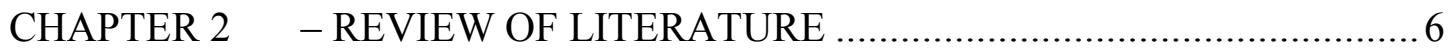

2.1 Blood Borne Pathogens; Not Covered In Standard - the problem ............... 6

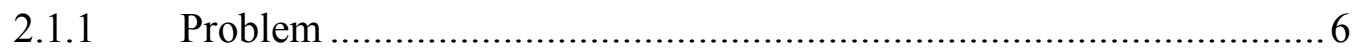

2.2 Identifying and Categorizing Workplace Hazards .......................................... 11

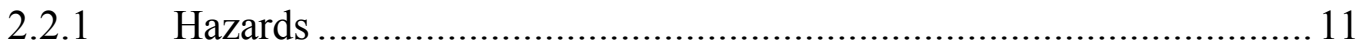

2.2.2 Transmission in the Workplace....................................................... 12

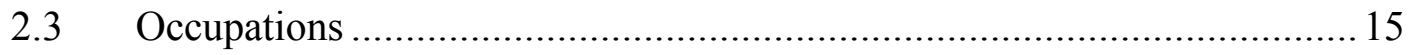

2.3.1 Surgeons / Physicians / Nurses (Involved in procedures) .................. 16

2.3.2 Dentist / Dental Care Workers....................................................... 21

2.3.3 Health Care / Laboratory Workers..................................................... 23

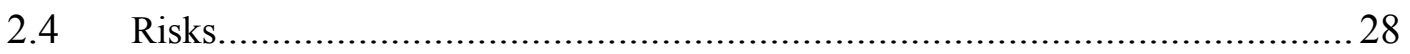

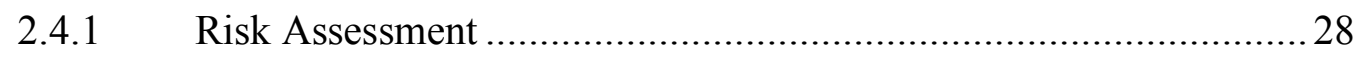

$2.5 \quad$ Summary

CHAPTER 3 - TEST APPRATUS / METHODS................................................ 32

3.1 General test setup study description........................................................ 32 


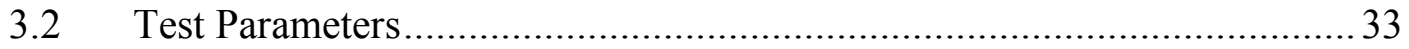

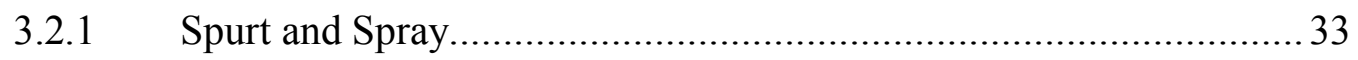

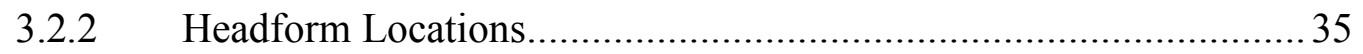

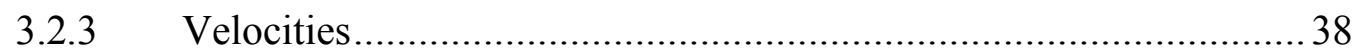

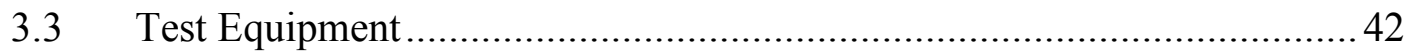

3.3.1 Anthropometric Headform......................................................... 43

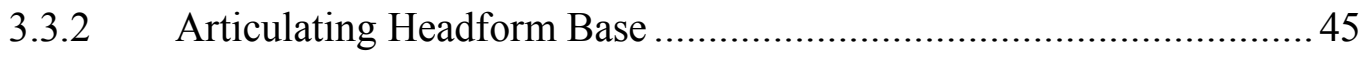

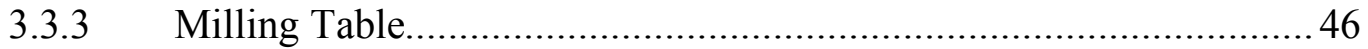

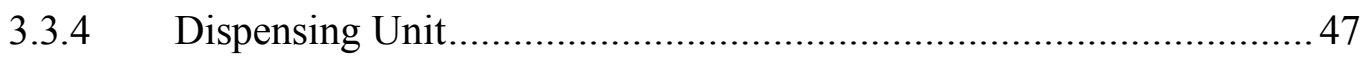

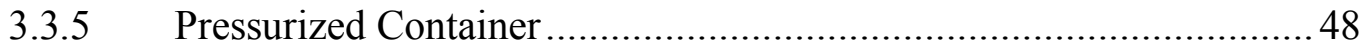

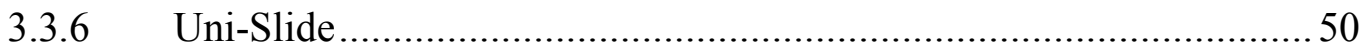

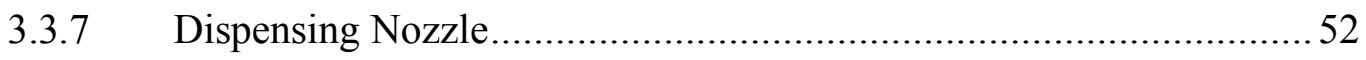

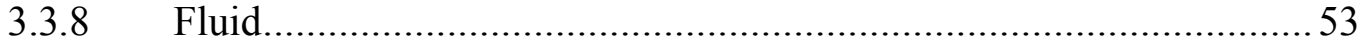

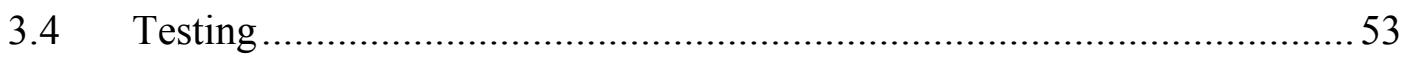

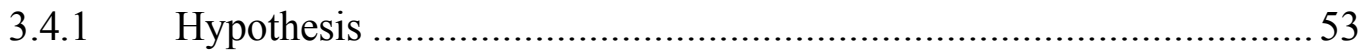

3.4.2 Eye and Face Protectors................................................................ 54

3.4.3 Test Criteria / Near Miss Ratings......................................................5

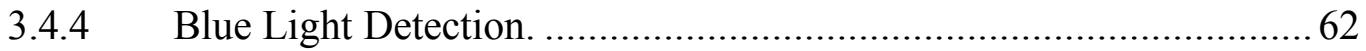

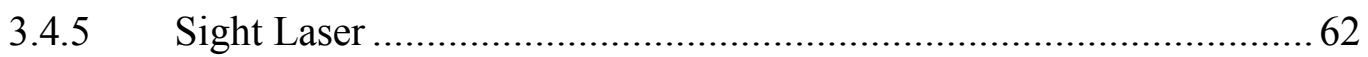

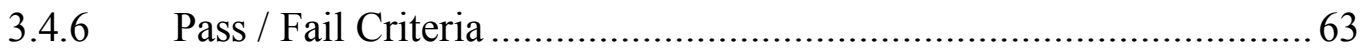

3.5 Defining Positions and Perimeters......................................................... 73

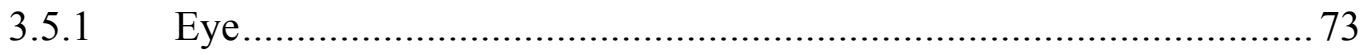

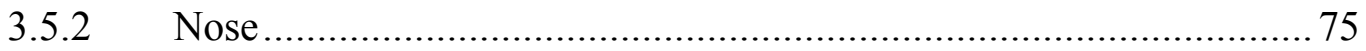

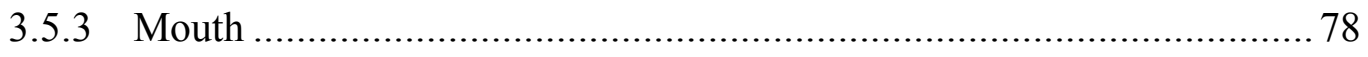




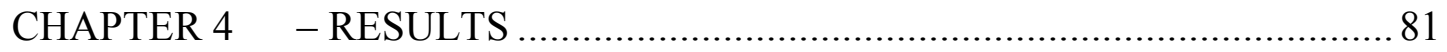

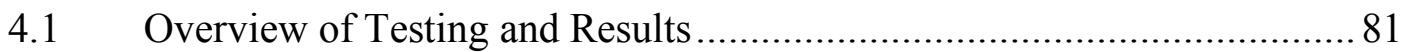

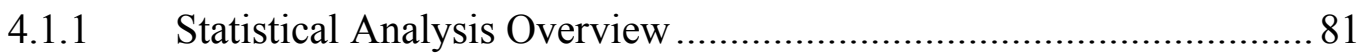

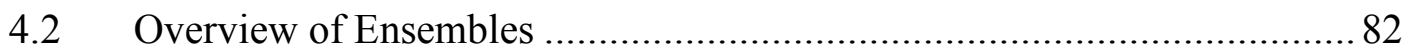

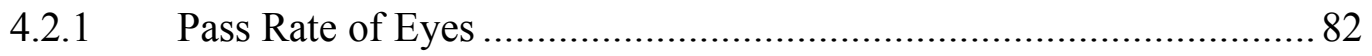

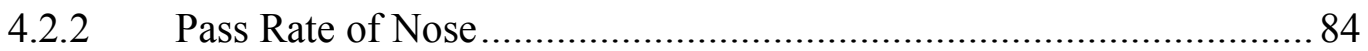

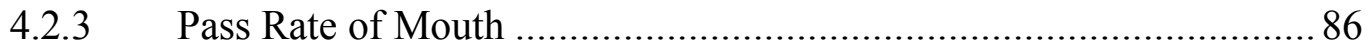

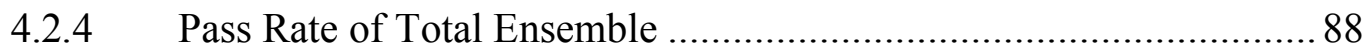

4.2.5 Left and Right Eye Failures ......................................................90

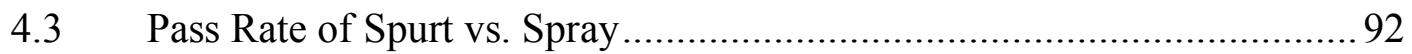

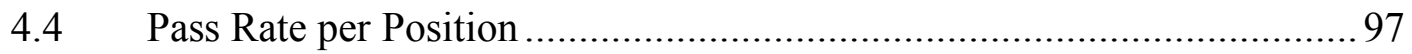

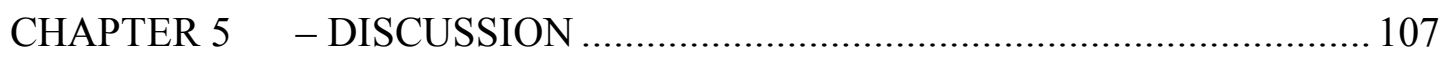

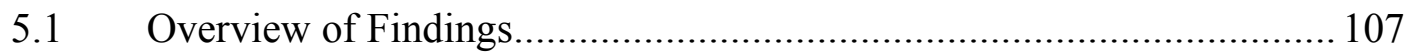

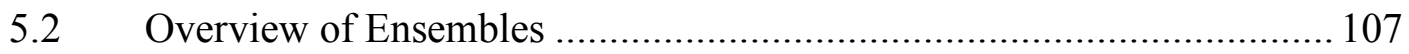

5.2.1 Total Pass Rate of Areas of Concern............................................. 107

5.2.2 Comparing Pass Rate of Areas of Concern .................................. 108

5.3 Left and Right Eye Comparison ........................................................ 109

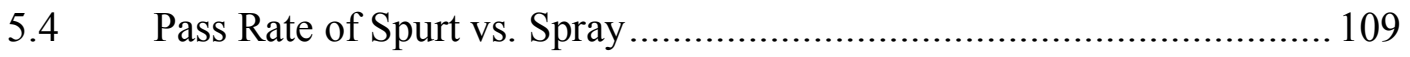

5.4.1 Pass Rate of Spurt vs. Spray - Eyes.............................................. 109

5.4.2 Pass Rate of Spurt vs. Spray - Nose ………………………....... 110

5.4.3 Pass Rate of Spurt vs. Spray - Mouth ……………….................. 110

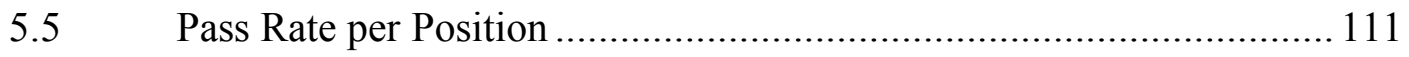

5.5.1 Pass Rate per Position - Eyes ................................................... 111

5.5.2 Pass Rate per Position - Nose................................................... 112

5.5.3 Pass Rate per Position - Mouth .................................................. 112

5.5.4 Total Pass Rate per Position per Area of Concern ........................ 112 


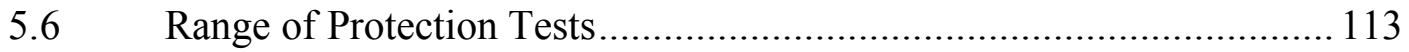

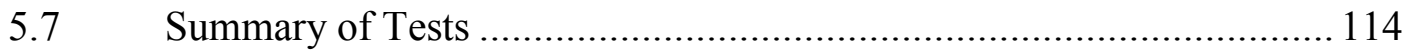

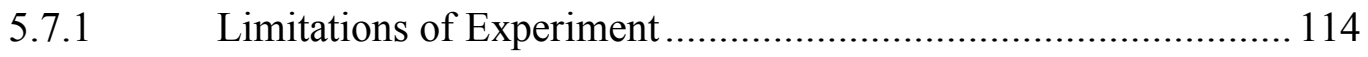

CHAPTER 6 -CONCLUSION AND RECOMMENDATIONS ......................116

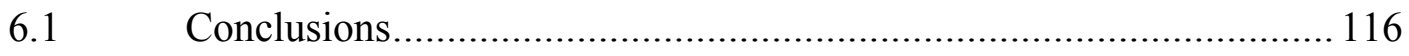

6.2 Recommendations for Future Work .................................................. 118

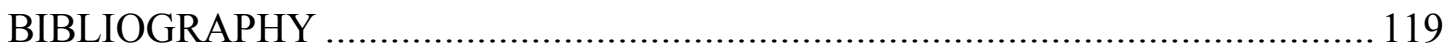

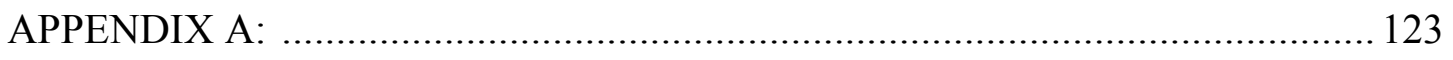

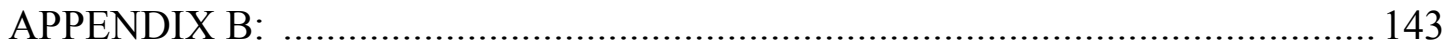

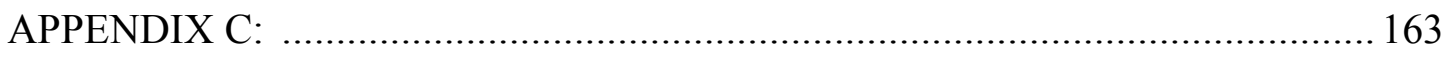

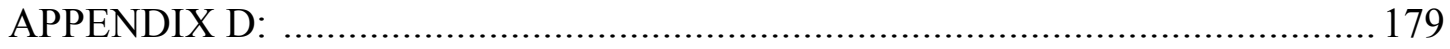

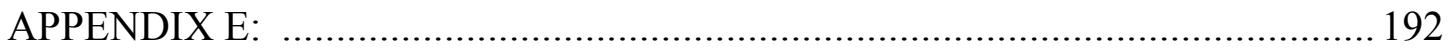




\section{List of Tables}

Table 2-1 Eye and Face Protector Selection Chart 1............................................ 9

Table 2-2 Eye and Face Protector Selection Chart 2 ........................................ 10

Table 2-3 Reports in Occupational Work Environment..................................... 16

Table 2-4 Exposed Medical Workers ............................................................... 17

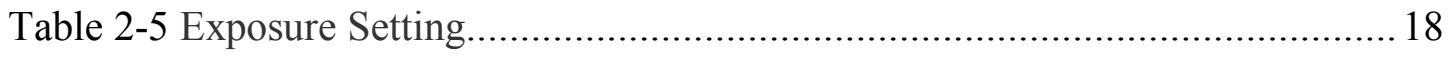

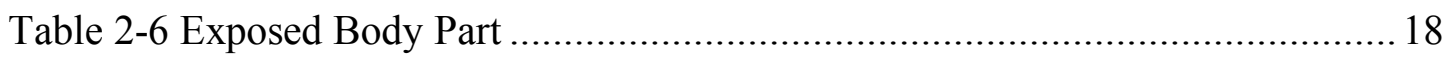

Table 2-7 Personal Experience With Facial Blood Splashes.................................. 20

Table 2-8 Health Care / Laboratory Exposure from Various Tasks ........................ 24

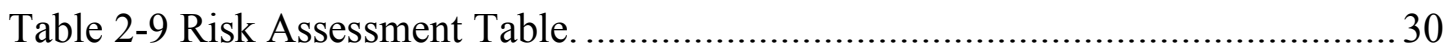

Table 3-1 European Anthropometric Headform Measurements............................. 44

Table 3-2 Eye Protector Data Sheet ............................................................... 58

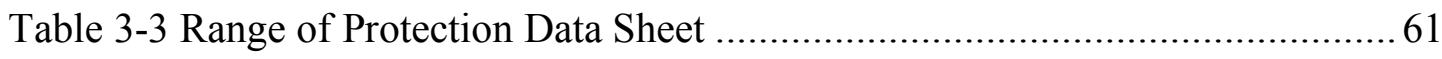

Table 3-4 Anthropometric Nose Landmarks ............................................... 76

Table 3-5 Nose Landmark Measurements ......................................................... 77

Table 3-6 Mouth Landmark Measurements........................................................ 80

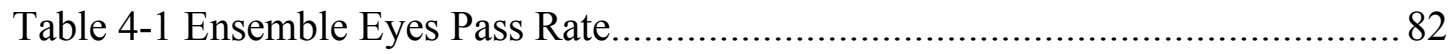

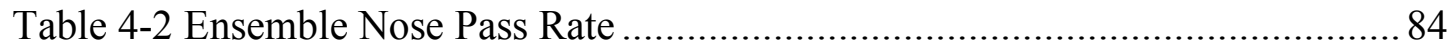

Table 4-3 Ensemble Mouth Pass Rate................................................................ 86

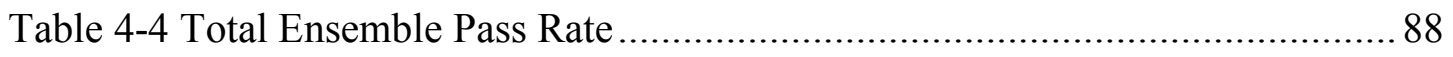


Table 4-5 Left and Right Eye Failures

Table 4-6 Left and Right Quadrant CI ............................................................ 90

Table 4-7 Left and Right Eye Statistical Analysis ............................................. 91

Table 4-8 Pass Rate of Eyes - Spurt vs. Spray ................................................. 92

Table 4-9 Pass Rate of Nose - Spurt vs. Spray.............................................. 93

Table 4-10 Pass Rate of Mouth - Spurt vs. Spray ........................................... 94

Table 4-11 Overall Ensemble Pass Rate of Spurt vs. Spray................................... 95

Table 4-12 CI of Overall Pass Rate of Spurt vs. Spray ........................................ 95

Table 4-13 Statistical Analysis of Spurt vs. Spray ........................................... 96

Table 4-14 Eyes Pass Rate per Position .............................................................. 97

Table 4-15 Eye Position Contrasts ........................................................... 97

Table 4-16 Nose Pass Rate per Position............................................................ 98

Table 4-17 Nose Positions Contrasts................................................................ 99

Table 4-18 Mouth Pass Rate per Position........................................................ 99

Table 4-19 Mouth Position Contrasts............................................................... 100

Table 4-20 Overall 95\% CI of Pass Distance per Ensemble for Eye Criteria ........... 104

Table 4-21 Random Number Generator for Testing Order ................................ 105

Table 5-1 Pass Rates of Range of Protection Tests............................................. 113 


\section{List of Figures}

Figure 1-1 Bottom Gap - Side View. ............................................................... 4

Figure 1-2 Bottom Gap - Bottom View........................................................ 4

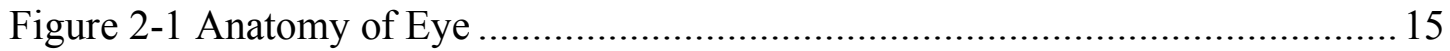

Figure 3-1 Spurt Cannula..................................................................................... 34

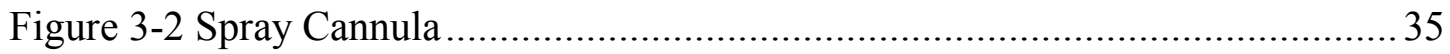

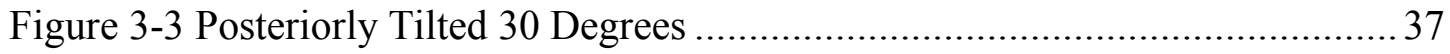

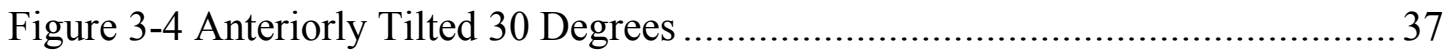

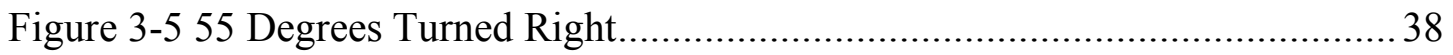

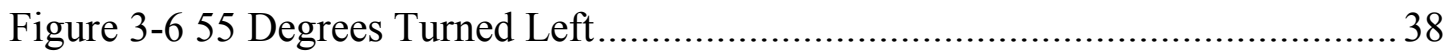

Figure 3-7 Excel Velocity Calculations and Table .................................................. 40

Figure 3-8 Predicted Velocity using Mass vs. cm/s with Upper / Lower Limit Lines 40

Figure 3-9 Predicted Velocity using PSI vs. cm/s................................................... 41

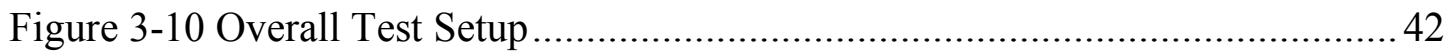

Figure 3-11 Headform Measurements ................................................................... 44

Figure 3-12 Anthropometric Headform............................................................... 45

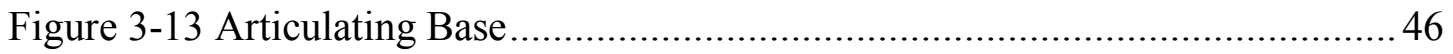

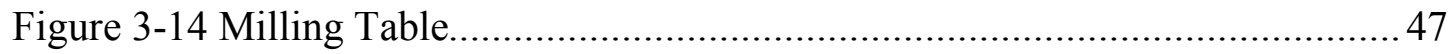

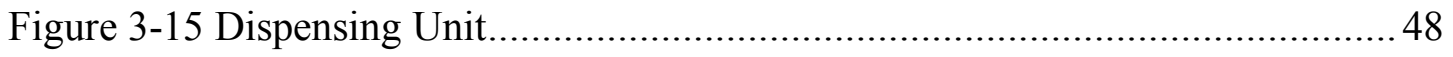

Figure 3-16 Pressurized Container ...................................................................... 49 
Figure 3-17 Uni-Slide

Figure 3-18 Nozzle .52

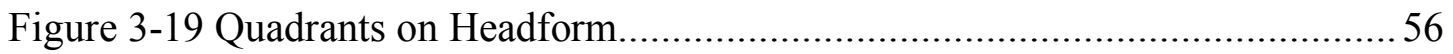

Figure 3-20 Range of Protection Horizontal .........................................................

Figure 3-21 Range of Protection Vertical..........................................................59

Figure 3-22 Laser Mounting to Uni-Slide Bracket .................................................. 62

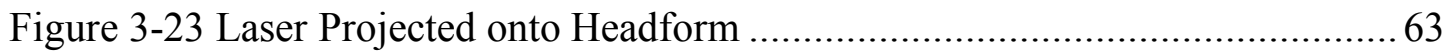

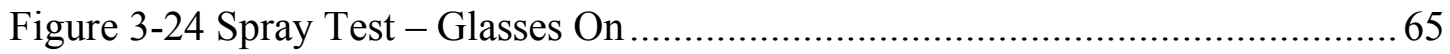

Figure 3-25 Eye Criteria Spray Test without Glasses- "Pass”.....................................66

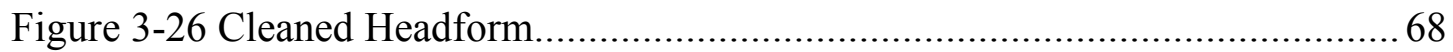

Figure 3-27 Spurt Test - Glasses On..................................................................... 69

Figure 3-28 Spurt Test without Glasses - "Fail" ................................................... 70

Figure 3-29 Spray in Real Time.................................................................. 71

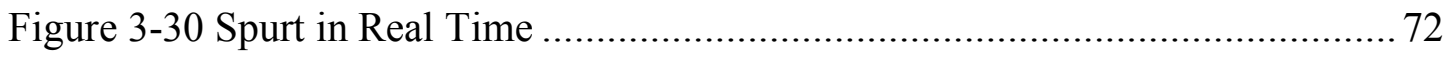

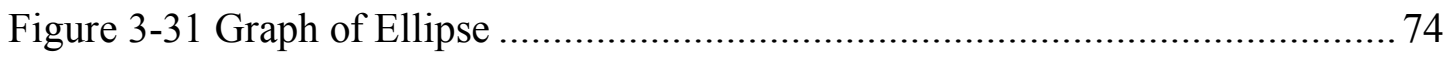

Figure 3-32 Average Eye Measurements ............................................................. 75

Figure 3-33 Anthropometric Nose Landmarks .................................................... 76

Figure 3-34 Nose Measurements of most Convex point - Points 4-5........................ 77

Figure 3-35 Anthropometric Mouth Landmarks.................................................. 79

Figure 3-36 Mouth Measurement between Left and Right Oral Commissure-Points

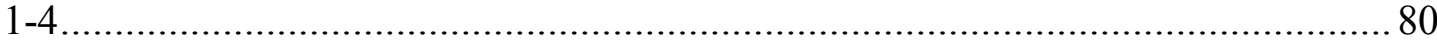


Figure 4-1 Eye Pass Rate

Figure 4-2 Nose Pass Rate 85

Figure 4-3 Mouth Pass Rate. 87

Figure 4-4 Total Ensemble Pass Rate

Figure 4-5 95\% Confidence Interval Plot of Ensembles Performance.

Figure 4-6 Left and Right Eye Failure 91

Figure 4-7 Pass Rate of Eye Criteria - Spurt vs. Spray. 92

Figure 4-8 Pass Rate of Nose Criteria - Spurt vs. Spray. 93

Figure 4-9 Pass Rate of Mouth Criteria - Spurt vs. Spray 94

Figure 4-10 Overall Ensemble Pass Rate of Spurt vs. Spray. 95

Figure 4-11 CI of Overall Pass Rate of Spurt vs. Spray. 96

Figure 4-12 Eyes Pass Criteria per Position 97

Figure 4-13 Nose Pass Criteria per Position 98

Figure 4-14 Mouth Pass Criteria per Position. 100

Figure 4-15 Total Pass Rate per Position per Area of Concern 101

Figure 4-16 Overall Total Pass Rate per Position..... 101 


\section{CHAPTER 1 - INTRODUCTION}

\subsection{Background}

The ANSI-ISEA Z87.1 American National Standard for Occupational and Educational Personal Eye and Face Protection Devices addresses many workplace hazards where eye and face protection is required. This standard is performance-based to allow for other designs and product types to be implemented to meet end user's needs. The standard also focuses on helping the end user select PPE that is most appropriate for his/her specific work environment.

ANSI Z87 committee has determined that a subcommittee needed to be formed to create a new standard. New test methods within the new ANSI Z87.62 standard will include a variety of testing procedures that mimic the different types of biohazard exposures that can be experienced (spurt and spray). ANSI has approved the ANSI Z87.62 subcommittee to look at "....criteria related to the general requirements, testing, permanent marking, selection, care and use of protectors to minimize or prevent exposure to the wearer's eyes and/or face caused by biological hazards including, but not limited to blood, body fluids or other potentially infectious materials (OPIMs) or microorganisms, viruses or toxins from a biological source that can affect human health. This standard is NOT intended to address hazards related to transmission of an infectious agent by particles, dust, or droplet nuclei that are suspended in the air, and which may require other additional forms of protection"(ANSI Z87.62). 
protection. In a vast majority of industry, workers are exposed to flying particles, liquid chemicals, gases or vapors, and blood borne pathogens. When a worker refers to ANSI Z87.1, it specifically states that blood borne pathogens are not covered in the standard.

"Certain hazardous exposures are not covered in this standard. These include, but are not limited to: blood borne pathogens, X-rays, high-energy particulate radiation, microwave, radio-frequency radiation, lasers, masers, and sports and recreation” (ANSI Z87.1).

\subsection{Objectives}

\section{Project Need}

This project is focusing on establishing minimum performance-oriented standard for a product that is widely used but for which no current standard exists for healthcare and related personnel, research facilities, or product manufacturers. Once minimum performance-oriented standards have been established, it will allow workers to be able to reference ANSI Z87.62 and have guidance for eye protectors for protection against biological hazards.

\section{Focus}

A subcommittee (ANSI Z87.62 Eye and Face Protection Used against Biological Hazards) has been formed to try and resolve this issue by creating a new standard, to include a more detailed description of the proper eye and face protection that workers exposed to biological hazards should be using. A testing method for eye and face protectors has been created to test that protectors are providing adequate worker 
protection.

In recent version and updates of the ANSI Z87.1 standards, protective eye wear are required to have efficient and easy-to-understand lens and frame markings. These markings help to make the selection process simpler and have increases in compliance (Eldridge 2017). All safety markings for ANSI Z87.1-2015 safety eyewear must be permanently and clearly marked on the frame or lens. This marking requirement includes goggles and face shields as well as safety glasses. A similar marking will be created to identify PPE that have been verified to protect against biological hazards.

Some of the types of biological hazards to workers in these types of working environments are debris, blood, and other bodily fluids. Very infrequently, a worker may choose to wear a face shield, which offers improved protection for debris as well as blood and other bodily splashes. This method is hardly ever used due to higher costs and many other inconveniences and discomforts caused to the wearer (Arsenault, 2016). In the Z87.1 standard, guidance for splash could lead a user choose to wear a face shield as well as a secondary protector such as safety glasses. If the worker does not need impact protection, this combination suggested by the standard could be unnecessary extra protection.

Dental care workers report routes of exposure most commonly in places where a user's glasses meet their mask. Front and side routes of entry are adequately blocked by a wearer's safety glasses, however, bottom and top gaps remain completely exposed. This puts the wearer at increased risk of exposure to blood borne pathogens (Arsenault, 2016). (See figure 1-1 and 1-2 below) 


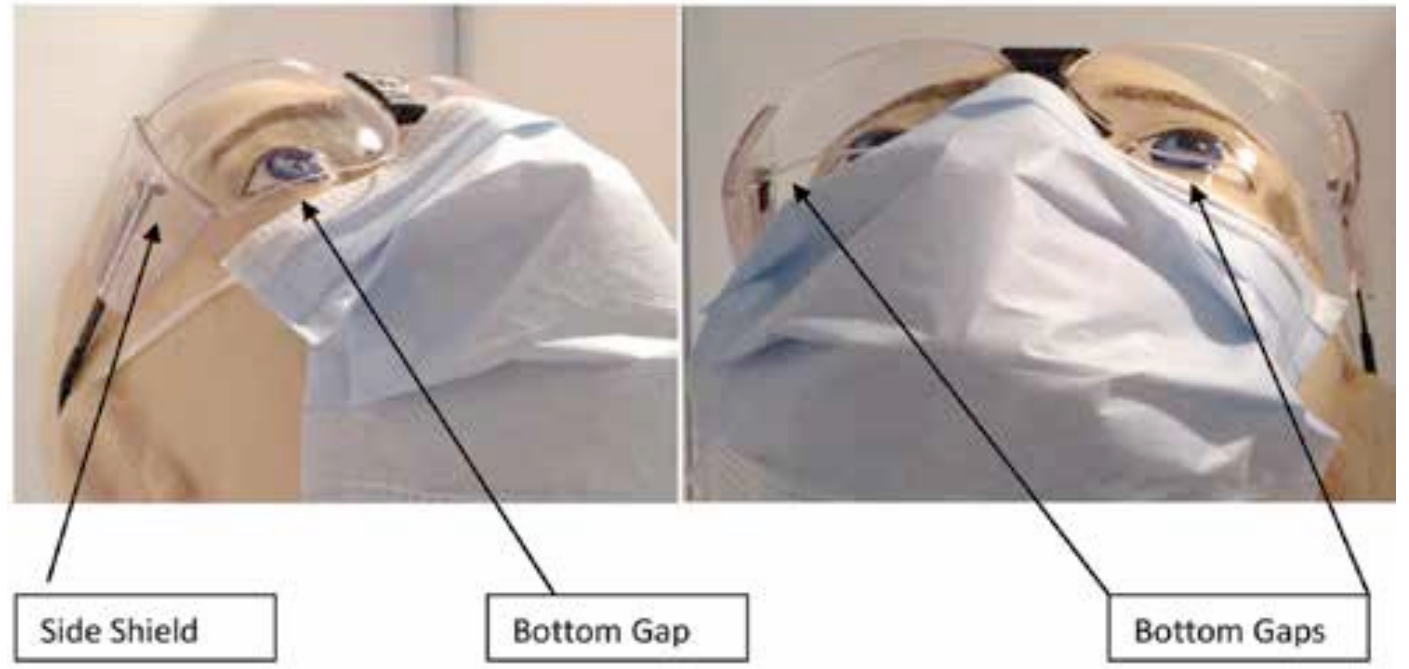

Figure 1-1: Bottom Gaps-Side View

Figure 1-2: Bottom Gaps- Bottom View

\subsection{Benefits of the research}

After completion of this project, we will be able to implement a standard into Z87.1 to protect a user from representative biological hazards and a establish minimum performance-oriented standard for a product that is widely used for which a new and current standard will exist for healthcare and related personnel; research and healthcare facilities; product manufacturers. We will also be able to set forth criteria related to the general requirements, testing, permanent marking, selection, care and use of protectors to minimize or prevent exposure to the wearer's eyes and/or face caused by biological hazards including, but not limited to blood, body fluids or other potentially infectious materials (OPIMs) or microorganisms, viruses or toxins from a biological source that 
can affect human health. This project's main objective is to establish a standard testing apparatus that all tests will be performed on or of a similar and equivalent testing apparatus to ensure concise and consistent testing across the broad spectrum of safety manufacturers and end users. It is designed to simulate high risk occupations with biological hazards and where eye and face PPE are worn. After the completion of the test apparatus and results have been obtained, these methods and data will provide input to the ANSI Z87.62 standard. 


\section{CHAPTER 2 - REVIEW OF LITERATURE}

\subsection{Blood Borne Pathogens; Not Covered In Standard - the problem}

\subsubsection{Problem}

Blood poses high risk to health in a laboratory or clinical setting due to transmissions in the workplace when infected person's blood enters another person's bloodstream through an open wound or a mucous membrane. These risks are greatest among healthcare workers, including: nurses, surgeons, laboratory assistants, doctors, phlebotomists, and laboratory technicians. Some standard precautions when working in and around these occupational hazards are to use the universal precautions. Universal precautions is an approach to infection control to treat all human blood and certain human body fluids as if they were known to be infectious for HIV, HBV and other blood borne pathogens. One of the best ways to prevent and protect yourself from infected blood is to wear appropriate personal protective equipment: gloves, goggles, etc. as required.

Many different job environments are covered in great detail in ANSI Z87.1 and end users are provided with ample amounts of information for selecting the correct eye and face protectors. However, within ANSI-ISEA Z87.1 there is no information on the use of protectors to aid against the risk of working with biological hazards such as blood borne pathogens.

Inside the OSHA general requirements standard "1910.133," it states;

$1910.133(a)$ 
General requirements.

1910.133(a) (1)

The employer shall ensure that each affected employee uses appropriate eye or face protection when exposed to eye or face hazards from flying particles, molten metal, liquid chemicals, acids or caustic liquids, chemical gases or vapors, or potentially injurious light radiation.

1910.133(a) (2)

The employer shall ensure that each affected employee uses eye protection that provides side protection when there is a hazard from flying objects. Detachable side protectors (e.g. clip-on or slide-on side shields) meeting the pertinent requirements of this section are acceptable.

1910.133(a) (3)

The employer shall ensure that each affected employee who wears prescription lenses while engaged in operations that involve eye hazards wears eye protection that incorporates the prescription in its design, or wears eye protection that can be worn over the prescription lenses without disturbing the proper position of the prescription lenses or the protective lenses.

1910.133(a) (4)

Eye and face PPE shall be distinctly marked to facilitate identification of the manufacturer.

$1910.133(b)$ 
Criteria for protective eye and face protection.

1910.133(b) (1)

Protective eye and face protection devices must comply with any of the following consensus standards:

1910.133(b) (1)(i)

ANSI/ISEA Z87.1-2010, Occupational and Educational Personal Eye and Face Protection Devices, incorporated by reference in $\S 1910.6$;

1910.133(b) (1) (ii)

ANSI Z87.1-2003, Occupational and Educational Personal Eye and Face Protection Devices, incorporated by reference in $§ 1910.6$; or

1910.133(b) (1) (iii)

ANSI Z87.1-1989 (R-1998), Practice for Occupational and Educational Eye and Face Protection, incorporated by reference in $§ 1910.6$;

1910.133(b) (2)

Protective eye and face protection devices that the employer demonstrates are at least as effective as protective eye and face protection devices that are constructed in accordance with one of the above consensus standards will be deemed to be in compliance with the requirements of this section (UNITED STATES DEPARTMENT OF LABOR).

When a worker goes to ANSI Z87.1, they will find a chart (as shown below-Table 1 and Table 2) which covers most all things that could be found in a working 
environment except for biological hazards. Within ANSI Z87.1, a worker would also

find information on "Hazard Assessment" which gives a brief overview of how to

correctly conduct an assessment. It also gives information on "Identifying Sources of

Hazards" during a working conditions walk through. This summary of "Identifying

Sources of Hazards," even includes a section for "dust, sparks, spray, and mist," but

these are for non-biohazardous particles (Table 2-1 and Table 2-2; ANSI Z87.62, pg.

46-52).

\begin{tabular}{|c|c|c|c|}
\hline Hazard & Protectors & Limitations & Marking1 \\
\hline \multicolumn{4}{|c|}{ MPACT - Chipping, grinding, machining, masonry work, riveting, and sanding } \\
\hline $\begin{array}{l}\text { Flying fragments, objects, } \\
\text { large chips, particles, } \\
\text { sand, dirt, etc. }\end{array}$ & $\begin{array}{l}\text { - Spectacles with side protection } \\
\text { - Goggles with direct or indirect } \\
\text { ventlation } \\
\text { - Faceshield worn over spectacles } \\
\text { or goggles } \\
\text { - Welding helmet worn over spec- } \\
\text { tacles or goggles } \\
\text { - Loose-fitting respirator worn over } \\
\text { spectacles or goggles } \\
\text { - Ful-facepiece respirators }\end{array}$ & $\begin{array}{l}\text { Caution should be exercised in the use of } \\
\text { metal frame protective devices in electri- } \\
\text { cal hazard areas. Metal frame protective } \\
\text { devices could potentially cause electrical } \\
\text { shock and electrical burn through contact } \\
\text { with, or thermal bums from exposure to } \\
\text { the hazards of electrical energy, which } \\
\text { include radiation from accidental arcs. } \\
\text { To provide adequate protection, ensure } \\
\text { goggles fit tightly to the face. } \\
\text { Atmospheric conditions and the restricted } \\
\text { ventilation of a protector can cause } \\
\text { lenses to fog. Frequent cleaning may be } \\
\text { required. }\end{array}$ & $\begin{array}{l}\text { Impact rated: } \\
+ \text { (spectacle lens) } \\
\mathrm{Z} 87+\text { (all other lens) } \\
\mathrm{Z} 87+\text { (plano frame) } \\
\mathrm{Z} 87-2+\text { (Rx frame) }\end{array}$ \\
\hline \multicolumn{4}{|c|}{ HEAT - Fumace operations - pouring, casting, hot dipping, gas cutting, and welding } \\
\hline Hot sparks & $\begin{array}{l}\text { - Spectacles with side protection } \\
\text { - Goggles with direct or indirect } \\
\text { ventlation } \\
\text { - Faceshield worn over specta- } \\
\text { cles or goggles } \\
\text { - Loose-fitting respirator worn over } \\
\text { spectacles } \\
\text { - Ful-facepiece respirator }\end{array}$ & $\begin{array}{l}\text { Spectacles, cup and cover type goggles } \\
\text { do not provide unlimited facial protection. } \\
\text { Operations involving heat may also in- } \\
\text { volve optical radiation. Protection from } \\
\text { both hazards shall be provided. }\end{array}$ & $\begin{array}{l}\text { NOTE: There are cur- } \\
\text { rently no marking des- } \\
\text { ignations for eye pro- } \\
\text { tection to heat or high- } \\
\text { temperature exposure } \\
\text { in the ANSI/ISEA } \\
\text { Z87.1-2015 standard. }\end{array}$ \\
\hline Splash from molten metal & $\begin{array}{l}\text { - Faceshield worn over goggles } \\
\text { - Loose-fitting respirator worn over } \\
\text { spectacles or goggles } \\
\text { - Ful-facepiece respirator }\end{array}$ & & \\
\hline
\end{tabular}

Table 2- 1: Eye and Face Protector Selection Guide 1 


\begin{tabular}{|l|l|l|l|}
\hline \multicolumn{1}{|c|}{ Hazard } & \multicolumn{1}{c|}{ Protectors } & Limitations & Marking $^{1}$ \\
\hline $\begin{array}{l}\text { High temperature expo- } \\
\text { sure }\end{array}$ & $\begin{array}{l}\text { - Screen faceshield over specta- } \\
\text { cles or goggles } \\
\text { - Reflective faceshield over spec- } \\
\text { tacles or goggles }\end{array}$ & & \\
\hline
\end{tabular}

\section{CHEMICAL - Liquids, acid and chemical handling, degreasing, plating.}

\begin{tabular}{|l|l|l|l|}
\hline $\begin{array}{l}\text { Splash, droplets and } \\
\text { sprays }\end{array}$ & $\begin{array}{l}\text { - Goggles with indirect ventilation } \\
\text { (eyecup or cover type) } \\
\text { - Faceshield worn over goggles) } \\
\text { - Loose-fitting respirator worn over } \\
\text { spectacles or goggles } \\
\text { - Ful-facepiece respirator }\end{array}$ & $\begin{array}{l}\text { Atmospheric conditions and the restricted } \\
\text { ventilation of a protector can cause } \\
\text { lenses to fog. Frequent cleaning may be } \\
\text { required. }\end{array}$ & $\begin{array}{l}\text { Splash/droplet: D3 } \\
\text { To provide adequate protection, ensure } \\
\text { goggles fit tightly to the face. }\end{array}$ \\
\hline Irritating Mist & $\begin{array}{l}\text { - Goggle with no ventlation (cover } \\
\text { type) } \\
\text { - Faceshield worn over goggles } \\
\text { - Loose-fitting respirator worn over } \\
\text { spectacles or goggles } \\
\text { - Ful-facepiece respirator }\end{array}$ & $\begin{array}{l}\text { Atmospheric conditions and the restricted } \\
\text { ventilation of a protector can cause } \\
\text { lenses to fog. Frequent cleaning may be } \\
\text { required. }\end{array}$ & $\begin{array}{l}\text { NOTE: There are cur- } \\
\text { rently no marking des- } \\
\text { ignations for eye pro- } \\
\text { tection to Irritating mists } \\
\text { exposure in the } \\
\text { ANSI//SEA Z87.1-2015 } \\
\text { standard. }\end{array}$ \\
\hline goggles fit tightly to the face.
\end{tabular}

\section{DUST - Woodworking, buffing, general dusty conditions}

\begin{tabular}{|c|c|c|c|}
\hline Nuisance dust & $\begin{array}{l}\text { - Goggles with direct or indirect } \\
\text { ventlation (eyecup or cover } \\
\text { type) } \\
\text { - Ful-facepiece respirator }\end{array}$ & $\begin{array}{l}\text { Atmospheric conditions and the restricted } \\
\text { ventilation of a protector can cause } \\
\text { lenses to fog. Frequent cleaning may be } \\
\text { required. } \\
\text { To provide adequate protection, ensure } \\
\text { goggles fit tightly to the face. }\end{array}$ & Dust D4 \\
\hline Fine dust & $\begin{array}{l}\text { - Goggles with indirect ventilation } \\
\text { or no ventlation } \\
\text { - Ful-facepiece respirator }\end{array}$ & $\begin{array}{l}\text { To provide adequate protection, ensure } \\
\text { goggles fit tightly to the face. }\end{array}$ & Fine dust: D5 \\
\hline \multicolumn{4}{|l|}{ OPTICAL RADIATION } \\
\hline Infrared Radiation (IR) & $\begin{array}{l}\text { - Spectacles with side protection } \\
\text { - Goggles with direct or indirect } \\
\text { ventlation } \\
\text { - Faceshield worn over spectacles } \\
\text { or goggles } \\
\text { - Welding helmet worn over spec- } \\
\text { tacles or goggles } \\
\text { - Loose-fitting respirator worn over } \\
\text { spectacles or goggles } \\
\text { - Ful-facepiece respirators }\end{array}$ & $\begin{array}{l}\text { For proper fit of protector, there shall be } \\
\text { no penetration of direct infrared spectra } \\
\text { light in all non-lens areas. } \\
\text { Side shields shall have filtering capability } \\
\text { equal to or greater than the front lenses. }\end{array}$ & $\begin{array}{l}\text { IR: } \mathbf{R} \text { and scale num- } \\
\text { ber }\end{array}$ \\
\hline
\end{tabular}

Table 2-2: Eye and Face Protector Selection Guide 2 
In the OSHA standard, it dictates that an employer must provide appropriate eye protection, which then leads the worker to ANSI for its descriptions of hazards and selections of different protectors. The selection guide for these protectors doesn't include all possible routes of entry (front, side, bottom, and top) or biological hazards such as blood borne pathogens. Since the standard calls for the employer to supply the employee with the most appropriate eye protector, they then would need to provide an eye protector that encompasses all entry routes and hazards such as blood borne pathogens.

\subsection{Identifying and Categorizing Workplace Hazards}

\subsubsection{Hazards}

Healthcare personnel are at risk for occupational exposure to blood borne pathogens. Blood borne pathogens are pathogenic microorganisms present in the human blood that can lead to diseases. The primary concerns of blood borne pathogens are hepatitis B virus (HBV), hepatitis $\mathrm{C}$ virus (HCV), and human immunodeficiency virus (HIV). HBV causes serious liver disease (Hepatitis B), which can become a chronic condition that causes permanent scarring of liver, leading to liver failure or liver cancer; there are an estimated 2,000-4,000 deaths per year in U.S.(CDC, 2015). HBV is much more transmissible than HIV and 50\% of infected people are unaware that they have HBV (CDC, 1997). Hepatitis C Virus (HCV) attacks the liver and leads to inflammation. Chronic infection develops in $75 \%-85 \%$ of patients with $70 \%$ developing active liver disease (CDC n.d.), and can result in long-term health problems, even death. Most 
infected people have no symptoms and don't know they are infected until decades later when liver damage shows up in routine tests. Human Immunodeficiency Virus (HIV) causes Acquired Immunodeficiency Syndrome (AIDS) and attacks the immune system cells which weakens and eventually destroys the immune system thus, leaving the body at higher risk of developing serious conditions such as pneumonia or cancer. It is estimated that close to 1 in 5 are unaware they are infected. Once a person is infected, the human body cannot get rid of the HIV completely. Some people experience flu-like symptoms (fever, chills, rash, night sweats, muscle aches, sore throat, fatigue, swollen lymph nodes, or mouth ulcers) 2-4 weeks after infection, while others may not feel sick and be unware of their infection (CDC, 2015).

\subsubsection{Transmission in the Workplace}

In most work situations, transmission is most likely to occur because of accidental puncture from contaminated needles, broken glass, or other sharps; contact between broken or damaged skin and infected body fluids; or contact between mucous membranes and infected body fluids. For example, if someone infected with HBV cut their finger on a piece of glass, and then you cut yourself on the now infected piece of glass, it is possible that you could contract the disease. Anytime there is blood-to-blood contact with infected blood or body fluids, there is a slight potential for transmission. Unbroken skin forms an impervious barrier against blood borne pathogens. However, infected blood can enter your system through:

- Open sores

- Cuts

- Abrasions

- Acne 
- Any sort of damaged or broken skin such as sunburn or blisters

Blood borne pathogens may also be transmitted through the mucous membranes of the eyes, nose and mouth. Important factors that influence the overall risk for occupational exposures to blood borne pathogens include the number of infected individuals in the patient population and the type and number of blood contacts. Most exposures do not result in infection. Following a specific exposure, the risk of infection may vary with factors such as these:

- The pathogen involved

- The type of exposure

- The amount of blood involved in the exposure

- The amount of virus in the patient's blood at the time of exposure

Using appropriate barriers such as gloves, eye and face protection, or gowns when contact with blood is expected can prevent many exposures to the eyes, nose, mouth, or skin.

Exposure to blood-borne pathogens poses a serious risk to health care workers (HCWs). Assessment of the risk of blood-borne pathogen transmission in the health care setting requires information derived from various sources, including surveillance data, studies of the frequency and preventability of blood contacts, seroprevalence studies among patients and HCWs, and prospective studies that assess the risk of seroconversion after an exposure to infected blood. Factors influencing the risk to an individual HCW over a lifetime career include the number and types of blood contact experienced by the worker, the prevalence of blood-borne pathogen infection among patients treated by the worker, and the risk of transmission of infection after a single blood contact. 
There are many modes of blood-borne pathogen transmission in the health care setting; blood-borne pathogen transmission occurs predominantly by percutaneous or mucosal exposure of workers to the blood or body fluids of infected patients (American Red Cross, 2001). Occupational exposures that may result in HIV, HBV, or HCV transmission include needle stick and other sharps injuries; direct inoculation of virus into cutaneous scratches, skin lesions, abrasions, or burns; and inoculation of virus onto mucosal surfaces of the eyes, nose, or mouth through accidental splashes. HIV, $\mathrm{HBV}$, and $\mathrm{HCV}$ do not spontaneously penetrate intact skin, and airborne transmission of these viruses does not occur.

The mode of transmission that this study is most concerned and directed towards is transmission through the eye, nose or mouth. If the conjunctiva of the eye is compromised; bacteria, viruses, and fungi can easily penetrate into the eye, blood vessels, or vitreous / aqueous humor. These risks are exacerbated by abrasions, swelling, allergies, infection, inflammation, dryness, conjunctivitis, sty, recent surgery, and workers who wear contacts. Below is Figure 2-1 that outlines the eye and its anatomy. The possible routes of transmission for the eyes are highlighted. 


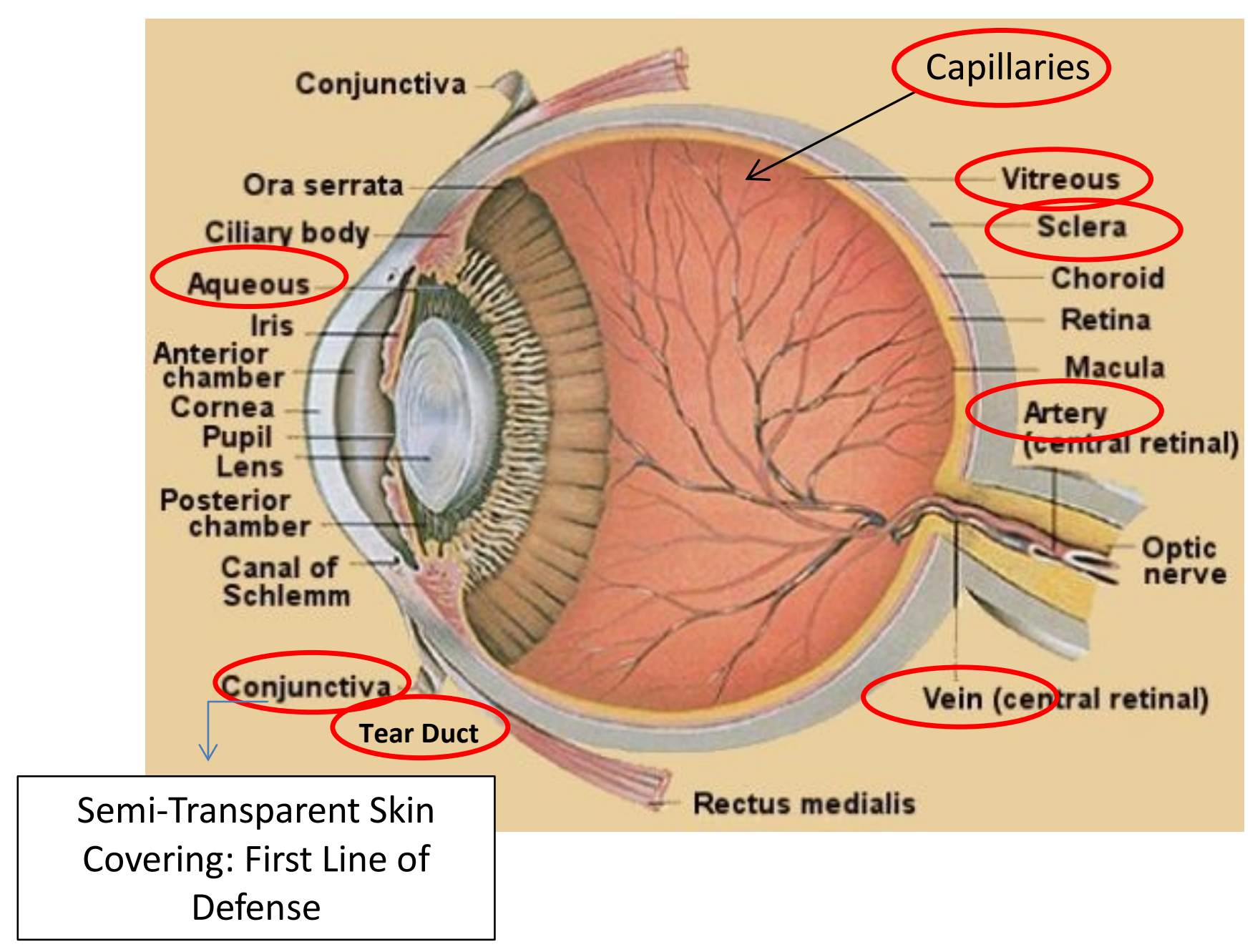

Figure 2-1: Anatomy of Eye

Source: (Mitchell 2016)

https://www.lhup.edu/ dsimanek/scenario/labman3/eye.htm

\subsection{Occupations}

High Hazard occupations that use eye and face protection can be sorted and analyzed based on a risk assessment and the most common biological hazard that is seen with each situation. The broad range of hazards that are being compared are propelled droplets, splashes, sprays, and other potentials infectious materials. The most common occupations that are seen to have the highest incidence rate of these hazards projected at the workers eyes would be nurses, doctors performing procedures, dental healthcare 
workers, and laboratory workers in the health related research fields (Mitchell 2016). Below is Table 2-3 which summarizes what specific occupational work environment gets the most exposure, subsequent infections, illnesses, and seroconversions.

\begin{tabular}{|c|c|}
\hline ICU & Influenza, HIV \\
\hline ER / Isolation & SARS \\
\hline Patient Room & HBV \\
\hline Lab / Research & Herpes B Virus \\
\hline Lab / Diagnostic & HIV, HCV \\
\hline Lab & Plague \\
\hline Ortho Surgery & Hepatitis, HIV \\
\hline Dental & HIV \\
\hline Security / Police & HCV \\
\hline Veterinary & Rabies \\
\hline Relief Workers & Ebola \\
\hline
\end{tabular}

Table 2-3: Reports in Occupational Work Environment

Source: (Mitchell 2016)

\subsubsection{Surgeons / Physicians / Nurses (Involved in procedure)}

The risk of blood borne pathogen transmission through accidental exposure is low, it is still at $0.5 \%$ for needle stick injury with percutaneous needles and at $0.1 \%$ for mucous membrane exposure (Beltrami et al., 2000). This mucous membrane exposure can be transmitted through ocular contact. While most surgeons take precautions to avoid needle stick injuries, potential infection via fluid exposure to the eyes might not be as well recognized 
as a hazard. Non sharps (mucocutaneous) exposure poses a problem as well. Such exposure can arise from incidents ranging from accidental splashing of blood into the eyes or a skin cut when starting or removing an I.V. catheter to disposing of body fluids or dressing an open wound. A 2003 study found nurses had a higher mucocutaneous exposure rate than physicians and medical technologists. More than one-third (39\%) of registered nurses and one-fourth (27\%) of licensed practical nurses said they'd experienced one or more mucocutaneous blood exposures in the previous 3 months_-but few reported their exposures (Delisio, 2017).

Looking at statistical data that categorizes the occupation of medical personal from the International Safety Center, one can see that the Doctors and Nurses are the highest exposed workers (Table 2-4).

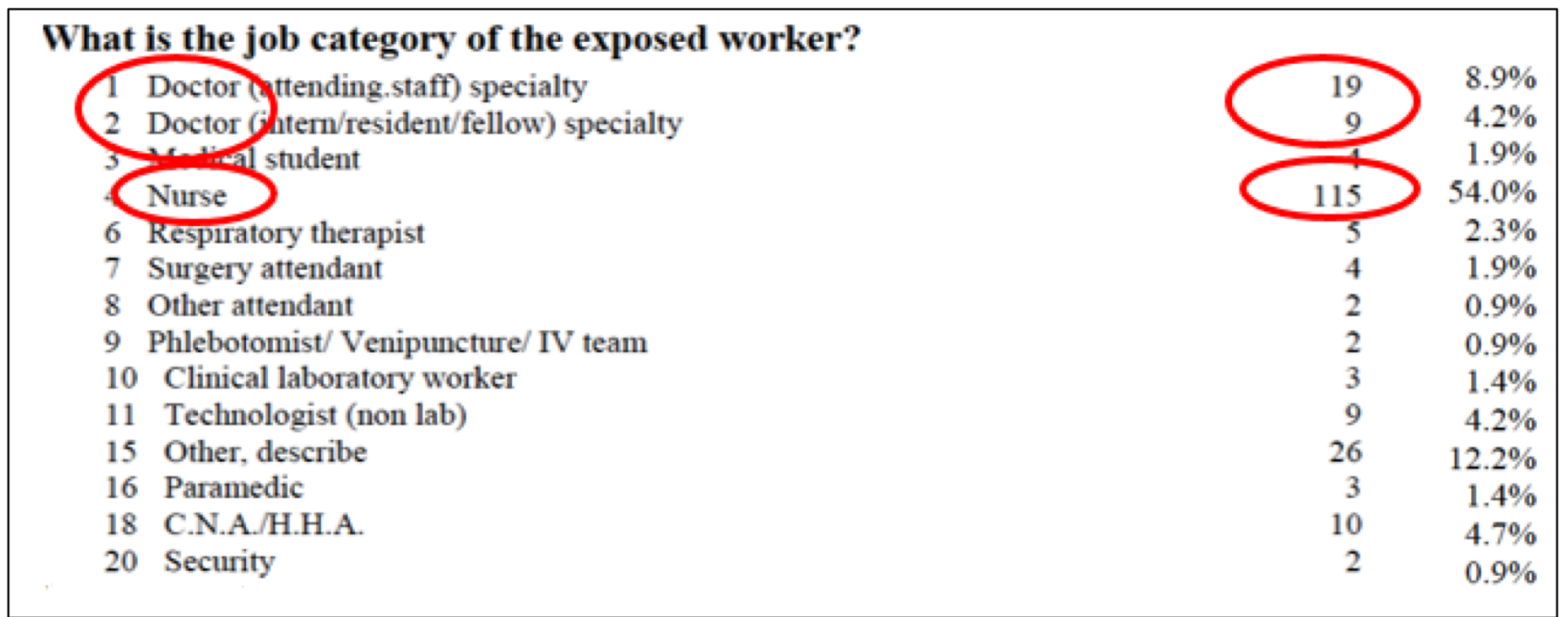

Table 2-4: Exposed Medical Workers

Source: (Mitchell 2016)

The data goes in depth to show where the exposure occurred. As seen, direct patient 
care is the greatest cause of splashes. This is due to the fact that patients have a lot of fluid, i.e. these exposure are happening where the patients are. $75.6 \%$ are from direct patient contact (Table 2-5). Furthermore in Table 2-6, data shows that the eyes or conjunctiva is the most exposed part in the total records at $65.7 \%$.

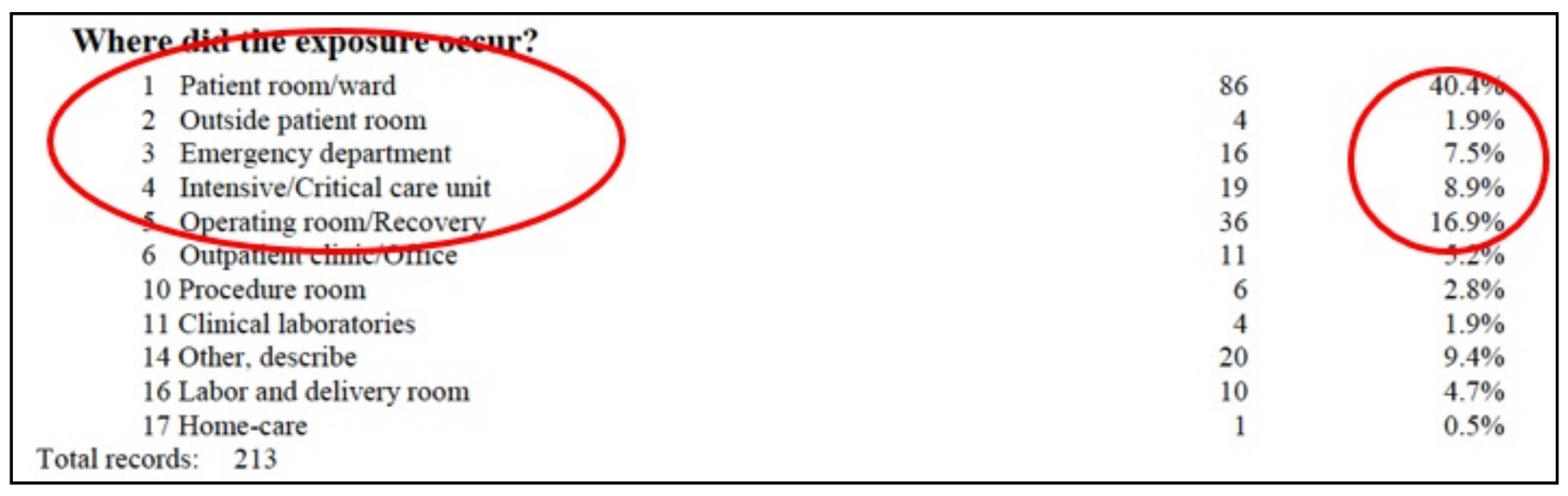

Table 2-5: Exposure Setting

Source: (Mitchell 2016)

\section{Was the exposed part?}

Intact skin

Non-intact skin

Eyes (conjunctiva)

Nose (mucosa)

Mouth (mucosa)

Other exposed parts

Total records: 216
$23.1 \%$

$13.4 \%$

$65.7 \%$

$3.7 \%$

$7.9 \%$

$10.2 \%$

Table 2-6: Exposed Body Part

Source: (Mitchell 2016)

In a study that was done to quantify how frequently body fluids splash the mask and lens of protective glasses it was found that from a total of 384 operations, $174(45 \%)$ showed blood or body fluid splash on the lens (Davies, 2007). A high incidence of 
splashes was found in vascular surgical procedures (79\%). All amputations showed splashes onto the protective lens of the eye protector. Also, the study showed that $50 \%$ of laparoscopic cases resulted in blood or body fluid splash on the protective lens (Davies, 2007). This study demonstrated that an overall $45 \%$ risk of blood and bodily fluid splash on protective spectacle lens during surgery. This agrees with previous studies where blood splash contamination recorded on spectacles and protective eye shields has varied from $25-51 \%$. This study has shown significantly more incidents of blood and body fluid splash when undertaking vascular operations and amputations. Vascular surgery does expose a surgeon to blood splash frequently due to common use of bone cutters and power saws. Blood and bodily fluids are often sprayed into the operating room. Not only is the primary surgeon at risk but their assistants were shown to be equally at risk of blood and bodily fluid splash to their eyes. With the abundance of HIV and hepatitis, it seems prudent to protect oneself against possible routes of transmission. The prevalence of HIV and hepatitis is increasing; therefore, although the transmission risk of HIV and hepatitis is low, the overall risk cannot be ignored. In a prospective epidemiological study performed on patients undergoing invasive radiological procedures in France, 944 patients were screened for hepatitis C virus. Ninety-one patients $(10 \%)$ tested positive for hepatitis C, of whom $82(90 \%)$ had a positive viremia result demonstrating a high potential for contamination through blood contacts (Davies, 2007).

Some surgeons and assistants will rely on their prescription spectacles as sole eye protection. With the majority of these spectacles being of a slim design, their effectiveness as an eye protector decreases. When looking at a survey done to asses 
current operating theatre eye wear practices, out of 71 surgeons, $84.5 \%$ that used their prescription eyewear as their eye protector had experienced prior periorbital blood splashes to the facial region, of those $19(26.8 \%)$ admitted to having been impacted in the eye (Chong, 2007). Personal estimates of rates of facial blood splash varied widely, from 0 to 21.7 events per month, while twelve (16.9\%) had previously intraoperatively un-gowned to clean themselves following a facial blood splash, and 6 $(8.5 \%)$ had sought infectious disease testing following conjunctival contamination (Chong, 2007). Two (2.8\%) admitted to contracting an illness from palpebral fissure contamination, comprising 1 case of viral papilloma and 1 case of conjunctivitis (Chong, 2007).

\begin{tabular}{lc|}
\hline Experience & $\begin{array}{c}\text { No. Participants } \\
\text { (\% population) }\end{array}$ \\
\hline Facial blood splashes previously? & $60(84.5)$ \\
Blood splash getting into the eye previously? & $19(26.8)$ \\
Had intraoperatively ungowned to clean after a & $12(16.9)$ \\
$\quad$ blood splash? & $6(8.5)$ \\
$\begin{array}{l}\text { Sought infectious disease testing following a blood } \\
\text { splash? }\end{array}$ & $2(2.8)$ \\
$\begin{array}{l}\text { Contracted an infectious disease from a blood } \\
\text { splash? }\end{array}$ & \\
\hline
\end{tabular}

Table 2-7: Personal Experience with Facial Blood Splashes

In an article written on the risks of blood splashes to the eye during surgery a study was approved and conducted by the Ethics Committee of the Faculty of Health Sciences of the University of Cape Town (Table 2-7). The study was undertaken to determine the incidence of blood splashes to the eyes during surgery. After the study concluded and results were analyzed it was found that the incidence of blood splashes (ocular) was $45 \%$; the study also found that the risk of mucocutaneous exposure via 
blood splashes to the eyes is either underestimated or not fully appreciated by health care workers (Silva, Mall, Panieri, Stupart, \& Kahn, 2009).

\subsubsection{Dentist / Dental Care workers}

Dental practice presents opportunities for cross-contamination. The dentist's face is at high-risk of infection transmission. A large number of pathogens are localized in the oral cavity, which can be transmitted in different ways during dental procedures, usually by means of air/water syringe and high-speed instruments. Two basic ways for spreading pathogenic microorganisms in a dental practice are blood and saliva through droplets of infected patients. The greatest risks for the dentist are hepatitis B and C viruses, and HIV virus that spread through blood and cause life-threatening diseases. Eye injuries can vary from mild irritation to blindness. The use of eye protection, such as protective goggles and visors, reduces the risk of eye damage or complete loss of vision while working with dangerous and floating materials. Therefore, all precautions should be taken, even when performing common procedures for which the risk expectancy is relatively low. Porter et al. investigated occupational injuries reported in dental hospitals over a period of 9 years and found that eye injuries accounted for $10 \%$ of incidents (Porter, 1990). Similarly, Wazzen et al. examined the 1 month prevalence of ocular injuries and infections among dental personnel which consists of dental assistants, dentists and technicians for which he found the foreign body related injury prevalence of dental personal, the dentists and technicians was 42.3\% (Wazzen, 2001). Research shows that approximately $48 \%$ of all dental providers suffer some sort of ocular trauma during their careers. It is worth noting that during one year, $27.6 \%$ of the dentists had contact with infectious material via damaged skin, and $28.1 \%$ of the 
dentists reported trans-mucosal contact. Half (54.7\%) of the dentists reported splashing infectious material on the conjunctiva of the eye (Garus-Pakowska, 2017).

Other research has demonstrated the inadequacy of the present dental mask and regularly worn protective eye wear. Some dental workers wear dental masks and protective eye wear while performing their routine procedures. However, just a general off the shelf eye protector is not sufficient enough. These eye protectors generally conform to ANSI Z87.1 for their impact ratings but the standard has nothing to conform to on blood borne pathogens. Dr. Peter Arsenault conducted experiments and published a report showing the different entry routes for exposures to the user's eyes. He states, "Also, the unavoidable generation of the bottom gaps renders the combination of regular protective eyewear and non-full face shield dental mask an unreasonably dangerous combination, since it is reasonably foreseeable that dental debris may reach the eyes of the dental practitioner through such open bottom gaps" (Arsenault, 2016).

Dr. Arsenault goes on to report a firsthand account of a student with an eye injury. The report states:

When I treated this patient I took all of the necessary precautions which include wearing a gown, gloves, face mask, and loupes with frames for eye protection. While cleaning the margins with a piece of floss some of the patient's saliva splashed into my eye. The patient's gingiva was bleeding and it was possible that some of his blood had splashed into my eye too. 
When this occurred my facemask and loupes were fully tightened. I was confused how this happened, so I examined how my loupes sat on my face and noticed a slight opening between my face and the frames just lateral to the ridge of my nose. I noticed there was a space not protected by my loupe frame or facemask which left my eyes exposed at certain angles. Even though I followed all the mandatory safety guidelines, my eyes were still susceptible to flying debris and an infectious disease. Immediately after the incident I went to the emergency room to wash my eye and was prescribed prophylaxis medication" (Arsenault, 2016).

The account goes on to talk about the medications he had to be on for treating an incident for infectious disease.

"The medications I took had dramatic side effects that made doing simple things feel more difficult. Fortunately, I was able to recover without any major problem. However, I believe the situation could have been avoided with proper eye protection. The current standard for eye wear is unacceptable and requires improvements for the safety of all dentists" (Arsenault, 2016).

\subsubsection{Health Care / Laboratory Workers}

When it comes to occupational risks in the health care working environment, most people think of slips, trips, and falls right away. There are many other very hazardous risks that tend to get overlook. These come in the form of blood borne 
pathogens exposures and infectious diseases. Most commonly, these hazardous risks are transmitted through sharps and bodily fluids (Splish Splash, 2003). These splashes, also known as mucocutaneous blood exposures can transfer pathogens through the eyes, nose, or mouth. Clinical lab work is at a very high risk because specimens that are in the lab are there because they are already suspected to have a contagion of some kind. Below Table 2-8 shows an outline of what the exposures are a result of. As one can see, the majority of the exposures in this type of setting is from specimen container leaks.

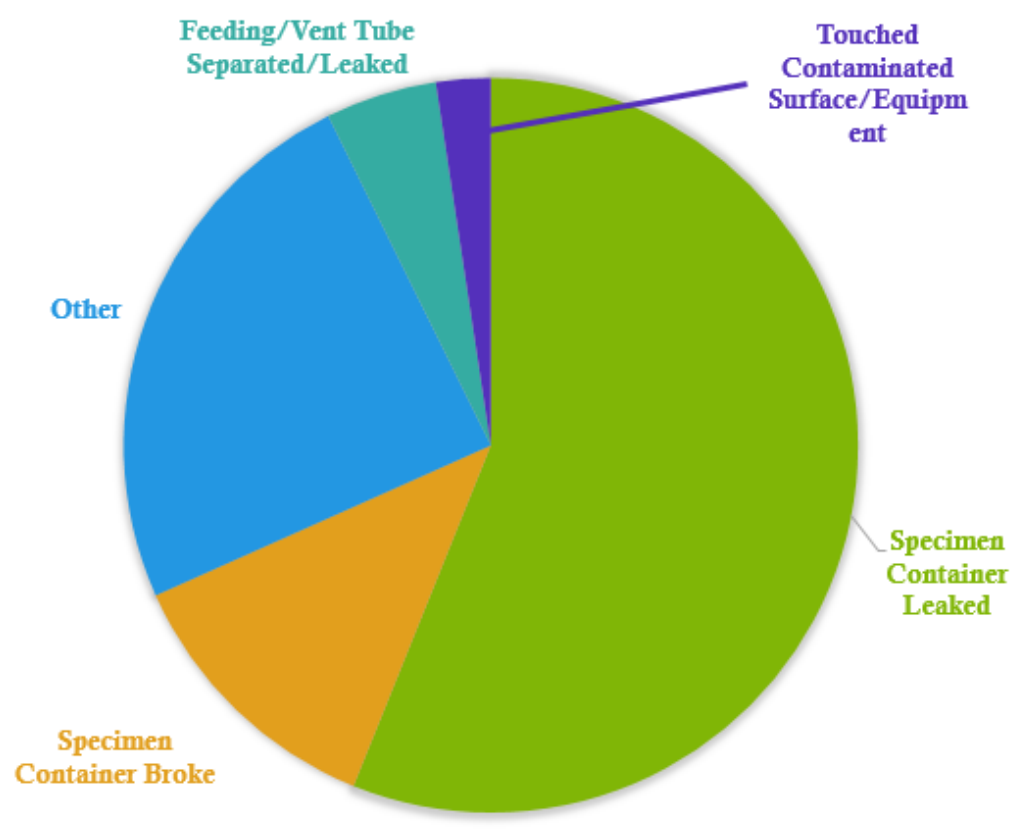

Table 2-8: Health Care / Laboratory Exposure from Various Tasks

Source: (Mitchell 2016)

Other health care and laboratory work is performed with more than just human contact. Many clinical lab workers may help with research while worker on animals such as primates. In some cases there have been documented incidents where an 
exposure has happened when working with animals. In 1997 a female worker at a primate center died from Cercopithecine herpesvirus (B virus) infection following a mucocutaneous exposure. This exposure happened after working with a rhesus macaque where biologic material splashed into her right eye. The worker was not wearing any eye protection due to the nature of task being deemed a "low risk." After the exposure to the eye, the worker wiped it and then irrigate the eye with water about 45 minutes later. After many ongoing days of hospital visits and ophthalmologists consults, the worker died 42 days later from refractory respiratory failure (NIOSH, 1999).

A study was done to simulate mucocutaneous exposures from a splash of infectious material onto the eye of a chimpanzee. This experiment was conducted involving direct eye inoculation of a chimpanzee with hepatitis B material that was known to be infectious. 50 micro liters of HLD-1 plasma (hepatitis B) was placed on the corneal surface of the eyes of the anesthetized chimpanzee (25 micro liters each eye). The Chimpanzee was refrained from rubbing its eyes for 10 minutes; afterward the eyes were gently blotted with absorbent tissue to remove excess fluid. After 9 weeks of observing the chimpanzee, it was found to be seropositive for hepatitis B surface antigen. After more observations over 25 weeks the chimpanzee was found to test positive for the last serological marker tested during the resolution of the disease. The results of this study directly confirm that eye inoculation of blood from hepatitis B patient may result in infection of a susceptible individual (Bond, Peterson, Favero, Ebert, \& Maynard, 1982). It is certain for reasonable and prudent recommendations that workers use protective eyeglasses in and instance where direct or indirect splashing of bodily fluids from a hepatitis B patient is 
possible (Bond, Peterson, Favero, Ebert, \& Maynard, 1982).

Nurses and health care workers provide relentless care to patients on a daily basis. Many tasks might be considered "not so hazardous." However, when you consider that nurses and other health care workers empty cups and containers, wash dirty bed pans, clean urine bottles, and handle catheter bags; these tasks then start to become more concerning. According to a 2003 study, 39 percent of registered nurses and 27 percent of licensed practical nurses experienced at least one mucocutaneous blood exposure (splash) in 3 months (Splish Splash, 2003). Many of these incidents go under reported. This is due to the inconvenience that it takes for the health care provider to report to employee health. It also can lead to a large list of tests to check for or treat for a transmissible disease. If anything is discovered that could result in infection, a round of prophylaxis is usually required for the health care provider. This medicine then leads to costly medical bills and a few weeks of feeling miserable. Occupational exposures such as splashes can lead to lost work days, financial burden, and physical impairment. They also can take an emotional toll on those exposed (Splish Splash, 2003).

Another study led by Doebbeling et. al. at the Veterans Administration found that in the previous three months, roughly 38 percent of RNs had experienced some sort of mucocutaneous blood exposure (a splash containing blood that lands on a caregiver where it could transfer a pathogen such as the eyes, nose or mouth). They also found that only about 73 percent of these injuries were reported (Doebbeling, 2003). Gershon et al. surveyed many different types of healthcare workers found that about 29 percent of respondents had some sort of exposure incident in the previous six 
months, of which, only about 44 percent were reported. To create significant change, as stated in the study by Gershon, "There must be a culture of safety. Senior leadership must endorse measures that will lead to a safer environment. These include availability of PPE, design of the environment to decrease contamination and utilizing devices that are engineered to be safer" (Gershen, 2000).

There are many studies being done to research and prove that splashes to the eye are a very prominent problem that isn't being addressed enough to protect health care workers. In a study done of US Medical students in Botswana, they found this issue to be almost as prominent as incident with sharps. Students were asked to describe each individual exposure, and were asked about whether the exposure was reported when it occurred, the circumstances surrounding the exposure, and whether PEP (post-exposure prophylaxis) was taken. Of the 82 students who received the survey, 67 responded. Seventeen of 67 (25.4\%) reported having a blood or body fluid exposure; eight were needle sticks, and nine were splashes. All splashes were eye splashes (Merlin, et al., 2010).

Many articles reviewed the use of face shields in the workplace. Most people still do not think that even a face shield is adequate protection against biological hazards (Roberge, 2016). From a journal review on face shields for infection control, Raymond Roberge discusses their uses and the additional need for research on infection control.

Face shields are PPE that are commonly used as barrier protection for infection control purposes by numerous workers. There currently is no standard regarding 
face/eye protection from biological hazards and this deficit needs to be remedied as quickly as possible. Due to the lack of a good facial seal peripherally that can allow for liquid penetration, face shields should not be used as solitary face/eye protection, but rather as adjunctive to other PPE (protective facemasks, goggles, etc.). Given the dearth of available data regarding the appropriate use of face shields for infection control, scientifically sound research needs to be conducted on the use of this form of PPE (Roberge, 2016).

\subsection{Risks}

The risk following a blood exposure to the eye, nose or mouth is unknown, but is believed to be very small; however, $\mathrm{HCV}$ infection from a blood splash to the eye has been reported. For HIV, the average risk of HIV infection after a needle stick or cut exposure to HIV-infected blood is $0.3 \%$ (about 1 in 300 ). The risk after an exposure of the eye, nose or mouth to HIV-infected blood is estimated to be on average, $0.1 \%$ (about 1 in 1000) (CDC, 2015).

\subsubsection{Risk Assessment}

Safety Professionals use a risk matrix to assess the various risks of hazards (and incidents) and other safety events. Severity is the amount of damage or harm a hazard could create and is ranked on a four point scale.

- Catastrophic 4 - Operating conditions are such that human error, environment, design deficiencies, element, subsystem or component failure, or procedural deficiencies may commonly cause death or major system loss, 
thereby requiring immediate cessation of the unsafe activity or operation.

- Critical 3 - Operating conditions are such that human error, environment, design deficiencies, element, subsystem or component failure or procedural deficiencies may commonly cause severe injury or illness or major system damage thereby requiring immediate corrective action.

- Marginal 2 - Operating conditions may commonly cause minor injury or illness or minor systems damage such that human error, environment, design deficiencies, subsystem or component failure or procedural deficiencies can be counteracted or controlled without severe injury, illness or major system damage.

- Negligible 1 - Operating conditions are such that personnel error, environment, design deficiencies, subsystem or component failure or procedural deficiencies will result in no, or less than minor, illness, injury or system damage.

(Risk Matrix Calculations)

Probability is the likelihood of the hazard occurring and is ranked on a five point scale:

- Frequent 5 - Likely to occur often in the life of an item

- Probable 4 - Will occur several times in the life of an item

- Occasional 3 - Likely to occur sometime in the life of an item.

- Remote 2 - Unlikely but possible to occur in the life of an item.

- Improbable 1 - So unlikely, it can be assumed occurrence may not be experienced

Risk Assessment -The Risk Assessment Values are determined by multiplying the 
scores for the Probability and Severity values together. The following Table 2-9

displays the default risk assessment values (Risk Matrix Calculations).

Severity

\begin{tabular}{|c|c|c|c|c|}
\hline Probablity & Catrastrophic - 4 & Critical - 3 & Marginal - 2 & Negligible - 1 \\
\hline Frequent - 5 & High - 20 & High-15 & High - 10 & Medium - 5 \\
\hline Probable - 4 & High - 16 & High - 12 & Serious - 8 & Medium - 4 \\
\hline Occasional - 3 & High - 12 & Serious - 9 & Medium - 6 & Low - 3 \\
\hline Remote-2 & Serious - 8 & Medium - 6 & Medium - 4 & Low -2 \\
\hline Improbable - 1 & Medium - 4 & Low -3 & Low - 2 & Low -1 \\
\hline
\end{tabular}

Table 2-9: Risk Assessment Table

Source: (Risk Matrix Calculations)

Given that the risk of infection after an exposure is relatively low (1 in 1000) due to exposure of the eye, nose, or mouth gives a notion that the risk should be in a moderate to low category. However, the probability of being exposed is relatively high within the occupation, given that statistics report it happening frequently and more than once a year and the severity of this risk is serious or disabling and life threatening, this puts the risk assessment matrix for these occupations for biological hazards of splashes to the eyes in a "High" category. 


\subsection{Summary}

According to the World Health Organization's description of health, health is a state of complete physical, mental, and social well-being and not merely the absence of disease (WHO). Eye health is becoming an increasingly important subject both for the health care system and the society. Workers need to be more aware of the potential risks and dangers when working in and around biological hazards that have potentials for splashes and spurts to the facial region. Since transmissions of infections and injuries of the eye may go unnoticed; chronic eye injuries are possible. There are many protective measures which can help to provide good protection for eye health. Eye protectors can reduce the risk of eye damage or complete loss of vision while working in hazardous conditions. Though there are numerous technological and medical advances in eye protectors for health care workers; there are still many incidents and injuries that do occur. Most health care workers refer to ANSI Z87.1 for information of eye protectors and proper selection. ANSI Z87.1 is lacking in the biological hazards and blood borne pathogens category for selection of eye protectors. Many research articles prove that there is a problem that needs to be addressed for protection against splashes and spurts to the eyes of the health care worker. ANSI Z87.62 will allow workers to have a reference and have guidance for eye protectors for protection against biological hazards. This project gives a test apparatus and standard criteria that all eye and face protectors for biological hazards will be performed on. This will ensure concise and consistent testing across the broad spectrum of safety manufacturers and end users for eye and face protectors. 


\section{CHAPTER 3 -TEST APPARATUS / METHODS}

\subsection{General test setup description}

This study evaluates the efficiency of manufacturer's eye and face PPE for protection against biological hazards such as blood borne pathogens. The test apparatus is replicating the hazards that a worker would see in average working conditions. The majority of these hazards are coming from the human body such as sneezes/coughs, puncture wounds, saliva/mucous, or instances of low velocity splashes from containers in laboratory conditions. The test apparatus replicates these conditions to best match the patterns, velocities, and volumes that would be a biological hazard to the worker. Eye protectors will be selected and placed on the anthropometric head as if being worn for occupational hazards. The headform will be adjusted at the specified distance for the specific criteria being tested (spurt or spray). The test will be conducted at varying headform locations and angles. Immediately after each shot at each location, the eye, nose, and mouth of the headform will be evaluated for any droplets of fluid. If any fluid is found to be on the eye, nose or mouth, then the eye protector and coordinating ensemble (eye protector and face mask) fails the test. This angle and location will be noted and the testing will continue to evaluate other locations and angles. Once testing is concluded, if the protector has any failure spots, then that particular eye protector will fail the criteria to be labeled for protector against biological hazards under ANZI Z87.62. If the eye protector passes all the testing locations, then that particular eye protector passes and is allowed to be labeled for protection against biological hazards under ANZI Z87.62. 


\subsection{Test Parameters}

\subsubsection{Spurt and Spray}

One criteria of a "shot" that will be used in evaluating eye protectors is the spurt test. The spurt is used to simulate a small arterial puncture or similar situation from a human at average blood pressure velocities. This speed of the simulated fluid for a "spurt" will be replicating the pressure from which an average human body could expel blood. These ranges will be from a low of $80 \mathrm{mmHg}$ to a high of $160 \mathrm{mmHg}$. These two ranges are equivalent to 10.7 and $21.3 \mathrm{kPa}$. These two pressures will have stream velocities projected from the nozzle of 450 and $635 \mathrm{~cm} / \mathrm{s}$ respectively. The proposed velocity for the test will be $635 \mathrm{~cm} / \mathrm{s}$ to replicate a worst case scenario. Based on ASTM F1862 Standard Test Method for Resistance of Medical Face Masks to Penetration by Synthetic Blood test criteria of a max volume of $2 \mathrm{ml}$, the volume of fluid that will be expelled for this test apparatus will follow that of which will be $2 \mathrm{ml}$ (ASTM F1862-Blood Spurt Tester). The spurt was tested at $30.48 \mathrm{~cm}$. This is based off the average distances that health care workers operate from their patients (Neck Health 2008). This is to test for the worst case scenario of being close to the patient. The nozzle for the spurt will be set at a horizontal distance of $30.48 \mathrm{~cm}$ for all spurt testing locations. The spurt criteria is achieved by using a detachable straight tubbed cannula fitted to the nozzle (Figure 3-1). 


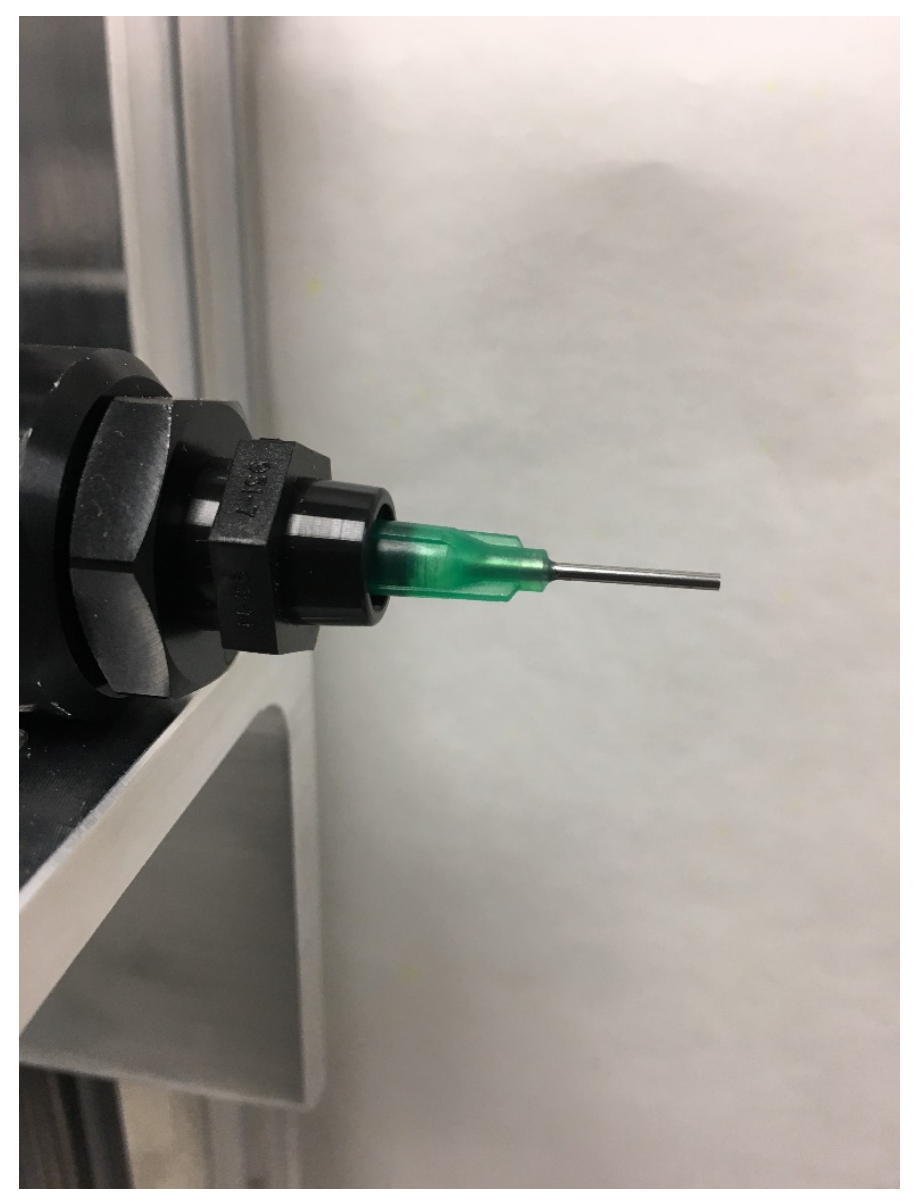

Figure 3-1: Spurt Cannula

The apparatus will also be testing eye and face protetors for protection against "spray". This spray is to replicate a human cough or sneeze. The speed of the fluid for a "spray" will be replicating the pressure from which an average human could expel a spray. The range of a sneeze and cough were conducted from a study by Hidekazu Nishimura. Nishimura concluded that the highest most common velocity is around $300-500 \mathrm{~cm} / \mathrm{s}$ at a horizontal distance of 30-60 cm(11.8-23.6”) (Nishimura, Sakata et al. 2013).The concentration of particles, optimal spray pattern and coverage is what the spray category will be mostly concerned with. This spray is mostly around $30-35 \mathrm{~cm}$ horizontally. The nozzle for the spray will be set at a distance of $30.48 \mathrm{~cm}$ horizontal to the point of impact. Based on personal interviews of Dr. Arsenault, the volume of fluid 
that will be sprayed at the headform will be that of at least $0.5 \mathrm{ml}$ and no more than 1 ml. (Arsenault). This spray criteria is achieved by using a detached spray tipped cannula fitted to the nozzle (Figure 3-2).

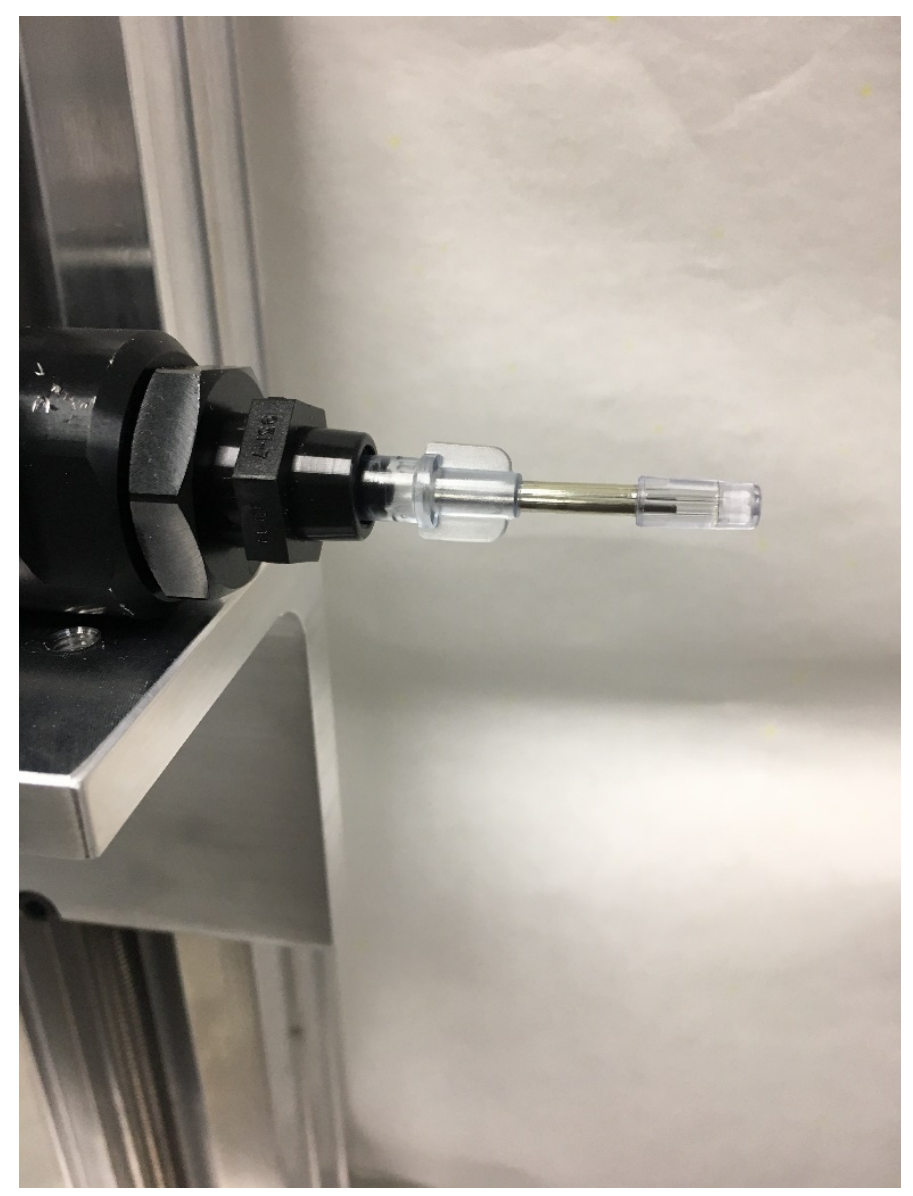

Figure 3-2: Spray Cannula

\subsubsection{Headform Locations}

Both the Spurt and Spray categories will be using the same shot target locations on the headform at their specified horizontal distances. The protector device shall be placed on the headform in the designated wearing position. For the spurt and spray dispensing shots, the headform will be manipulated into 4 main locations. These locations will share a common reference point from which all locations will be measured. The exact 
center between the eyes on the headform was used to aim all target locations. The first 2 locations will be with the headform centered across the sagittal plane. The sagittal plane divides the body into left and right. On a person it would pass through the midline structures such as the spine and navel. The first centered sagittal plane shot will be with the headform tilted posteriorly 30 degrees off the coronal plane (Figure 33). The nozzle should be aimed 1" below the center point of eyes on the bridge of the nose. The second sagittal plane shot will be with the headform titled anteriorly 30 degrees off the coronal plane (Figure 3-4). The nozzle should be aimed 2" above the center point of the eyes on the forehead of the headform. The angle of which the headform will be tilted anteriorly and posteriorly is capturing the average angle at which a health care worker would angle their head to in relation to the patients head (Pirvu, 2014). The third and fourth shot will be to the left and right temple area of the headform. The headform will be centered across the sagittal and coronal plane in a vertical fashion. A coronal plane is any vertical plane that divides the body into ventral and dorsal sections (belly and back). On a person's head, this would divide it into the front (facial portion) and back (back of the head). It then needs to be turned 55 degrees to the left and right for the third and fourth shot respectively, and not centered at the bridge (Figure 3-5, Figure 3-6) (Arsenault, 2016). The nozzle should be adjusted to the same height of the center point of the eyes for the targeted location. These manipulations will be referred to as Up, Down, Right, and Left; as they are shown in order below. The target locations above (2") and below (1") the center point of the eyes was chosen to get more varying locations for spurts and sprays. If every shot was placed at the center point of the eyes on the headform manipulations then the test would not be examining any other areas of protection from the eyewear but the center 
point ( in between the eyes / bottom gap). By varying these locations 2" above, 1" below, 55 degree left and right, the test is examining more areas of protection of the eye wear and mask. (Top, Bottom, Left, Right) This in addition to the Range of Protection test which the target location is always at the center point of the eyes gives a large range of examination of the ensembles protection.

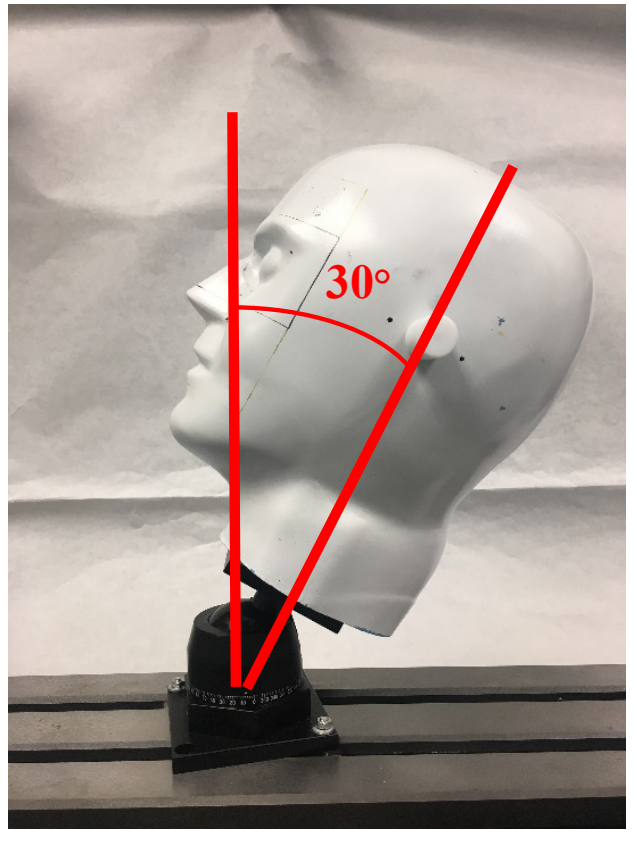

Figure 3-3: Posteriorly Titled 30 Degrees

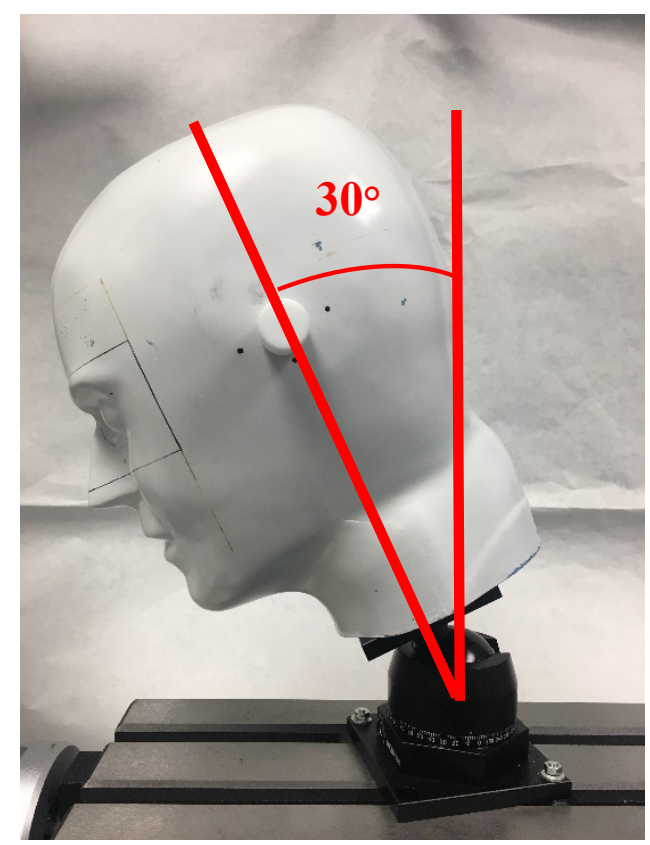

Figure 3-4: Anteriorly Tilted 30 Degrees 


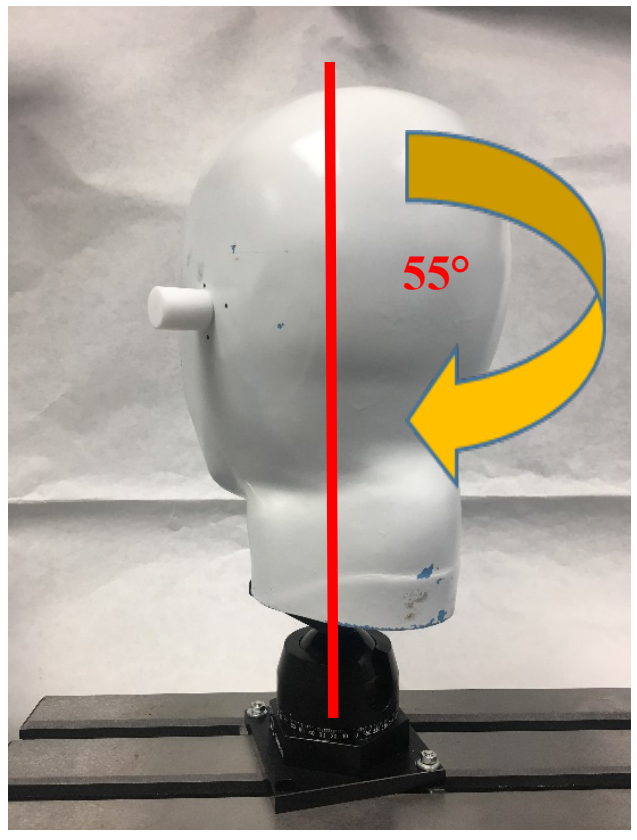

Figure 3-5: 55 Degrees Turned Right

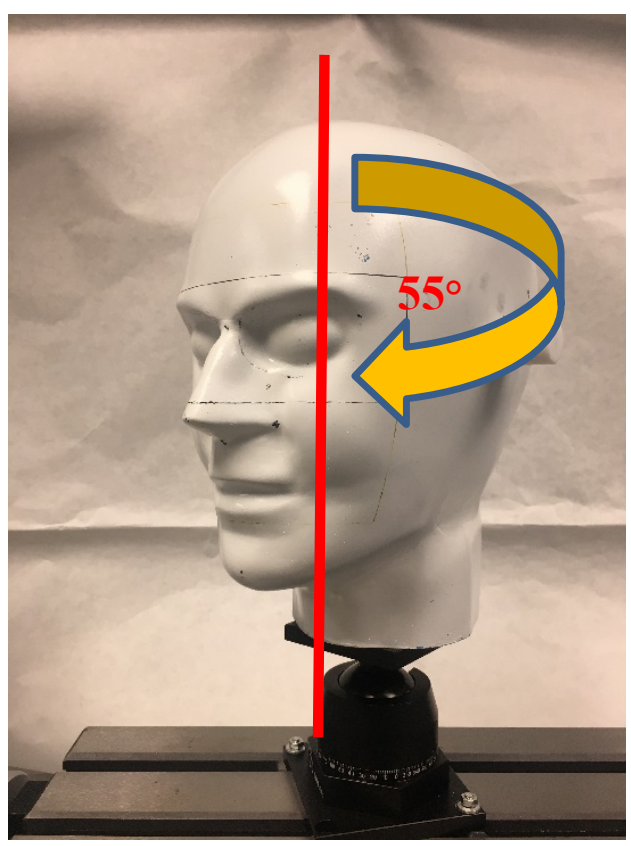

Figure 3-6: 55 Degrees Turned Left

\subsubsection{Velocities}

The velocities that will be used for the speed of the spurt and spray are based off of averages of human bodily fluids that could be expelled naturally. The velocity of the stream that exits the test apparatus is deduced from the volume of the stream produced over a known period of time through a known area (1). Since the electronic dispensing unit can easily control the period of time and pressure at which the stream exits from, the flow velocity can be calculated. It is also easier and more accurate to measure the weight rather than the volume of the spurt and knowing the density of the fluid being used. 


$$
\begin{aligned}
& v=Q / t A \\
& \begin{array}{l}
v=\text { flow velocity } \\
Q=\text { flow volume } \\
t=\text { duration of the flow } \\
\mathrm{A}=\text { cross sectional area of the orifice }
\end{array} \\
& \begin{array}{l}
\omega=\mathrm{Q} \delta \\
\delta=\text { density of the test fluid } \\
\omega=\text { weight of the spurt } \\
\mathrm{Q}=\text { volume of the spurt }
\end{array}
\end{aligned}
$$

By using the difference in weight of streams shot in known times and using a derived equation, the steady state streams exit velocity can be estimated (3)

$$
\left(\omega_{2}-\omega_{1}\right)=\mathrm{v} \frac{\pi \delta d^{2}}{4}\left(t_{2}-t_{1}\right)
$$

This equation can also be represented as:

$$
\begin{aligned}
& \left(\omega_{2}-\omega_{1}\right)=\frac{v(t 2-t 1)}{C} \\
& \mathrm{C}=\frac{4}{\pi \delta d^{2}}
\end{aligned}
$$

The constant C (5) can be recalculated for fluids with other specific gravities that are less than 0.995 or greater than 1.015. It can also be recalculated when using different sized diameter cannulas on the nozzle. The equation for the value $\mathrm{C}$ can also be used to build tables of target velocities for limits and different spurt weights for varying test requests. Figure 3-16 shows tables built for easy calculation for target weights and velocities. This table has been rebuilt and manipulated for these tests from ASTM F1862. During experimentation with the different velocities and pressures, I was able to use a chronograph to validate the exit velocities with the estimated velocities using the Excel equations (Figure 3-7). A forecasted graph through Excel aids in getting a quick estimate of the pressure needed in the container for exit velocities (Figure 3-8). 
Another useful forecasted graph to estimate exit velocities during tester setup is weight

vs velocity (Figure 3-9). These forecasted graphs are making predictions about a value

based on past and present data by using analysis of trends.

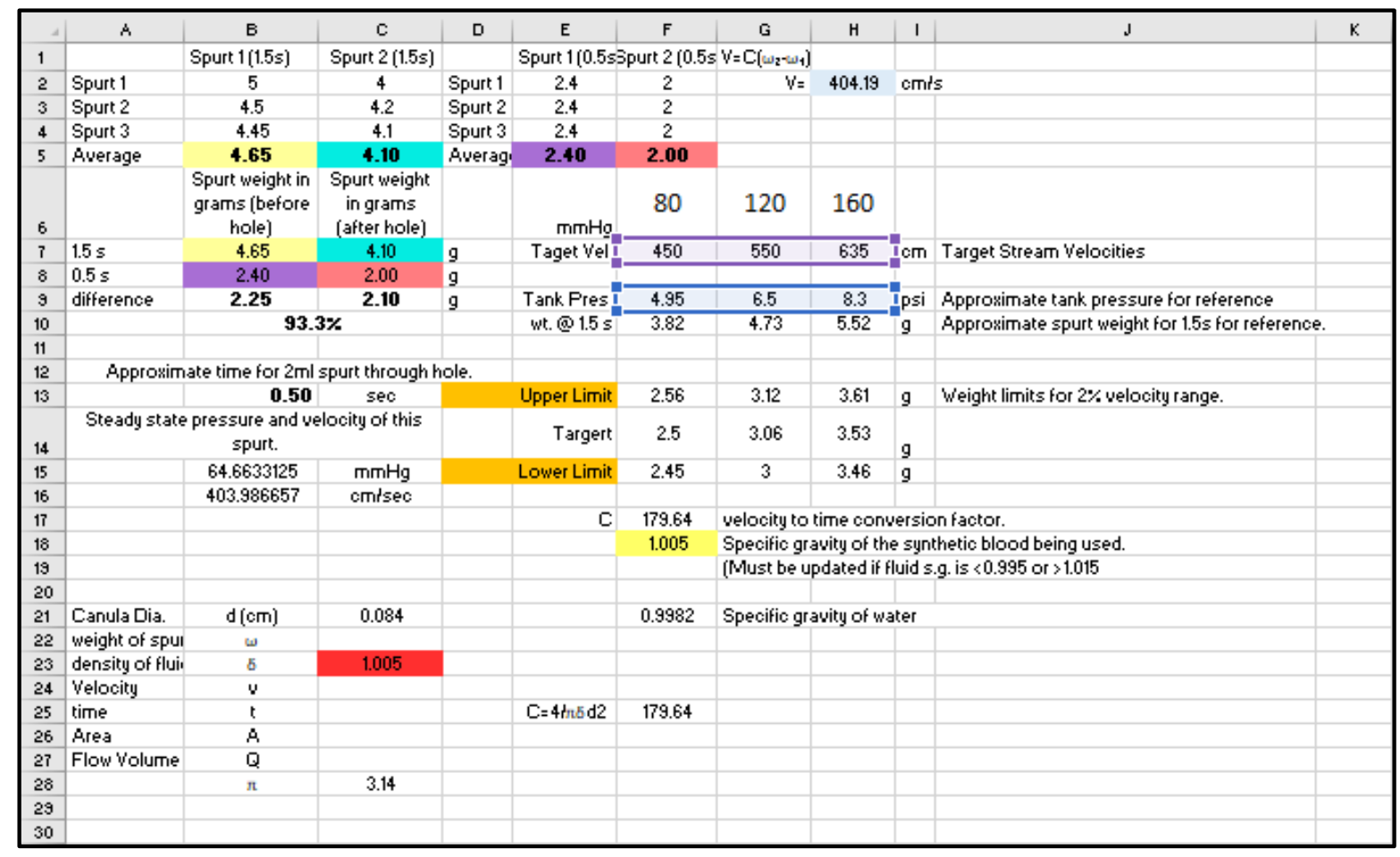

Figure 3-7: Excel Velocity Calculations and Tables

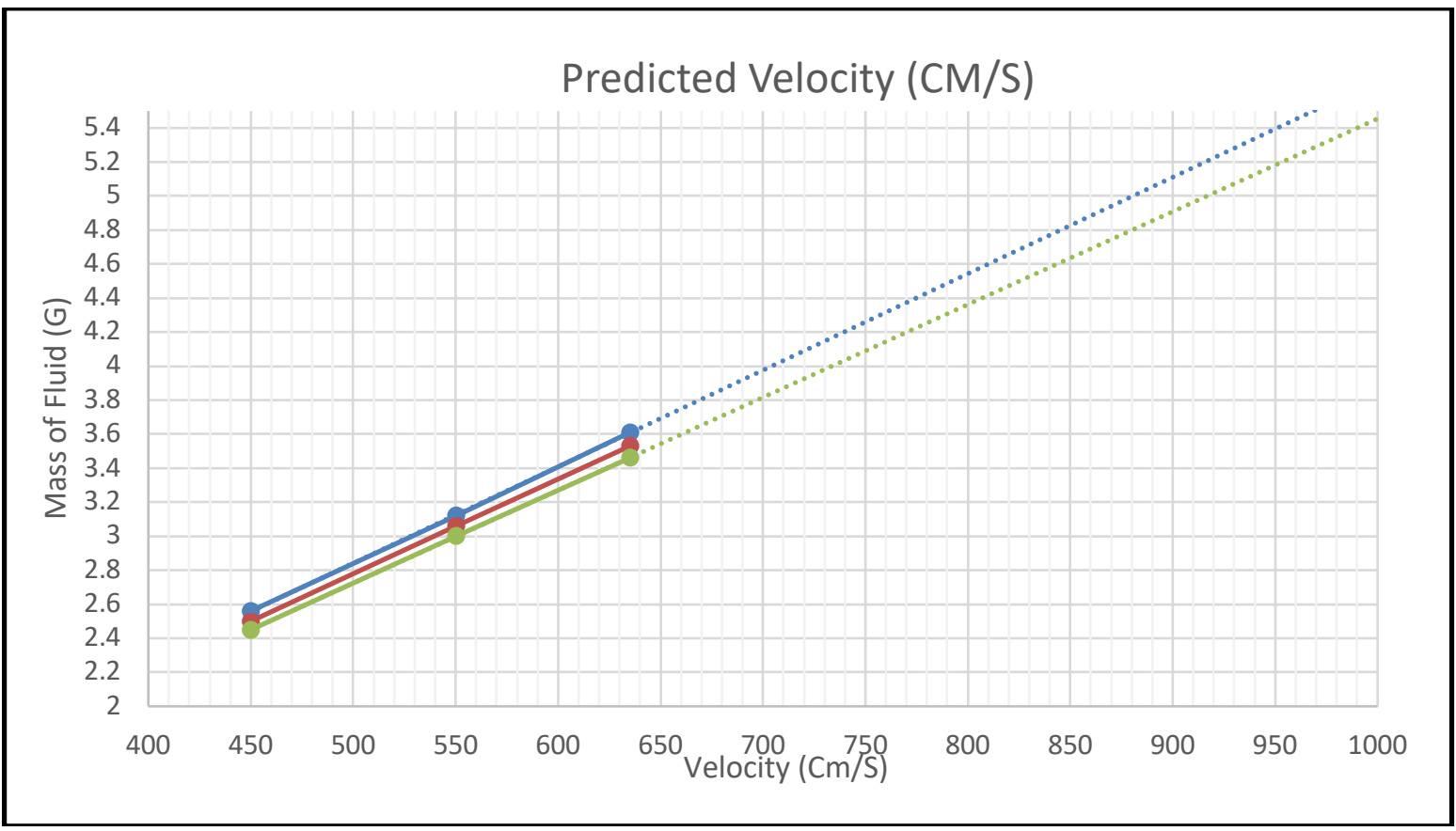

Figure 3-8: Predicted Velocity using Mass vs cm/s with Upper and Lower Limit Lines 


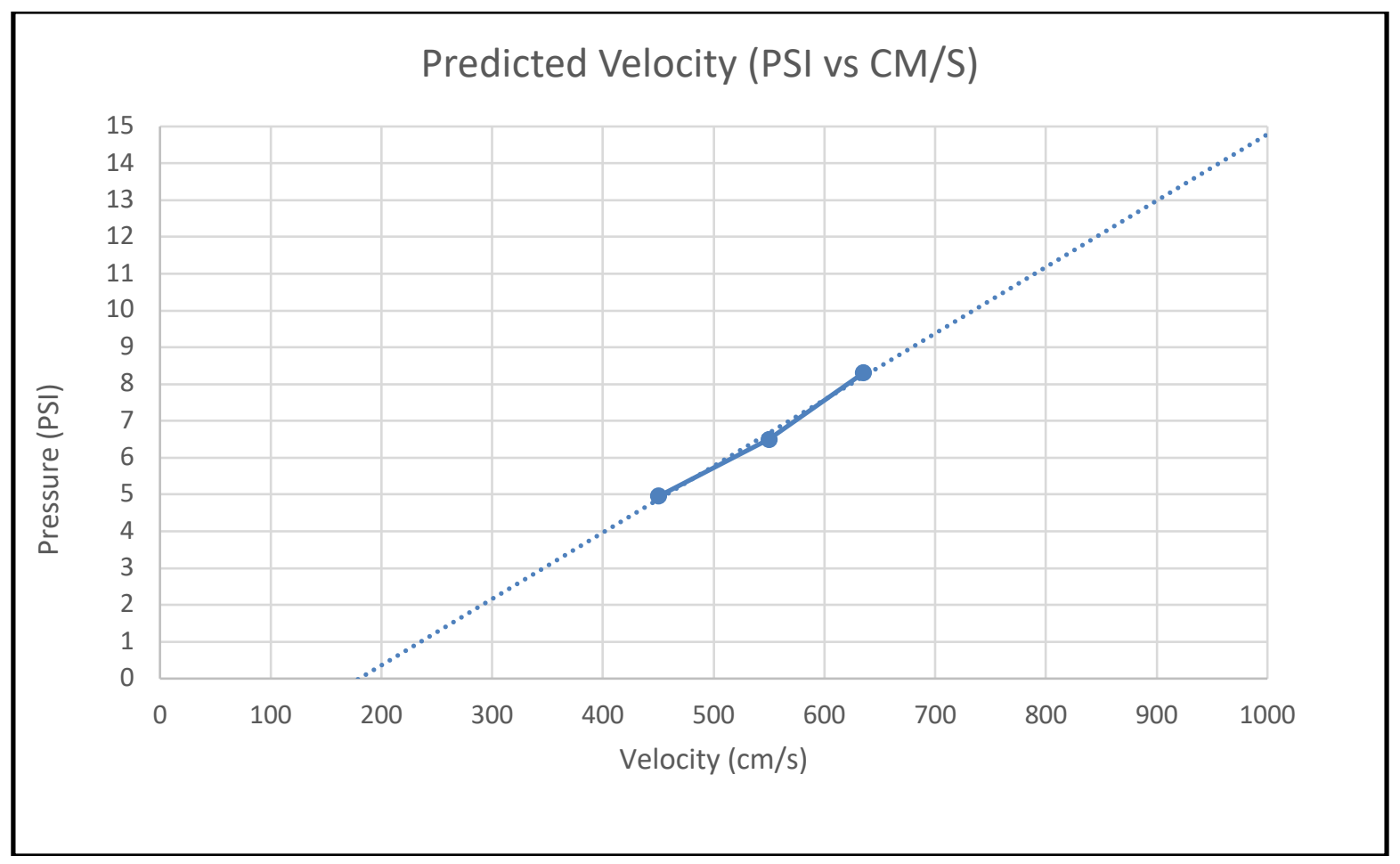

Figure 3-9: Predicted Velocity using PSI vs $\mathrm{cm} / \mathrm{s}$ 


\subsection{Test Equipment}

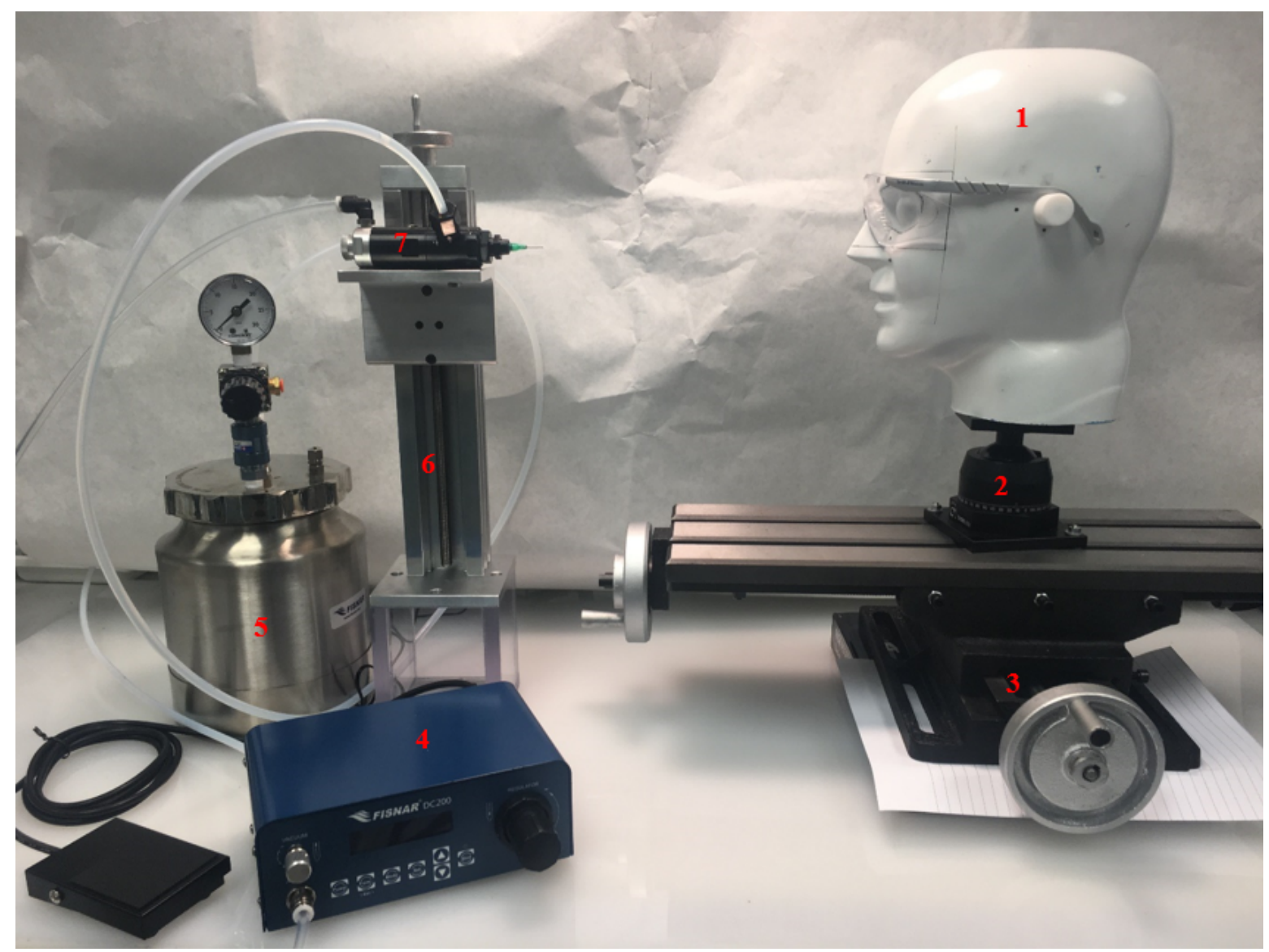

\begin{tabular}{|c|l|}
\hline $3-10.1$ & Anthropometric Headform \\
\hline $3-10.2$ & Articulating Base \\
\hline $3-10.3$ & Milling Table \\
\hline $3-10.4$ & Dispensing Unit \\
\hline $3-10.5$ & Pressurized Container \\
\hline $3-10.6$ & Uni-Slide \\
\hline $3-10.7$ & Nozzle \\
\hline
\end{tabular}

Figure 3-10: Overall Test Setup 


\subsubsection{Anthropometric Headform}

The headform that will be used for this test will be the medium sized anthropometric European headform of the $50^{\text {th }}$ percentile adult male due to its existing prevalence in ANSI Z87 (ANSI-ISEA Z87.1, 2015). Unless otherwise specified by the manufacturer, the medium sized headform will be used. If the selected eye protector explicitly states that it is for a smaller head, then a smaller sized anthropometric headform (or equivalent) will be used for testing. Once the size of the headform is selected for the testing, all tests will be conducted with the same headform. Other headforms may be used if known or demonstrated to give equivalent results (Figure 310.1, Figure 3-11, and Figure 3-12). 


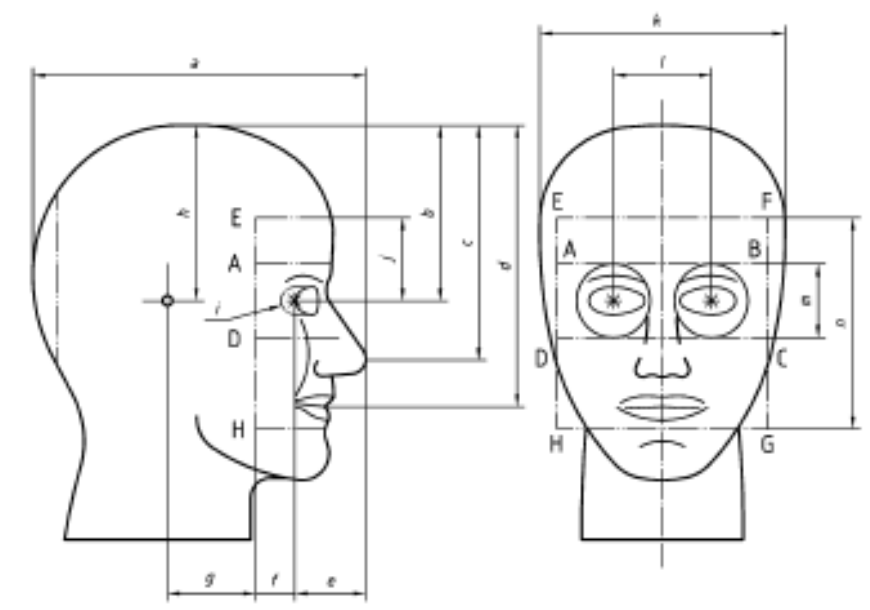

Figure 3-11: Headform Measurements

\begin{tabular}{|c|c|c|}
\hline \multirow[t]{2}{*}{ Dimension } & \multicolumn{2}{|c|}{ Value } \\
\hline & Medium size head & Small size head \\
\hline $\mathrm{a}$ & $218 \mathrm{~mm}$ (8.6 in.) & $205 \mathrm{~mm}$ (8.1 in.) \\
\hline $\mathrm{b}$ & $111 \mathrm{~mm}$ (4.4 in.) & $110 \mathrm{~mm}$ (4.3 in.) \\
\hline c & $144 \mathrm{~mm}(5.7 \mathrm{in})$ & $131 \mathrm{~mm}(5.2 \mathrm{in})$ \\
\hline $\mathrm{d}$ & $178 \mathrm{~mm}(7.0 \mathrm{in})$. & $166 \mathrm{~mm}(1.7 \mathrm{in})$ \\
\hline $\mathrm{e}$ & $45 \mathrm{~mm}(1.8 \mathrm{in})$. & $42 \mathrm{~mm}$ (1.7 in.) \\
\hline$f$ & $18 \mathrm{~mm}$ (0.7 in.) & $18 \mathrm{~mm}(0.7 \mathrm{in})$. \\
\hline $\mathrm{g}$ & $60 \mathrm{~mm}$ (2.4 in.) & $53 \mathrm{~mm}$ (2.1 in.) \\
\hline $\mathrm{h}$ & $111 \mathrm{~mm}$ (4.4 in.) & $110 \mathrm{~mm}(4.3 \mathrm{in})$. \\
\hline Radius i & $10 \mathrm{~mm}(0.4 \mathrm{in})$. & $10 \mathrm{~mm}(0.4 \mathrm{in})$. \\
\hline $\bar{j}$ & $58 \mathrm{~mm}$ (2.0 in. $)$ & $48 \mathrm{~mm}$ (1.9 in.) \\
\hline $\mathrm{k}$ & $156 \mathrm{~mm}$ (6.1 in. ) & $146 \mathrm{~mm}(5.7 \mathrm{in})$. \\
\hline 1 & $64 \mathrm{~mm}$ (2.5 in.) & $54 \mathrm{~mm}(2.1 \mathrm{in})$. \\
\hline $\mathrm{m}$ & $52 \mathrm{~mm}$ (2.0 in.) & $48 \mathrm{~mm}$ (1.9 in.) \\
\hline $\mathrm{n}$ & $134 \mathrm{~mm}$ (5.3 in.) & $118 \mathrm{~mm}(4.6 \mathrm{in})$. \\
\hline
\end{tabular}

Table 3-1: European Anthropometric Headform Measurements

Source: (ANSI-ISEA Z87.1, 2015) 


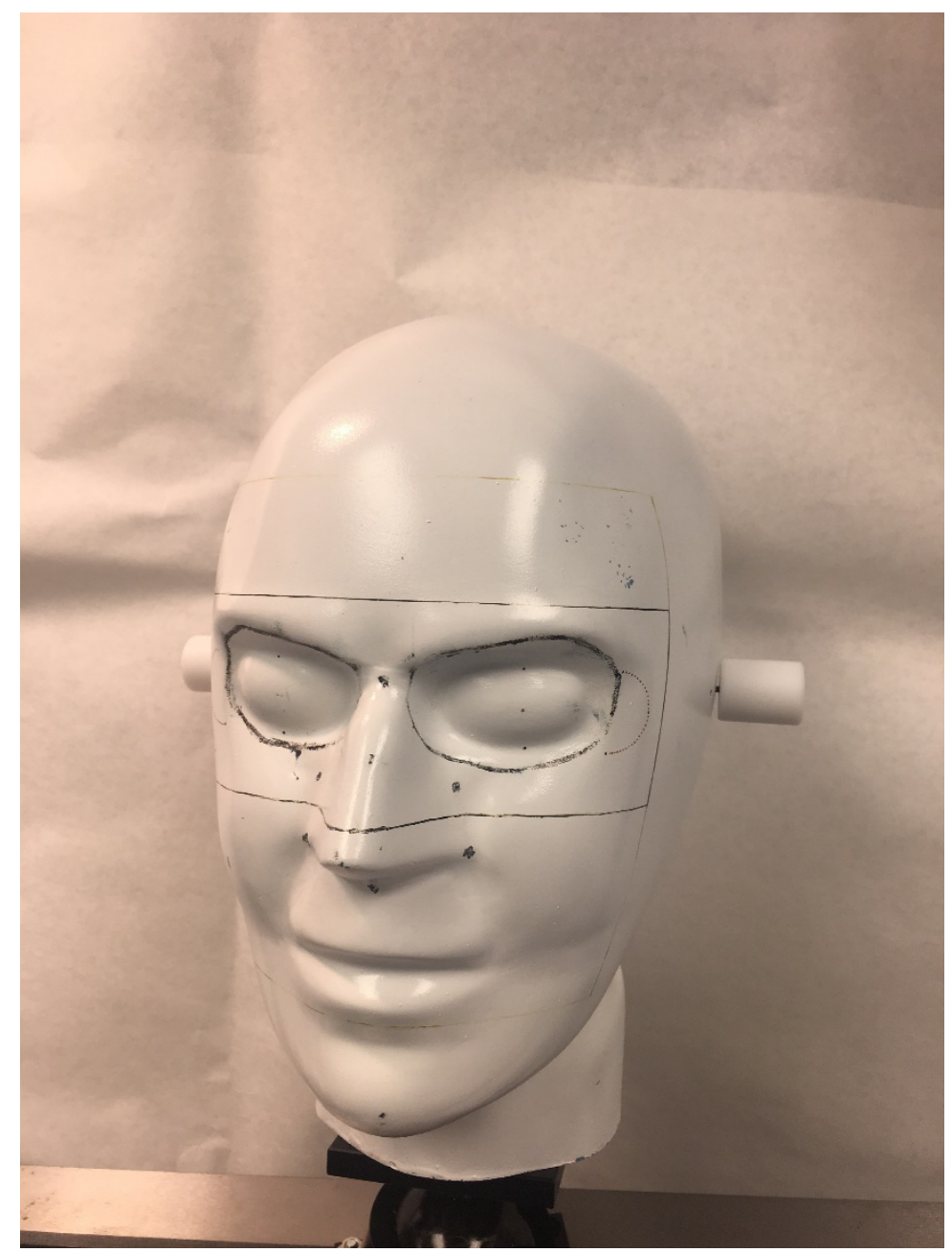

Figure 3-12: Anthropometric Headform

\subsubsection{Articulating Headform Base}

The headform for which the eye protectors will be placed on needs to be able to be manipulated in varying angles and rotations around a central point. This is possible by mounting the headform onto an articulating base. The base can be rotated 360 degrees and has the ability for the headform to be angled nearly 90 degrees downward in any direction. Having this ability to manipulate the headform into varying angles and 
rotations allows the test to best replicate how a workers head would be angled during their working conditions (Figure 3-10.2, Figure 3-13).

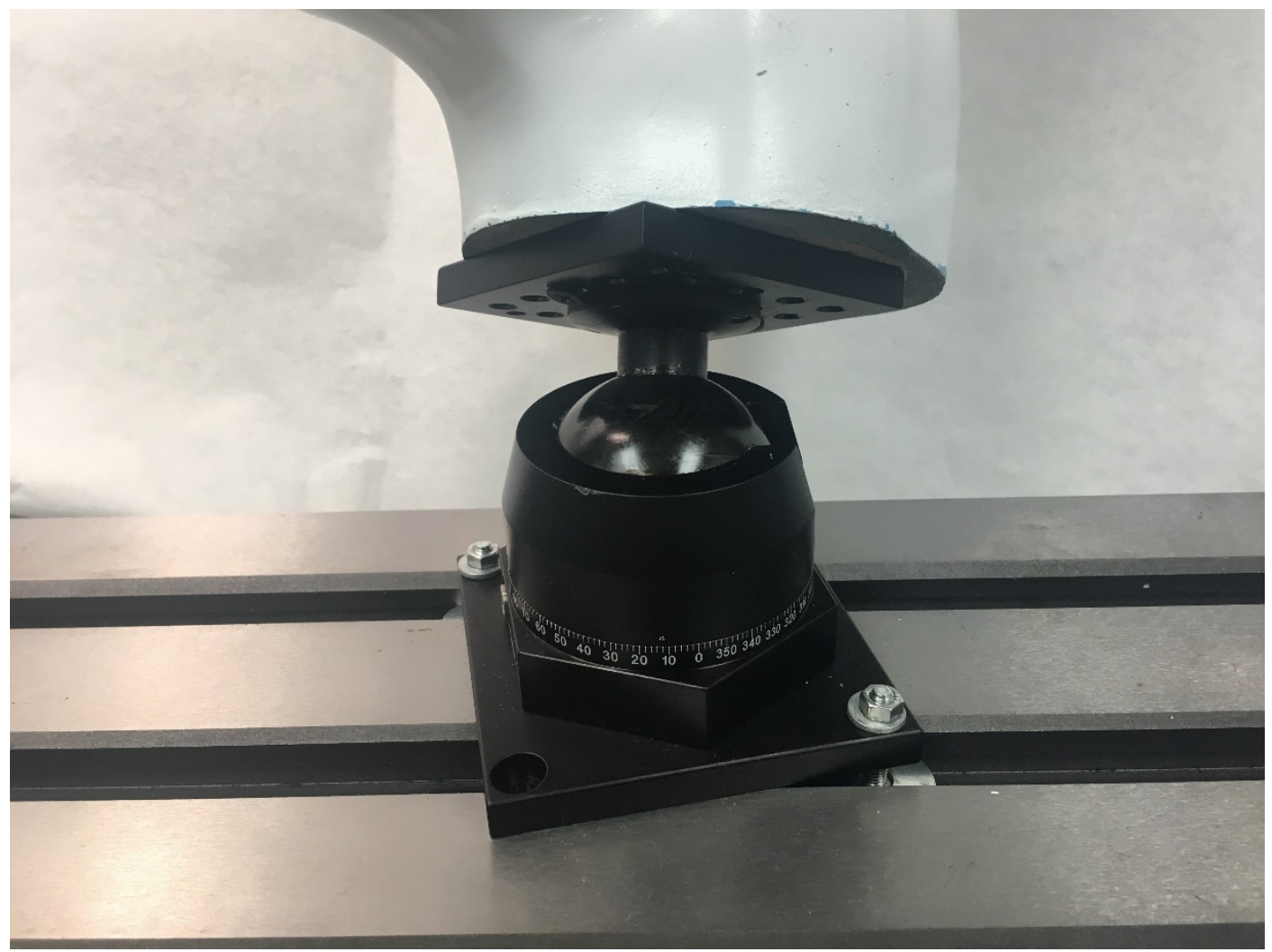

Figure 3-13 Articulating Base

\subsubsection{Milling Table}

To be able to compensate for varying distances and locations on the headform, the articulating base will be mounted onto a milling table. By having the headform mounted onto the milling table, it gives 12 " of longitudinal travel and 7.5 " of transverse travel. This will allow the headform great range of locations for testing. The milling table also offers precise adjustments for both lateral and transverse movement for easy replications of testing (Figure 3-10.3, Figure 3-14). 


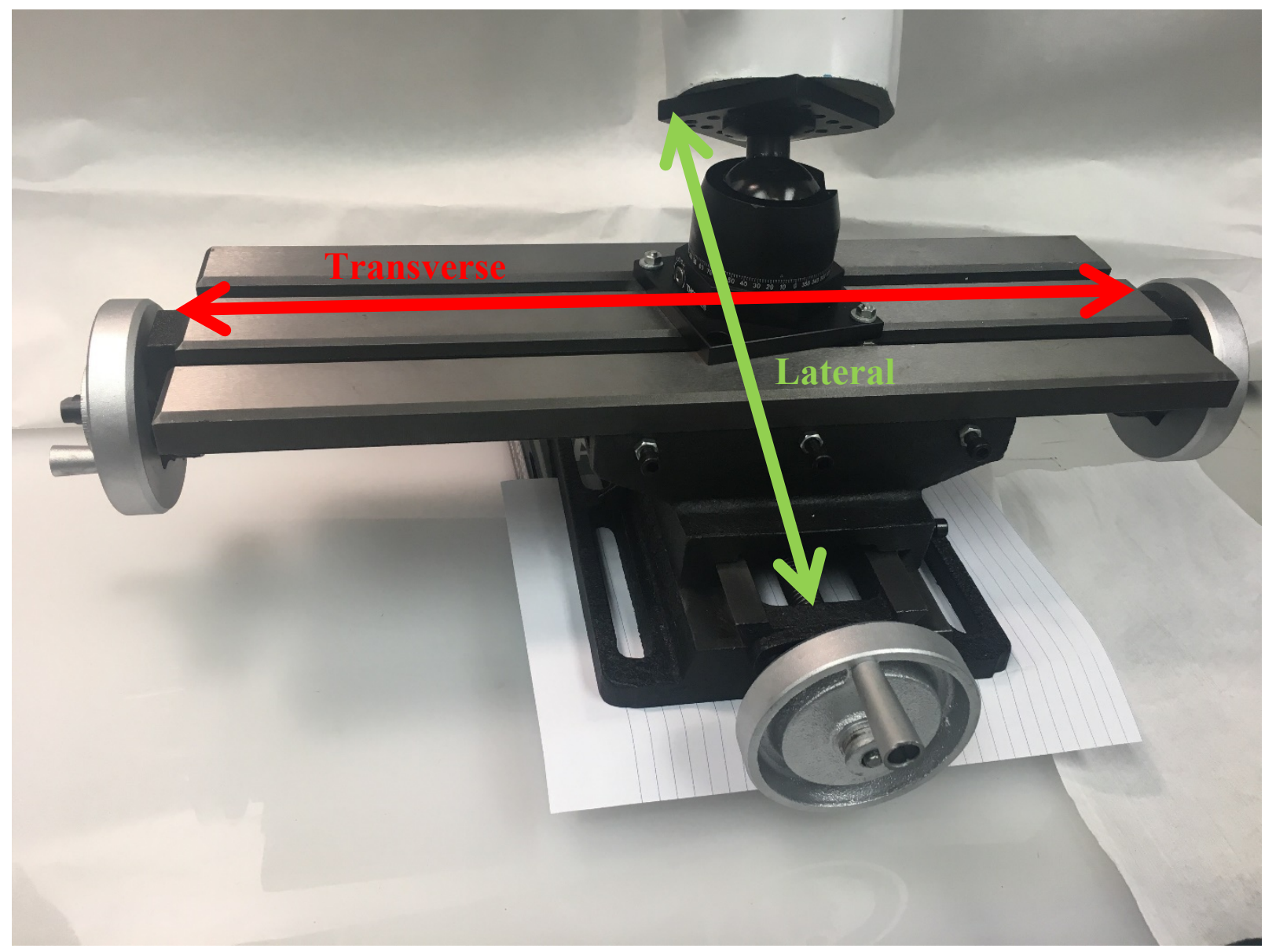

Figure 3-14: Milling table

\subsubsection{Dispensing Unit}

The fluid that will be used to assess penetration will be dispersed through an electronic digital dispenser. The DC 200 which will be used for testing offers a wide variety of dispensing applications. It has precise accuracy for dispensing specific volumes. It also has multi regulators for input air pressure which can be set to ensure consistent pressure all throughout the dispensing time. This controlling makes it easy to get 
precise shots of fluid across all tests for consistency (Figure 3-10.4, Figure 3-15).

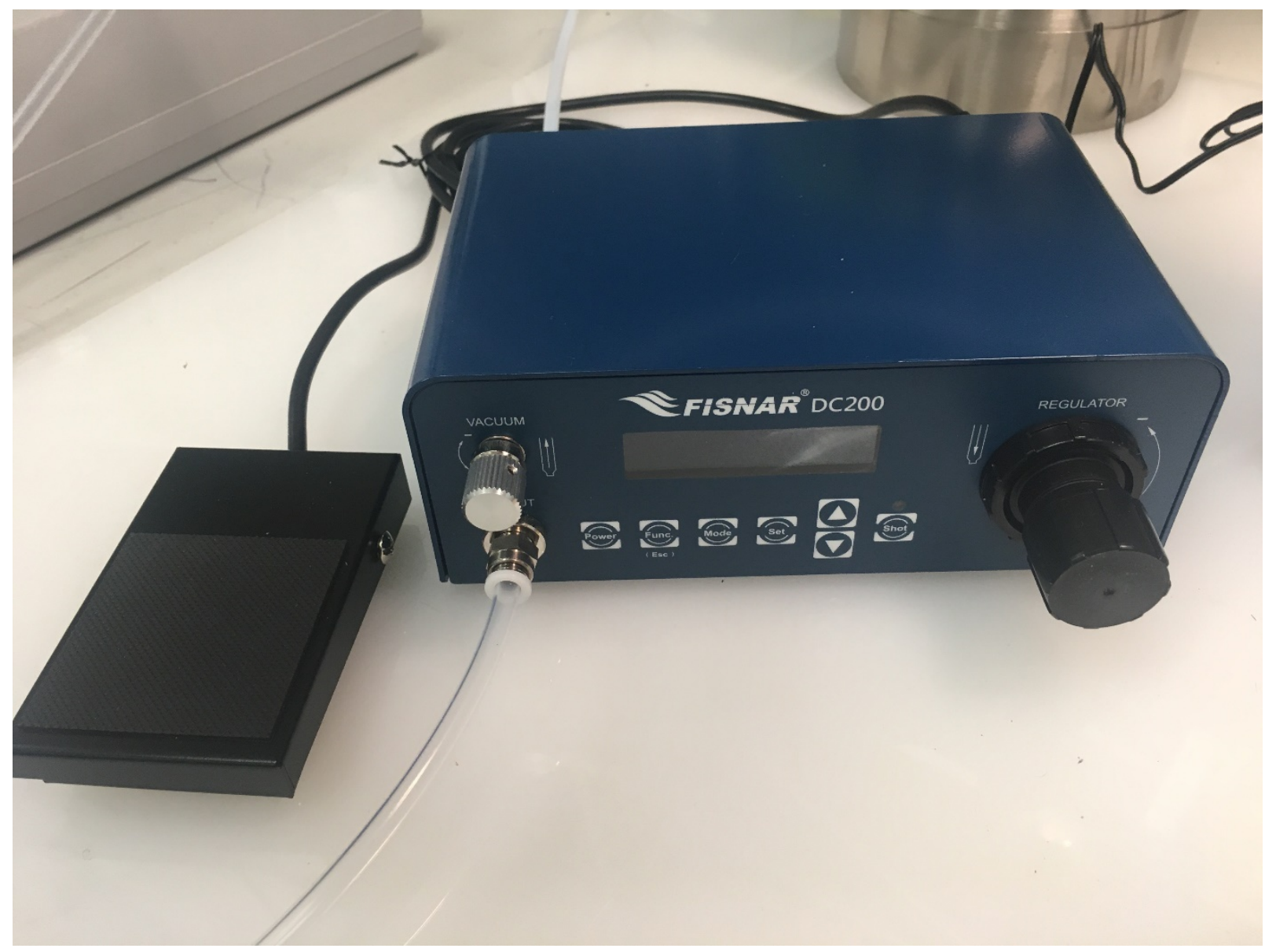

Figure 3-15: Dispensing Unit

\subsubsection{Pressurized Container}

The pressurized container in the test apparatus contains the fluid which is air fed to the nozzle for delivery. On top of the container is an external air regulator which controls the exit velocity of the shot of fluid. The increase or decrease of air pressure in the tank is proportional to the increase or decrease of exit velocity (Figure 3-10.5, Figure 3-16). 


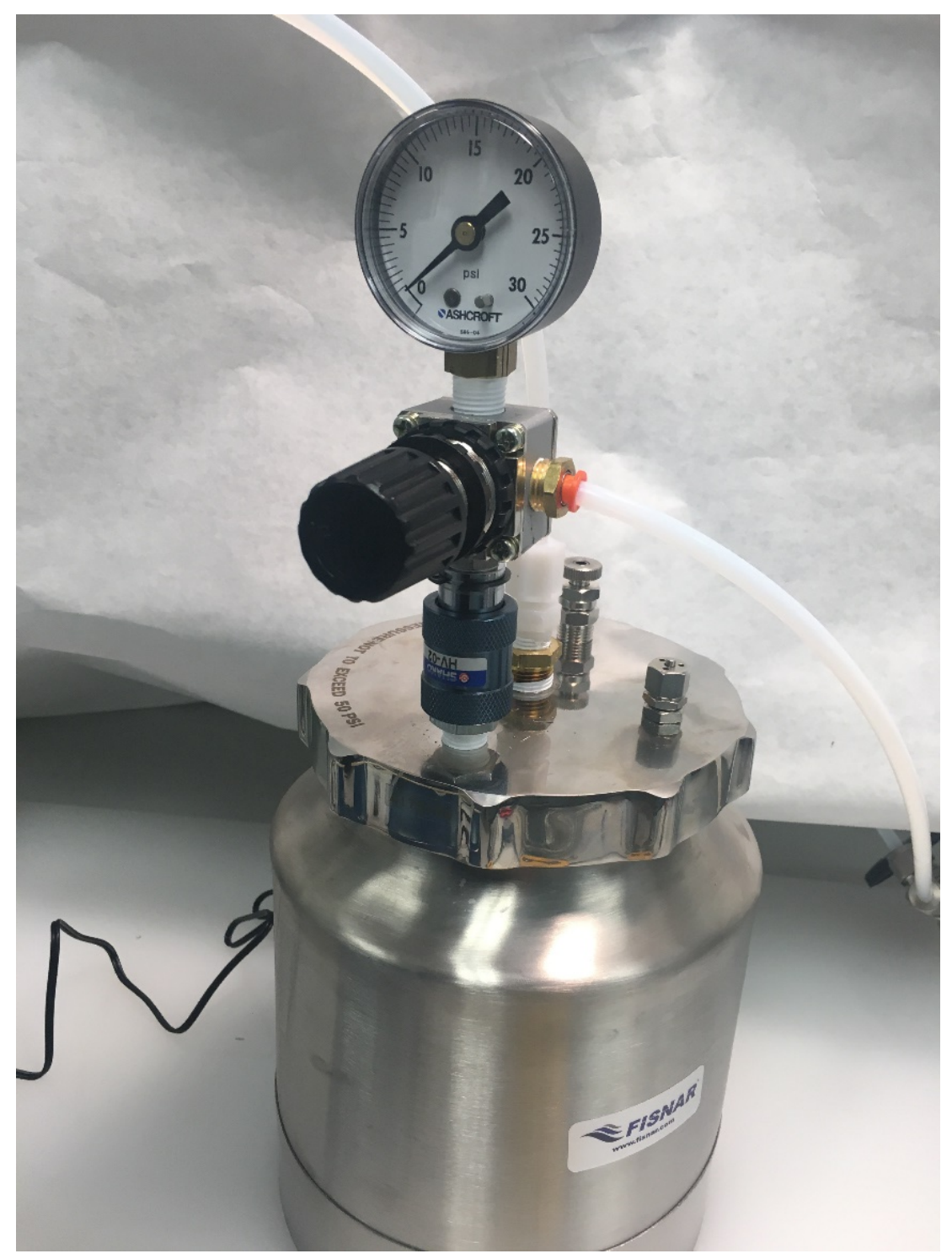

Figure 3-16: Pressurized Container 


\subsubsection{Uni-slide}

A Uni- slide stand is set up in the middle of the apparatus and offers a large range of vertical travel for the nozzle. The Uni-slide stand has a horizontal mounting bracket with which the dispensing nozzle is attached. The vertical travel of the slide allows the test to place the shot upon the headform at any vertical distance wanted. It allows for a very wide range of test requested locations for future testing. The slide has a screw track driven hand crank which gives high precision to vertical adjustments (Figure 310.6, Figure 3-17). 


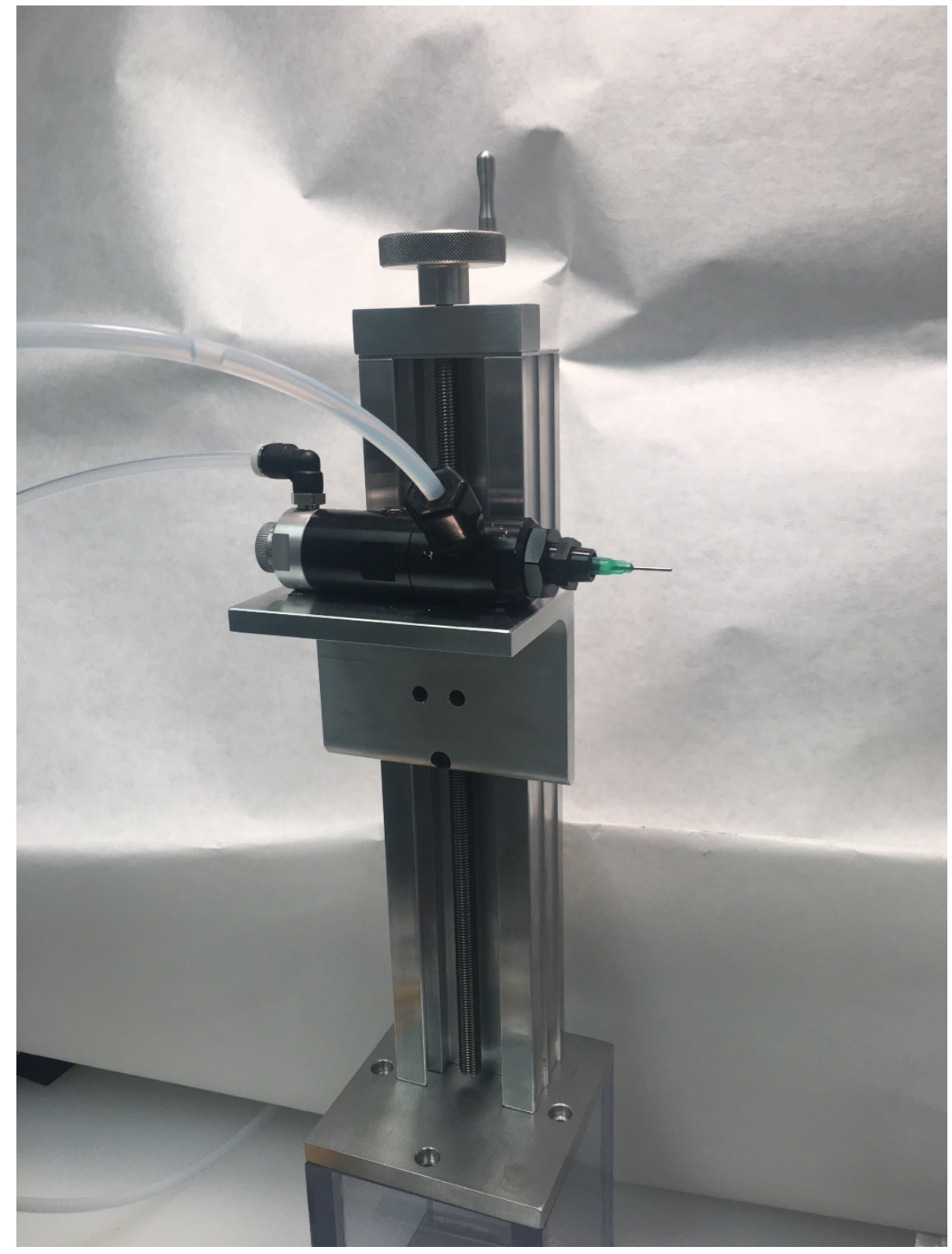

Figure 3-17: Uni-Slide 


\subsubsection{Dispensing Nozzle}

The dispensing valve chosen for this test apparatus is a multipurpose poppet-type pneumatic valve. It can dispense a wide range of liquids viscosity with precision making it ideal for the use of fluid / bodily fluids. This style of dispensing valve has its own shot volume control valve making it much more efficient at dialing in exact shot volumes for repeated testing. The valve also has a built in negative pressure control that eliminates the lumping at the end of the needle after dispensing shots. This negative pressure control feature aids in precise consistent shots (Figure 3-10.7, Figure 3-18).

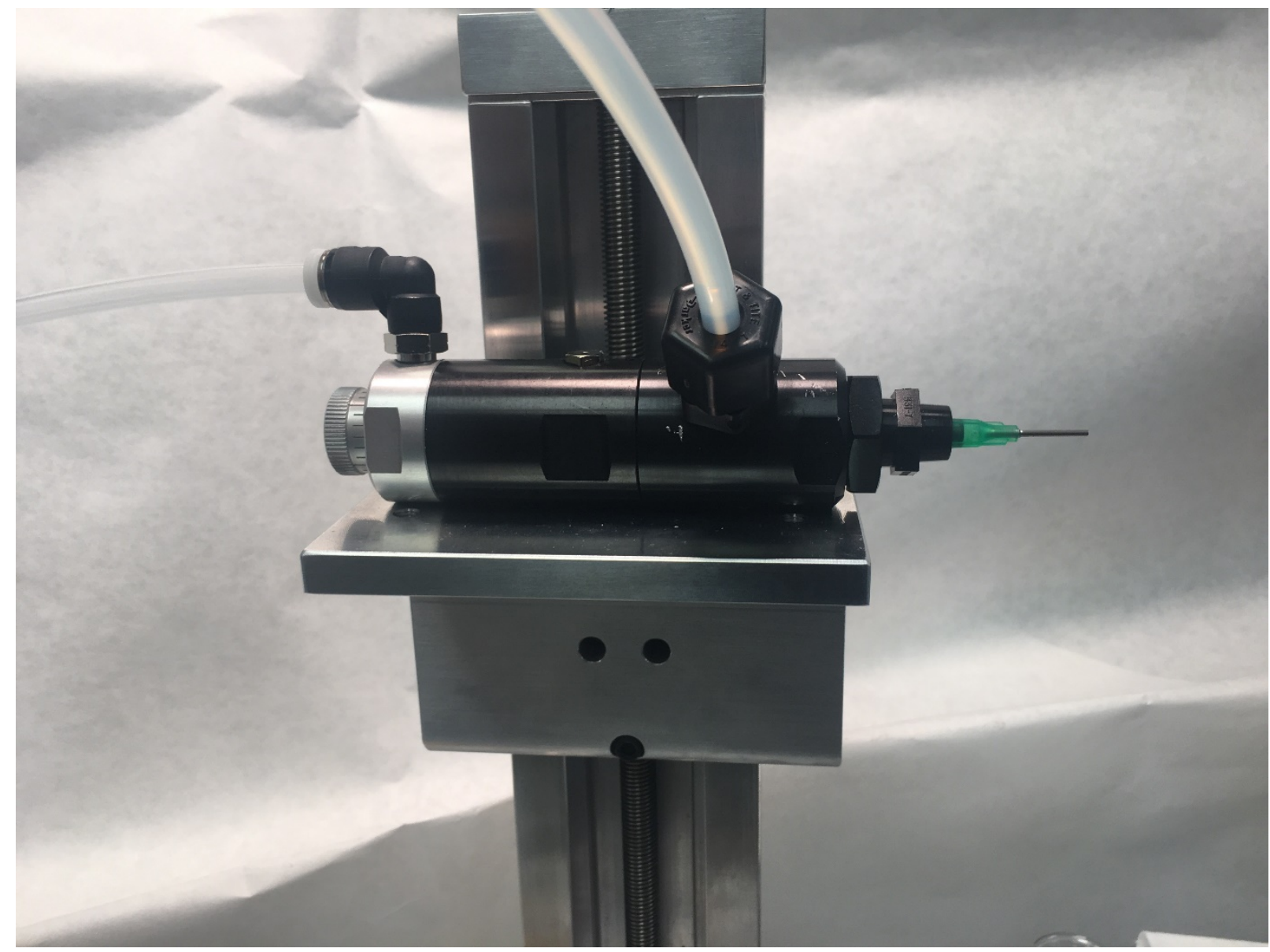

Figure 3-18: Nozzle 


\subsubsection{Fluid}

The fluid that will be used in the dispensing of shots at specific locations on the headform will be a mixture of saline and a surfactant. This new recipe yields a fluid that has physical properties much more similar to the physical properties of blood. The main property that is most concerning is having the correct viscosity of the fluid to that of blood. The average viscosity of blood is 3-4 centipoise (cP). The surface tension range for blood and body fluids is approximately $42-60$ dynes/cm (Harkins and Harkins). The lower end of the range of surface tension, the higher penetration it will have. By using the saline, it is simulating the typical bodily fluids that could be expelled or come in contact with another person. Using the Saline in addition to a fastacting surfactant will simulate a worst case scenario as well as bring the surface tension properties much closer to real blood properties (Portnoff). In addition to the saline and a fast acting surfactant, we added fluorescein dye which is highly visible under blue light. This dye will aid in detection of any fluid on the eye of the headform and will yield in clear decisions of pass or fail results.

\subsection{Testing}

\subsubsection{Hypothesis}

This test apparatus is designed to evaluate the efficacy of eye and face protection against biological hazards such as blood borne pathogens. The null hypothesis of this study is that current ANSI Z87.1 eye protectors will not pass the criteria from this test to be labeled for protection against biological hazards. 
By using this test apparatus and testing procedure, typical eye and face protection was tested against the testing apparatus to see how effective they are with the apparatus's replicated biohazardous conditions. These tests evaluate coverage protection from biohazards, however they will not evaluate the ability of PPE to be decontaminated from biohazards. With this testing apparatus we are looking for a test method to represent or mimic the biological hazards that are found in the workplace environments of clinical laboratories, surgical/nursing, and dentistry. When looking at these occupations the probability of being exposed is relatively high, given that statistics report it happening frequently and more than once a year. The severity of this risk is serious or disabling and life threatening which puts the risk assessment for these occupations for biological hazards of splashes to the eyes and face as a high risk. The testing apparatus will sufficiently produce repeatable testing criteria and standards across a range of eye and face protectors that are being used in the 3 occupational settings. We are using this testing apparatus and test method to develop a basis of testing of eye and face protectors that reduce exposures to the areas of concern for the hazardous occupations mentioned.

\subsubsection{Eye and Face Protectors}

Types, models, and combinations of eye and face protection vary from occupation to occupation, e.g. a surgeon will don different eye and face PPE than a dentist would, therefore a variety of samples will be collected from different manufacturers and occupational settings. The different types, styles, and combinations of currently used eye and face protectors will be from the main high hazard occupations that are being explored (Dental, Health Care, and Laboratory). To determine the most popular brands/models, a one question survey will be sent to health care professionals in the 
various fields to ascertain their preference. The top models will be evaluated using the criteria described below, regardless if they are stamped with ANSI Z87.1 or not.

All tests being conducted will be randomized for the order in which they are conducted (Spurt positions 1-4 / Spray positions 1-4). The first initial spurt tests will all be conducted at a high velocity as well as high volume of fluid ( $2 \mathrm{ml}$ spurt / $1 \mathrm{ml}$ spray). If the PPE passes, then there will not be any subsequent tests done under the proven assumption that if the PPE passes at high velocity and high volume then it would also pass at a lower velocity or lower volume. If the PPE fails at the High velocity and High volume, then it will be considered for examination testing under lower velocities and lower volumes of fluid.

A "high" exit velocity will be in the range of $600 \mathrm{~cm} / \mathrm{s}$. This is to mimic the varying velocities of fluids found within an occupational environment. A "high" volume of fluid will be $2 \mathrm{ml}$. A data sheet will be logged with the model and style of eye protector being tested prior to testing and then completed with the test results during testing. (Table 3-2).

\subsubsection{Test Criteria / Near Miss Ratings}

All PPE tests that are conducted will receive a Pass or Fail criteria. All tests that are given a Pass or Fail rating will also be measured for the distance that the fluid is in relation to the Pass or Fail. If the test passes then the fluid that is closest to the perimeter of the eyes, nose, or mouth will be measured and recorded. If the test fails then the fluid that is closest to the center of the area of concern (Eye, Nose, or Mouth), will be measured and recorded. The quadrant that the fluid which is measured is in will also be recorded. This quadrant is set up as a simple XY graph with corresponding 
quadrants (Figure 3-19).

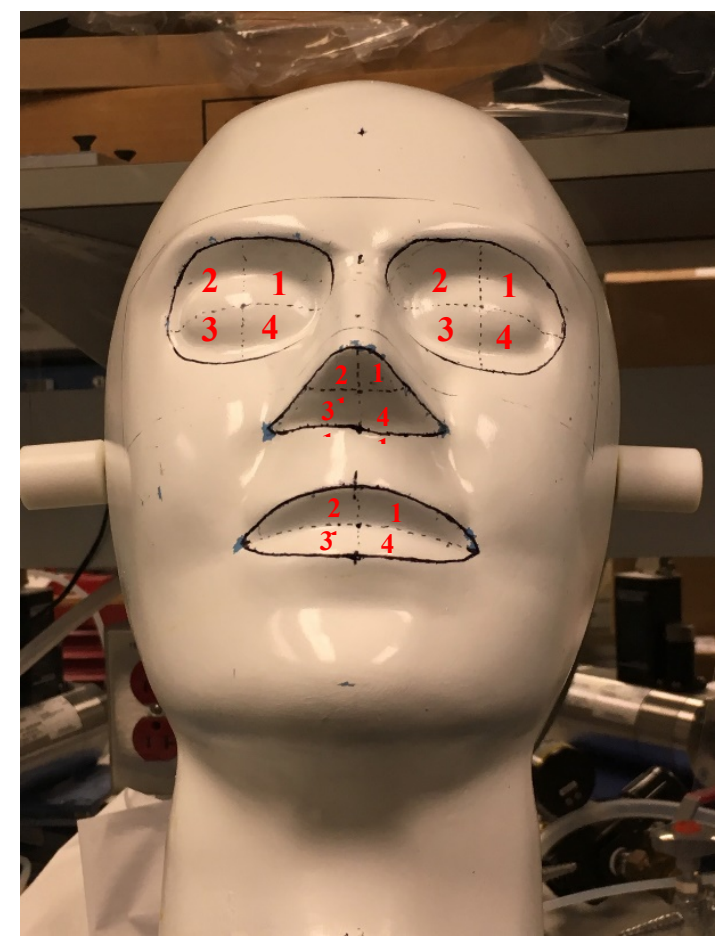

Figure 3-19: Quadrants on Headform

This test will be conducted 10 times for every ensemble that is being evaluated. A near miss rating could be given at a later date for more testing of products and helpful descriptions of how a product performs. This rating would be based off distances circling the perimeter such as fictitious concentric circles. Each region between the fictitious concentric rings will be what determines the ratings. These concentric circles will be $5 \mathrm{~mm}$ each. If the fluid is within the concerned area then if would fail and the rating therefore would be a 4 . If fluid is within $5 \mathrm{~mm}$ of the perimeter or the eyes, nose, or mouth, then the rating would a 3 ; if fluid is within $10 \mathrm{~mm}$ of the perimeter or the eyes, nose, or mouth, then the rating would a 2; if fluid is within $15 \mathrm{~mm}$ of the perimeter or the eyes, nose, or mouth, then the rating would a 1 ; if the fluid is at a greater distance than $15 \mathrm{~mm}$ from the perimeter of the eyes, nose, or mouth then it 
would get a rating of 0 . With each shot, the distance from the perimeter of the area of concern to the closest fluid would be record in the data sheet as well.

Another criteria that was evaluated is the range of protection for every ensemble. For this range of protection evaluation, the headform's ensemble will be tested on a horizontal plane and rotated about it. These degrees of rotation will be tested at 0,30 , 60 , and 90 degrees of rotation to the right, and then 30,60 , and 90 degrees to the left (degrees of rotation are oriented from the nozzle being the origin). The headform's ensemble will then be tested on a vertical plane. These degrees of rotation will be tested at $0,30,60$, and near 90 degrees of rotation to the up, and then 30,60 , and near 90 degrees to the down (degrees of rotation are oriented from the nozzle being the origin) (Figure 3-20: Range of Protection Horizontal, Figure 3-21: Range of Protection Vertical, Table 3-3: Range of Protection Data Sheet).

With this experimental design the outcomes are categorical and are dependent variables with two possible values (Pass or Fail) and all factors are categorical or indicator functions, the best model to use is a $2 \times 4$ logistic regression. By using a 2x4 table we can get a good look at unadjusted preliminary data from which we can draw estimates about the ensembles. Based on the time frame and limited resources (money and material) we decided upon a sample size of 10 replications. With this sample size it will give us 80 observations per ensemble with 800 total observations. This will provide a $2 \times 4 \times 10$ model which can be looked at for interactions between ensemble and Spurt/Spray as well as interactions between ensemble and head positions. 


\begin{tabular}{|c|c|c|c|c|c|c|c|c|c|c|c|c|c|}
\hline 1 & Brand & Model & & & Eyes & & & Nose & & & Mouth & & \\
\hline & x 10 & & & & $\begin{array}{l}\text { Pass } \\
\text { Fail }\end{array}$ & \begin{tabular}{|l} 
Dist. to \\
closest \\
fluid \\
$(\mathrm{mm})$
\end{tabular} & 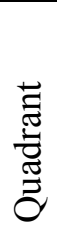 & $\begin{array}{l}\text { Pass } \\
\text { Fail }\end{array}$ & $\begin{array}{l}\text { Dist. to } \\
\text { closest } \\
\text { Fluid } \\
(\mathrm{mm})\end{array}$ & 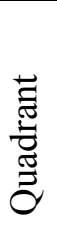 & $\begin{array}{l}\text { Pass } \\
\text { Fail }\end{array}$ & $\begin{array}{l}\text { Dist. to } \\
\text { closest } \\
\text { Fluid } \\
(\mathrm{mm})\end{array}$ & 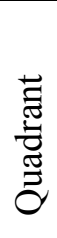 \\
\hline 1 & Spurt & $\begin{array}{l}\text { High } \\
\text { Vel. } \\
635 \\
\mathrm{~cm} / \mathrm{s}\end{array}$ & $\begin{array}{l}\text { High } \\
\text { Vol. } \\
(2 \mathrm{ml})\end{array}$ & Up & & & & & & & & & \\
\hline 2 & Spurt & $\begin{array}{l}\text { High } \\
\text { Vel. } \\
635 \\
\mathrm{~cm} / \mathrm{s}\end{array}$ & $\begin{array}{l}\text { High } \\
\text { Vol. } \\
(2 \mathrm{ml})\end{array}$ & Down & & & & & & & & & \\
\hline 3 & Spurt & $\begin{array}{l}\text { High } \\
\text { Vel. } \\
635 \\
\mathrm{~cm} / \mathrm{s}\end{array}$ & $\begin{array}{l}\text { High } \\
\text { Vol. } \\
(2 \mathrm{ml})\end{array}$ & Right & & & & & & & & & \\
\hline 4 & Spurt & $\begin{array}{l}\text { High } \\
\text { Vel. } \\
635 \\
\mathrm{~cm} / \mathrm{s}\end{array}$ & $\begin{array}{l}\text { High } \\
\text { Vol. } \\
(2 \mathrm{ml})\end{array}$ & L & & & & & & & & & \\
\hline 1 & Spray & $\begin{array}{l}500 \\
\mathrm{~cm} / \mathrm{s}\end{array}$ & $1 \mathrm{ml}$ & $\mathrm{Up}$ & & & & & & & & & \\
\hline 2 & Spray & $\begin{array}{l}500 \\
\mathrm{~cm} / \mathrm{s}\end{array}$ & $1 \mathrm{ml}$ & Down & & & & & & & & & \\
\hline 3 & Spray & $\begin{array}{c}500 \\
\mathrm{~cm} / \mathrm{s}\end{array}$ & $1 \mathrm{ml}$ & Right & & & & & & & & & \\
\hline 4 & Spray & $\begin{array}{l}500 \\
\mathrm{~cm} / \mathrm{s}\end{array}$ & $1 \mathrm{ml}$ & Left & & & & & & & & & \\
\hline
\end{tabular}

Table 3-2: Eye Protector Data Sheet 


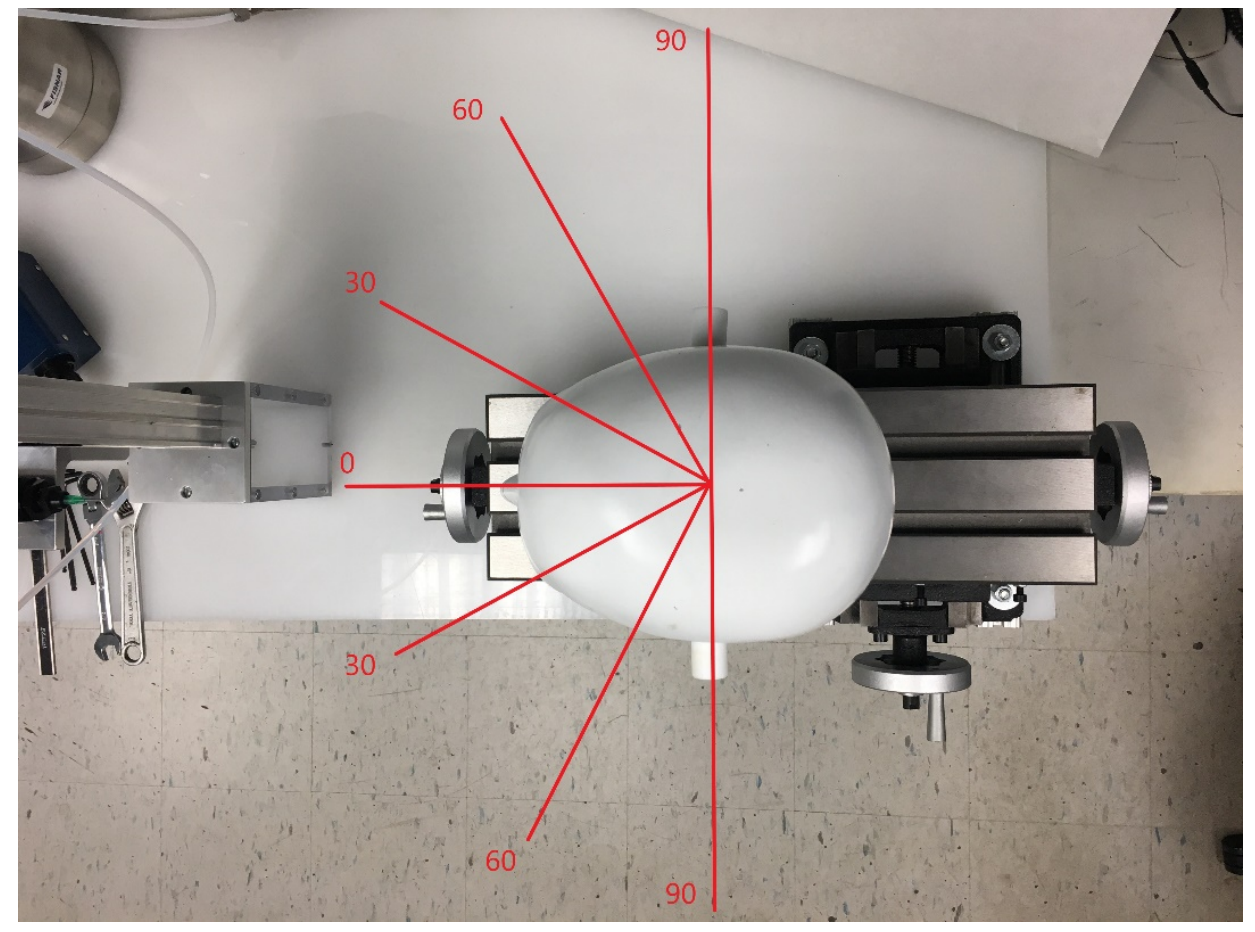

Figure 3-20: Range of Protection Horizontal

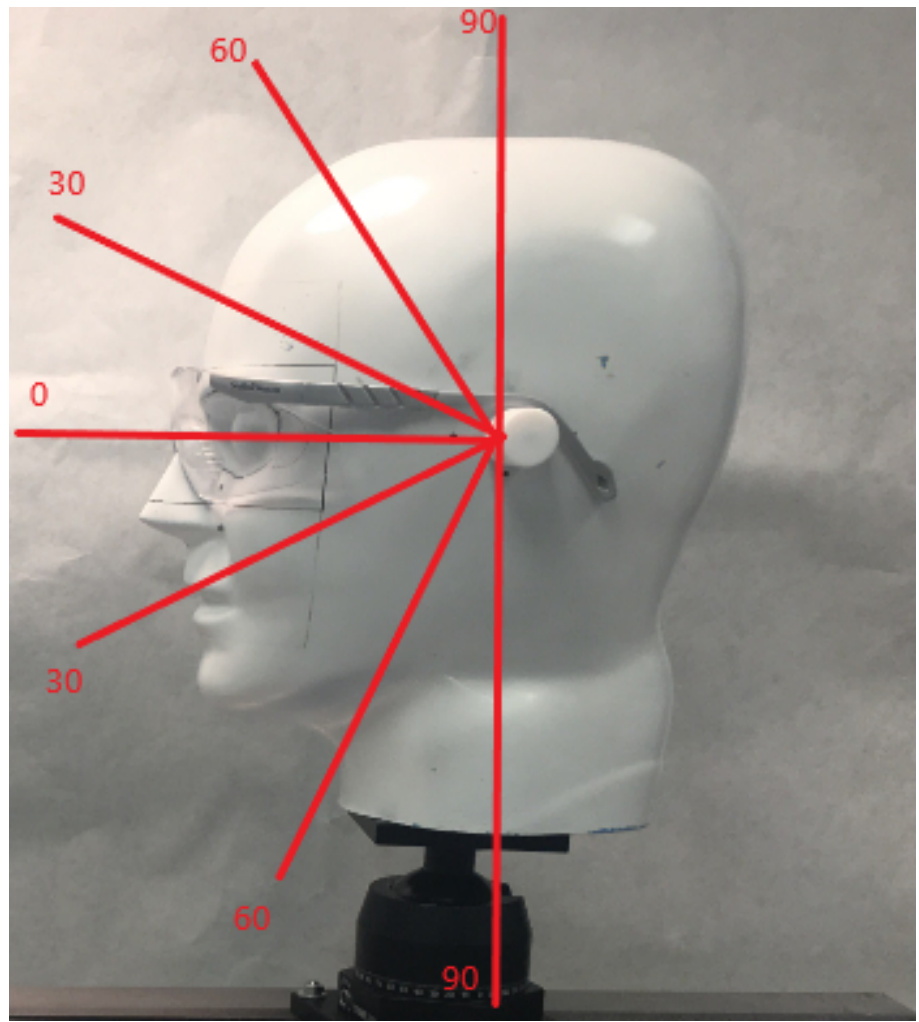

Figure 3-21: Range of Protection Vertical 


\begin{tabular}{|c|c|c|c|c|c|c|c|c|c|c|c|c|c|}
\hline $\begin{array}{l}\text { Repeat } \\
\text { x } 1\end{array}$ & & & & & Eyes & & & Nose & & & Mouth & & \\
\hline & & & & & $\begin{array}{l}\text { Pass } \\
\text { Fail }\end{array}$ & $\begin{array}{l}\text { Dist. } \\
\text { To } \\
\text { Closest } \\
\text { Fluid } \\
\mathrm{mm}\end{array}$ & $\begin{array}{l}\frac{1}{\frac{1}{\pi}} \\
\frac{0}{0} \\
\frac{\pi}{0} \\
\frac{0}{2}\end{array}$ & $\begin{array}{l}\text { Pass } \\
\text { Fail }\end{array}$ & $\begin{array}{l}\text { Dist. } \\
\text { To } \\
\text { Closest } \\
\text { Fluid } \\
\mathrm{mm}\end{array}$ & $\begin{array}{l}\frac{n}{2} \\
\frac{\pi}{\pi} \\
\frac{\pi}{0} \\
\frac{\pi}{2} \\
\sigma\end{array}$ & $\begin{array}{l}\text { Pass } \\
\text { Fail }\end{array}$ & $\begin{array}{l}\text { Dist. } \\
\text { To } \\
\text { Closest } \\
\text { Fluid } \\
\mathrm{mm}\end{array}$ & $\begin{array}{l}\frac{1}{c} \\
\frac{\pi}{0} \\
\frac{0}{0} \\
\frac{\pi}{0} \\
\frac{0}{\sigma}\end{array}$ \\
\hline 90 & Spurt & $\begin{array}{l}\text { High } \\
\text { Vel. } \\
635 \\
\mathrm{~cm} / \mathrm{s}\end{array}$ & $\begin{array}{l}\text { High } \\
\text { Volume } \\
2 \mathrm{ml}\end{array}$ & $\begin{array}{l}\text { Horizontal } \\
\text { plane }\end{array}$ & & & & & & & & & \\
\hline 60 & Spurt & $\begin{array}{l}\text { High } \\
\text { Vel. } \\
635 \\
\mathrm{~cm} / \mathrm{s}\end{array}$ & $\begin{array}{l}\text { High } \\
\text { Volume } \\
2 \mathrm{ml}\end{array}$ & $\begin{array}{l}\text { Horizontal } \\
\text { plane }\end{array}$ & & & & & & & & & \\
\hline 30 & Spurt & $\begin{array}{l}\text { High } \\
\text { Vel. } \\
635 \\
\mathrm{~cm} / \mathrm{s}\end{array}$ & $\begin{array}{l}\text { High } \\
\text { Volume } \\
2 \mathrm{ml}\end{array}$ & $\begin{array}{l}\text { Horizontal } \\
\text { plane }\end{array}$ & & & & & & & & & \\
\hline 0 & Spurt & $\begin{array}{l}\text { High } \\
\text { Vel. } \\
635 \\
\mathrm{~cm} / \mathrm{s}\end{array}$ & $\begin{array}{l}\text { High } \\
\text { Volume } \\
2 \mathrm{ml}\end{array}$ & $\begin{array}{l}\text { Horizontal } \\
\text { plane }\end{array}$ & & & & & & & & & \\
\hline 30 & Spurt & $\begin{array}{l}\text { High } \\
\text { Vel. } \\
635 \\
\mathrm{~cm} / \mathrm{s}\end{array}$ & $\begin{array}{l}\text { High } \\
\text { Volume } \\
2 \mathrm{ml}\end{array}$ & $\begin{array}{l}\text { Horizontal } \\
\text { plane }\end{array}$ & & & & & & & & & \\
\hline 60 & Spurt & $\begin{array}{l}\text { High } \\
\text { Vel. } \\
635 \\
\mathrm{~cm} / \mathrm{s} \\
\end{array}$ & $\begin{array}{l}\text { High } \\
\text { Volume } \\
2 \mathrm{ml}\end{array}$ & $\begin{array}{l}\text { Horizontal } \\
\text { plane }\end{array}$ & & & & & & & & & \\
\hline 90 & Spurt & $\begin{array}{l}\text { High } \\
\text { Vel. } \\
635 \\
\mathrm{~cm} / \mathrm{s} \\
\end{array}$ & $\begin{array}{l}\text { High } \\
\text { Volume } \\
2 \mathrm{ml}\end{array}$ & $\begin{array}{l}\text { Horizontal } \\
\text { plane }\end{array}$ & & & & & & & & & \\
\hline 90 & Spurt & $\begin{array}{l}\text { High } \\
\text { Vel. } \\
635 \\
\mathrm{~cm} / \mathrm{s} \\
\end{array}$ & $\begin{array}{l}\text { High } \\
\text { Volume } \\
2 \mathrm{ml}\end{array}$ & $\begin{array}{l}\text { Vertical } \\
\text { Plane }\end{array}$ & & & & & & & & & \\
\hline 60 & Spurt & $\begin{array}{l}\text { High } \\
\text { Vel. } \\
635 \\
\mathrm{~cm} / \mathrm{s}\end{array}$ & $\begin{array}{l}\text { High } \\
\text { Volume } \\
2 \mathrm{ml}\end{array}$ & $\begin{array}{l}\text { Vertical } \\
\text { Plane }\end{array}$ & & & & & & & & & \\
\hline 30 & Spurt & $\begin{array}{l}\text { High } \\
\text { Vel. } \\
635 \\
\mathrm{~cm} / \mathrm{s}\end{array}$ & $\begin{array}{l}\text { High } \\
\text { Volume } \\
2 \mathrm{ml}\end{array}$ & $\begin{array}{l}\text { Vertical } \\
\text { Plane }\end{array}$ & & & & & & & & & \\
\hline 0 & Spurt & High & High & Vertical & & & & & & & & & \\
\hline
\end{tabular}




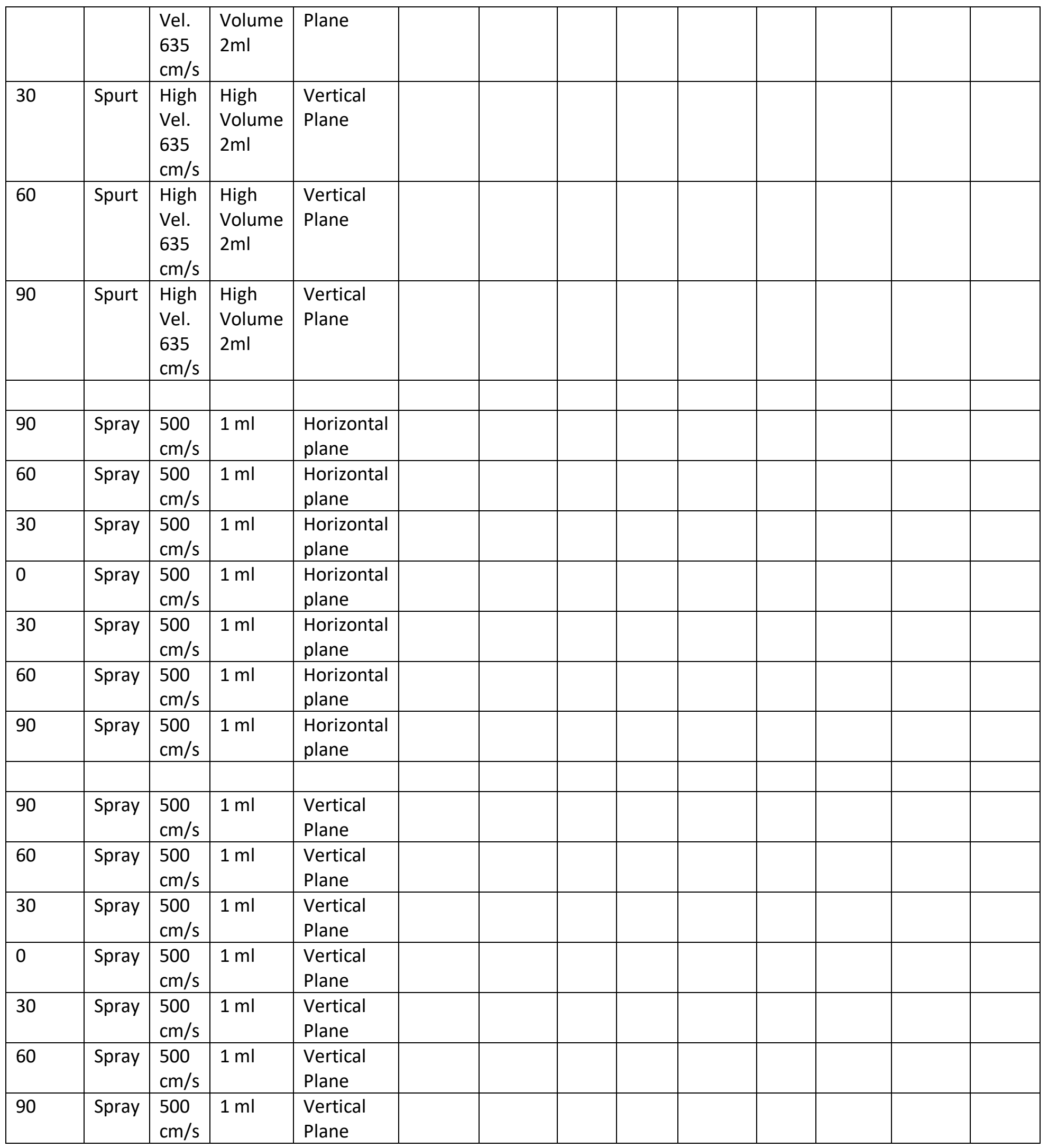

Table 3-3: Range of Protection Data Sheet 


\subsubsection{Blue light Detection}

A strong blue light is used to shine onto the headform for optimal visual inspection of a pass or fail rating of any fluid that may reach the headforms eyes. A light source of 494 $\mathrm{nm}$ (light blue) will make a $512 \mathrm{~nm}$ color (bright green) of the fluid.

\subsubsection{Sight Laser}

The addition of a small battery operated cross haired laser will be mounted to the mounting bracket on the Uni-slide (Figure 3-22). This laser will project bright horizontal and vertical lines onto the anthropometric head for leveling and aligning it into its specified test manipulations quickly and efficiently (Figure 3-23). Although this sight laser is not a "must have" for this apparatus to function, it will highly aid in testing.

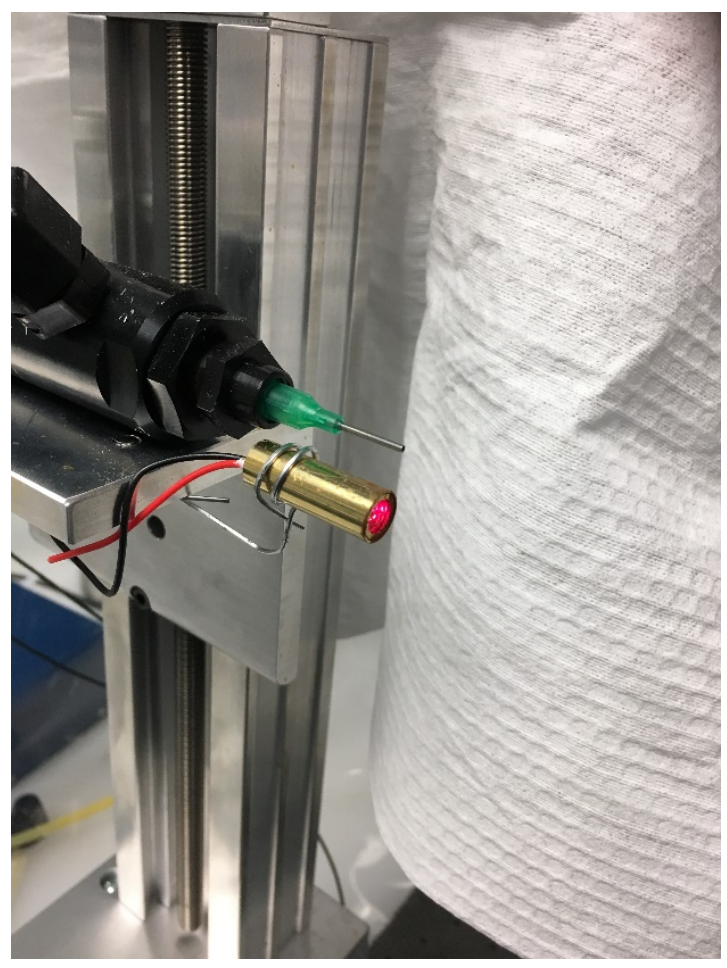

Figure 3-22: Laser Mounting to Uni-Slide Bracket 


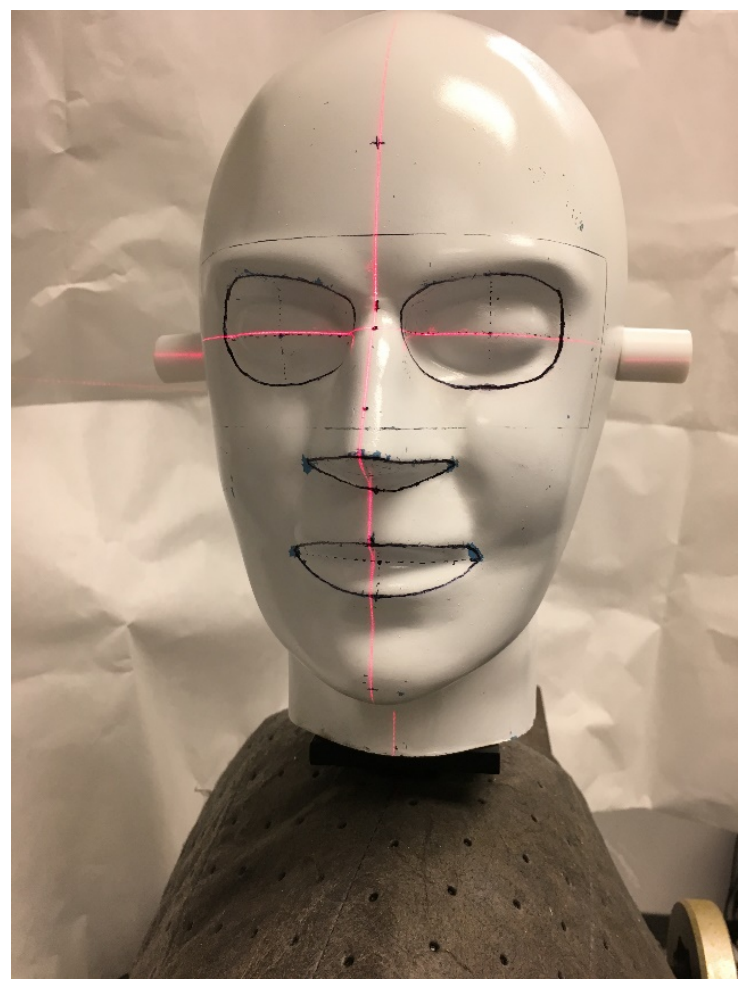

Figure 3-23: Laser Projected onto Headform

\subsubsection{Pass / Fail criteria}

Once the eye wear and corresponding ensemble (e.g. eye protector and face mask) is mounted on the European $50^{\text {th }}$ percentile or equivalent headform in a wearer's normal position, the tester will then verify the target locations / distances to be accurate. The tester will then turn on the blue light used for visual indication of any fluid on the eyes, nose, or mouth of the headform and ensure that the lighting is suitable for inspection. The tester will administer a single shot of fluid to the targeted area, ensuring that the fluid hits the target area of the headform, the tester will then visually inspect the headforms eyes, nose, and mouth for any fluid within $5 \mathrm{sec}$ of impact. If the tester suspects that there is fluid on the eye of the headform, they may use a cotton absorbent 
swab or similar item to lightly daub the eye area. If there is no evidence of fluid on the headforms eyes, nose, or mouth, then the eye protector and corresponding ensemble passes that particular targeted location for the specified shot criteria. The eye protector and corresponding face mask must pass all spurt and spray target locations for it to pass the entire test. If there is evidence of fluid on the eyes of the headform then the eye protector fails that particular targeted location; if there is evidence of fluid on the nose or mouth of the headform then the face mask fails that particular targeted location. The tester will record what type of shot the eye protector or face mask failed on (spurt or spray) as well as the targeted location (Up, Down, Right, Left) (Table 3-1).

Referencing Figures 3-24 through 3-30 below are some preliminary tests done to show the detection of the dye in a blue light with a spray and spurt test on the headform. The headform was not manipulated with any angles and was placed $30.48 \mathrm{~cm}$ away with a targeted location centered at the bridge of the nose. The headform was angled for the best light condition for a picture but was not angled for the duration of the test. The exit velocity was estimated to be around $435 \mathrm{~cm} / \mathrm{s}$. If this location and particular eye protector were to be placed in the testing criteria, they would have passed the spray test but would have failed the spurt test. Once the spray and spurt were administered, the headform was thoroughly wiped off and checked to make sure there was no residual fluid left behind (Figure 3-26). 


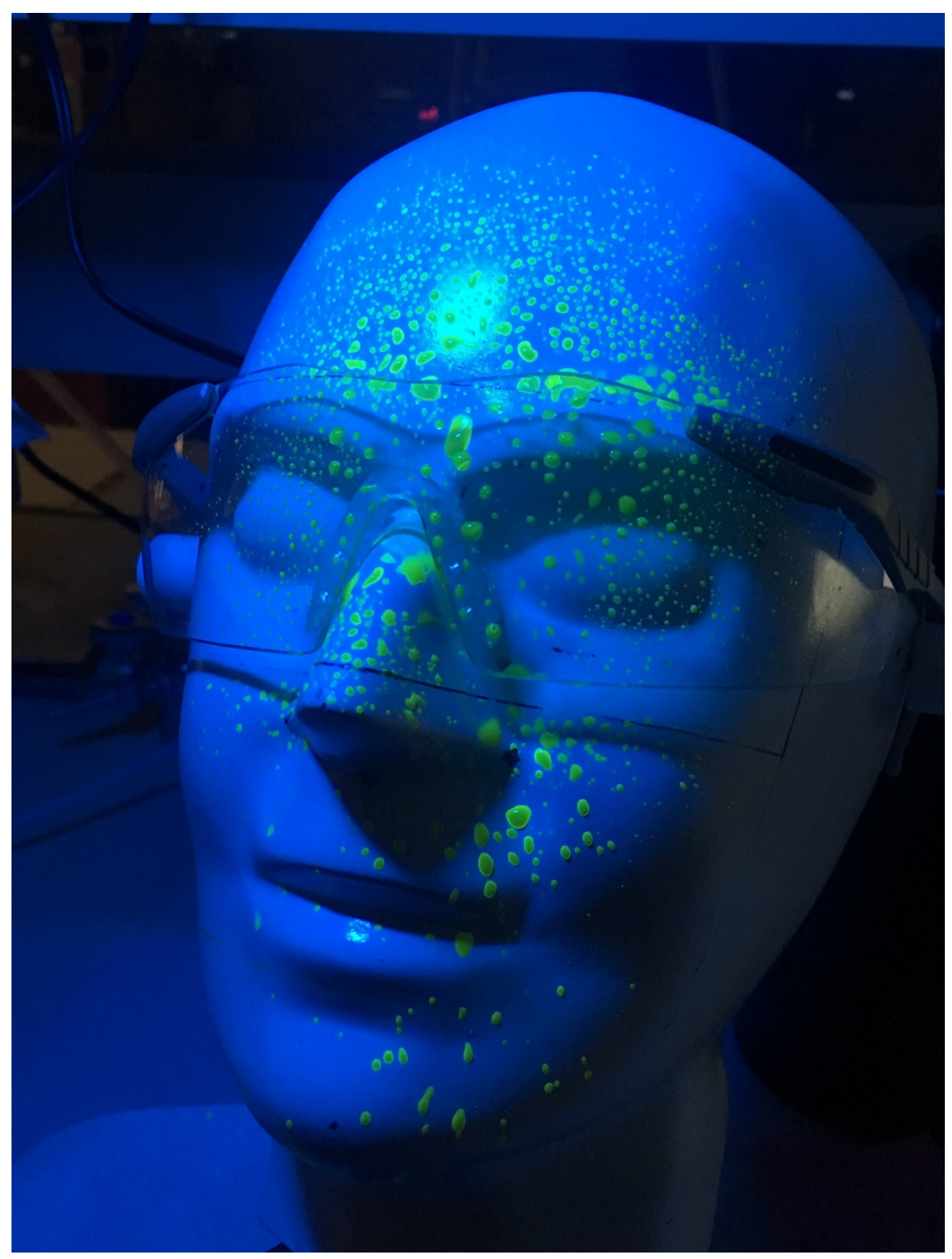

Figure 3-24: Spray Test- Glasses On

Figure 3-24 photo was immediately taken after the spray was conducted. The glasses will be removed carefully and a visual inspection of the eyes will take place next to determine if this is a "Pass" or "Fail." 


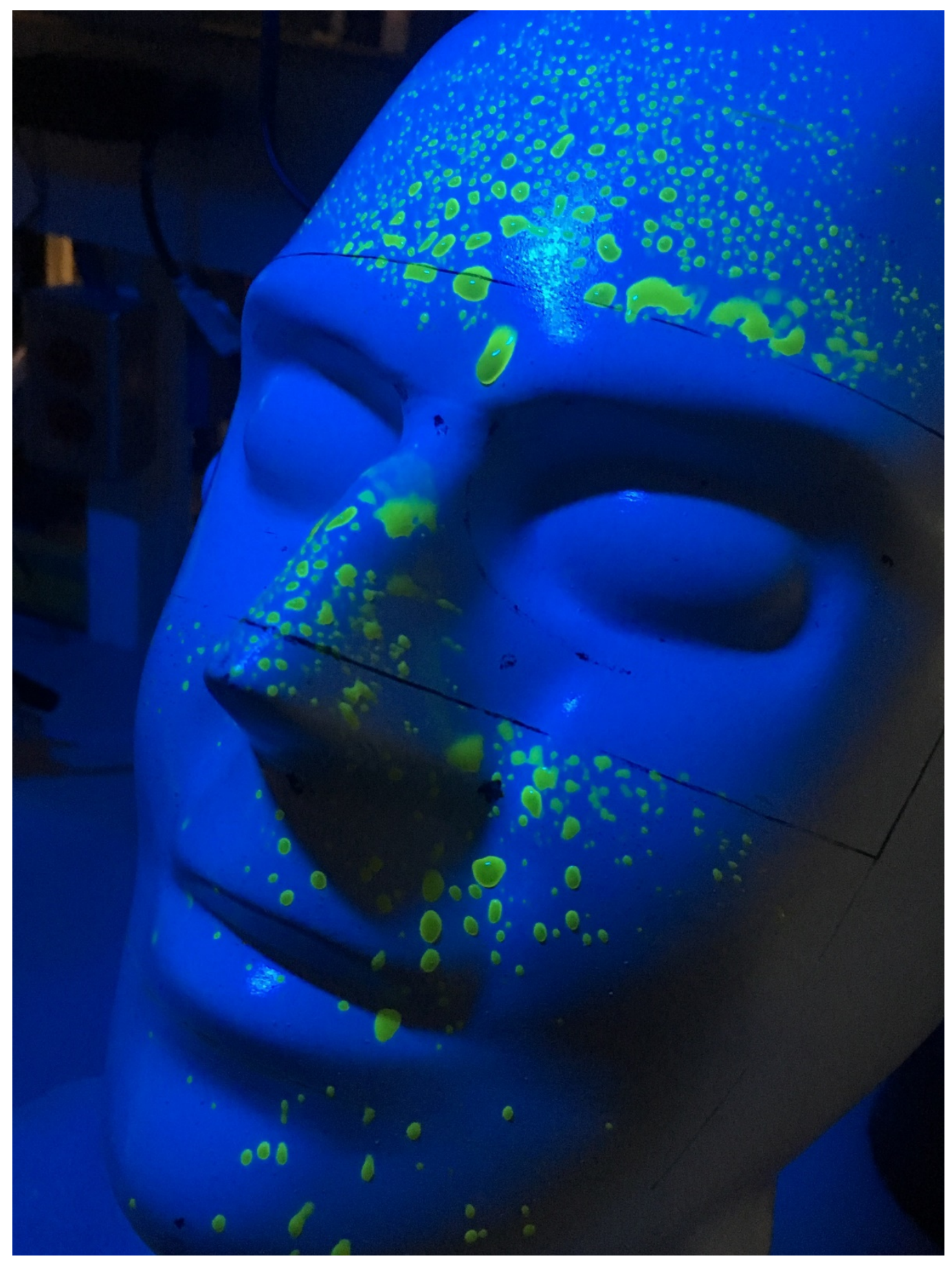

Figure 3-25: Eye Criteria Spray Test without Glasses- "Pass"

After the glasses have been removed a detailed visual inspection was conducted on the eyes of the headform. Figure 3-25 shows that no fluid is on the eyes of the headform therefore classifying this particular section of the spray test as a "Pass" This example 
test is solely looking at penetration to the eyes of the wearer. The nose and mouth are not part of this test shot. The wearer should be wearing other appropriate PPE to protect the nose and mouth area. When conducting a test on complete PPE attire on the headform, a pass or fail will also be assigned to the equipment being used to protect the nose and mouth. If any fluid or fluid residue is within the area of concern for the nose then a "Fail" is assigned. If any fluid or fluid residue is within the area of concern of the mouth then a "Fail" is assigned. If fluid outside of the perimeter of the area of concern of the nose or mouth then a "Pass" will be assigned. 


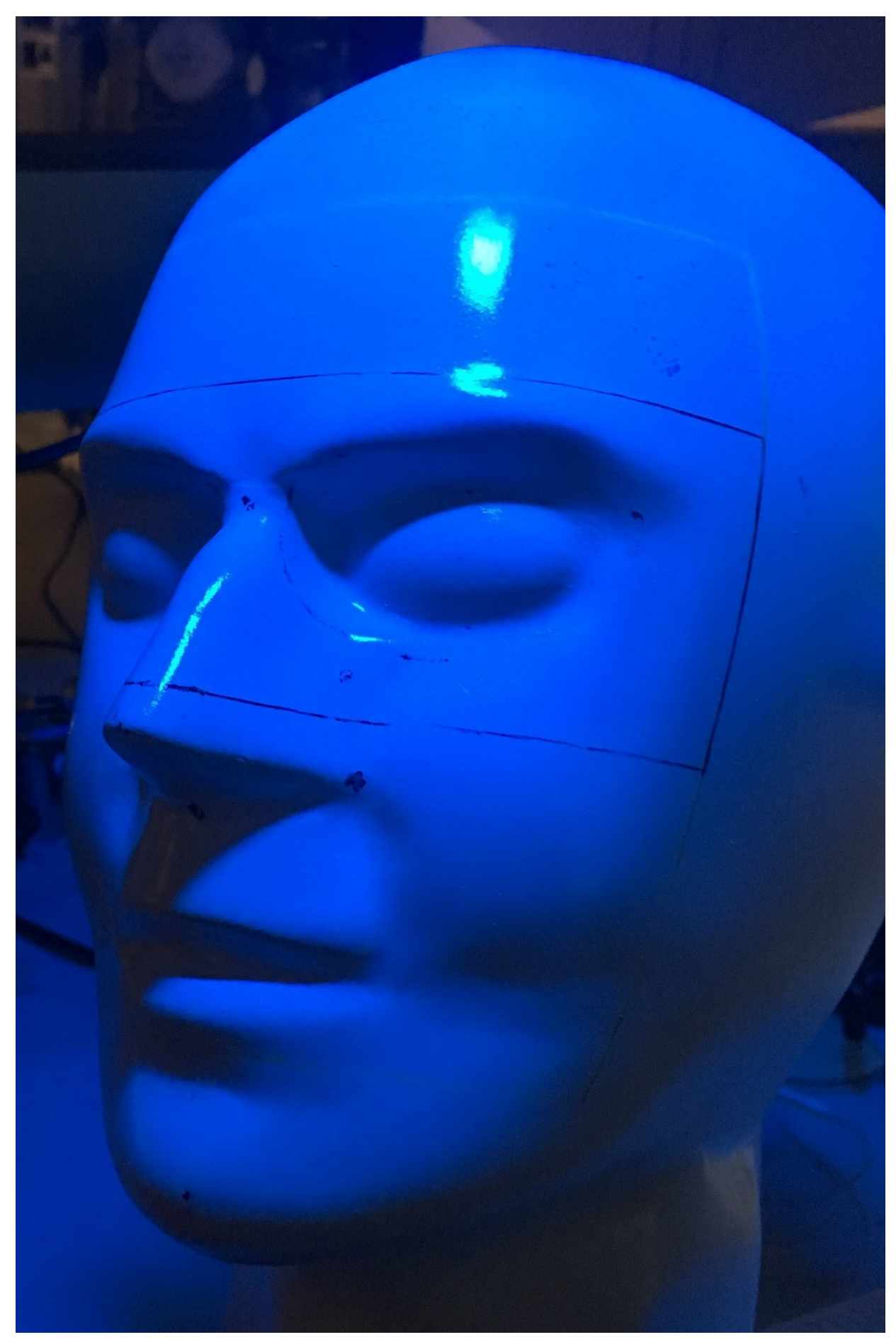

Figure 3-26: Cleaned Headform

Figure 3-26 shows that after a test has been conducted the headform can easily be wiped off and visually checked for any leftover fluid or fluid residue. The test apparatus was then changed over to next conduct a spurt test. 


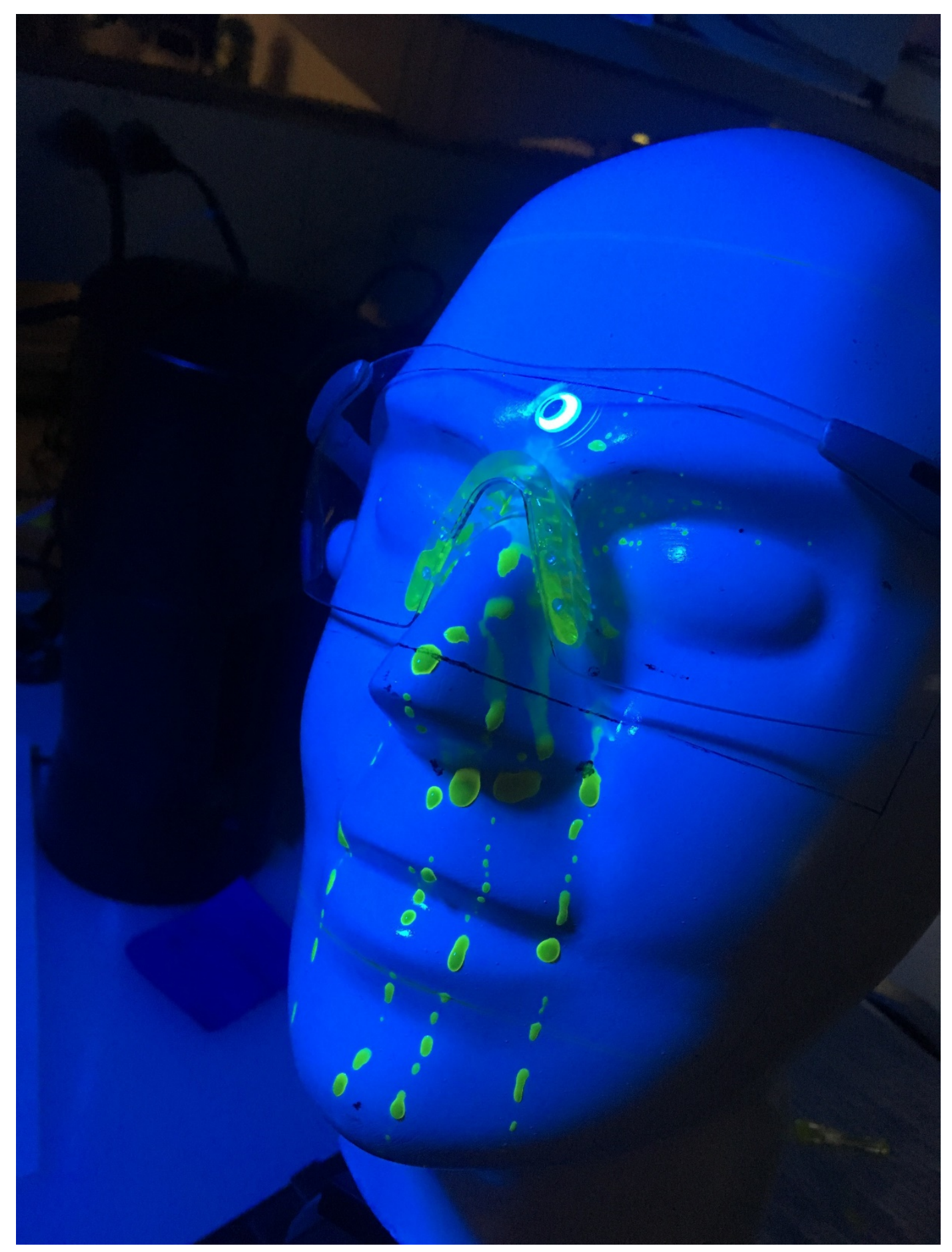

Figure 3-27: Spurt Test - Glasses On

Figure 3-27 photo was taken immediately after the spurt test was conducted. The glasses will be removed carefully and a visual inspection of the eyes will take place next to determine if this is a "Pass" or "Fail." 


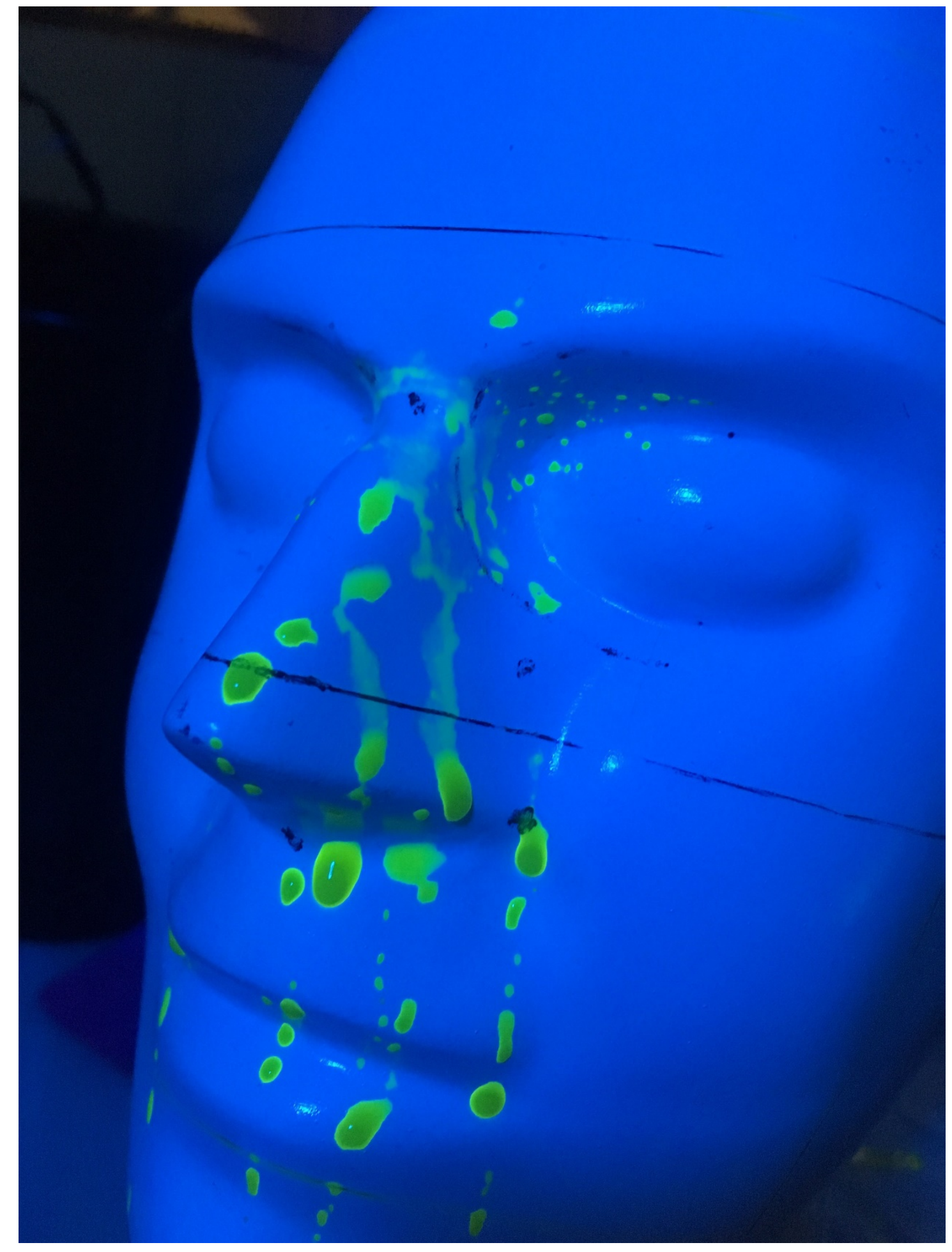

Figure 3-28: Spurt Test without Glasses - "Fail"

After the glasses have been removed a detailed visual inspection was conducted on the eyes of the headform. Figure 3-28 shows that fluid is on the eyes of the headform 
therefore classifying this particular section of the spurt test as a "Fail"

As one can clearly see that for a pass or fail it is very easily distinguished whether or not the fluid has penetrated the glasses and is on the eye of the headform or not (Figure 3-28). In the following figures (Figure 3-29 and 3-30), one can see the entire shot (spray and spurt) as it exits from the nozzle and impacts on the targeted location of the headform. From there one can see how the fluid dispersers depending on the different shot pattern. The spurt is much more penetrable to the headforms eyes than the spray is. Whereas the spray covers more facial area than the spurt. This test was conducted as an example to show how the fluid is used for verifying pass and fail criteria. When a real test is conducted the headform will be fully fitted with appropriate eye and face protection which covers the nose and mouth.

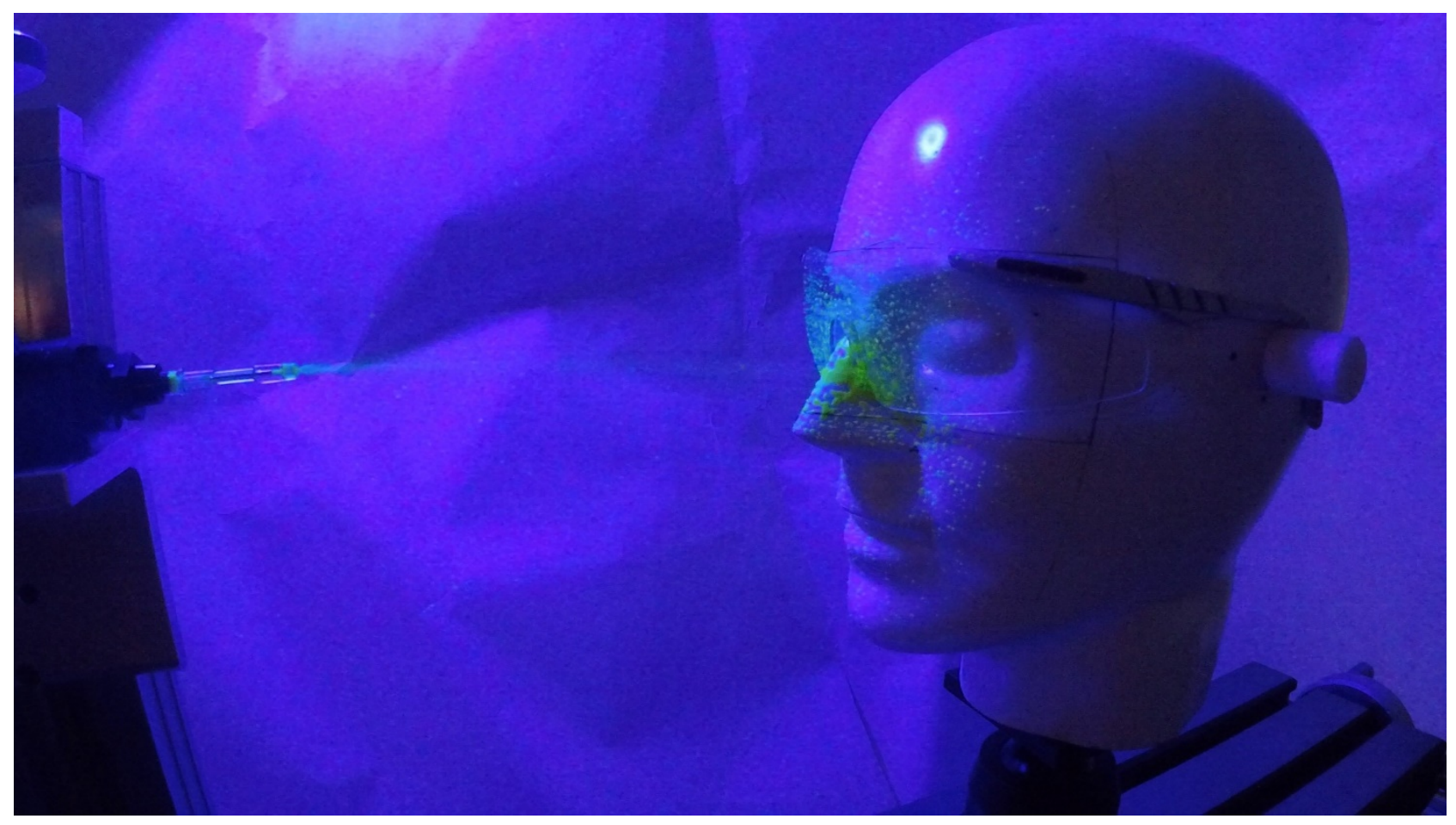

Figure 3-29: Spray in Real Time 


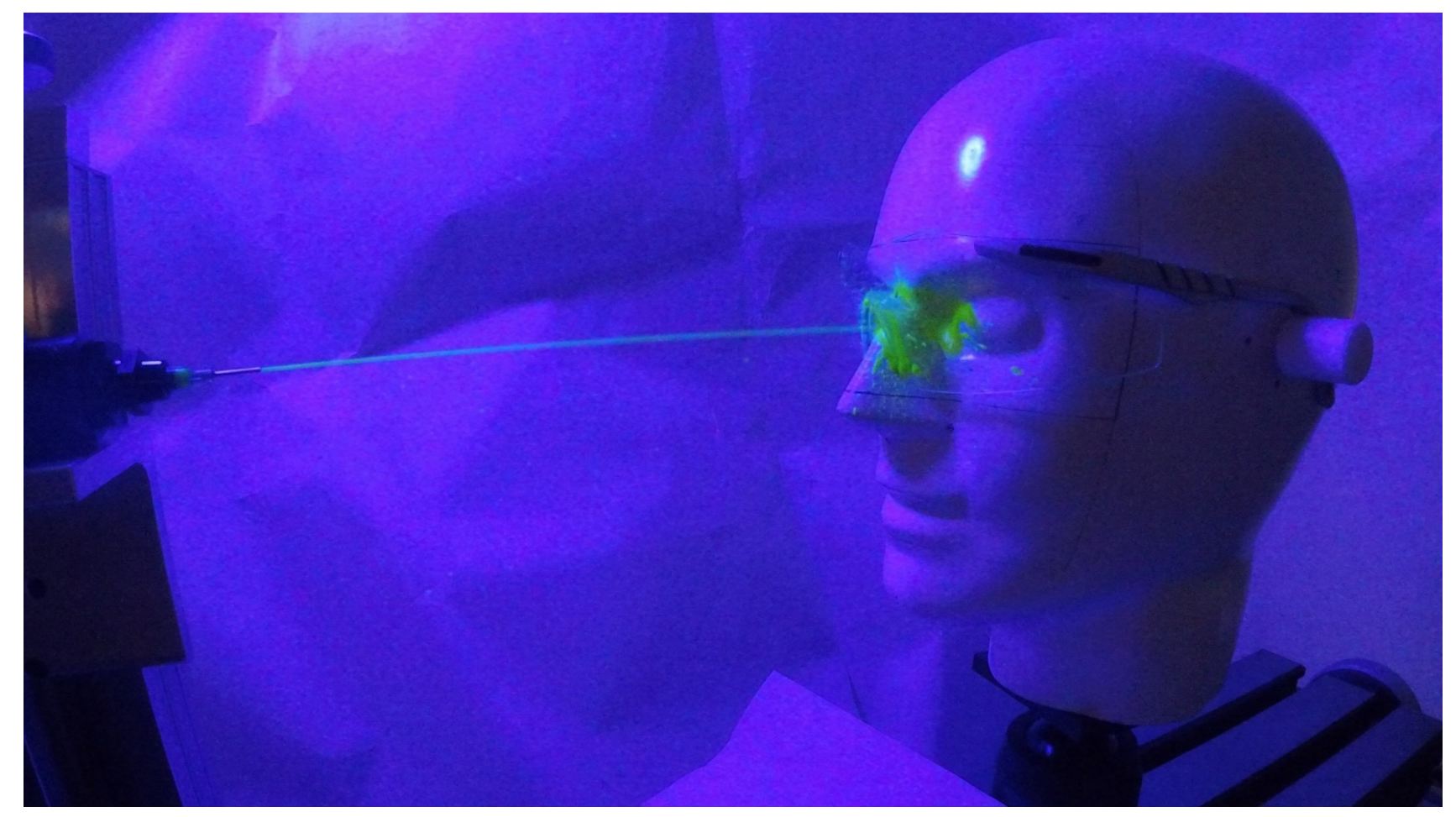

Figure 3-30: Spurt in Real Time 


\subsection{Defining Positions and Perimeters}

\subsubsection{Eye}

The size of the human adult eye is approximately $24.2 \mathrm{~mm}$ (transverse) x $23.7 \mathrm{~mm}$ (sagittal). The eyeball size may vary from about $21 \mathrm{~mm}$ to $27 \mathrm{~mm}$ in the transverse plane (Bekerman, 2014). When considering the human orbit, the height is usually 35 $\mathrm{mm}$ whereas the typical width is approximately $40 \mathrm{~mm}$ (Turvey, 2012). The average aperture height of the eye is around $10-14 \mathrm{~mm}$ while the eyelid covers about another 2$3 \mathrm{~mm}$ of the eye itself. The average dimensions of the human eyelid are around 28-32 $\mathrm{mm}$ wide and around 4-5 $\mathrm{mm}$ in height/thickness when the eye is opened (Eyeplastics). This total height of the eye and eyelids are around 23-25 $\mathrm{mm}$ from bottom to top. Through other studies done on the anatomy of the eye and orbit size, adults were found to have heights and widths slightly larger than that of 35 and $40 \mathrm{~mm}$. Other studies show that the thicknesses and widths of the eyelid vary a few millimeters as well. Therefore, it would be reasonable to want to protect at distances slightly greater than these parameters. Since the parameters stated previously are only averages of adults. There are some outliers that would need to have the parameters a little bigger. To accommodate the variety in sizes, an ellipse shape is used with height of $35 \mathrm{~mm}$ and width of $50 \mathrm{~mm}$. The height should remain the same because this distance is based off the orbital bone. This distance will cover the height of the eye plus the eye lids when opened. The reason that the width needs to be lengthened is that the eye lid runs across the horizontal plane of the eye and leaves areas exposed such as the corners of the eye and the tear duct. This oversized parameter is to take in account for adults having larger sized eyes, varying sized tear ducts, and larger orbital sockets. By using an 
oversized elliptical parameter the eye will then be completely encompassed (Figure 332). Any fluid or fluid residue that is found within the perimeter of the ellipse will be considered a "fail" for the eye. The ellipse parameters will have its dimensions based off the center of the eye. From there a major and minor axis will be created of lengths of $35 \mathrm{~mm}$ in height (minor) and $50 \mathrm{~mm}$ in width (major). This ellipse shape will follow the orbital bone. The 45 degree diagonal measurements will be $42 \mathrm{~mm}$ in length (Figure 3-31).

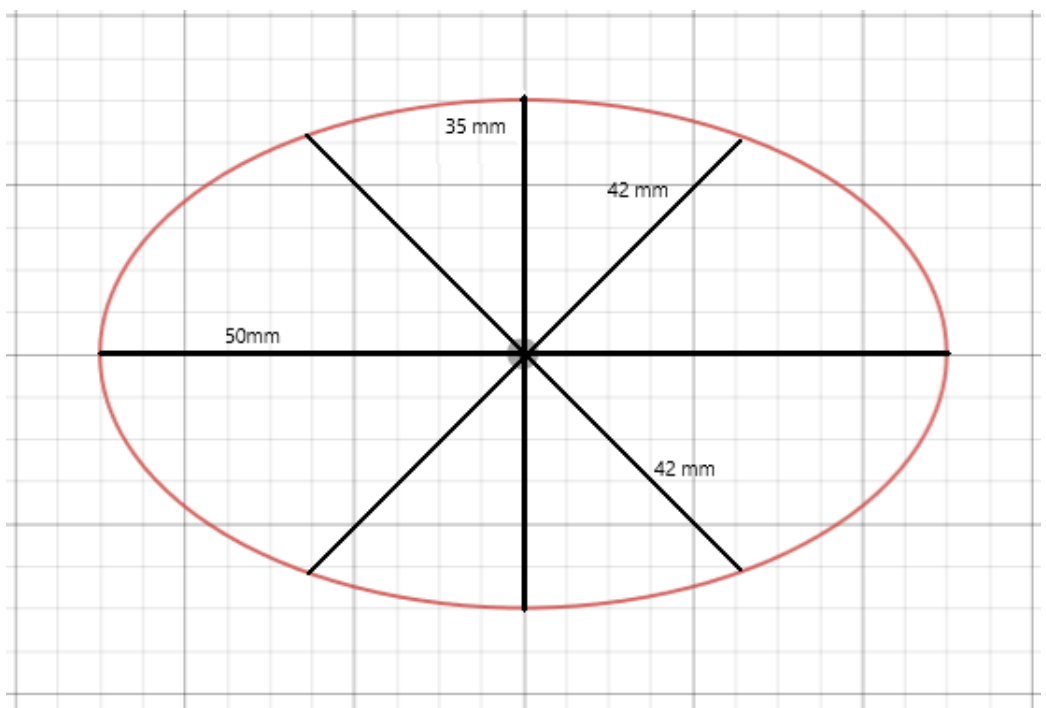

Figure 3-31: Graph of Ellipse 


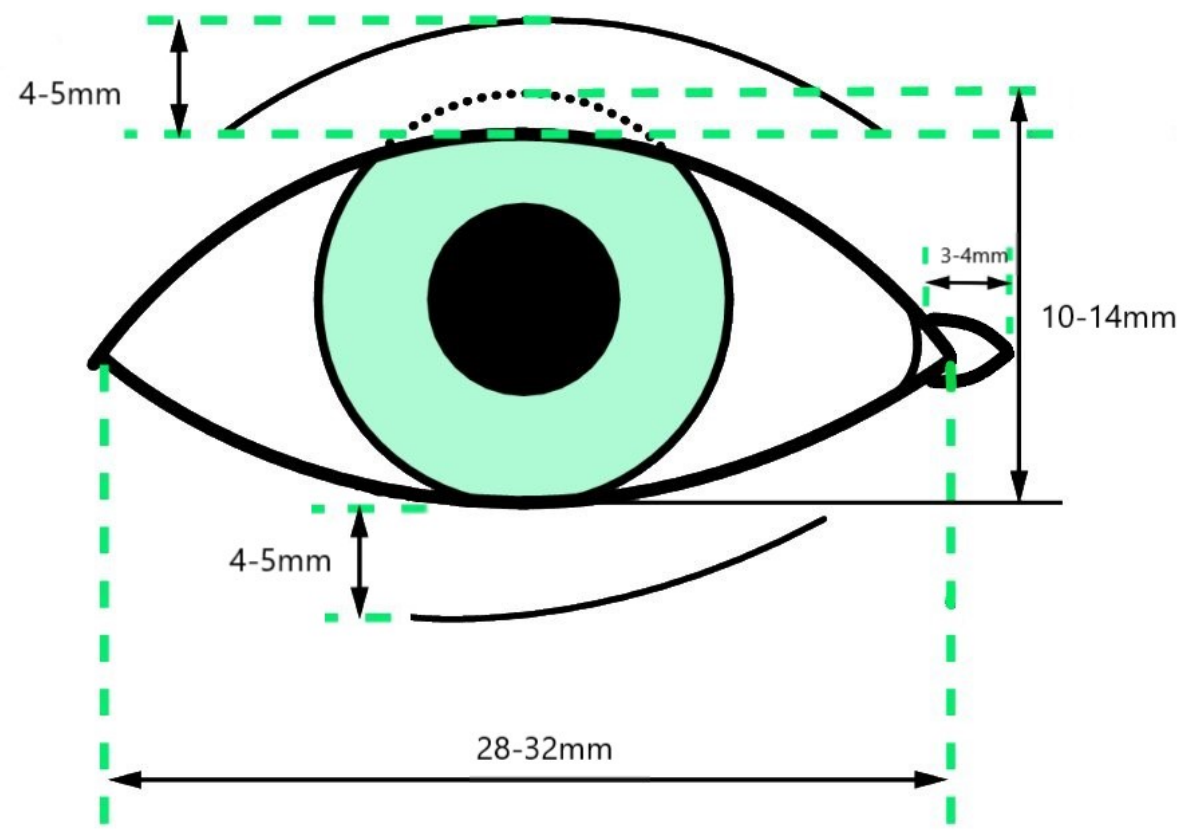

(Elsevier, 2008)

Figure 3-32: Average Eye Measurements

\subsubsection{Nose}

Nose exposure will be evaluated using the 6 landmarks shown below. Connecting the points from 1-3-2-5-6-4-1 creates a perimeter along the bottom surface area of the nose. Any fluid or fluid residue that is found within this perimeter will be considered a "fail" for the nose. 


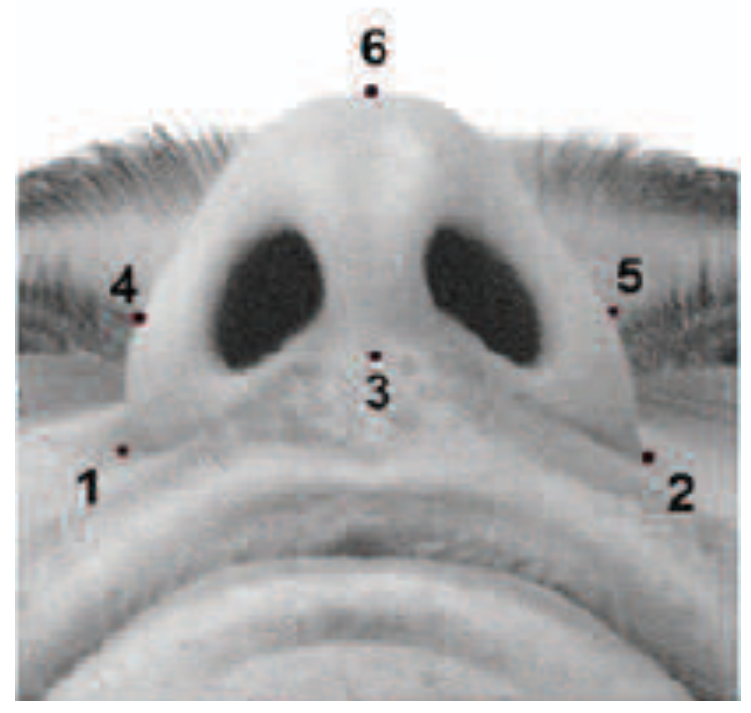

(Etoz, 2011)

Figure 3-33: Anthropometric Nose landmarks

The nose perimeter measurements are defined in Figure 3-33 and Table 3-5 below for the European anthropometric headform.

\begin{tabular}{|l|l|}
\hline $1-2$ & Alare, the point where the nasal blade (ala nasi) extends farthest out. \\
\hline 3 & Subnasal, the midpoint of the columella base. \\
\hline $4-5$ & The most convex point of lateral cruris of alar cartilage. \\
\hline 6 & Pronasal, the most prominent point on the nasal tip. \\
\hline
\end{tabular}

Table 3-4: Anthropometric Nose Landmarks 


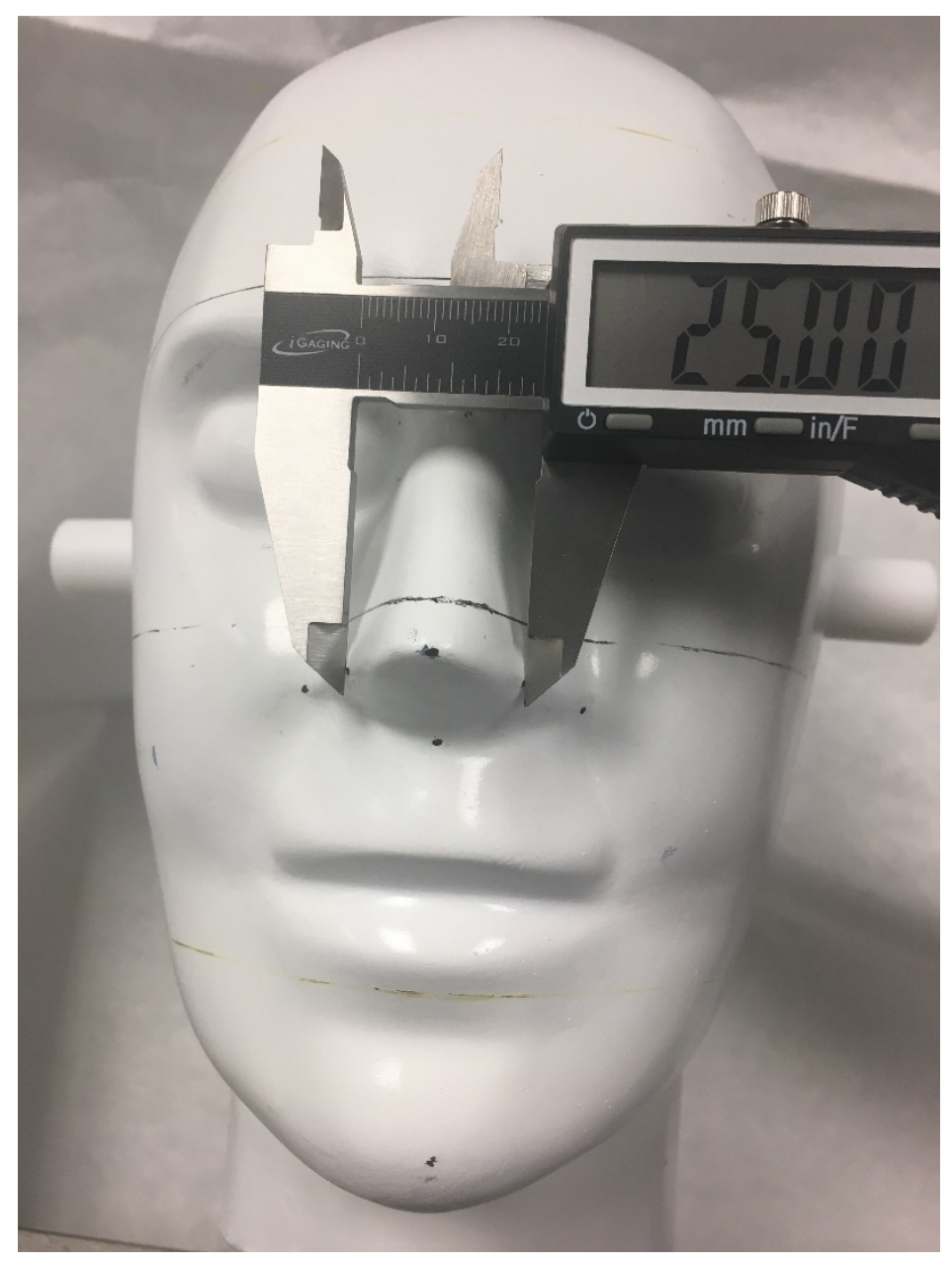

Figure 3-34: Nose measurement of most convex point- Points 4-5.

\begin{tabular}{|l|l|}
\hline $1-3$ & $27 \mathrm{~mm}$ \\
\hline $3-2$ & $27 \mathrm{~mm}$ \\
\hline $1-4$ & $18 \mathrm{~mm}$ \\
\hline $2-5$ & $18 \mathrm{~mm}$ \\
\hline $4-6$ & $20 \mathrm{~mm}$ \\
\hline $5-6$ & $20 \mathrm{~mm}$ \\
\hline $4-5$ & $25 \mathrm{~mm}$ \\
\hline $3-6$ & $22 \mathrm{~mm}$ \\
\hline
\end{tabular}

Table 3-5: Nose Landmark Measurements 


\subsubsection{Mouth}

Figure 3-35 shows anthropometric landmarks that are widely used for the mouth. A perimeter formed by connecting the points (1-2-3-4-5-1) defines the mouth. Any fluid or fluid residue that falls within this perimeter will be considered a "fail" for the mouth.

The perimeter will start at the left oral commissure or cheilion. This is where the lateral aspects of the vermilion of the upper and lower lips join. (Figure 3-35-point 1) From point 1 , the perimeter will travel along the contour of the line formed by the vermilion border of the upper lip. In a frontal view, this line resembles an archer's bow, which curves medially and superiorly from the commissures to the paramedian peaks located at the bases of the pillars of the philtrum (crista philtrae) (Figure 3-35- points 2 and 3) with an inferior convexity lying between those peaks. The philtrum is the vertical groove in the midline of the upper lip bordered by these lateral pillars (ridges). From points $2-3$, the perimeter will travel to point 4 which resides as the right oral commissure or cheilion (Figure 3-35-point 4). From point 4, the perimeter will travel along the contour of the line formed by the vermilion border of the lower lip until it reaches the lowest apex of the lower lip, which will be point 5 . From point 5 the line will continue along the contour of the line formed by the vermillion border of the lower lip until it reconnects with point 1 . 


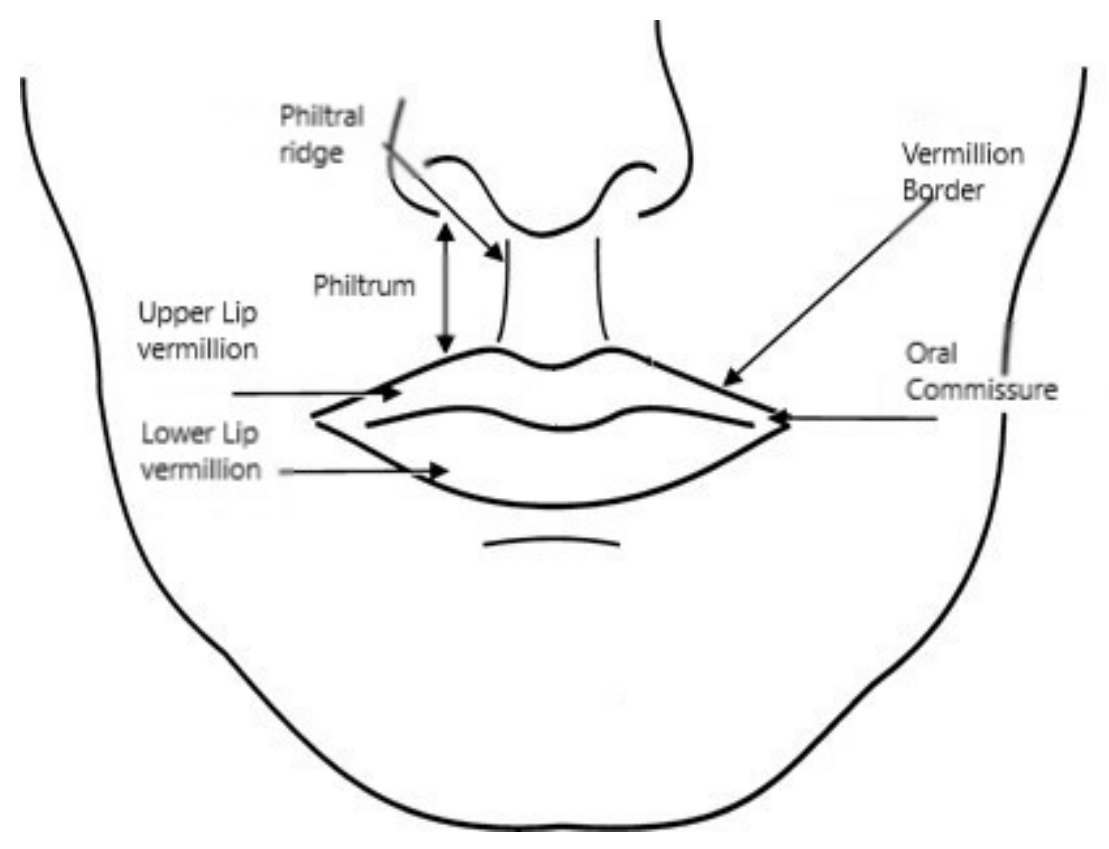

Source: (Raschke, et al., 2016)

Figure 3-35: Anthropometric Mouth Landmarks

The mouth perimeter measurements are defined in Figure 3-36 and Table 3-6 below for the European anthropometric headform. 


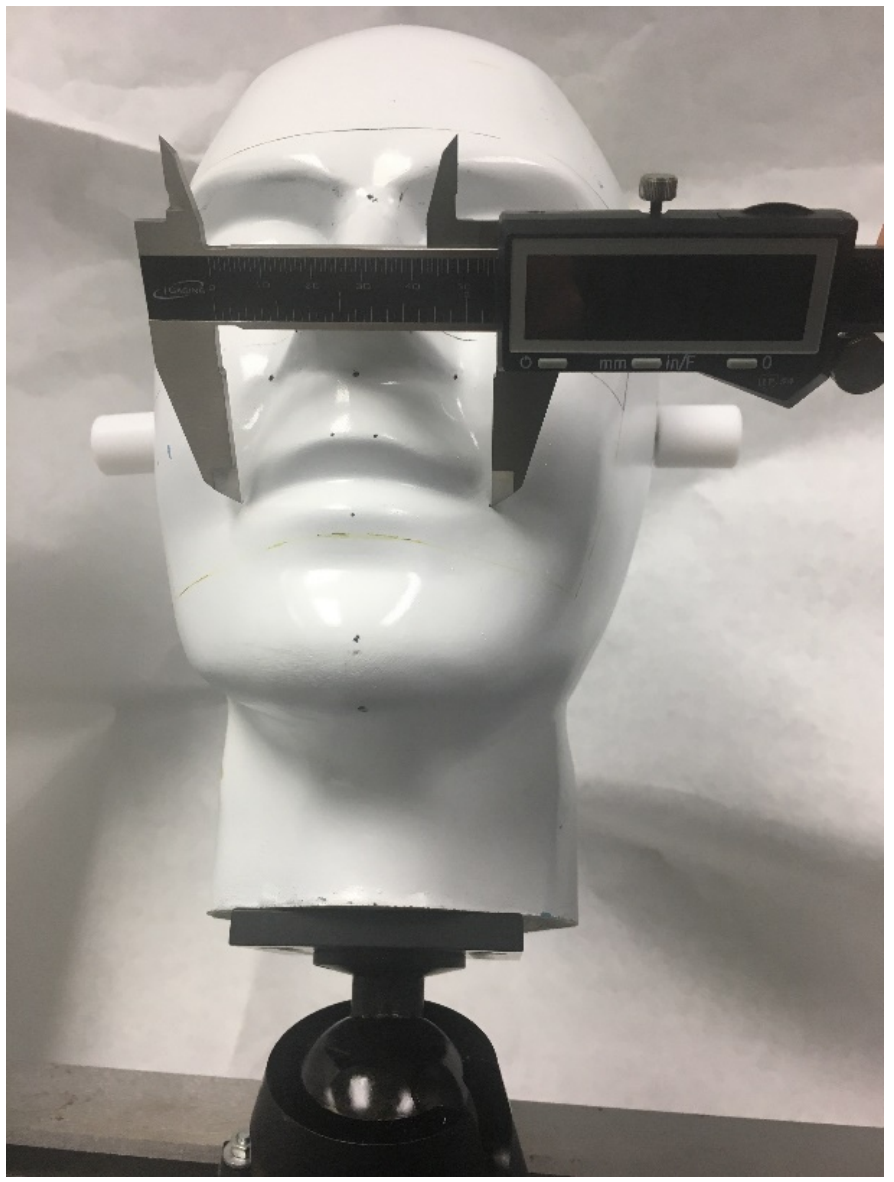

Figure 3-36: Mouth measurement between left and right oral commissure-Points 1-4.

\begin{tabular}{|l|l|}
\hline $1-2$ & $31 \mathrm{~mm}$ \\
\hline $2-3$ & $10 \mathrm{~mm}$ \\
\hline $3-4$ & $31 \mathrm{~mm}$ \\
\hline $4-5$ & $33.5 \mathrm{~mm}$ \\
\hline $5-1$ & $33.5 \mathrm{~mm}$ \\
\hline $1-4$ & $56.5 \mathrm{~mm}$ \\
\hline $2-5$ & $18 \mathrm{~mm}$ \\
\hline $3-5$ & $18 \mathrm{~mm}$ \\
\hline
\end{tabular}

Table 3-6: Mouth Landmark Measurements 


\section{CHAPTER 4 - Results}

\subsection{Overview of Testing and Results}

This study evaluated the efficacy of protection of different ensembles that are currently used in occupational settings with high probability of biohazard exposure. This test apparatus is designed to mimic those hazards where PPE is needed for eye and face protection. Significant results and observations were found in a few areas within the make-up of each ensemble and between ensembles themselves. Each ensemble (10 total) will be referred to as a corresponding letter (A-J). This is to refrain from mentioning any brands, makes, or models of PPE that were used in testing. Some description of the ensemble will be given. All ensembles (eye protector and face mask) were assembled based on the survey that was appointed to high hazards occupational settings in the surrounding areas. The specific names of these occupational work settings will also be omitted from the results.

\subsubsection{Statistical Analysis Overview}

When comparing two ensembles, a sample size of $n=80$ for each ensemble provides $80 \%$ statistical power (at a type I rate [alpha] of 0.05 ) to detect a difference in the error rates of $21 \%$. This study will have enough power to detect a difference if one ensemble has a pass rate of $50 \%$ and another ensemble has a pass rate of $71 \%$. Or if one ensemble has a pass rate of $50 \%$ and the other has a pass rate of $29 \%$. The power to detect larger differences in the pass rates will be greater than $80 \%$. With smaller variances (pass rates larger or smaller than $50 \%$ ), the study will have $80 \%$ power to detect smaller differences. The results will be further discussed in the following chapter. 


\subsection{Overview of Ensembles}

\subsubsection{Pass Rate of Eyes}

\begin{tabular}{|c|c|c|c|c|c|c|c|c|c|}
\hline \multicolumn{3}{|c|}{ Ensemble } & \multicolumn{7}{|c|}{ Eyes } \\
\hline \multirow{4}{*}{ A } & \multirow{2}{*}{ Spurt } & \multirow{2}{*}{$\begin{array}{c}\text { Pass } \\
\text { Fail }\end{array}$} & 10 & 0 & 10 & 10 & 30 & 101 & $80 \%$ \\
\hline & & & 0 & 10 & 0 & 0 & 10 & $\mathrm{UCl}$ & $95 \%$ \\
\hline & \multirow[t]{2}{*}{ Spray } & Pass & 10 & 10 & 10 & 10 & 40 & 70 & \\
\hline & & Fail & 0 & 0 & 0 & 0 & 0 & 10 & $88 \%$ \\
\hline \multirow[t]{4}{*}{ B } & \multirow[t]{2}{*}{ Spurt } & \multirow{2}{*}{$\begin{array}{c}\text { Pass } \\
\text { Fail }\end{array}$} & 2 & 0 & 10 & 10 & 22 & $\mathrm{LCl}$ & $68 \%$ \\
\hline & & & 8 & 10 & 0 & 0 & 18 & $\mathrm{UCl}$ & $87 \%$ \\
\hline & \multirow[t]{2}{*}{ Spray } & Pass & 10 & 10 & 10 & 10 & 40 & 62 & \\
\hline & & Fail & 0 & 0 & 0 & 0 & 0 & 18 & $78 \%$ \\
\hline \multirow[t]{4}{*}{$C$} & \multirow[t]{2}{*}{ Spurt } & Pass & 10 & 10 & 10 & 10 & 40 & $\mathrm{LCl}$ & NA \\
\hline & & Fail & 0 & 0 & 0 & 0 & 0 & $\mathrm{UCl}$ & NA \\
\hline & \multirow[t]{2}{*}{ Spray } & Pass & 10 & 10 & 10 & 10 & 40 & 80 & \\
\hline & & Fail & 0 & 0 & 0 & 0 & 0 & 0 & $100 \%$ \\
\hline \multirow[t]{4}{*}{ D } & \multirow[t]{2}{*}{ Spurt } & Pass & 8 & 8 & 10 & 10 & 36 & $\mathrm{LCl}$ & $74 \%$ \\
\hline & & Fail & 2 & 2 & 0 & 0 & 4 & $\mathrm{UCl}$ & $91 \%$ \\
\hline & \multirow[t]{2}{*}{ Spray } & Pass & 0 & 10 & 10 & 10 & 30 & 66 & \\
\hline & & Fail & 10 & 0 & 0 & 0 & 10 & 14 & $83 \%$ \\
\hline \multirow[t]{4}{*}{$E$} & \multirow[t]{2}{*}{ Spurt } & Pass & 9 & 10 & 10 & 10 & 39 & $\mathrm{LCl}$ & $96 \%$ \\
\hline & & Fail & 1 & 0 & 0 & 0 & 1 & $\mathrm{UCl}$ & $10 \%$ \\
\hline & \multirow[t]{2}{*}{ Spray } & Pass & 10 & 10 & 10 & 10 & 40 & 79 & \\
\hline & & Fail & 0 & 0 & 0 & 0 & 0 & 1 & $99 \%$ \\
\hline \multirow[t]{4}{*}{$\mathbf{F}$} & \multirow{2}{*}{ Spurt } & Pass & 3 & 1 & 10 & 10 & 24 & $\mathrm{LCl}$ & $56 \%$ \\
\hline & & Fail & 7 & 9 & 0 & 0 & 16 & $\mathrm{UCl}$ & $77 \%$ \\
\hline & \multirow[t]{2}{*}{ Spray } & Pass & 5 & 4 & 10 & 10 & 29 & 53 & \\
\hline & & Fail & 5 & 6 & 0 & 0 & 11 & 27 & $66 \%$ \\
\hline \multirow[t]{4}{*}{ G } & \multirow[t]{2}{*}{ Spurt } & Pass & 0 & 0 & 10 & 10 & 20 & $\mathrm{LCl}$ & $25 \%$ \\
\hline & & Fail & 10 & 10 & 0 & 0 & 20 & $\mathrm{UCl}$ & $45 \%$ \\
\hline & Spray & Pass & 0 & 7 & 1 & 0 & 8 & 28 & \\
\hline & & Fail & 10 & 3 & 9 & 10 & 32 & 52 & $35 \%$ \\
\hline H & Spurt & Pass & 4 & 2 & 10 & 10 & 26 & $\mathrm{LCl}$ & $49 \%$ \\
\hline & & Fail & 6 & 8 & 0 & 0 & 14 & UCI & 71\% \\
\hline & Spray & Pass & 2 & 10 & 10 & 0 & 22 & 48 & \\
\hline & & Fail & 8 & 0 & 0 & 10 & 18 & 32 & $60 \%$ \\
\hline$I$ & Spurt & Pass & 0 & 0 & 10 & 10 & 20 & $\mathrm{LCl}$ & $44 \%$ \\
\hline & & Fail & 10 & 10 & 0 & 0 & 20 & $\mathrm{UCl}$ & $66 \%$ \\
\hline & Spray & Pass & 0 & 10 & 7 & 7 & 24 & 44 & \\
\hline & & Fail & 10 & 0 & 3 & 3 & 16 & 36 & $55 \%$ \\
\hline $\mathbf{J}$ & Spurt & Pass & 0 & 0 & 10 & 10 & 20 & $\mathrm{LCl}$ & $18 \%$ \\
\hline & & Fail & 10 & 10 & 0 & 0 & 20 & UCl & $37 \%$ \\
\hline & Spray & Pass & 0 & 0 & 2 & 0 & 2 & 22 & \\
\hline & & Fail & 10 & 10 & 8 & 10 & 38 & 58 & $28 \%$ \\
\hline
\end{tabular}

Table 4-1: Ensemble Eyes Pass Rate 


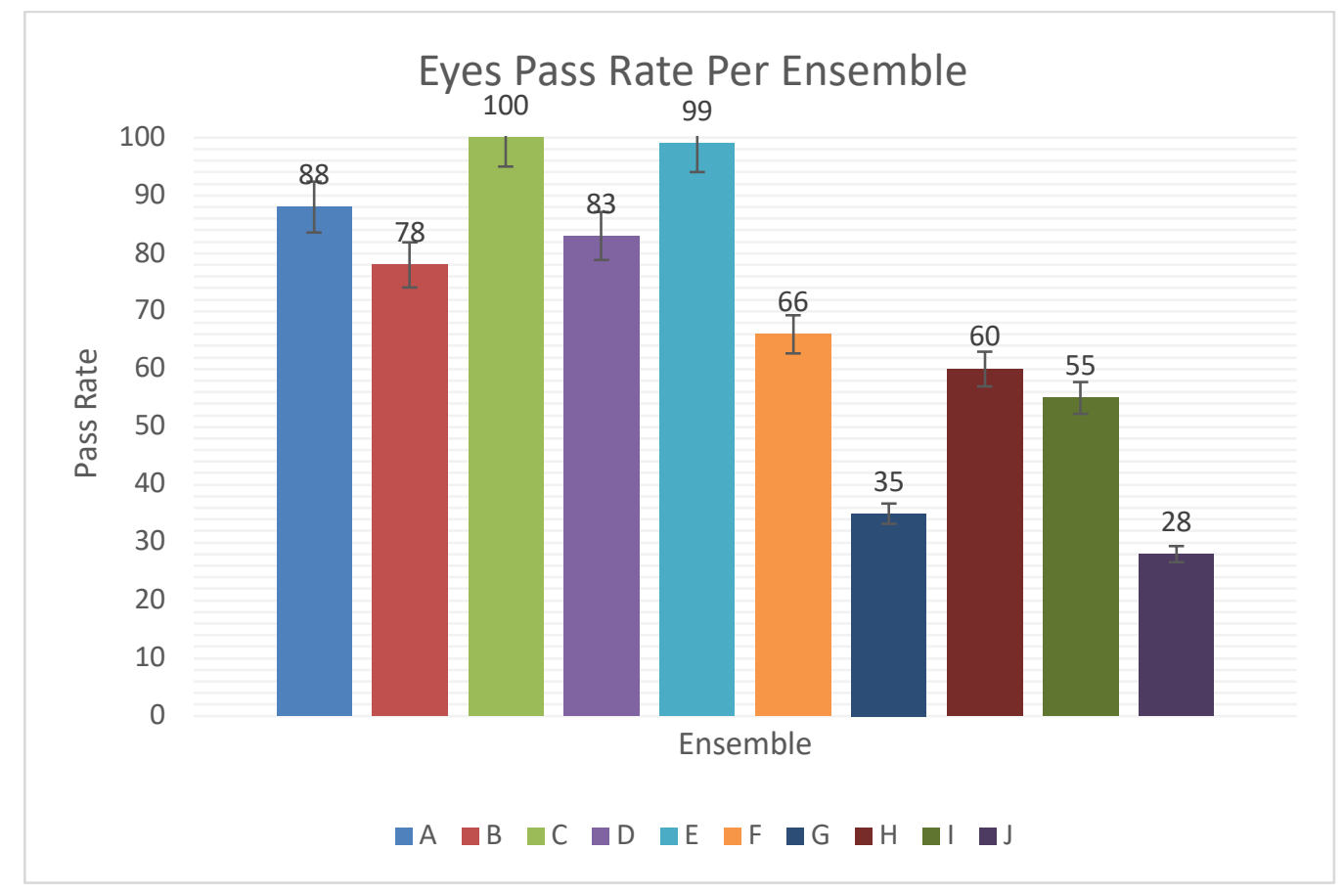

Figure 4-1: Eyes Pass Rate

Looking at Table 4-1, one can see that Ensemble C (100\%) and Ensemble E (99\%) had the highest pass rates in the area of concern of the eyes. This is shown again graphically in Figure 4-1. The total pass rate of all ensembles for the eyes was $69 \%$. 


\subsubsection{Pass Rate of Nose}

\begin{tabular}{|c|c|c|c|c|c|c|c|c|c|}
\hline \multirow{2}{*}{\multicolumn{3}{|c|}{ Ensemble }} & \multicolumn{7}{|l|}{ Nose } \\
\hline & & & Up & Down & Left & Right & & & PassRate \\
\hline \multirow[t]{4}{*}{ A } & \multirow[t]{2}{*}{ Spurt } & \multirow{2}{*}{$\begin{array}{c}\text { Pass } \\
\text { Fail }\end{array}$} & 10 & 2 & 10 & 10 & 32 & $\mathrm{LCl}$ & $83 \%$ \\
\hline & & & 0 & 8 & 0 & 0 & 8 & $\mathrm{UCl}$ & $97 \%$ \\
\hline & \multirow[t]{2}{*}{ Spray } & Pass & 10 & 10 & 10 & 10 & 40 & 72 & \\
\hline & & Fail & 0 & 0 & 0 & 0 & 0 & 8 & $90 \%$ \\
\hline \multirow[t]{4}{*}{ B } & \multirow[t]{2}{*}{ Spurt } & Pass & 10 & 10 & 10 & 10 & 40 & $\mathrm{LCl}$ & NA \\
\hline & & Fail & 0 & 0 & 0 & 0 & 0 & $\mathrm{UCl}$ & NA \\
\hline & \multirow[t]{2}{*}{ Spray } & Pass & 10 & 10 & 10 & 10 & 40 & 80 & \\
\hline & & Fail & 0 & 0 & 0 & 0 & 0 & 0 & $100 \%$ \\
\hline \multirow[t]{4}{*}{ C } & \multirow{2}{*}{ Spurt } & Pass & 10 & 10 & 10 & 10 & 40 & $\mathrm{LCl}$ & NA \\
\hline & & Fail & 0 & 0 & 0 & 0 & 0 & $\mathrm{UCl}$ & NA \\
\hline & \multirow{2}{*}{ Spray } & Pass & 10 & 10 & 10 & 10 & 40 & 80 & \\
\hline & & Fail & 0 & 0 & 0 & 0 & 0 & 0 & $100 \%$ \\
\hline \multirow[t]{4}{*}{ D } & \multirow[t]{2}{*}{ Spurt } & Pass & 10 & 10 & 10 & 10 & 40 & $\mathrm{LCl}$ & NA \\
\hline & & Fail & 0 & 0 & 0 & 0 & 0 & $\mathrm{UCl}$ & NA \\
\hline & \multirow[t]{2}{*}{ Spray } & Pass & 10 & 10 & 10 & 10 & 40 & 80 & \\
\hline & & Fail & 0 & 0 & 0 & 0 & 0 & 0 & $100 \%$ \\
\hline \multirow[t]{4}{*}{$E$} & \multirow[t]{2}{*}{ Spurt } & Pass & 10 & 10 & 10 & 10 & 40 & $\mathrm{LCl}$ & NA \\
\hline & & Fail & 0 & 0 & 0 & 0 & 0 & $\mathrm{UCl}$ & NA \\
\hline & \multirow[t]{2}{*}{ Spray } & Pass & 10 & 10 & 10 & 10 & 40 & 80 & \\
\hline & & Fail & 0 & 0 & 0 & 0 & 0 & 0 & $100 \%$ \\
\hline \multirow[t]{4}{*}{$\mathbf{F}$} & \multirow[t]{2}{*}{ Spurt } & Pass & 10 & 1 & 10 & 10 & 31 & $\mathrm{LCl}$ & $82 \%$ \\
\hline & & Fail & 0 & 9 & 0 & 0 & 9 & $\mathrm{UCl}$ & $96 \%$ \\
\hline & \multirow[t]{2}{*}{ Spray } & Pass & 10 & 10 & 10 & 10 & 40 & 71 & \\
\hline & & Fail & 0 & 0 & 0 & 0 & 0 & 9 & $89 \%$ \\
\hline \multirow[t]{4}{*}{ G } & \multirow[t]{2}{*}{ Spurt } & Pass & 8 & 0 & 10 & 10 & 28 & $\mathrm{LCl}$ & $77 \%$ \\
\hline & & Fail & 2 & 10 & 0 & 0 & 12 & $\mathrm{UCl}$ & $93 \%$ \\
\hline & Spray & Pass & 10 & 10 & 10 & 10 & 40 & 68 & \\
\hline & & Fail & 0 & 0 & 0 & 0 & 0 & 12 & $85 \%$ \\
\hline H & Spurt & Pass & 10 & 3 & 10 & 10 & 33 & $\mathrm{LCl}$ & $85 \%$ \\
\hline & & Fail & 0 & 7 & 0 & 0 & 7 & UCl & $97 \%$ \\
\hline & Spray & Pass & 10 & 10 & 10 & 10 & 40 & 73 & \\
\hline & & Fail & 0 & 0 & 0 & 0 & 0 & 7 & $91 \%$ \\
\hline$I$ & Spurt & Pass & 2 & 3 & 10 & 10 & 25 & $\mathrm{LCl}$ & $73 \%$ \\
\hline & & Fail & 8 & 7 & 0 & 0 & 15 & $\mathrm{UCl}$ & $90 \%$ \\
\hline & Spray & Pass & 10 & 10 & 10 & 10 & 40 & 65 & \\
\hline & & Fail & 0 & 0 & 0 & 0 & 0 & 15 & $81 \%$ \\
\hline $\mathrm{J}$ & Spurt & Pass & 9 & 2 & 10 & 10 & 31 & $\mathrm{LCl}$ & $82 \%$ \\
\hline & & Fail & 1 & 8 & 0 & 0 & 9 & $\mathrm{UCl}$ & $96 \%$ \\
\hline & Spray & Pass & 10 & 10 & 10 & 10 & 40 & 71 & \\
\hline & & Fail & 0 & 0 & 0 & 0 & 0 & 9 & $89 \%$ \\
\hline
\end{tabular}

Table 4-2: Ensemble Nose Pass Rate 


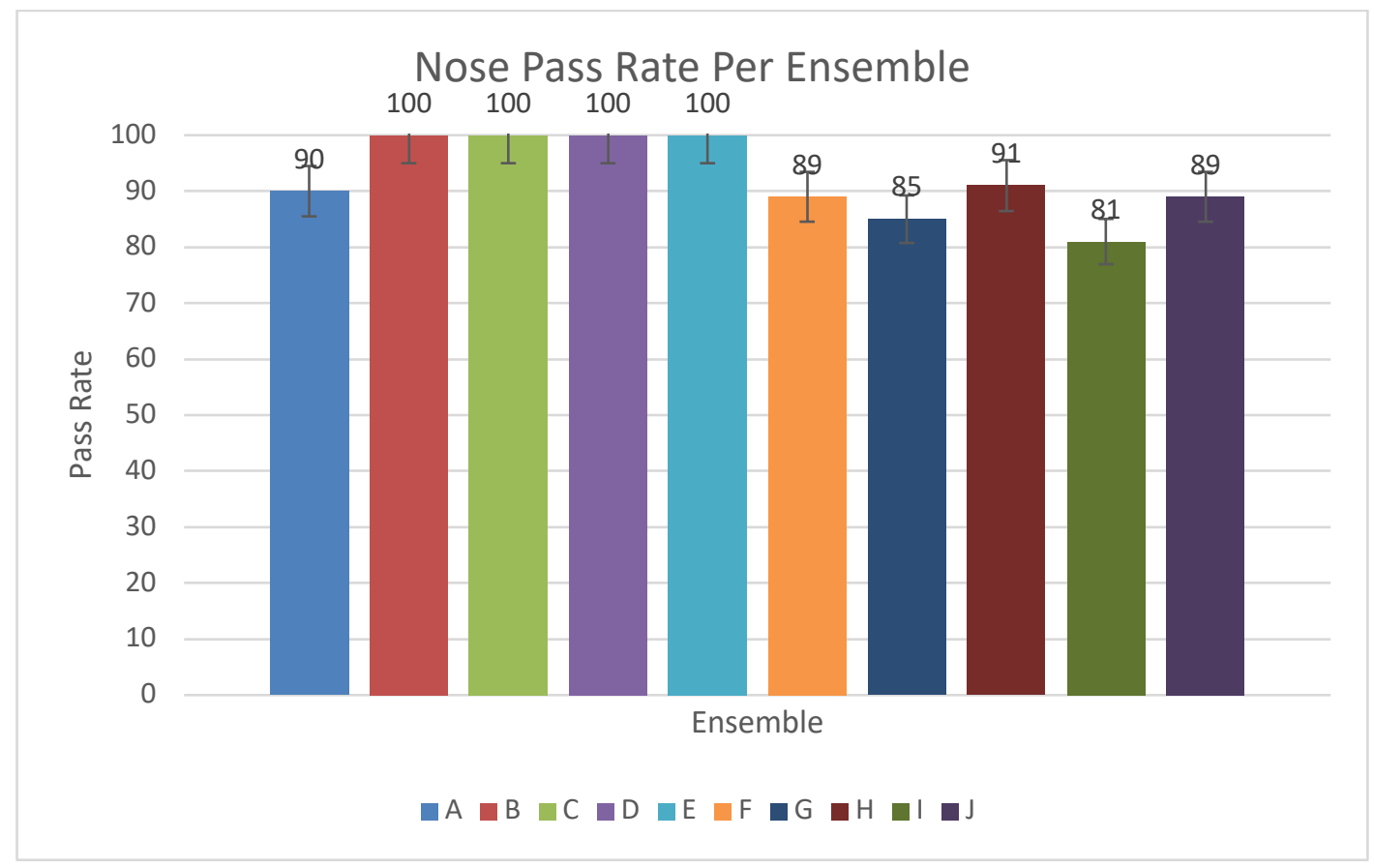

Figure 4-2: Nose Pass Rate

Looking at Table 4-2, one can see that Ensemble B, C, D, and E (100\%) had the highest pass rates in the area of concern of the Nose. This is shown again graphically in Figure 4-2. The total pass rate of ensembles for the nose is $93 \%$. The pass rate is $24 \%$ higher for the nose than the eyes. 


\subsubsection{Pass Rate of Mouth}

\begin{tabular}{|c|c|c|c|c|c|c|c|c|c|}
\hline \multicolumn{3}{|c|}{ Ensemble } & \multicolumn{7}{|l|}{ Mouth } \\
\hline \multirow{4}{*}{ A } & \multirow{2}{*}{ Spurt } & \multirow{2}{*}{$\begin{array}{c}\text { Pass } \\
\text { Fail }\end{array}$} & Up & $\frac{\text { DOWn }}{4}$ & $\begin{array}{c}\text { Lett } \\
10\end{array}$ & $\frac{{ }^{\text {KIgnt }}}{10}$ & 34 & $\mathrm{LCl}$ & $87 \%$ \\
\hline & & & 0 & 6 & 0 & 0 & 6 & $\mathrm{UCl}$ & $98 \%$ \\
\hline & \multirow[t]{2}{*}{ Spray } & Pass & 10 & 10 & 10 & 10 & 40 & 74 & \\
\hline & & Fail & 0 & 0 & 0 & 0 & 0 & 6 & $93 \%$ \\
\hline \multirow[t]{4}{*}{ B } & \multirow[t]{2}{*}{ Spurt } & Pass & 10 & 4 & 10 & 10 & 34 & $\mathrm{LCl}$ & $87 \%$ \\
\hline & & Fail & 0 & 6 & 0 & 0 & 6 & $\mathrm{UCl}$ & $98 \%$ \\
\hline & \multirow[t]{2}{*}{ Spray } & Pass & 10 & 10 & 10 & 10 & 40 & 74 & \\
\hline & & Fail & 0 & 0 & 0 & 0 & 0 & 6 & $93 \%$ \\
\hline \multirow[t]{4}{*}{ C } & \multirow[t]{2}{*}{ Spurt } & Pass & 10 & 10 & 10 & 10 & 40 & $\mathrm{LCl}$ & NA \\
\hline & & Fail & 0 & 0 & 0 & 0 & 0 & $\mathrm{UCl}$ & NA \\
\hline & \multirow{2}{*}{ Spray } & Pass & 10 & 10 & 10 & 10 & 40 & 80 & \\
\hline & & Fail & 0 & 0 & 0 & 0 & 0 & 0 & $100 \%$ \\
\hline \multirow[t]{4}{*}{ D } & \multirow[t]{2}{*}{ Spurt } & Pass & 10 & 9 & 10 & 10 & 39 & $\mathrm{LCl}$ & $96 \%$ \\
\hline & & Fail & 0 & 1 & 0 & 0 & 1 & $\mathrm{UCl}$ & $100 \%$ \\
\hline & \multirow[t]{2}{*}{ Spray } & Pass & 10 & 10 & 10 & 10 & 40 & 79 & \\
\hline & & Fail & 0 & 0 & 0 & 0 & 0 & 1 & $99 \%$ \\
\hline \multirow[t]{4}{*}{$E$} & \multirow[t]{2}{*}{ Spurt } & Pass & 10 & 10 & 10 & 10 & 40 & $\mathrm{LCl}$ & NA \\
\hline & & Fail & 0 & 0 & 0 & 0 & 0 & $\mathrm{UCl}$ & NA \\
\hline & \multirow[t]{2}{*}{ Spray } & Pass & 10 & 10 & 10 & 10 & 40 & 80 & \\
\hline & & Fail & 0 & 0 & 0 & 0 & 0 & 0 & $100 \%$ \\
\hline \multirow[t]{4}{*}{$F$} & \multirow[t]{2}{*}{ Spurt } & Pass & 10 & 0 & 10 & 10 & 30 & $\mathrm{LCl}$ & $80 \%$ \\
\hline & & Fail & 0 & 10 & 0 & 0 & 10 & $\mathrm{UCl}$ & $95 \%$ \\
\hline & \multirow[t]{2}{*}{ Spray } & Pass & 10 & 10 & 10 & 10 & 40 & 70 & \\
\hline & & Fail & 0 & 0 & 0 & 0 & 0 & 10 & $88 \%$ \\
\hline \multirow[t]{4}{*}{$\mathbf{G}$} & \multirow[t]{2}{*}{ Spurt } & Pass & 8 & 7 & 10 & 10 & 35 & $\mathrm{LCl}$ & $88 \%$ \\
\hline & & Fail & 2 & 3 & 0 & 0 & 5 & $\mathrm{UCl}$ & $99 \%$ \\
\hline & \multirow[t]{2}{*}{ Spray } & Pass & 10 & 10 & 10 & 10 & 40 & 75 & \\
\hline & & Fail & 0 & 0 & 0 & 0 & 0 & 5 & $94 \%$ \\
\hline H & Spurt & Pass & 10 & 3 & 10 & 10 & 33 & $\mathrm{LCl}$ & $85 \%$ \\
\hline & & Fail & 0 & 7 & 0 & 0 & 7 & $\mathrm{UCl}$ & $97 \%$ \\
\hline & Spray & Pass & 10 & 10 & 10 & 10 & 40 & 73 & \\
\hline & & Fail & 0 & 0 & 0 & 0 & 0 & 7 & $91 \%$ \\
\hline$I$ & Spurt & Pass & 1 & 3 & 10 & 10 & 24 & $\mathrm{LCl}$ & $71 \%$ \\
\hline & & Fail & 9 & 7 & 0 & 0 & 16 & $\mathrm{UCl}$ & $89 \%$ \\
\hline & Spray & Pass & 10 & 10 & 10 & 10 & 40 & 64 & \\
\hline & & Fail & 0 & 0 & 0 & 0 & 0 & 16 & $80 \%$ \\
\hline J & Spurt & Pass & 6 & 1 & 10 & 10 & 27 & $\mathrm{LCl}$ & $76 \%$ \\
\hline & & Fail & 4 & 9 & 0 & 0 & 13 & $\mathrm{UCl}$ & $92 \%$ \\
\hline & Spray & Pass & 10 & 10 & 10 & 10 & 40 & 67 & \\
\hline & & Fail & 0 & 0 & 0 & 0 & 0 & 13 & $84 \%$ \\
\hline
\end{tabular}

Table 4-3: Ensemble Mouth Pass Rate 


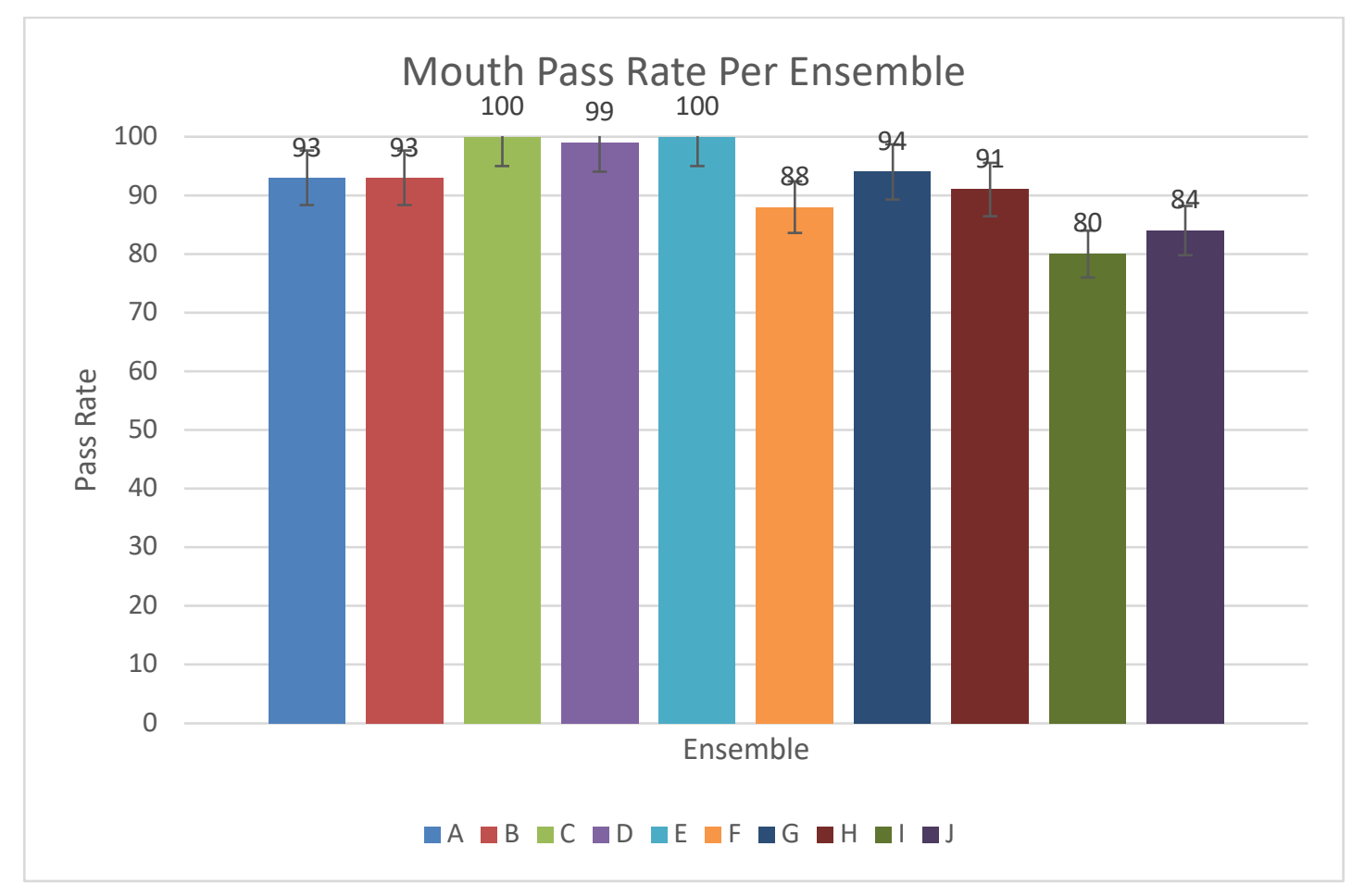

Figure 4-3: Mouth Pass Rate

Looking at Table 4-3, one can see that Ensemble C and E (100\%) and Ensemble D $(99 \%)$ had the highest pass rates in the area of concern of the Mouth. This is shown again graphically in Figure 4-3. The overall ensembles pass rate for the Mouth is $92 \%$. The overall ensembles pass rate is $23 \%$ higher for the mouth than the eyes, and $1 \%$ lower than the overall ensembles pass rate for the nose. 


\subsubsection{Pass Rate of Total Ensemble}

\begin{tabular}{|c|c|c|c|c|c|}
\hline \multicolumn{3}{|c|}{ Ensemble } & \multicolumn{3}{|c|}{$\begin{array}{l}\text { Total Ensemble } \\
\text { Pass Rate }\end{array}$} \\
\hline \multirow[t]{4}{*}{$A$} & Spurt & Pass & 96 & $\mathrm{LCl}$ & $86 \%$ \\
\hline & & Fail & 24 & $\mathrm{UCl}$ & $94 \%$ \\
\hline & Spray & Pass & 120 & 216 & \\
\hline & & Fail & 0 & 24 & $90 \%$ \\
\hline \multirow[t]{4}{*}{ B } & Spurt & Pass & 96 & $\mathrm{LCl}$ & $86 \%$ \\
\hline & & Fail & 21 & $\mathrm{UCl}$ & $94 \%$ \\
\hline & Spray & Pass & 120 & 216 & \\
\hline & & Fail & 0 & 24 & $90 \%$ \\
\hline \multirow[t]{4}{*}{ C } & Spurt & Pass & 120 & $\mathrm{LCl}$ & NA \\
\hline & & Fail & 0 & $\mathrm{UCl}$ & NA \\
\hline & Spray & Pass & 120 & 240 & \\
\hline & & Fail & 0 & 0 & $100 \%$ \\
\hline \multirow[t]{4}{*}{ D } & Spurt & Pass & 115 & $\mathrm{LCl}$ & $91 \%$ \\
\hline & & Fail & 5 & $\mathrm{UCl}$ & $97 \%$ \\
\hline & Spray & Pass & 110 & 225 & \\
\hline & & Fail & 10 & 15 & $94 \%$ \\
\hline \multirow[t]{4}{*}{$E$} & Spurt & Pass & 119 & $\mathrm{LCl}$ & $99 \%$ \\
\hline & & Fail & 1 & $\mathrm{UCl}$ & $100 \%$ \\
\hline & Spray & Pass & 120 & 239 & \\
\hline & & Fail & 0 & 1 & $99.60 \%$ \\
\hline \multirow[t]{4}{*}{$F$} & Spurt & Pass & 85 & $\mathrm{LCl}$ & $76 \%$ \\
\hline & & Fail & 35 & $\mathrm{UCl}$ & $86 \%$ \\
\hline & Spray & Pass & 109 & 194 & \\
\hline & & Fail & 11 & 46 & $81 \%$ \\
\hline \multirow[t]{4}{*}{ G } & Spurt & Pass & 83 & $\mathrm{LCl}$ & $66 \%$ \\
\hline & & Fail & 37 & $\mathrm{UCl}$ & $77 \%$ \\
\hline & Spray & Pass & 88 & 171 & \\
\hline & & Fail & 32 & 69 & 71\% \\
\hline \multirow[t]{4}{*}{$\mathrm{H}$} & Spurt & Pass & 92 & $\mathrm{LCl}$ & $76 \%$ \\
\hline & & Fail & 28 & $\mathrm{UCl}$ & $86 \%$ \\
\hline & Spray & Pass & 102 & 194 & \\
\hline & & Fail & 18 & 46 & $81 \%$ \\
\hline \multirow[t]{4}{*}{ I } & Spurt & Pass & 69 & $\mathrm{LCl}$ & $66 \%$ \\
\hline & & Fail & 51 & $\mathrm{UCl}$ & $78 \%$ \\
\hline & Spray & Pass & 104 & 173 & \\
\hline & & Fail & 16 & 67 & $72 \%$ \\
\hline \multirow[t]{4}{*}{ J } & Spurt & Pass & 78 & $\mathrm{LCl}$ & $61 \%$ \\
\hline & & Fail & 42 & $\mathrm{UCl}$ & $73 \%$ \\
\hline & Spray & Pass & 82 & 160 & \\
\hline & & Fail & 38 & 80 & $67 \%$ \\
\hline
\end{tabular}

Table 4-4: Total Ensemble Pass Rate 


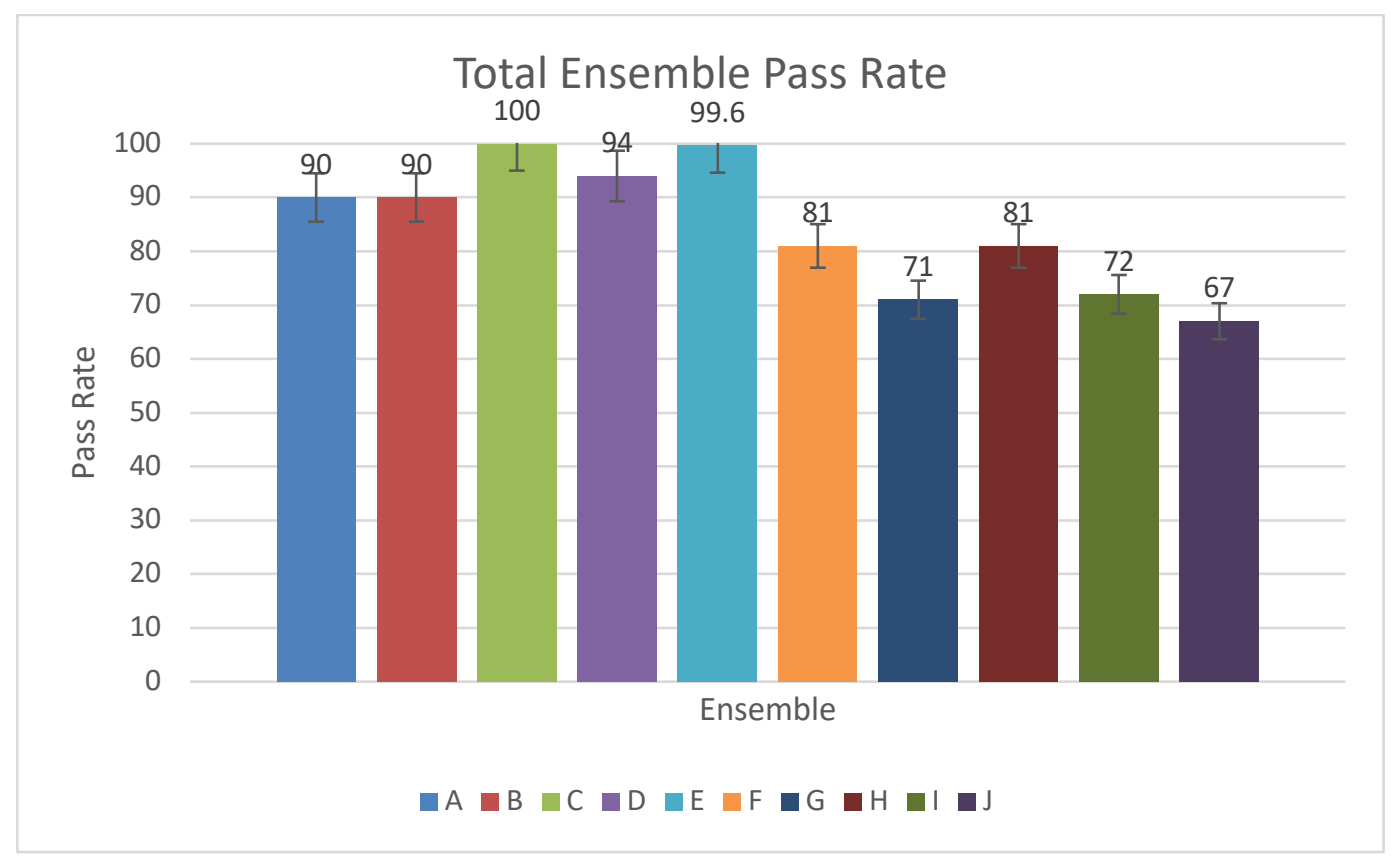

Figure 4-4: Total Ensemble Pass Rate

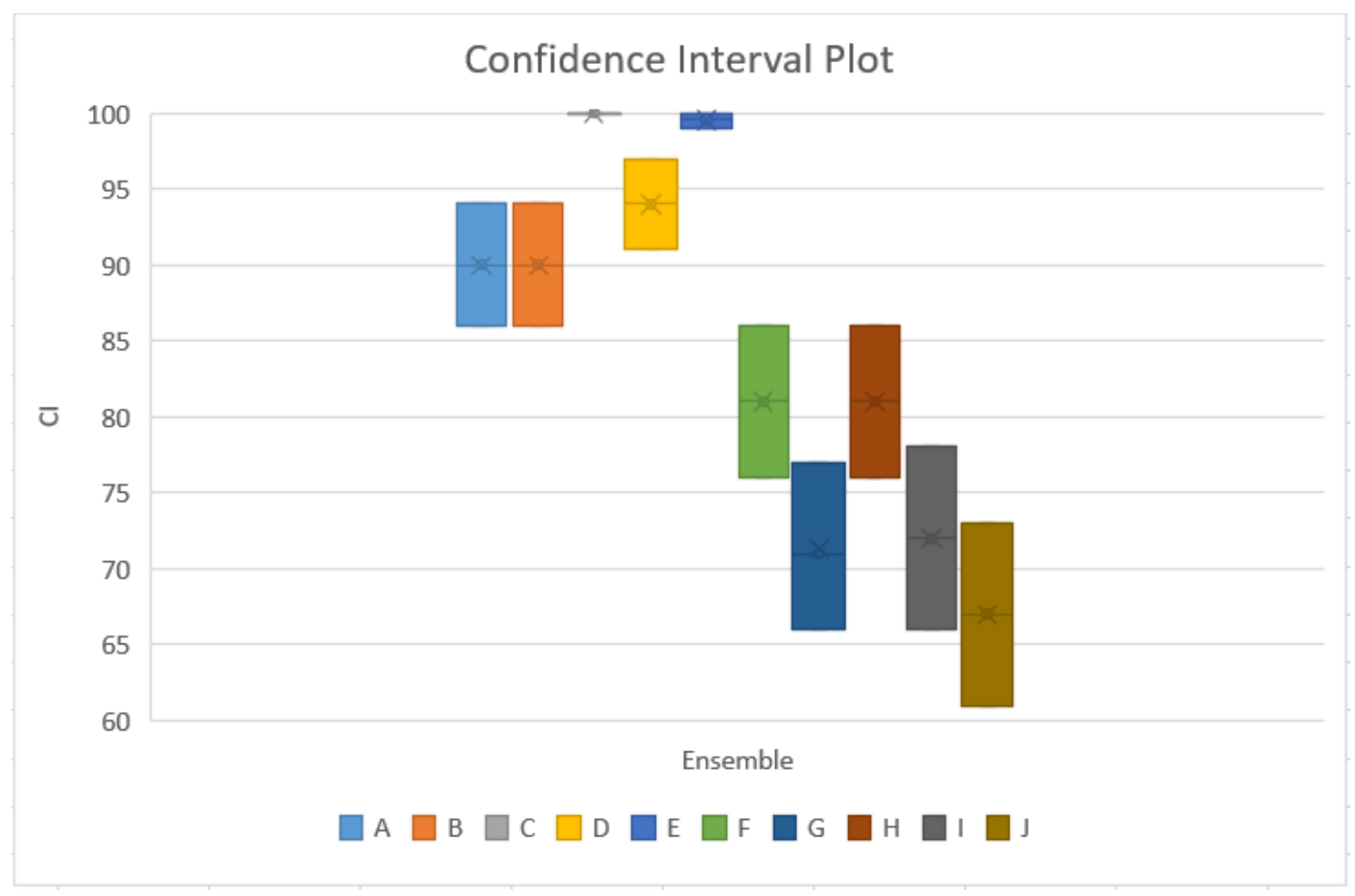

Figure 4-5: 95\% Confidence Interval Plot of Ensembles Performance 
Looking at Table 4-4, one can see that Ensemble C (100\%) and Ensemble E (99.6\%) had the highest total ensemble pass rate. This is shown again graphically in Figure 4-4. This comparison is also further confirmed with Figure 4-5 to show their performance and significance to each other's performance.

\subsubsection{Left and Right Eye Failures}

\begin{tabular}{|c|c|c|c|c|c|c|}
\hline \multicolumn{3}{|c|}{ Left Eye } & & \multicolumn{3}{|c|}{ Right Eye } \\
\hline Quadrant & Total & & & Quadrant & Total & \\
\hline LQ1 & 26 & $20 \%$ & & R Q1 & 24 & $22 \%$ \\
\hline LQ2 & 28 & $22 \%$ & & $\mathrm{R} Q 2$ & 17 & $15 \%$ \\
\hline LQ3 & 32 & $25 \%$ & & $\mathrm{R} Q 3$ & 27 & $25 \%$ \\
\hline LQ4 & 41 & $32 \%$ & & R Q4 & 42 & $38 \%$ \\
\hline L Total & 127 & $54 \%$ & & R Total & 110 & $46 \%$ \\
\hline
\end{tabular}

Table 4-5: Left and Right Eye Failures

\begin{tabular}{|c|c|c|c|c|c|}
\hline & $\mathrm{LCl}$ & $\mathrm{UCl}$ & & $\mathrm{LCl}$ & $\mathrm{UCl}$ \\
\hline L Q1 & 13 & 27 & R Q2 & 9 & 22 \\
\hline L Q2 & 15 & 29 & R Q1 & 14 & 30 \\
\hline LQ3 & 18 & 33 & R Q3 & 17 & 33 \\
\hline LQ4 & 24 & 40 & R Q4 & 29 & 47 \\
\hline
\end{tabular}

Table 4-6: Left and Right Quadrant CI 


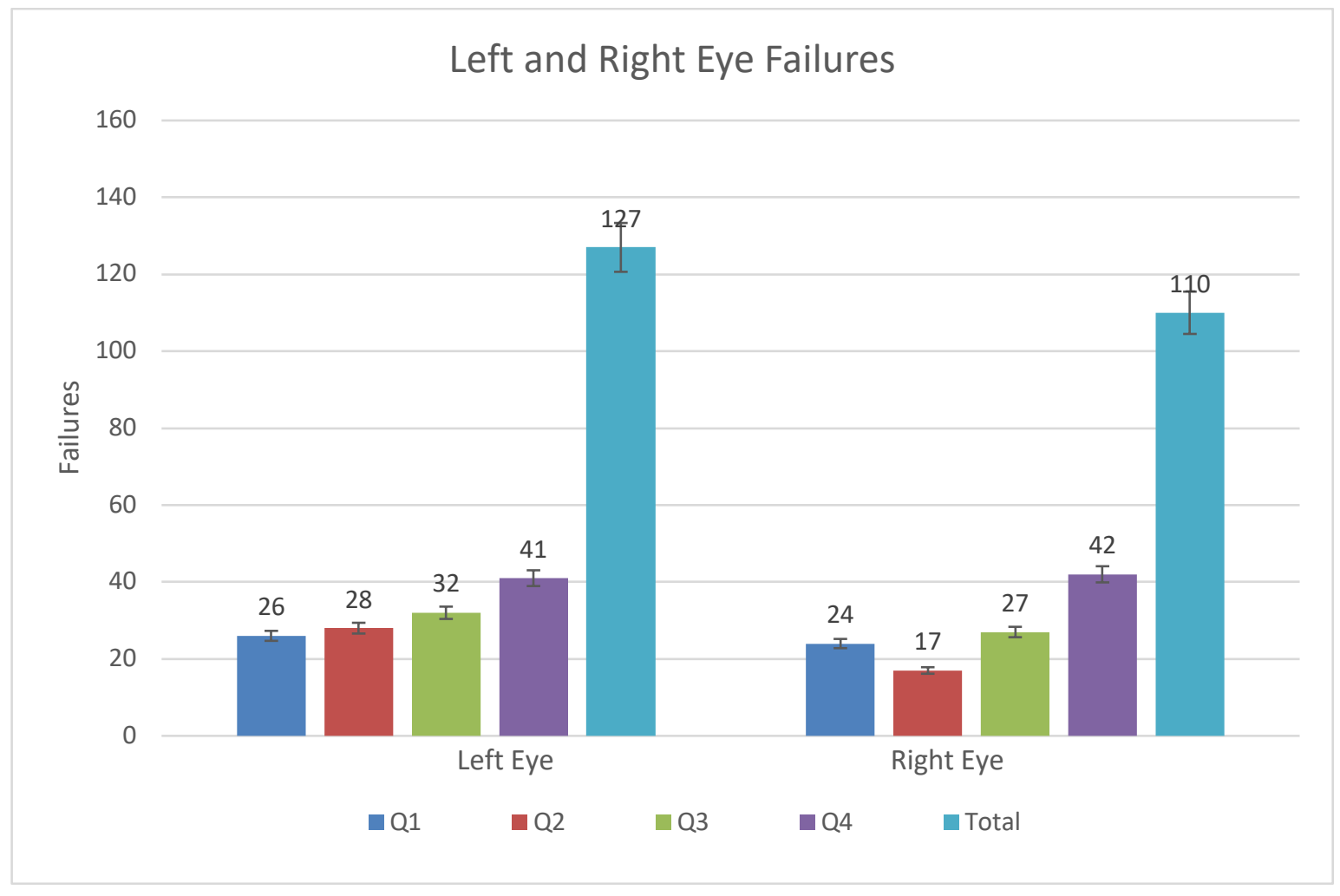

Figure 4-6: Left and Right Eye Failures

\begin{tabular}{|c|c|c|c|c|c|}
\hline \multicolumn{3}{|c|}{ Left Eye } & \multicolumn{3}{|c|}{ Right Eye } \\
\hline 127 & 237 & & 110 & 237 & \\
\hline prop & 0.535865 & $54 \%$ & prop & 0.464135 & $46 \%$ \\
\hline SE & 0.032395 & 0.032 & SE & 0.032395 & 0.032 \\
\hline $\mathrm{LCl}$ & 0.472371 & $47 \%$ & $\mathrm{LCl}$ & 0.400641 & $40 \%$ \\
\hline $\mathrm{UCl}$ & 0.599359 & $60 \%$ & $\mathrm{UCl}$ & 0.527629 & $53 \%$ \\
\hline
\end{tabular}

Table 4-7: Left and Right Eye Statistical Analysis

When looking at Table 4-7, one can see that there is no significant difference between right or left eyes, or between quadrants within the eyes. This also proves to ensure that the test apparatus is consistent within its testing operations. 


\subsection{Pass Rate of Spurt vs Spray}

\begin{tabular}{|c|c|c|c|c|}
\hline & Spray & Spurt & Spray & Spurt \\
\hline A & 40 & 30 & $100 \%$ & $75 \%$ \\
\hline B & 40 & 22 & $100 \%$ & $55 \%$ \\
\hline C & 40 & 40 & $100 \%$ & $100 \%$ \\
\hline D & 30 & 36 & $75 \%$ & $90 \%$ \\
\hline E & 40 & 39 & $100 \%$ & $98 \%$ \\
\hline F & 29 & 24 & $73 \%$ & $60 \%$ \\
\hline G & 8 & 20 & $20 \%$ & $50 \%$ \\
\hline H & 22 & 26 & $55 \%$ & $65 \%$ \\
\hline I & 24 & 20 & $60 \%$ & $50 \%$ \\
\hline J & 2 & 20 & $5 \%$ & $50 \%$ \\
\hline Total & $69 \%$ & $69 \%$ & & \\
\hline
\end{tabular}

Table 4-8: Pass Rate of Eyes - Spurt vs Spray

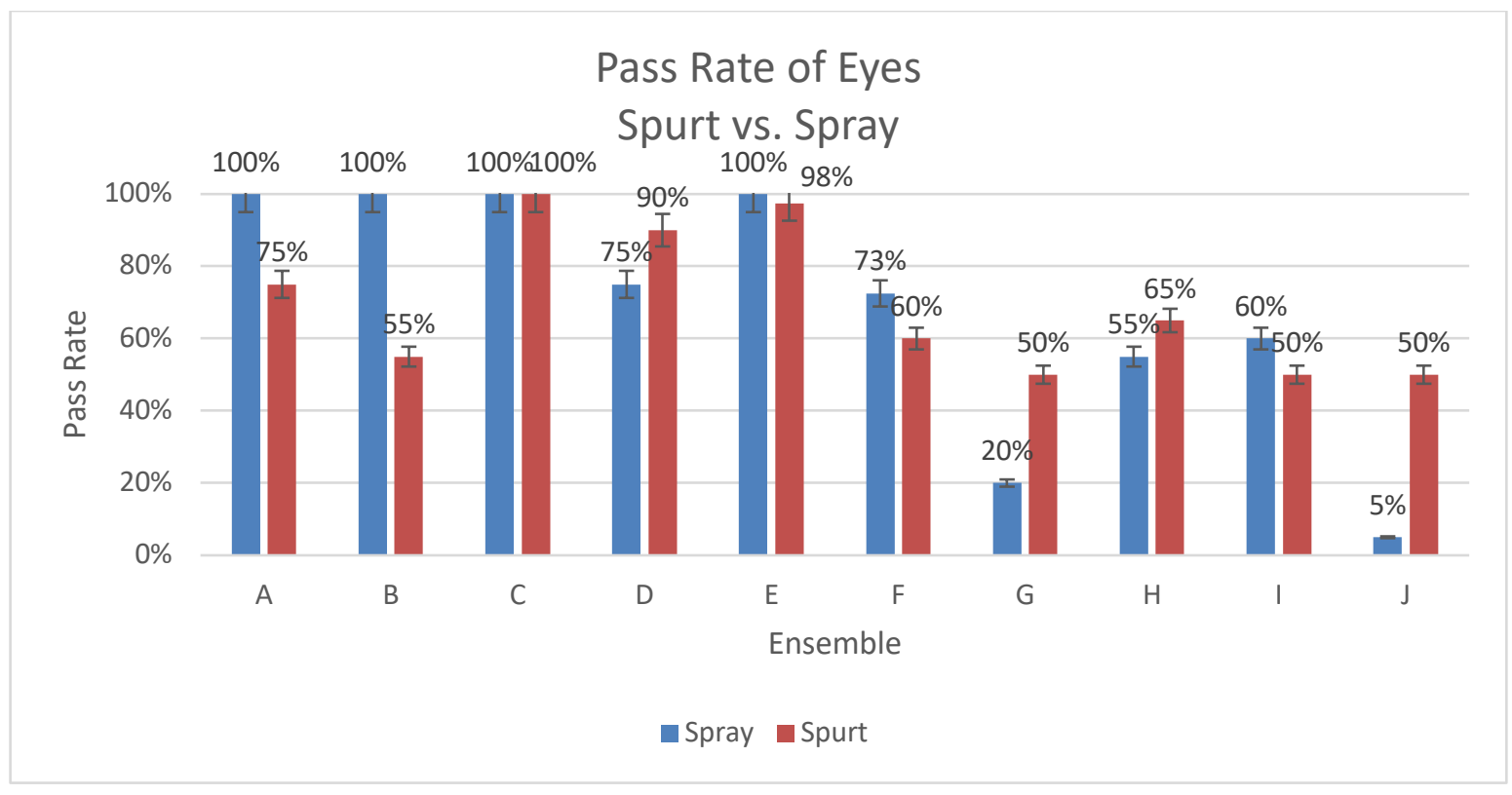

Figure 4-7: Pass Rate of Eye Criteria - Spurt vs Spray 


\begin{tabular}{|c|c|c|c|c|}
\hline & Spurt & Spray & Spurt & Spray \\
\hline A & 32 & 40 & $80 \%$ & $100 \%$ \\
\hline B & 40 & 40 & $100 \%$ & $100 \%$ \\
\hline C & 40 & 40 & $100 \%$ & $100 \%$ \\
\hline D & 40 & 40 & $100 \%$ & $100 \%$ \\
\hline E & 40 & 40 & $100 \%$ & $100 \%$ \\
\hline F & 31 & 40 & $78 \%$ & $100 \%$ \\
\hline G & 28 & 40 & $70 \%$ & $100 \%$ \\
\hline H & 33 & 40 & $83 \%$ & $100 \%$ \\
\hline I & 25 & 40 & $63 \%$ & $100 \%$ \\
\hline J & 31 & 40 & $78 \%$ & $100 \%$ \\
\hline Total & $85 \%$ & $100 \%$ & & \\
\hline
\end{tabular}

Table 4-9: Pass Rate of Nose - Spurt vs Spray

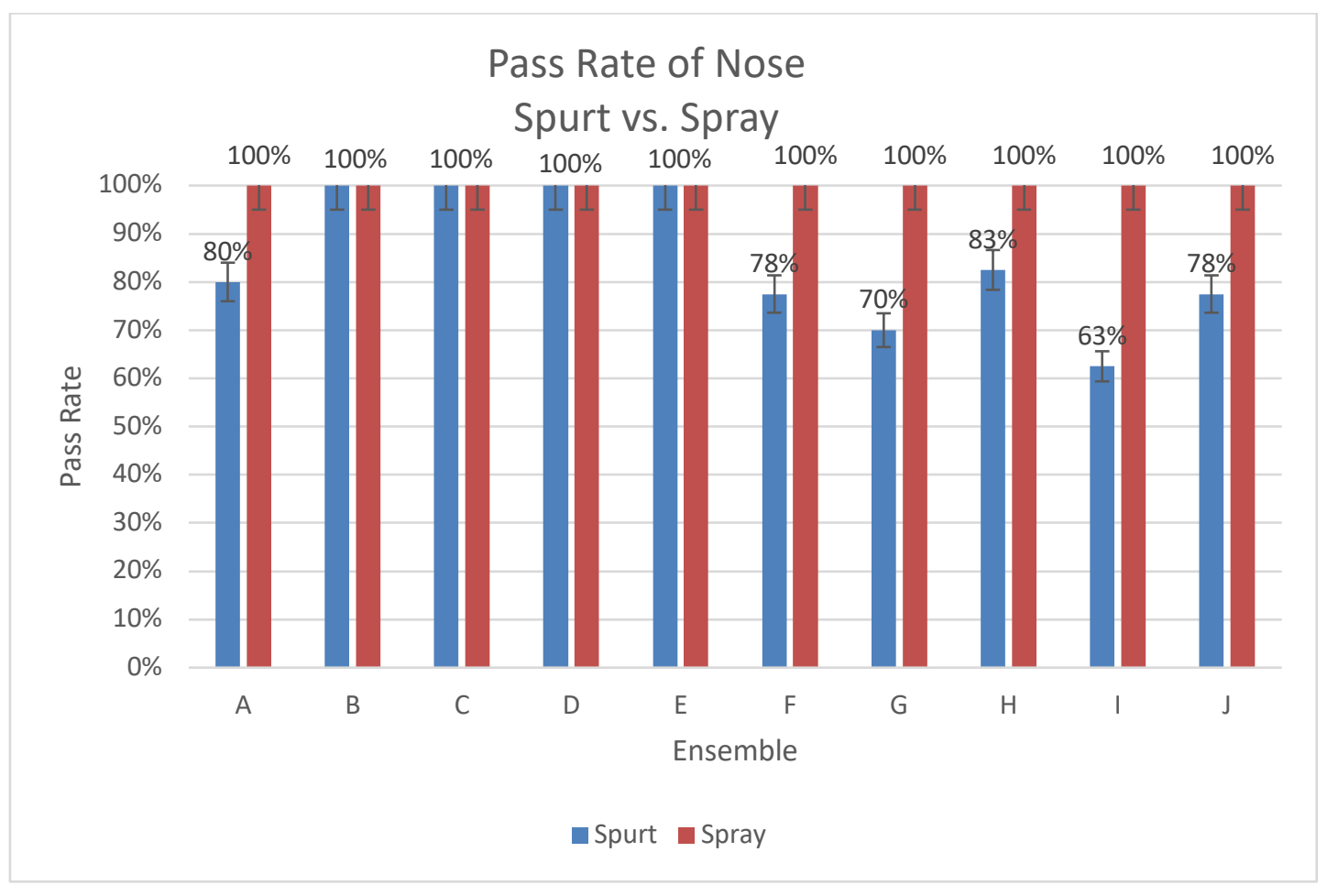

Figure 4-8: Pass Rate of Nose Criteria - Spurt vs Spray 


\begin{tabular}{|c|c|c|c|c|}
\hline & Spurt & Spray & Spurt & Spray \\
\hline A & 34 & 40 & $85 \%$ & $100 \%$ \\
\hline B & 34 & 40 & $85 \%$ & $100 \%$ \\
\hline C & 40 & 40 & $100 \%$ & $100 \%$ \\
\hline D & 39 & 40 & $98 \%$ & $100 \%$ \\
\hline E & 40 & 40 & $100 \%$ & $100 \%$ \\
\hline F & 30 & 40 & $75 \%$ & $100 \%$ \\
\hline G & 35 & 40 & $88 \%$ & $100 \%$ \\
\hline H & 33 & 40 & $83 \%$ & $100 \%$ \\
\hline I & 24 & 40 & $60 \%$ & $100 \%$ \\
\hline J & 27 & 40 & $68 \%$ & $100 \%$ \\
\hline Total & $84 \%$ & $100 \%$ & & \\
\hline
\end{tabular}

Table 4-10: Pass Rate of Mouth - Spurt vs Spray

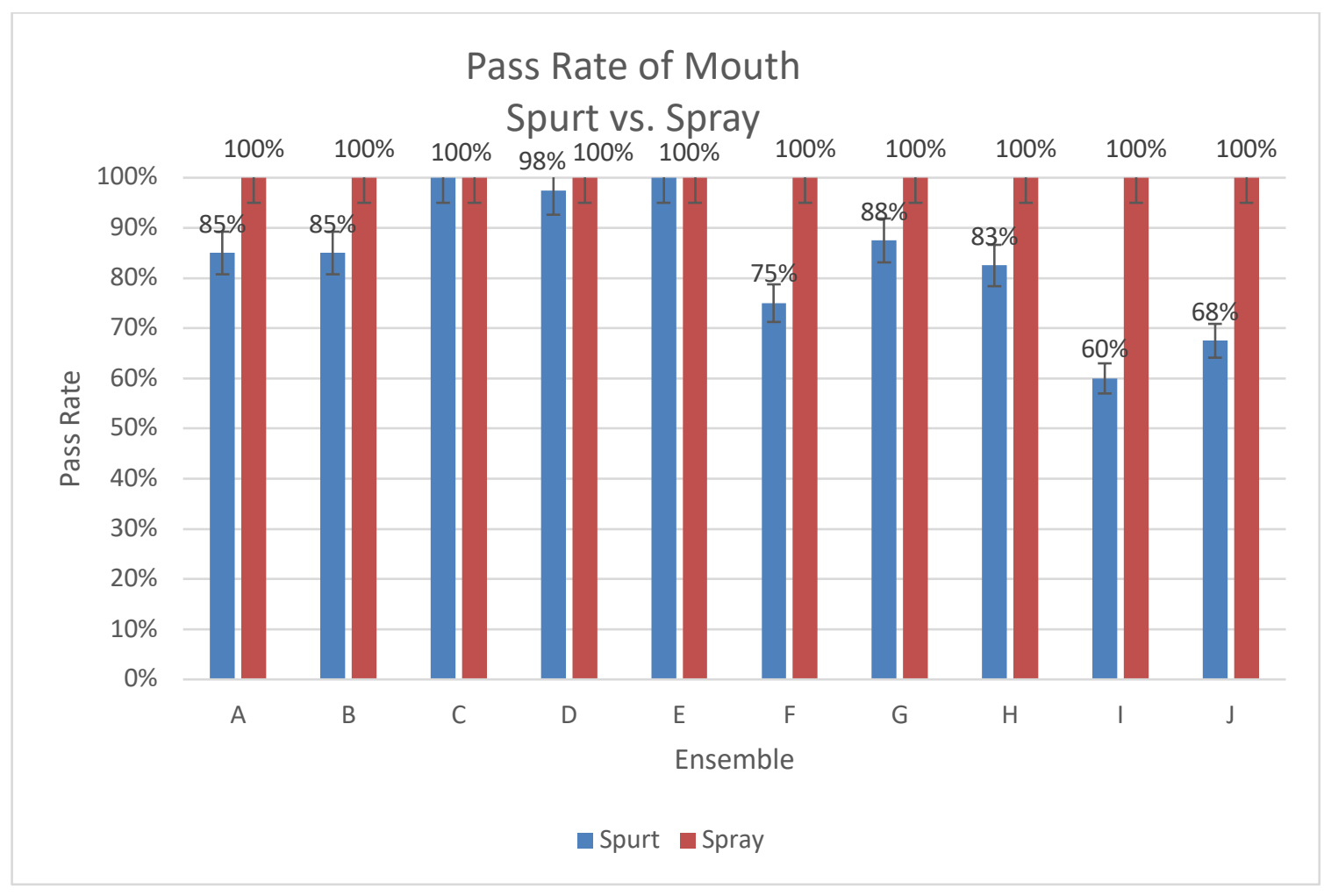

Figure 4-9: Pass Rate of Mouth Criteria - Spurt vs Spray 


\begin{tabular}{|l|rr|}
\hline Spurt & 953 & $79 \%$ \\
Spray & 1075 & $90 \%$ \\
\hline
\end{tabular}

Table 4-11: Overall Ensemble Pass Rate of Spurt vs Spray

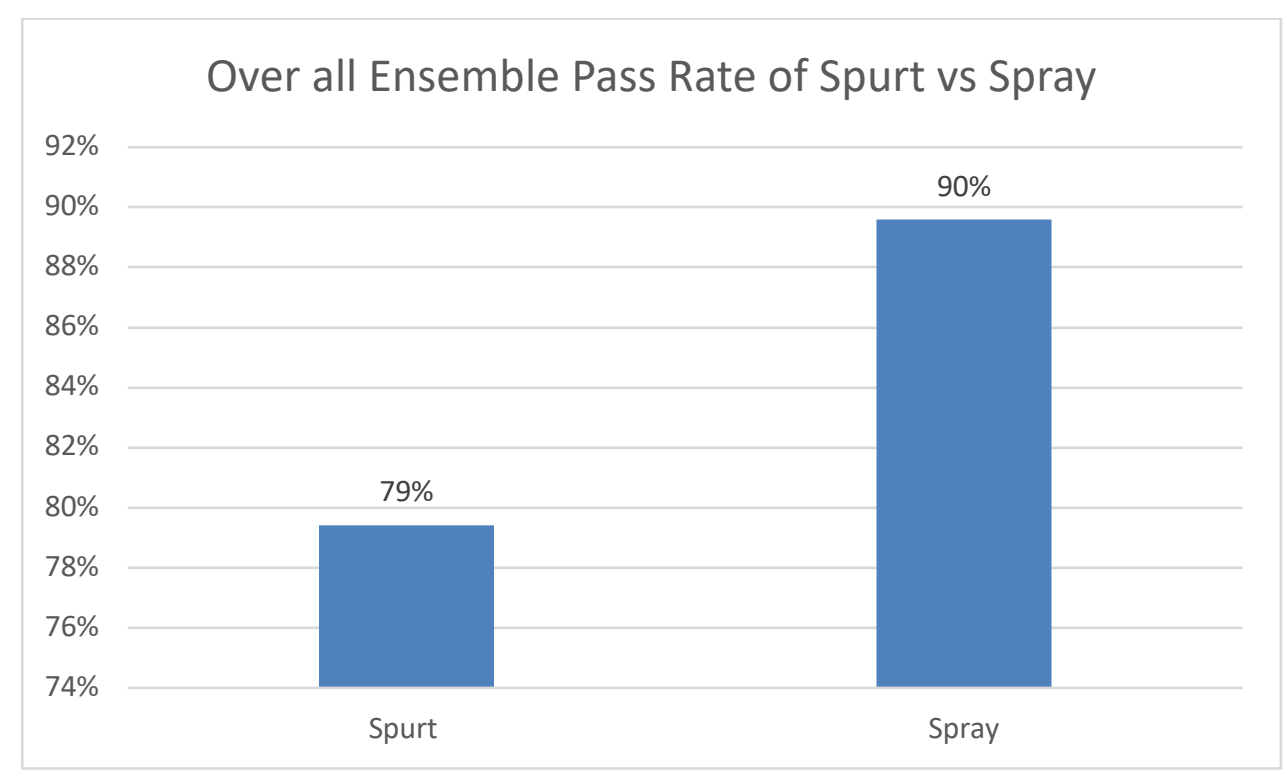

Figure 4-10: Overall Ensemble Pass Rate of Spurt vs Spray

\begin{tabular}{|c|cc|}
\hline \multirow{3}{*}{ Spurt } & $\mathrm{LCl}$ & $\mathrm{UCl}$ \\
\cline { 2 - 3 } Spray & 77 & 82 \\
& 88 & 91 \\
\hline
\end{tabular}

Table 4-12: CI of Overall Pass Rate of Spurt vs Spray 
Figure 4-11: CI of Overall Pass Rate of Spurt vs Spray

\begin{tabular}{|l|l|r|r|r|r|r|}
\hline \multicolumn{7}{|c|}{ Analysis of Maximum Likelihood Estimates } \\
\hline Parameter & & DF & Estimate & $\begin{array}{r}\text { Standard } \\
\text { Error }\end{array}$ & $\begin{array}{r}\text { Wald } \\
\text { Chi-Square }\end{array}$ & Pr > ChiSq \\
\hline type1 & Spray-E & 1 & 0.0627 & 0.1120 & 0.3130 & 0.5758 \\
\hline type1 & Spray-N & 1 & 8.0958 & 56.8641 & 0.0203 & 0.9581 \\
\hline type1 & Spray-M & 1 & 7.9343 & 60.3654 & 0.0173 & 0.8954 \\
\hline
\end{tabular}

Table 4-13: Statistical Analysis of Spurt vs Spray

Table 4-13 above is looking at the significance of spurt vs spray between the 3 areas of concern (Eyes, Nose, and Mouth). It is found that there is no significant difference between spurt and spray by the SAS data output. 


\subsection{Pass Rate per Position}

\begin{tabular}{|l|c|r|r|r|r|}
\hline & & Up & Down & Left & Right \\
\hline Spurt & Pass & $46 \%$ & $31 \%$ & $100 \%$ & $100 \%$ \\
\hline Spray & Pass & $47 \%$ & $81 \%$ & $80 \%$ & $67 \%$ \\
\hline Eyes & Total & $47 \%$ & $56 \%$ & $90 \%$ & $84 \%$ \\
\hline
\end{tabular}

Table 4-14: Eyes Pass Rate per Position

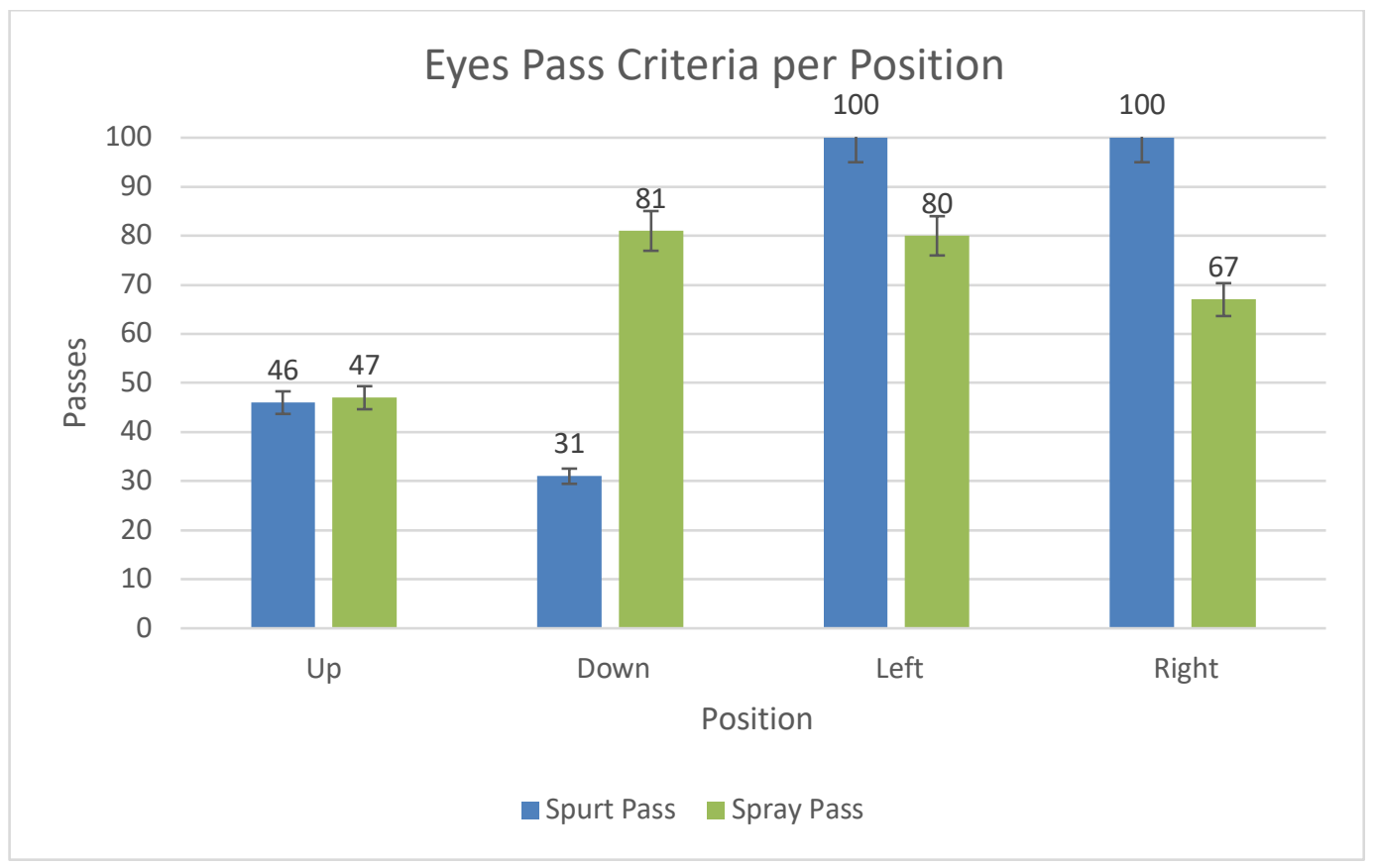

Figure 4-12: Eyes Pass Criteria per Position

\begin{tabular}{|l|r|r|r|}
\hline \multicolumn{4}{|c|}{ Contrast Test Results } \\
\hline Contrast & DF & $\begin{array}{r}\text { Wald } \\
\text { Chi-Square }\end{array}$ & Pr $>$ ChiSq \\
\hline $\mathbf{1}$ v 2 & 1 & 8.8573 & 0.0029 \\
\hline $\mathbf{1}$ v 3 & 1 & 94.6000 & $<.0001$ \\
\hline $\mathbf{1}$ v 4 & 1 & 90.3394 & $<.0001$ \\
\hline $\mathbf{2}$ v 3 & 1 & 64.7605 & $<.0001$ \\
\hline $\mathbf{2}$ v 4 & 1 & 60.2873 & $<.0001$ \\
\hline $\mathbf{3}$ v 4 & 1 & 0.3214 & 0.5707 \\
\hline
\end{tabular}

Table 4-15: Eye Positions Contrasts 
In Table 4-15, we comparing the significance between positions 1, 2, 3, and 4 when looking at the results from the eyes. One can see that the only 2 positions that are not significantly different. Therefore we can conclude that there are differences in between positions 1 and 3, 1 and 4, 2 and 3, and 2 and 4 (1-Up, 2-Down, 3-Left, and 4-Right).

\begin{tabular}{|l|l|r|r|r|r|}
\hline & & Up & Down & Left & Right \\
\hline Spurt & Pass & $89 \%$ & $51 \%$ & $100 \%$ & $100 \%$ \\
\hline Spray & Pass & $100 \%$ & $100 \%$ & $100 \%$ & $100 \%$ \\
\hline Nose & Total & $95 \%$ & $76 \%$ & $100 \%$ & $100 \%$ \\
\hline
\end{tabular}

Table 4-16: Nose Pass Rate per Position

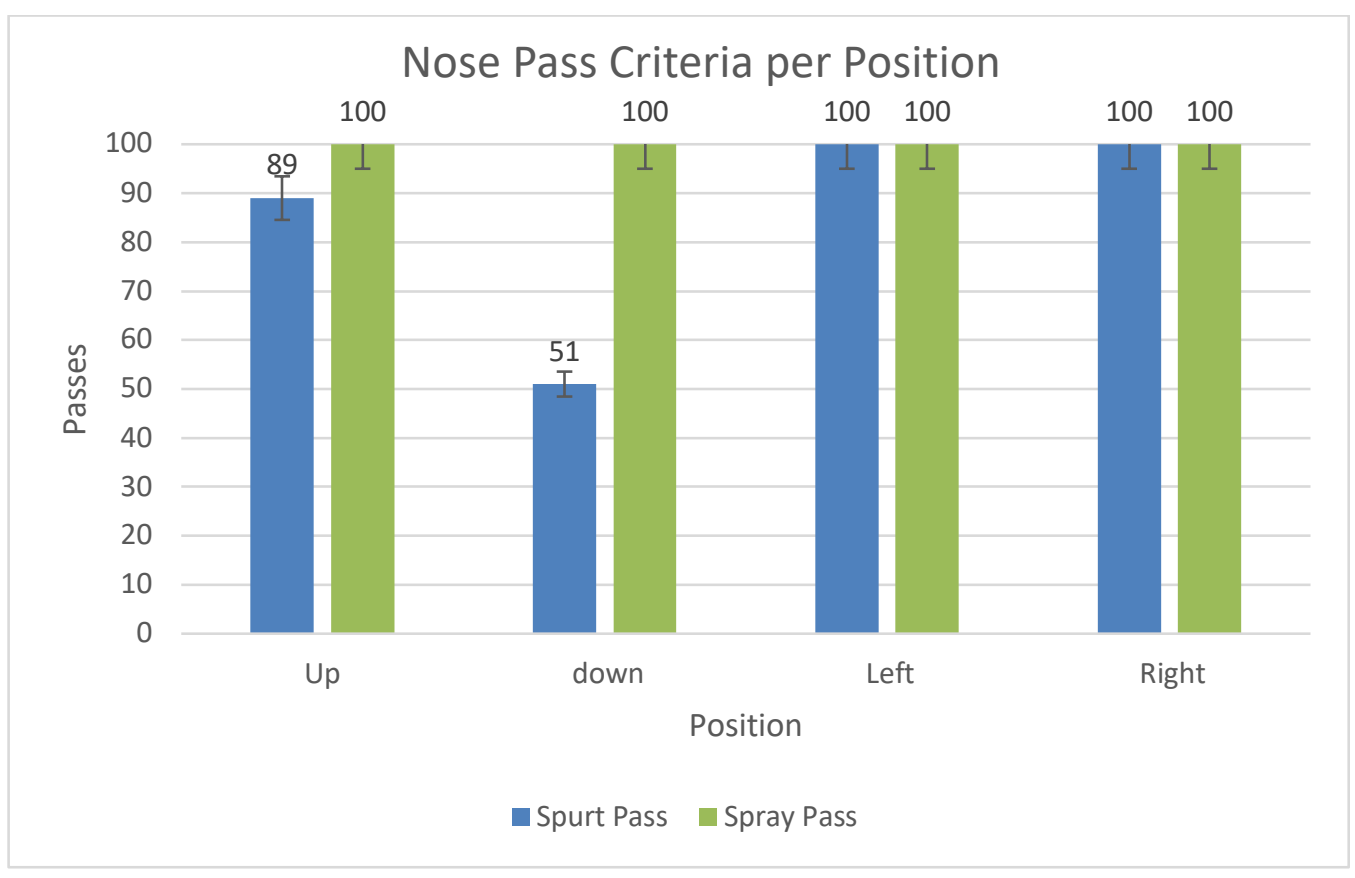

Figure 4-13: Nose Pass Criteria per Position 


\begin{tabular}{|l|r|r|r|}
\hline \multicolumn{4}{|c|}{ Contrast Test Results } \\
\hline Contrast & DF & $\begin{array}{r}\text { Wald } \\
\text { Chi-Square }\end{array}$ & Pr > ChiSq \\
\hline $\mathbf{1}$ v $\mathbf{2}$ & 1 & 36.6124 & $<.0001$ \\
\hline $\mathbf{1}$ v 3 & 1 & 0.0053 & 0.9420 \\
\hline $\mathbf{1}$ v 4 & 1 & 0.0053 & 0.9420 \\
\hline $\mathbf{2} \mathbf{~ 3}$ & 1 & 0.0088 & 0.9254 \\
\hline $\mathbf{2}$ v 4 & 1 & 0.0088 & 0.9254 \\
\hline $\mathbf{3}$ v 4 & 1 & 0.0000 & 1.0000 \\
\hline
\end{tabular}

Table 4-17: Nose Positions Contrasts

In Table 4-17, we are comparing the significance between positions 1, 2, 3, and 4 when looking at the results from the nose. Therefore we can conclude that there are differences in between positions 1 and 2. (1-Up, 2-Down, 3-Left, and 4-Right). Due to many of the nose positions having high passing rates the contrasts between positions are limited in their detection level.

\begin{tabular}{|l|l|r|r|r|r|}
\hline & & Up & Down & Left & Right \\
\hline Spurt & Pass & $85 \%$ & $51 \%$ & $100 \%$ & $100 \%$ \\
\hline Spray & Pass & $100 \%$ & $100 \%$ & $100 \%$ & $100 \%$ \\
\hline Mouth & Total & $93 \%$ & $76 \%$ & $100 \%$ & $100 \%$ \\
\hline
\end{tabular}

Table 4-18: Mouth Pass Rate per Position 


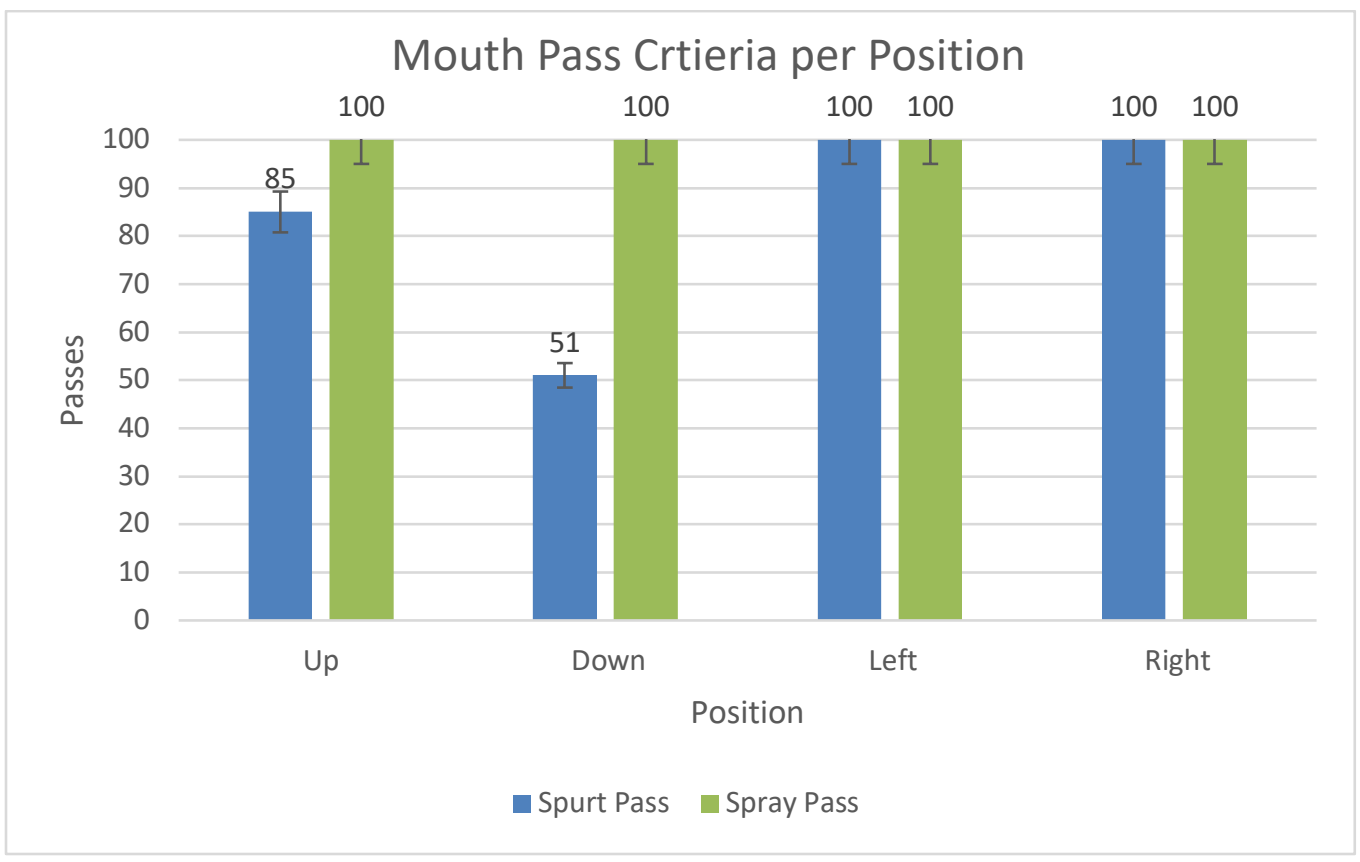

Figure 4-14: Mouth Pass Criteria per Position

\begin{tabular}{|l|r|r|r|}
\hline \multicolumn{4}{|c|}{ Contrast Test Results } \\
\hline Contrast & DF & $\begin{array}{r}\text { Wald } \\
\text { Chi-Square }\end{array}$ & Pr $>$ ChiSq \\
\hline $\mathbf{1}$ v $\mathbf{2}$ & 1 & 26.2149 & $<.0001$ \\
\hline $\mathbf{1} \mathbf{v} \mathbf{3}$ & 1 & 0.0055 & 0.9408 \\
\hline $\mathbf{1} \mathbf{v} \mathbf{4}$ & 1 & 0.0055 & 0.9408 \\
\hline $\mathbf{2} \mathbf{~ 3}$ & 1 & 0.0081 & 0.9283 \\
\hline $\mathbf{2} \mathbf{~ \mathbf { 4 }}$ & 1 & 0.0081 & 0.9283 \\
\hline $\mathbf{3} \mathbf{v} \mathbf{4}$ & 1 & 0.0000 & 1.0000 \\
\hline
\end{tabular}

Table 4-19: Mouth Positions Contrasts

In Table 4-19, we are comparing the significance between positions 1, 2, 3, and 4 when looking at the results from the mouth. Therefore we can conclude that there are differences in between positions 1 and 2 (1-Up, 2-Down, 3-Left, and 4-Right). Due to many of the mouth positions having high passing rates the contrasts between positions are limited in their detection level. 


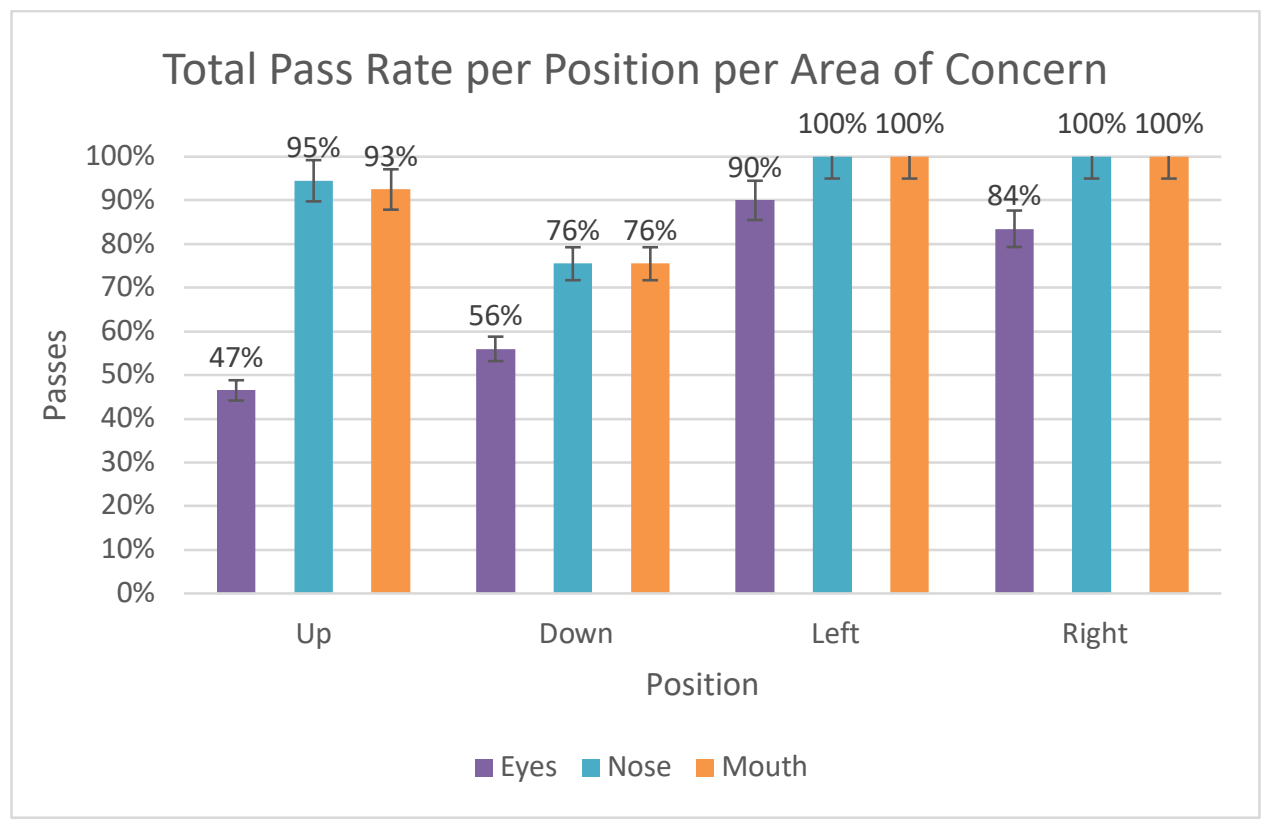

Figure 4-15: Total Pass Rate per Position per Area of Concern

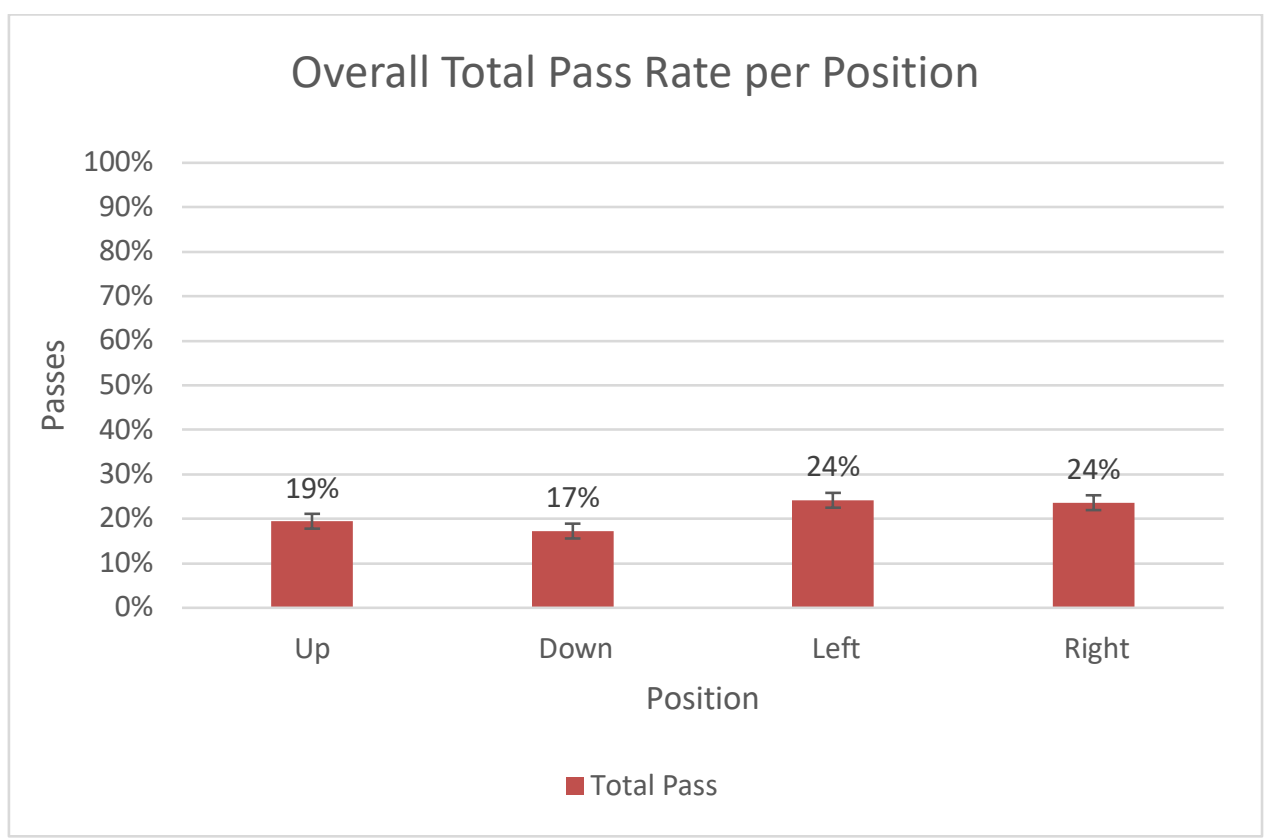

Figure 4-16: Overall Total Pass Rate per Position

Figure 4-15 shows the total pass rate for each position per area of concern. While Figure 4-16 shows the overall total pass rate per position when combining the pass rate of all three of the areas of concern (Eyes, Nose, and Mouth). 
(below) which depicts the mean, standard deviation, variance, and an upper and lower $95 \%$ confidence interval of the distance of passes for each ensemble for spurt and spray. Table 4-20 for the eye criteria is useful to reflect the reliability of the estimates based on the observed data. These confidence intervals are intended to offer assurance that all data obtained in the future with this apparatus and procedure should include the true value of the data with a given level of confidence. Any future group mean can be compared to these and declared "the same" or "different."

\begin{tabular}{|r|c|l|l|r|r|r|r|r|}
\hline Obs & Ensemble & position2 & type1 & mean & standdev & variance & low95 & up95 \\
\hline $\mathbf{1}$ & A & Down & Spray & 16.6750 & 0.9278 & 0.861 & 16.011 & 17.339 \\
\hline $\mathbf{2}$ & A & Left & Spray & 19.0750 & 3.0092 & 9.055 & 16.922 & 21.228 \\
\hline $\mathbf{3}$ & A & Left & Spurt & 20.2540 & 1.7025 & 2.898 & 19.036 & 21.472 \\
\hline $\mathbf{4}$ & A & Right & Spray & 17.9860 & 2.3538 & 5.540 & 16.302 & 19.670 \\
\hline $\mathbf{5}$ & A & Right & Spurt & 17.8100 & 3.4714 & 12.050 & 15.327 & 20.293 \\
\hline $\mathbf{6}$ & A & Up & Spray & 24.4920 & 1.4595 & 2.130 & 23.448 & 25.536 \\
\hline $\mathbf{7}$ & A & Up & Spurt & 19.3350 & 6.7772 & 45.931 & 14.487 & 24.183 \\
\hline $\mathbf{8}$ & B & Down & Spray & 40.8980 & 11.7074 & 137.064 & 32.523 & 49.273 \\
\hline $\mathbf{9}$ & B & Down & Spurt & 55.5500 &. &. & & \\
\hline $\mathbf{1 0}$ & B & Left & Spray & 42.8860 & 9.2647 & 85.834 & 36.258 & 49.514 \\
\hline $\mathbf{1 1}$ & B & Left & Spurt & 33.6970 & 15.1501 & 229.525 & 22.859 & 44.535 \\
\hline $\mathbf{1 2}$ & B & Right & Spray & 44.6010 & 8.1343 & 66.167 & 38.782 & 50.420 \\
\hline $\mathbf{1 3}$ & B & Right & Spurt & 41.2080 & 25.3405 & 642.143 & 23.080 & 59.336 \\
\hline $\mathbf{1 4}$ & B & Up & Spray & 59.4590 & 5.1856 & 26.890 & 55.749 & 63.169 \\
\hline $\mathbf{1 5}$ & B & Up & Spurt & 18.5150 & 23.5679 & 555.444 & -193.234 & 230.264 \\
\hline $\mathbf{1 6}$ & C & Down & Spray & 34.4650 & 1.9207 & 3.689 & 33.091 & 35.839 \\
\hline $\mathbf{1 7}$ & C & Down & Spurt & 34.0290 & 9.8360 & 96.746 & 26.993 & 41.065 \\
\hline $\mathbf{1 8}$ & C & Left & Spray & 40.8160 & 5.8184 & 33.854 & 36.654 & 44.978 \\
\hline $\mathbf{1 9}$ & C & Left & Spurt & 51.1580 & 5.0464 & 25.466 & 47.548 & 54.768 \\
\hline
\end{tabular}




\begin{tabular}{|c|c|c|c|c|c|c|c|c|}
\hline Obs & Ensemble & position2 & type1 & mean & standdev & variance & low95 & up95 \\
\hline 20 & $\mathrm{C}$ & Right & Spray & 42.8390 & 7.2155 & 52.064 & 37.677 & 48.001 \\
\hline 21 & $\mathrm{C}$ & Right & Spurt & 53.5110 & 2.7375 & 7.494 & 51.553 & 55.469 \\
\hline 22 & $\mathrm{C}$ & Up & Spray & 51.2840 & 4.7379 & 22.448 & 47.895 & 54.673 \\
\hline 23 & $\mathrm{C}$ & Up & Spurt & 37.4980 & 2.8049 & 7.867 & 35.492 & 39.504 \\
\hline 24 & D & Down & Spray & 20.5730 & 11.4871 & 131.954 & 12.356 & 28.790 \\
\hline 25 & D & Left & Spray & 13.1800 & 2.5994 & 6.757 & 11.321 & 15.039 \\
\hline 26 & D & Left & Spurt & 20.9470 & 3.3058 & 10.928 & 18.582 & 23.312 \\
\hline 27 & D & Right & Spray & 11.8240 & 3.3774 & 11.407 & 9.408 & 14.240 \\
\hline 28 & $\mathrm{D}$ & Right & Spurt & 18.8220 & 5.7901 & 33.526 & 14.680 & 22.964 \\
\hline 29 & D & Up & Spurt & 7.9050 & 10.4336 & 108.861 & -0.818 & 16.628 \\
\hline 30 & $\mathrm{E}$ & Down & Spray & 29.4540 & 8.2486 & 68.040 & 23.553 & 35.355 \\
\hline 31 & $\mathrm{E}$ & Down & Spurt & 43.5033 & 3.7424 & 14.005 & 34.207 & 52.800 \\
\hline 32 & E & Left & Spray & 48.9350 & 10.2740 & 105.556 & 41.585 & 56.285 \\
\hline 33 & $\mathrm{E}$ & Left & Spurt & 47.3380 & 6.7367 & 45.383 & 42.519 & 52.157 \\
\hline 34 & E & Right & Spray & 47.3250 & 8.0792 & 65.274 & 41.545 & 53.105 \\
\hline 35 & $\mathrm{E}$ & Right & Spurt & 42.8280 & 5.0567 & 25.571 & 39.211 & 46.445 \\
\hline 36 & E & Up & Spray & 52.7410 & 17.8736 & 319.466 & 39.955 & 65.527 \\
\hline 37 & E & Up & Spurt & 26.6233 & 23.0622 & 531.864 & 8.896 & 44.350 \\
\hline 38 & $\mathrm{~F}$ & Down & Spray & 5.0850 & 6481 & 7.013 & 0.871 & 9.299 \\
\hline 39 & $\mathrm{~F}$ & Down & Spurt & & & & & \\
\hline 40 & $\mathrm{~F}$ & Left & Spray & 10.6120 & 1.9871 & 3.948 & 9.191 & 12.033 \\
\hline 41 & $\mathrm{~F}$ & Left & Spurt & 16.2080 & 4.9092 & 24.101 & 12.696 & 19.720 \\
\hline 42 & $\mathrm{~F}$ & Right & Spray & 10.9920 & 4.6364 & 21.497 & 7.675 & 14.309 \\
\hline 43 & $\mathrm{~F}$ & Right & Spurt & 15.2190 & 2.8195 & 7.950 & 13.202 & 17.236 \\
\hline 44 & $\mathrm{~F}$ & Up & Spray & 16.1360 & 4.1840 & 17.506 & 10.941 & 21.331 \\
\hline 45 & $\mathrm{~F}$ & Up & Spurt & 3.4433 & 1.9358 & 3.747 & -1.366 & 8.252 \\
\hline 46 & G & Down & Spray & 3.2086 & 0.8650 & 0.748 & 2.409 & 4.009 \\
\hline 47 & G & Left & Spurt & 17.1930 & 5.8286 & 33.973 & 13.023 & 21.363 \\
\hline 48 & G & Right & Spray & 0.0810 & & & & \\
\hline
\end{tabular}




\begin{tabular}{|r|c|l|r|r|r|r|r|r|}
\hline Obs & Ensemble & position2 & type1 & mean & standdev & variance & low95 & up95 \\
\hline $\mathbf{4 9}$ & G & Right & Spurt & 12.9430 & 2.4144 & 5.829 & 11.216 & 14.670 \\
\hline $\mathbf{5 0}$ & H & Down & Spray & 6.3850 & 1.3051 & 1.703 & 5.451 & 7.319 \\
\hline $\mathbf{5 1}$ & H & Down & Spurt & 1.4100 & 0.7071 & 0.500 & -4.943 & 7.763 \\
\hline $\mathbf{5 2}$ & H & Left & Spray & 8.0910 & 2.6350 & 6.943 & 6.206 & 9.976 \\
\hline $\mathbf{5 3}$ & H & Left & Spurt & 13.1900 & 5.2152 & 27.199 & 9.459 & 16.921 \\
\hline $\mathbf{5 4}$ & H & Right & Spray & 11.3610 & 2.8547 & 8.149 & 9.319 & 13.403 \\
\hline $\mathbf{5 5}$ & H & Right & Spurt & 12.3670 & 4.0398 & 16.320 & 9.477 & 15.257 \\
\hline $\mathbf{5 6}$ & H & Up & Spray & 6.3700 & & & &. \\
\hline $\mathbf{5 7}$ & H & Up & Spurt & 8.8950 & 3.4778 & 12.095 & 3.361 & 14.429 \\
\hline $\mathbf{5 8}$ & I & Down & Spray & 2.7100 & 1.2866 & 1.655 & 1.790 & 3.630 \\
\hline $\mathbf{5 9}$ & I & Left & Spray & 2.4957 & 0.5940 & 0.353 & 1.946 & 3.045 \\
\hline $\mathbf{6 0}$ & I & Left & Spurt & 17.2420 & 3.3224 & 11.038 & 14.865 & 19.619 \\
\hline $\mathbf{6 1}$ & I & Right & Spray & 3.6800 & 1.9467 & 3.790 & 1.880 & 5.480 \\
\hline $\mathbf{6 2}$ & I & Right & Spurt & 15.4920 & 3.8213 & 14.602 & 12.758 & 18.226 \\
\hline $\mathbf{6 3}$ & J & Left & Spurt & 21.2210 & 4.7275 & 22.350 & 17.839 & 24.603 \\
\hline $\mathbf{6 4}$ & J & Right & Spray & 3.8650 & 0.6576 & 0.432 & -2.043 & 9.773 \\
\hline $\mathbf{6 5}$ & J & Right & Spurt & 19.2300 & 4.1360 & 17.106 & 16.271 & 22.189 \\
\hline
\end{tabular}

Table 4-20: Overall 95\% CI of Pass Distance per Ensembles for Eye Criteria 


\begin{tabular}{|c|c|c|c|c|c|}
\hline Spurt & & & Spray & & \\
\hline Type & Order & Random & Type & Order & Random \\
\hline 1 & 4 & 0.110105 & 1 & 3 & 0.771812 \\
\hline 1 & 1 & 0.866044 & 1 & 4 & 0.899898 \\
\hline 1 & 3 & 0.575045 & 1 & 2 & 0.620639 \\
\hline 1 & 2 & 0.209213 & 1 & 1 & 0.253192 \\
\hline 2 & 4 & 0.100062 & 2 & 3 & 0.434974 \\
\hline 2 & 3 & 0.64155 & 2 & 1 & 0.67247 \\
\hline 2 & 1 & 0.271539 & 2 & 4 & 0.107855 \\
\hline 2 & 2 & 0.639137 & 2 & 2 & 0.48079 \\
\hline 3 & 2 & 0.308732 & 3 & 4 & 0.485787 \\
\hline 3 & 1 & 0.035325 & 3 & 1 & 0.034049 \\
\hline 3 & 3 & 0.61792 & 3 & 2 & 0.626298 \\
\hline 3 & 4 & 0.644714 & 3 & 3 & 0.065569 \\
\hline 4 & 4 & 0.454954 & 4 & 3 & 0.972744 \\
\hline 4 & 3 & 0.515109 & 4 & 1 & 0.755114 \\
\hline 4 & 2 & 0.146152 & 4 & 4 & 0.509375 \\
\hline 4 & 1 & 0.279676 & 4 & 2 & 0.007701 \\
\hline 5 & 2 & 0.247228 & 5 & 2 & 0.677996 \\
\hline 5 & 1 & 0.272828 & 5 & 4 & 0.473996 \\
\hline 5 & 4 & 0.896784 & 5 & 3 & 0.672279 \\
\hline 5 & 3 & 0.342129 & 5 & 1 & 0.391638 \\
\hline 6 & 1 & 0.241775 & 6 & 2 & 0.416609 \\
\hline 6 & 2 & 0.127472 & 6 & 4 & 0.599407 \\
\hline 6 & 4 & 0.706046 & 6 & 3 & 0.503911 \\
\hline 6 & 3 & 0.821264 & 6 & 1 & 0.584669 \\
\hline 7 & 4 & 0.490619 & 7 & 4 & 0.495893 \\
\hline 7 & 1 & 0.477712 & 7 & 2 & 0.321757 \\
\hline 7 & 3 & 0.095565 & 7 & 1 & 0.630011 \\
\hline 7 & 2 & 0.049422 & 7 & 3 & 0.623625 \\
\hline 8 & 4 & 0.871248 & 8 & 1 & 0.21115 \\
\hline 8 & 1 & 0.330814 & 8 & 2 & 0.595587 \\
\hline 8 & 2 & 0.8773 & 8 & 3 & 0.781672 \\
\hline 8 & 3 & 0.359281 & 8 & 4 & 0.607079 \\
\hline 9 & 1 & 0.389863 & 9 & 2 & 0.149353 \\
\hline 9 & 4 & 0.103653 & 9 & 4 & 0.000394 \\
\hline 9 & 3 & 0.722085 & 9 & 3 & 0.890708 \\
\hline 9 & 2 & 0.3049 & 9 & 1 & 0.194994 \\
\hline 10 & 3 & 0.206174 & 10 & 4 & 0.577079 \\
\hline 10 & 1 & 0.781835 & 10 & 3 & 0.717418 \\
\hline 10 & 4 & 0.415395 & 10 & 2 & 0.18312 \\
\hline 10 & 2 & 0.740884 & 10 & 1 & 0.994418 \\
\hline
\end{tabular}

Table 4-21: Random Number Generator for Testing Order

In Table 4-21 one will see how the order of testing was randomized. This table was

created in Excel where the type and order was assigned to the random number that was 
generated. The "order" was then sorted by "type" making each series of position (1-4) randomized for the 10 replications of each spurt and spray categories. 


\section{CHAPTER 5 - Discussion}

\subsection{Overview of Findings}

During the initial start of this project the original hypothesis was stated that current ANSI Z87.1 eye protectors will not pass the criteria from this test to be labeled for protection against biological hazards. The test matrix was set up to include 10 ensembles (e.g eye protector and face mask) that were currently being used in high hazard occupations for biological protection. Out of the 10 ensembles that were tested on the apparatus for spurt and spray protection, only 1 ensemble passed the testing criteria fully (Ensemble C). This particular ensemble did not have any failures on any of the head manipulations in any of the areas of concern. The other 9 ensembles failed in 1 or more of the head manipulations. Within this general result, $90 \%$ of the eye and face protection currently used for biological hazard protection would not pass proposed Z87.62 testing criteria.

\subsection{Overview of Ensembles}

\subsubsection{Total Pass Rate of Areas of Concern}

When looking at the particular areas of concern (Eyes, Nose, and Mouth) we can see that the Nose and the Mouth were more effectively protected than the eyes for this testing procedure. The Nose and the Mouth had a total pass rate of $93 \%$ and $92 \%$ respectively. While the total pass rate for the Eyes was $69 \%$. This can be expected as the Nose and the Mouth are more adequately covered by most face masks and leave fewer and smaller gaps than eye protectors tend to do. The face mask tend to press tightly against the face which seals most areas. Most face masks also have a built in wire strip at the top which a wearer is instructed to conform to the curvature of the 
nose and upper cheeks. This also aids in closing the gaps for added protection to the Nose and Mouth. Eye protectors that were testing did not have these features. Some sit at the face closer than others which aided in protection to the Eyes, but most still had large gaps. The eye protectors that performed best were built in an effort to close these gaps (top gap, bottom gap and side gaps). Most eye protectors do provide some sort of side protection but few had adequate protection for the top and bottom gaps.

\subsubsection{Comparing Pass Rate of Areas of Concern}

When looking at individual ensembles pass rates for the Eyes, we can see that Ensemble C (100\%) and E (99\%) proved to provide the best protection. The next highest total pass rate for the eyes was Ensemble A (88\%). Looking at the overall pass rate for the Nose we can see that there are multiple ensembles that offered a high level of protection. Ensemble B, C, D, and E, all had a pass rate of 100\%. The next highest was Ensemble A at $90 \%$. The Overall pass rate for the Nose was again $24 \%$ higher than that of the eyes. Comparing the pass rates now with that of the Mouth we again can see higher levels of protection for passing rates. Ensembles $\mathrm{C}$ and $\mathrm{E}$ both had a passing rate of 100\%, while the next highest are Ensemble D (99\%) and Ensemble G

(94\%). The overall ensembles pass rate is $23 \%$ higher for the mouth than the eyes, and $1 \%$ lower than the overall ensembles pass rate for the nose. Looking at the Total Ensemble pass rate, we can see that Ensemble $\mathrm{C}$ was the only one to have zero failures, therefore having a pass rate of $100 \%$. However, Ensemble E did complete the testing procedure with an end Total Ensemble Pass Rate of $99.6 \%$ making it a very close $2^{\text {nd }}$ for best protective Ensemble. When comparing the Ensembles to each other based on their performance, we can look into a histogram plot using the ensembles upper and 
lower confidence intervals to analyze significance between them (Figure 4-5). Since Ensemble $\mathrm{C}$ had a passing rate of $100 \%$ it cannot have true confidence intervals, however I included it on the analysis to represent a perfect score (Figure 4-4). Ensemble $\mathrm{C}$ and $\mathrm{E}$ have significantly better protective performance than the other 8 ensembles. From this plot, a conclusion can also be drawn that Ensemble D has significantly better protective performance than Ensembles F, G, H, I, and J, but cannot determine a difference between Ensemble A and B.

\subsection{Left and Right Eye Comparison}

When looking at Table 4-5 and Table 4-7, we can conclude that testing between the Left and the Right eye were consistently even. This helps to see how much variance is within the test procedure and apparatus itself. The ideal perfect test would have the same amount of failures in the Left eye as the Right eye but due to testing error, fluid being unpredictable, and human error this might not happen. However, the statistical analysis of the data between the left and the right eye showed that the left nor the right eye had significant differences in failures between them. Further, we can look at Table 4-6 and see that there is no significant difference between any quadrants in the Left eye to its corresponding quadrant in the Right eye. This demonstrates that the test apparatus and method are consistent within its testing operations.

\subsection{Pass Rate of Spurt vs Spray}

\subsubsection{Pass Rate of Spurt vs Spray - Eyes}

Looking at the specific area of concern of the Eyes in regards to the pass rate of Spurt vs Spray we can see that in Table 4-8 and Figure 4-7 that the Spray looks graphically 
to be much more consistent at passing. When this data is broken down in the table by percentages of all the ensembles it actually comes out to be $69 \%$ for both Spurt and Spray pass rates. When looking at the overall total passes for the eyes of spurt and spray there was no statistical significant difference between the 2 tests. This is further conveyed by looking at the SAS data output in Table 4-13 for the Eyes section.

\subsubsection{Pass Rate of Spurt vs Spray - Nose}

Looking at the specific area of concern of the Nose in regards to the pass rate of Spurt vs Spray we can see that in Table 4-9 and Figure 4-8, we can see that there was a much higher rate of Passing than in the Eyes as shown in other areas previously. When looking at the table we can see that the Spray had a $100 \%$ pass rate while the Spurt had an $85 \%$ pass rate. When looking at the SAS data output in Table 4-13 for the Nose section, it reports that there is no statistical difference between Spurt and Spray. However, the large amount of $10 / 10$ or $100 \%$ pass rates causes the power of the test to decrease quickly because of the decrease in variance as the rate gets closer to $100 \%$. This causes the test to lose power of being able to detect small differences within the data set. Hence, the data output to report no significant difference between spurt and spray for the Nose. This is why we must also look to the data table to see the actual percent passing rate and draw conclusions from it.

\subsubsection{Pass Rate of Spurt vs Spray - Mouth}

Looking at the specific area of concern of the Mouth in regards to the pass rate of Spurt vs Spray we can see that in Table 4-10 and Figure 4-9, we can see that there was a much higher rate of Passing than in the Eyes as shown in other areas previously. When looking at the table we can see that the Spray had a 100\% pass rate while the Spurt had 
an $84 \%$ pass rate. When looking at the SAS data output in Table 4-13 for the Mouth section, it reports that there is no statistical difference between Spurt and Spray.

However, the large amount of $10 / 10$ or $100 \%$ pass rates causes the power of the test to decrease quickly because of the decrease in variance as the rates get closer to $100 \%$. This causes the test to lose power of being able to detect small differences within the data set. Hence, the data output to report no significant difference between spurt and spray for the Mouth. This is why we must also look to the data table to see the actual percent passing rate and draw conclusions from it. Both the Nose and the Mouth show to have more failures in Spurt than in Spray. This conclusion is also supported by Table 4-12, which does show that there is a significant difference in Spurt vs Spray. This is due to the volume and concentration of this volume delivered to a more specific target location. The Spurt delivers $2 \mathrm{ml}$ of fluid to a very small area, where as the spray delivers $1 \mathrm{ml}$ of fluid to a very spread out area. Most all of the failures that were to the Nose and Mouth were due to a "Run Through" of fluid. This was caused by the fluid not actually penetrating through the mask but from running through the seal from top to bottom. The "Run Through" would leave a small trail of fluid from where it initially impacted down the nose and mouth. Occasionally the fluid would stop at the nose and not make it to the mouth or bypass the nose and hit the mouth due to the larger surface area of the mouth.

\subsection{Pass Rate per Position}

\subsubsection{Pass Rate per Position-Eyes}

When looking at Table 4-14, we can see that the majority of the passes in the Eyes were in the Left or Right $(90 \%$ and $84 \%)$ head manipulation position. The majority of 
the failures were in the Up position (pass rate-47\%). Looking at Table 4-15, the contrasts of the positions, we can conclude that there is no significant difference between position 3 and 4 (Left and Right). We can conclude that all other interactions between positions are significantly different when compared in the eye area. This is supported by Table 4-14.

\subsubsection{Pass Rate per Position-Nose}

When looking at Table 4-16, we can see that the majority of the passes in the Nose were in the Left or Right (100\% and 100\%) head manipulation position. This was closely followed by the Up position with a pass rate of $95 \%$. The majority of the failures were in the Down position (pass rate- 76\%). Looking at Table 4-17, we can conclude that there is a significant difference between positions 1 and 2 (Up and Down). All other interactions between positions show no significant difference. This is supported by Table 4-16.

\subsubsection{Pass Rate per Position -Mouth}

When looking at Table 4-18, we can see that the majority of the passes in the Mouth were in the Left or Right (100\% and 100\%) head manipulation position. This was closely followed by the Up position with a pass rate of $93 \%$. The majority of the failures were in the Down position (pass rate- 76\%). Looking at Table 4-19, we can conclude that there is a significant difference between positions 1 and 2 (Up and Down). All other interactions between positions show no significant difference. This is supported by Table 4-18.

\subsubsection{Total Pass Rate per Position per Area of Concern}

When looking at Figure 4-15, we can see that Left and the Right positions have the highest passing rate for the Eyes, Nose, and Mouth; closely followed by the Up 
positions. The Down position as a whole appears to present itself with the lowest passing rate. Going even further by looking at Figure 4-16, we can see that the Down position has the lowest pass rate overall with $17 \%$. The second lowest is the Up position with $19 \%$ and the highest pass rates are Left and Right positions with $24 \%$ each.

\subsection{Range of Protection Tests}

A pilot test was also conducted for a "Range of Protection Test." This test only had 1 replication of each position for each ensemble due to time and material constraints. This was a means to measure how far each Ensemble would offer protection on a horizontal and vertical plane. This test did prove to have some interested findings that could be further investigated. Some of the generalized findings of all ensembles are seen in Tables 5-1.

\begin{tabular}{|r|r|r|r|}
\hline Position & \multicolumn{1}{|l}{ lyes } & \multicolumn{1}{|c|}{ Nose } \\
& \multicolumn{3}{|c|}{ Pass Rate } \\
\hline $90 \mathrm{R}$ & $85 \%$ & $100 \%$ & $100 \%$ \\
\hline $60 \mathrm{R}$ & $90 \%$ & $100 \%$ & $100 \%$ \\
\hline $30 \mathrm{R}$ & $75 \%$ & $100 \%$ & $100 \%$ \\
\hline 0 & $50 \%$ & $80 \%$ & $85 \%$ \\
\hline $30 \mathrm{~L}$ & $75 \%$ & $100 \%$ & $100 \%$ \\
\hline $60 \mathrm{~L}$ & $90 \%$ & $100 \%$ & $100 \%$ \\
\hline $90 \mathrm{~L}$ & $85 \%$ & $100 \%$ & $100 \%$ \\
\hline $90 \mathrm{U}$ & $45 \%$ & $95 \%$ & $100 \%$ \\
\hline $60 \mathrm{U}$ & $40 \%$ & $95 \%$ & $95 \%$ \\
\hline $30 \mathrm{U}$ & $30 \%$ & $95 \%$ & $95 \%$ \\
\hline $30 \mathrm{D}$ & $50 \%$ & $95 \%$ & $100 \%$ \\
\hline $60 \mathrm{D}$ & $75 \%$ & $90 \%$ & $100 \%$ \\
\hline $90 \mathrm{D}$ & $80 \%$ & $85 \%$ & $95 \%$ \\
\hline
\end{tabular}

Table 5-1: Pass Rates of Range of Protection Tests

From Table 5-1, we can see that in the areas of concern of the Nose and Mouth that the 0 degree target location is the position with the lowest pass rate. This is a straight on 
target location to the bridge of the nose centered across the eyes. The lowest Pass rate for the area of concern for the Eyes was 30 degree up. We can see that the majority of the failures were in the looking "Up" position. This pilot Range of Protection Test was to do a quick investigation of other areas of protection with ensembles.

\subsection{Summary of Tests}

By looking at all the data as a whole and by running the tests first hand, I can conclude that the test apparatus does operate efficiently and is very repeatable with little variance. I also conclude that it ensures concise and consistent testing across the broad spectrum of safety manufacturers and end users. This provides an important first step to simulate high risk biological hazardous occupations where eye and face PPE are worn.

\subsubsection{Limitations of Experiment}

During the Range of Protection Tests, one limitation of the testing apparatus is that it cannot have a target location of a complete 90 degree posterior or anterior head tilt. This is due to how the head is attached to the articulating base and milling table. It is also due to the range of travel that which the nozzle is mounted to. If the range of travel was longer and the articulating base gave more clearance, then it would be able to test a true 90 degree posterior or anterior head tilt.

Experimental data must always be evaluated with due consideration to the accuracy of measurement equipment used and human error of running the test operations. Many 
measurements were taken to have the error reduced to a minimal amount. The addition of the cross haired laser made a huge impact on the consistency of leveling the head during its different manipulations. A standalone self-leveling laser was also used to reduce the error in head positioning. This self-leveling laser was used to ensure the cross hair lasers degree of level was correct. A spirit level was also used to triple check the degree of level during testing operations.

This study addresses the regulatory aspects of Eye and Face Protection and not Respiratory protection. The researcher recognizes that 1 head form does not include race or other head sizes outside of the $50^{\text {th }}$ percentile. Future research will include more heads and more anthropometric characteristics. It can also include testing on human subjects with no hazardous fluid. The researcher recognizes such real-life conditions such as sweating and skin conductivity may affect results. Future research may address this. 


\section{CHAPTER 6 - Conclusions and Recommendations}

\subsection{Conclusions}

When looking back at the individual data reports of all the ensembles, we can draw some conclusions about how each ensemble performed and why. As stated earlier the 2 ensembles that had the best protective performance were Ensemble C and E. Ensemble $\mathrm{C}$ had an overall protective performance pass rate of 100\%, while Ensemble E had an overall pass rate of $99.6 \%$. These 2 ensembles both utilized the effectiveness of a "face shield." Ensemble C was a full face shield that was sealed at the forehead and hung downward. Because of this it passed all tests in the 4 head manipulations and all tests in the Range of Protection Test. Ensemble E also used the same idea of a face shield but was built within the mask and protruded upwards. Ensemble E only failed in one position of the 4 manipulations and another in the Range of Protection Tests. In these particular positions it presented a small gap between the face shield and the mask that was not adequately sealed in the Up position. Because of this slight gap, it caused failures. If this gap was closed by either sealing it or extended the face shield downward more, then I believe this Ensemble E would pass completely. The eye and face protectors that incorporate a "shield" into their design perform best for protection against biological hazards.

When taking the eyes only into consideration, the bottom gap is the position in which the most amount of failures occur. The "Up" position was designed to investigate this area. This bottom gap is hard to seal solely with eye protectors unless they are built specifically to seal this gap. This is why a face shield design protects best in this area. Of the ensembles tested 2 were of a "full face shield" type and 1 was a mask built for 
bottom gap protection in addition to separate eye protectors. All 3 of these ensembles protected the best against this bottom gap from spurts and sprays.

The other position that is hard to protect against penetration around is the top gap or the "Down" position. This position is hard to protect because of the gap that is left between the eye protector and the forehead. The ensembles that did the best in this area, tended to sit very close to the forehead to minimize fluid penetration. The best way to protect against spurts and sprays in this position is to seal this gap. Ensemble C that completely passed this test used a foam pad that made that seal possibly. This allow for no fluid to get through. Even if the ensemble did not have an actual "seal," ones that did contour to the forehead performed better.

Other conclusions that can be made about ensembles are that the eye protectors that have more of a side shield to accommodate for the side gaps do tend to protect better. Some of the eye protectors, though sleek in appearance, did not protect as well as others that had a larger surface area to the sides. The classic "lab safety glasses" design of eye protectors that were tested performed best at protection against spurts and sprays from the sides.

When looking at the SAS data output, it gives a skewed outlook on significant differences with Spurt vs Spray in some areas. This is why the data has been analyzed in multiple ways to draw the best conclusions. After analyzing the data in several areas, it can be concluded that Spurt and Spray are significantly different (Table 4-12). For this reason it is crucial to keep both elements within the test procedure. By using 
both aspects of Spurt and Spray, the test is able to investigate PPE's protective performance at a much broader spectrum.

\subsection{Recommendations for Future Work}

Some recommendations for future work would be to gather more data and have a larger sample size. It's good to have large data sets because the larger the data set, the more we can extract insights that we trust from that data set. This is especially true when looking at the Range of Protection Test. I think that for future work this test would be beneficial to further investigate using more replications. In this study, time and material constraints only allowed for 1 replication per ensemble. I would recommend going as far as 10 replications or more depending on time and material.

Another aspect of this test that could be further investigated is to decrease the degrees for when the Range of Protection Test tested at. In this study, we looked at positions separated every 30 degrees. By increasing the positions tested, or decrease the gap between degrees, the test would give more specific data for each ensemble and a more precise "Range of Protection". I would recommend to test at every 10 degrees.

Another alteration to the test apparatus that could be made for the betterment of testing would be to increase the travel distance on the Uni-Slide stand. By increasing this travel distance the nozzle would be able to have more target locations at a lower angle. This would give the head manipulation a true 90 degree posterior or anterior tilt. Another aspect that could be positively altered is to give the articulating base more clearance when moving the headform at extreme degrees. With these two changes it would give the test apparatus an even greater variety of testing options. 


\section{BIBLIOGRAPHY}

Al Wazzan KA, Almas K, Al Qahtani MQ, Al Shethri SE, Khan N. Prevalence of ocular injuries, conjunctivitis and use of eye protection among dental personnel in riyadh, saudi arabia. Int Dent J. 2001;51(2):89-94. doi: 10.1002/j.1875595X.2001.tb00828.x.

American Red Cross. (2001). Preventing exposures to bloodborne pathogens among paramedics. doi:10.26616/nioshpub2010139

Arsenault, P. (n.d.). Eye Safety in Dentistry and Associated Liability. Journal of the Massachusetts Dental Society, 12-16. Retrieved January 20, 2018.

Arsenault, P. (2018, June 21). Personal communication

Beltrami, E. M., Williams, I. T., Shapiro, C. N., \& Chamberland, M. E. (2000). Risk and Management of Blood-Borne Infections in Health Care Workers. Clinical Microbiology Reviews, 13(3), 385-407.

Beden Ü., Beltram M. (2012) Periorbital Anthropometric Measurements. In: Preedy V. (eds) Handbook of Anthropometry. Springer, New York, NY

Bloodborne infection from sharps and mucocutaneous exposure: A continuing problem. (2017, July 10). Retrieved from

Bloodborne Pathogens Standard 29 CFR 1910.1030(b)

Bouzaher, A., Bahmed, L., Masao, F. et al. J Fail. Anal. and Preven. (2015) 15: 860. https://doi.org/10.1007/s11668-015-0019-4

Bond, W. W., Peterson, N. J., Favero, M. S., Ebert, J. W., \& Maynard, J. E. (1982, March). Retrieved from https://www.ncbi.nlm.nih.gov/pmc/articles/PMC272133/

CDC. (2003). Exposure to Blood. What Healthcare Personnel Need to Know, 1-10

CDC. (2018, July 10). HIV/AIDS. Retrieved from https://www.cdc.gov/hiv/basics/index.html

Chong, S. J., Smith, C., Bialostocki, A., \& Mcewan, C. N. (2007). Do Modern Spectacles Endanger Surgeons? Annals of Surgery, 245(3), 495-501. doi:10.1097/01.sla.0000252406.94464.16

Davies, C., Khan, M., Ghauri, A., \& Ranaboldo, C. (2007). Blood and Body Fluid Splashes During Surgery - The Need for Eye Protection and Masks. The Annals of The Royal College of Surgeons of England, 89(8), 770-772. doi:10.1308/003588407x209301

De Sio, S., Traversini, V., Rinaldo, F., Colasanti, V., Buomprisco, G., Perri, R., ... Guerra, F. (2018). Ergonomic risk and preventive measures of musculoskeletal 
disorders in the dentistry environment: an umbrella review. PeerJ, 6, e4154. http://doi.org/10.7717/peerj.4154

Doebbeling BN, Vaughn TE, McCoy KD, Beekmann SE, Woolson RF, Ferguson KJ, Torner JC. (2003) Percutaneous injury, blood exposure, and adherence to standard precautions: are hospital-based health care providers still at risk? Clin Infect Dis, 37(8), 1006-13.

E. (2008, September 22). Home. Retrieved from https://www.elsevier.com/books/dictionary-of-optometry-and-visualscience/millodot/978-0-7020-2958-5

Etoz, A. (2011). Anthropometric Analysis of the Nose. Rhinoplasty. doi:10.5772/27218

Eyeplastics. (n.d.). Cosmetic Plastic and Reconstructive Surgery eyelid, orbit tear duct. Retrieved from https://www.eyeplastics.com/eyelid-anatomy-eyelidblepharoplasty-or-eyelift-surgery.html

Garus-Pakowska, A., Górajski, M., \& Szatko, F. (2017). Knowledge and Attitudes of Dentists with Respect to the Risks of Blood-Borne Pathogens-A CrossSectional Study in Poland. International Journal of Environmental Research and Public Health, 14(1), 69. http://doi.org/10.3390/ijerph14010069

Gershon RR, Karkashian CD, Grosch JW, Murphy LR, Escamilla-Cejudo A, Flanagan PA, Bernacki E, Kasting C, Martin L. (2000) Hospital safety climate and its relationship with safe work practices and workplace exposure incidents. Am J Infect Control, Jun; 28(3), 211-21.

Harkins, H. N., \& Harkins, W. D. (1929). The Surface Tension Of Blood Serum, And The Determination Of The Surface Tension Of Biological Fluids. Journal of Clinical Investigation, 7(2), 263-281. doi:10.1172/jci100228

How to Measure Working Distance for Your Dental Loupes - L.A. Lens. (n.d.). Retrieved from https://www.la-lens.com/blogs/in-the-news/49805637-how-tomeasure-working-distance-for-your-dental-loupes

Inessa Bekerman, Paul Gottlieb, and Michael Vaiman, "Variations in Eyeball Diameters of the Healthy Adults," Journal of Ophthalmology, vol. 2014, Article ID 503645, 5 pages, 2014. https://doi.org/10.1155/2014/503645

John Colvin. Eye Injuries and the Dentist Australian Dental Journal Dec. 1978, M.B., F.S., D.O., F.R.C.S., F.R.A.C.S., F.R.A.C.O.

Matela, D. (2012, April 13). Watch Out: The Importance of Protecting Your Eyes In the Industrial Workplace. Retrieved from http://www.ehstoday.com/ppe/eye_face_head/watch_importance_protecting

M. E. (2017, June 02). What Does ANSI Z87.1 Mean? - Safety Glasses USA. Retrieved 
from https://blog.safetyglassesusa.com/what-does-ansi-z87-1-2010-certifiedmean/

Merlin, J. S., Morrison, G., Gluckman, S., Lipschik, G., Linkin, D. R., Lyon, S., Friedman, H. (2010). Blood and Body Fluid Exposures Among US Medical Students in Botswana. Journal of General Internal Medicine, 26(5), 561-564. doi:10.1007/s11606-010-1586-4

Mitchel, A 2016, Overview of Occupational Exposures to Blood and Body Fluids in Healthcare Settings, Power point, International Safety Center, delivered 15 August 2016.

Neck health: The three ergonomic criteria for loupes selection. (2008, September 01). Retrieved from https://www.dentaleconomics.com/articles/print/volume98/issue-9/columns/preventing-pain-in-dentistry/neck-health-the-threeergonomic-criteria-for-loupes-selection.html

NIOSH Hazard ID, HID 5 - cercopithecine herpesvirus 1 (B Virus) infection resulting from ocular exposure. (1999). doi:10.26616/nioshpub99100

Nishimura, H., et al. (2013). "A new methodology for studying dynamics of aerosol particles in sneeze and cough using a digital high-vision, high-speed video system and vector analyses." PLoS ONE 8(11).

Ohlendorf, D., Erbe, C., Hauck, I., Nowak, J., Hermanns, I., Ditchen, D., ... Groneberg, D. A. (2016). Kinematic analysis of work-related musculoskeletal loading of trunk among dentists in Germany. BMC Musculoskeletal Disorders, 17, 427. http://doi.org/10.1186/s12891-016-1288-0

Pîrvu, C., Pătraşcu, I., Pîrvu, D., \& Ionescu, C. (2014). The dentist's operating posture ergonomic aspects. Journal of Medicine and Life, 7(2), 177-182

Porter K, Scully C, Theyer Y, Porter S. Occupational injuries to dental personnel. J Dent. 1990;18(5):258-262. doi: 10.1016/0300-5712(90)90025-A.

Portnoff, L. (n.d.). The Surface Tension of Fluid used for ASTM. Journal of Testing and Evaluation, 1-21.

Raschke, G., Eberl, P., Thompson, G., Guntsch, A., Peisker, A., Schultze-Mosgau, S., . . . Beuer, F. (2016). Wearing complete dental prostheses - Effects on perioral morphology. Medicina Oral Patología Oral Y Cirugia Bucal, 0-0. doi:10.4317/medoral.21102

Risk Matrix Calculations - Severity, Probability, and Risk Assessment. Retrieved from https://www.industrysafe.com/blog/risk-matrix-calculations-severity-probabilityand-risk-assessment/

Roberge, R. J. (2016). Face shields for infection control: A review. Journal of Occupational and Environmental Hygiene, 13(4), 235-242. 
doi:10.1080/15459624.2015.1095302

Silva, R. D., Mall, A., Panieri, E., Stupart, D., \& Kahn, D. (2009, February 1). Risk of blood splashes to the eye during surgery. South African Journal of Surgery.

Turvey, T. A., \& Golden, B. A. (2012). Orbital Anatomy for the Surgeon. Oral and Maxillofacial Surgery Clinics of North America, 24(4), 525-536. http://doi.org/10.1016/j.coms.2012.08.003

USA, ASTM. (n.d.). Resistance of Medical Face Masks to Pentration by Fluid (pp. 118). ASTM International.

USA, ASTM-ISEA Z87.1. (n.d.). American National Standard for Occupation and Educational Personal Eye and Face Protection Devices. (pp. 1-64). ASTM International.

UNITED STATES DEPARTMENT OF LABOR.” Occupational Safety and Health Administration,www.osha.gov/pls/oshaweb/owadisp.show_document?p_table $=\mathrm{S}$ TANDARDS\&p_id $=9778$

Saltzman DJ, Williams RA, Gelfand DV, Wilson SE. The surgeon and AIDS: twenty years later. Arch Surg 2005; 140: 961-7.

Valachi,B.(2008, January 02). How To Design For Ergonomics In Your Dental Practice. Retrieved from https://www.dentalcompair.com/Featured-Articles/1956Ergonomic-Must-haves-in-the-New-Dental-Office/

Van den Bosch WA, Leenders I, Mulder P. Topographic anatomy of the eyelids, and the effects of sex and age. British Journal of Ophthalmology 1999;83:347-352 


\section{APPENDIX A: WORK INSTRUCTIONS}




\section{PURPOSE}

This establishes the procedure to evaluate the protective performance of eye and face protection from a small velocity stream (spurt and spray) of synthetic blood Eye and Face PPE Tester.

\section{2. $\mathrm{SCOPE}$}

This procedure applies to the operation of the instrument when used to test the protective performance eye and face protection in simulation of high hazard occupations where biological hazards from spurts and sprays are present.

\section{SUMMARY OF TEST METHOD}

\subsection{OPERATION}

3.1.1. A volume of synthetic blood is disbursed at an ensemble by a pneumatically controlled valve from a set distance to simulate the spurt or spray of blood or other body fluid onto the ensemble. Any evidence of synthetic blood penetration on the areas of concern constitutes a failure.

3.1.2. Results are reported in the test matrix as pass/fail, the distance from failure or to passing, and the quadrant of a failure for each area of concern.

\subsection{EVALUATION}

3.2.1. Ensembles are evaluated at velocities of $635 \mathrm{~cm} / \mathrm{s}$ for spurt and estimated of $300-500 \mathrm{~cm} / \mathrm{s}$ for spray. These velocities correspond to the velocity exiting a small arterial at human blood pressure of $160 \mathrm{~mm} / \mathrm{Hg}$ as well as the max average velocity of human sneeze/cough with sufficient spray pattern at the specified average distance of $30.48 \mathrm{~cm}$.

\section{MATERIALS AND SET-UP}

\subsection{MATERIALS REQUIRED}

4.1.1. Test ensembles (eye protector and face mask or complete unit) and synthetic blood solution.

4.1.2. Lab coat, safety glasses, gloves, *not necessary but helpful*-laser level, spirit level, cross hair laser mounted to nozzle platform.

\subsection{PREPARATION OF TEST APPARATUS AND CALIBRATION}

4.2.1. Install a clean spurt cannula on the front of the nozzle valve. The cannula attaches to the exit of the valve. The standard size for this method is a $1.27 \mathrm{~cm}$ (0.5 in.) long 18 gauge stainless steel cannula with an internal diameter of 0.084 $\mathrm{cm}(0.033$ in.) Deviations from the standard cannula must be noted in the test 
report.

4.2.2. Fill the reservoir with fresh synthetic blood (approximately 1 liter) (see Fluid Preparation SOP at end).

4.2.3. Adjust the reservoir pressure to deliver the desired steady-state fluid velocity ( $6.5 \mathrm{psi})$ a target velocity of $635 \mathrm{~cm} / \mathrm{s})$

4.2.4. Set the valve timer to 0.5 seconds. Collect and weigh the amount of liquid delivered over a 0.5 second spurt.

4.2.5. Set the valve timer to 1.5 seconds. Collect and weigh the amount of liquid delivered over a 1.5 second spurt.

4.2.6. Calculate the difference in weight of the two spurts.

4.2.7. Adjust the reservoir pressure and repeat steps 4.2.3 to 4.2.6. until the weight difference is within the target range shown in Table 1 below. Record this weight.

Weight Difference (g) for a 1 Second Difference in Spurt Duration.

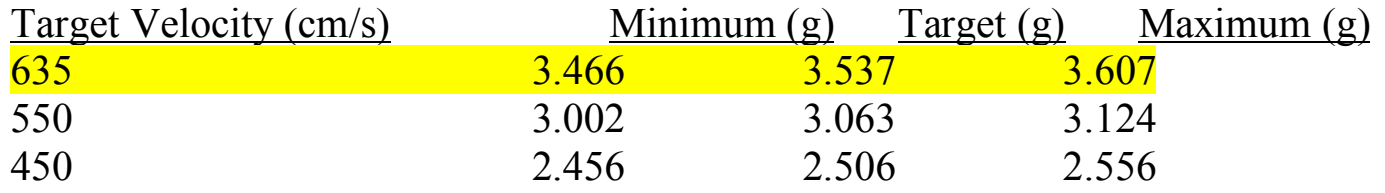

Table 1. Target difference in weights plus lower and upper limits for a velocity range within $2 \%$ of the target.

4.2.8. Record the pressure in the reservoir and use this as the initial reservoir pressure in subsequent testing to expedite set-up.

4.2.9. Once the reservoir pressure has been set (per target velocity), maintain the same pressure in tank throughout testing.

\subsection{POSITIONING OF THE CANNULA NOZZLE}

4.3.1. Aim the nozzle so that the stream makes contact where the center of the cross hair lasers is pointing on the headform (assuming the laser has been installed and leveled).

*Example Test Order of Positions will be Up-1, Down-2, Left-3, Right-4*

4.3.2. Set the valve time to $\sim 0.44 \mathrm{sec}$. for Spurt and $\sim .60 \mathrm{sec}$. for Spray. Squirt the fluid into a graduated cylinder to ensure that $2 \mathrm{ml}$-spurt or $1 \mathrm{ml}$ spray is being delivered. Adjust the valve time accordingly to achieve $2 \mathrm{ml}$ or $1 \mathrm{ml}$. 
4.3.3. Place the headform in the desired head manipulation for the testing order.

(Up-1) The headform must be centered and anteriorly titled 30 degrees. The headform must be $30.48 \mathrm{~cm}$ away from the tip of the cannula to the target locations. The target location for this position is 2 " above the center point of the midline from the left and right eye on the forehead. Adjust the uni-slide mount so the sighted in cross hair laser is at this point

(Down-2) The headform must be centered and posteriorly titled 30 degrees. The headform must be $30.48 \mathrm{~cm}$ away from the tip of the cannula to the target locations. The target location for this position is 1 " below the center point of the midline from the left and right eye on the bridge of the nose. Adjust the unislide mount so the sighted in cross hair laser is at this point

(Left-3) The headform must be centered across the coronal and sagittal plane in a vertical fashion. Adjust the uni-slide mount so the sighted in cross hair laser is aimed at the center point between the eyes across the midline from the left and right eye. Rotate the headform clockwise 55 degrees. This is the target location (temple area). The headform must be $30.48 \mathrm{~cm}$ away from the tip of the cannula to the target location.

(Right-4) The headform must be centered across the coronal and sagittal plane in a vertical fashion. Adjust the uni-slide mount so the sighted in cross hair laser is aimed at the center point between the eyes across the midline from the left and right eye. Rotate the headform counter-clockwise 55 degrees. This is the target location (temple area). The headform must be $30.48 \mathrm{~cm}$ away from the tip of the cannula to the target location.

4.3.4. Once the headform is adjust into the position specified by the testing order and aimed to the target location corresponding to the head manipulation, Don the PPE for this test. Check to make sure the target location is still accurate with the nozzle, press the pedal to shoot the fluid onto the headform.

4.3.5. Within $5 \mathrm{sec}$. of shooting the fluid onto the headform, carefully remove the PPE and check for any fluid within the areas of concentration. Measure record the data into the test matrix with a caliper. If the fluid is within an area of concern it is deemed a failure. Measure from the center of area of concern to the closest fluid droplet and record this data. Record the quadrant that the fluid is in. If the fluid is outside the area of concern, measure from the perimeter of this area of concern to the closest fluid droplet and record this data.

4.3.6. After the completion of a set of "spurts" or "sprays", ensure that the test apparatus is delivering $2 \mathrm{ml}$ or $1 \mathrm{ml}$ of test liquid by collecting and weighing the output passing through the targeting hole. If the delivered 
output has shifted more than $(2 \%)$, repeat the calibration procedure in Sections 4.2.4.

\subsection{CLEANING}

4.4.1. If the cannula is left for 1 hour or more without use after passing synthetic blood during testing, replace with a clean cannula and clean the used cannula by immersing in isopropyl alcohol for 24 hours and rinsing with distilled water.

4.4.2. Following testing, clean system lines and the reservoir with distilled water. Do not use isopropyl alcohol or other solvents on the valve or system lines, they could damage the valve.

\section{TEST PROCEDURE AND QUALITATIVE EVALUATION}

\subsection{TEST PROCEDURE AND EVALUATION}

5.1.1. Once the headform is adjust into the position specified by the testing order and aimed to the target location corresponding to the head manipulation, Don the PPE for this test. Check to make sure the target location is still accurate with the nozzle, press the pedal to shoot the fluid onto the headform.

5.1.2. Within $5 \mathrm{sec}$. of shooting the fluid onto the headform, carefully remove the PPE and inspect for any fluid within the areas of concentration. The use of the blue light makes inspection much more effective. Measure and record the data into the test matrix with a caliper. If the fluid is within an area of concern it is deemed a failure. Measure from the center of area of concern to the closest fluid droplet and record this data. Record the quadrant that the fluid is in. If the area of concern passes, measure from the perimeter of this area of concern to the closest fluid droplet and record this data.

5.1.3. After the completion of a set of "spurts" or "sprays", ensure that the test apparatus is delivering $2 \mathrm{ml}$ or $1 \mathrm{ml}$ of test liquid by collecting and weighing the fluid. If the delivered output has shifted more than $(2 \%)$, repeat the calibration procedure in Sections 4.2.4. 


\section{REPORTS}

*See Test Matrix*

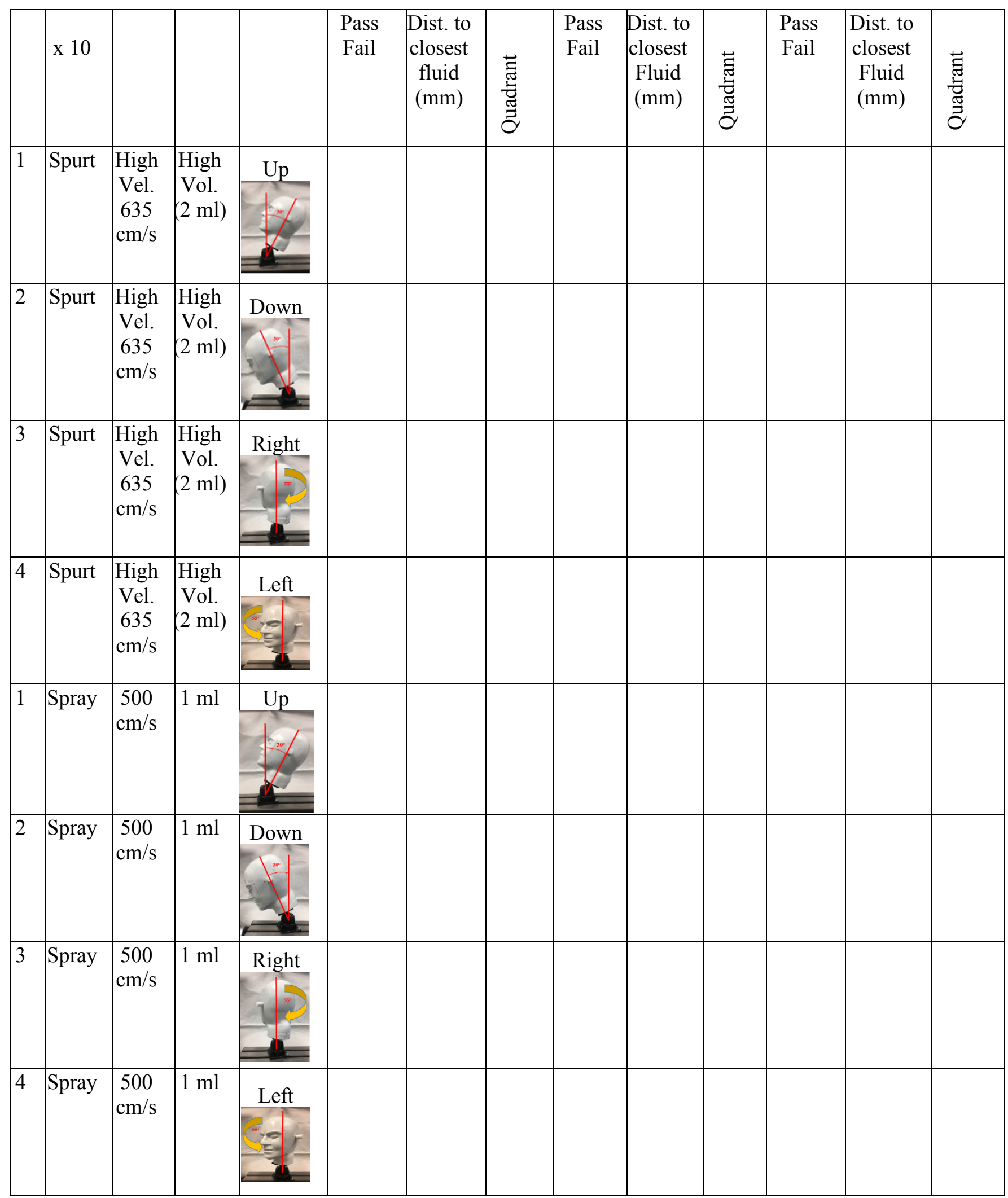




\section{SETTING UP LANDMARKS}

\subsection{Eyes}

The ellipse parameters will have its dimensions based off the center of the eye. From there a major and minor axis will be created of lengths of $35 \mathrm{~mm}$ in height (minor) and $50 \mathrm{~mm}$ in width (major). This ellipse shape will follow the orbital bone. The 45 degree diagonal measurements will be $42 \mathrm{~mm}$ in length (Figure 6-1: Graph of Ellipse).

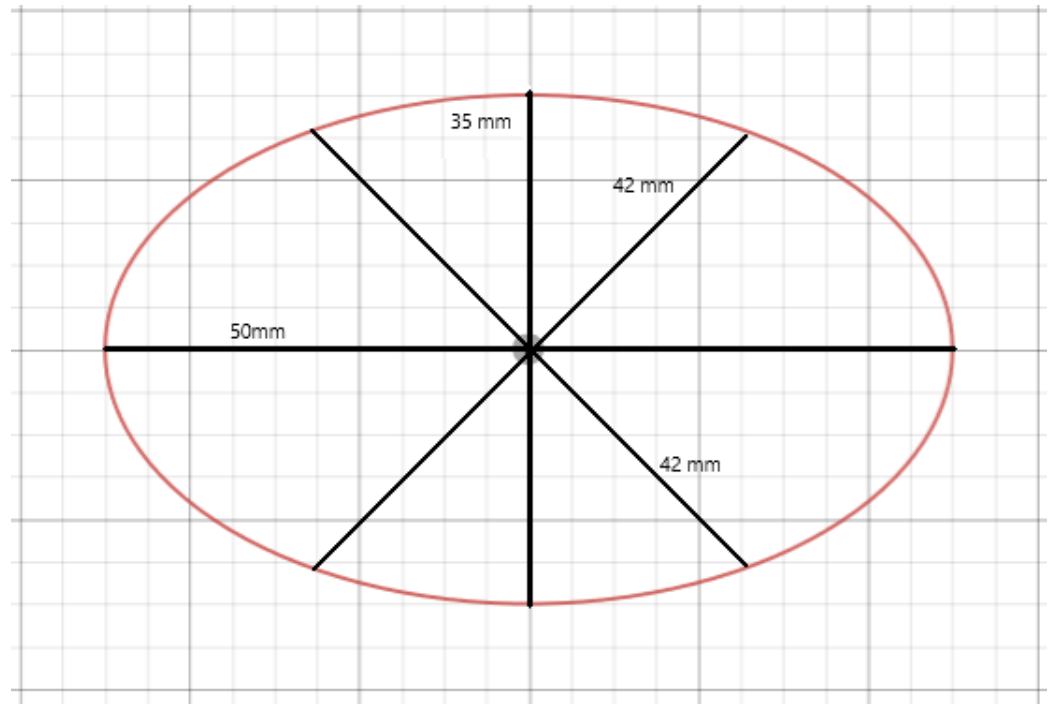

Figure 7-1: Graph of Ellipse 


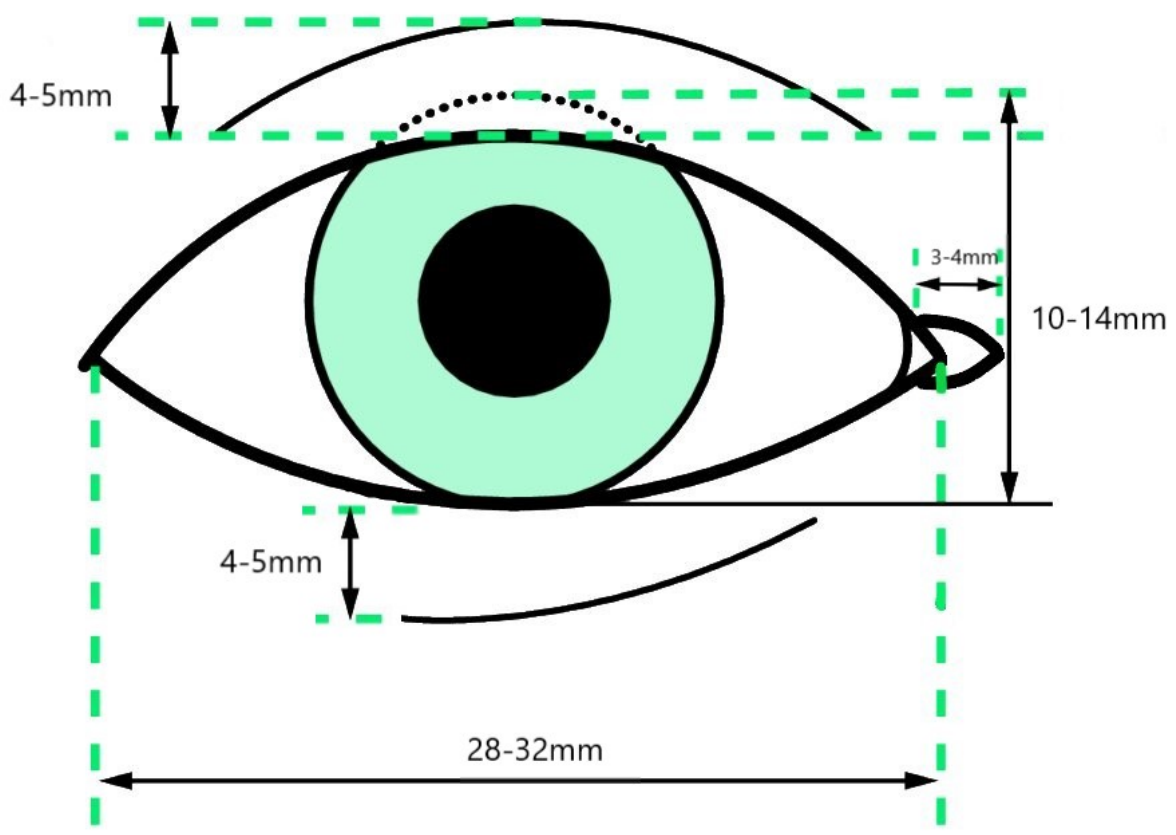

(Elsevier, 2008)

Figure 7-2: Average Eye Measurements

\subsection{Nose}

Nose exposure will be evaluated using the 6 landmarks shown below. Connecting the points from 1-3-2-5-6-4-1 creates a perimeter along the bottom surface area of the nose. Any fluid or fluid residue that is found within this perimeter will be considered a "fail" for the nose. 


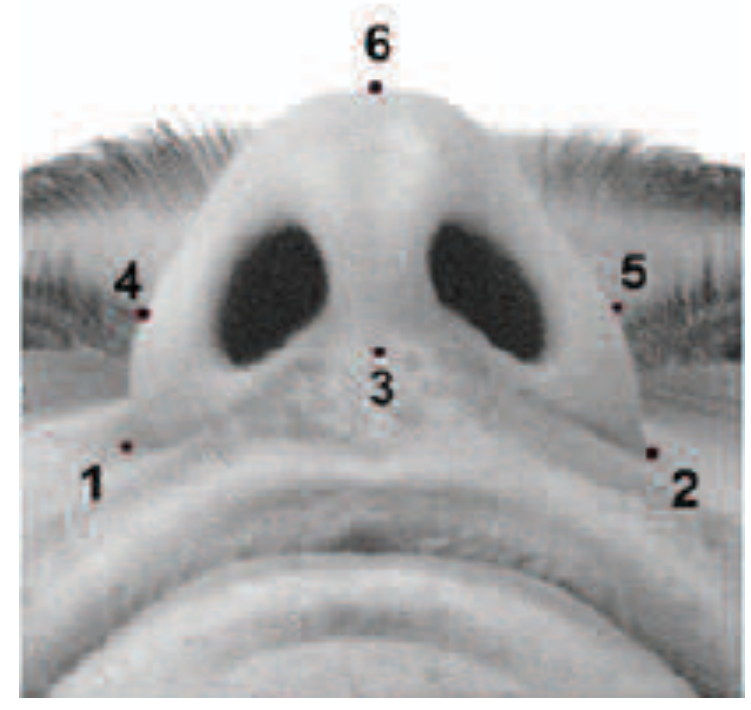

(Etoz, 2011)

Figure7-3: Anthropometric Nose landmarks

The nose perimeter measurements are defined in Figure 6-2 and Table 6-2 below for the European anthropometric headform.

\begin{tabular}{|l|l|}
\hline $1-2$ & Alare, the point where the nasal blade (ala nasi) extends farthest out. \\
\hline 3 & Subnasal, the midpoint of the columella base. \\
\hline $4-5$ & The most convex point of lateral cruris of alar cartilage. \\
\hline 6 & Pronasal, the most prominent point on the nasal tip. \\
\hline
\end{tabular}

Table 7-1: Anthropometric Nose Landmarks 


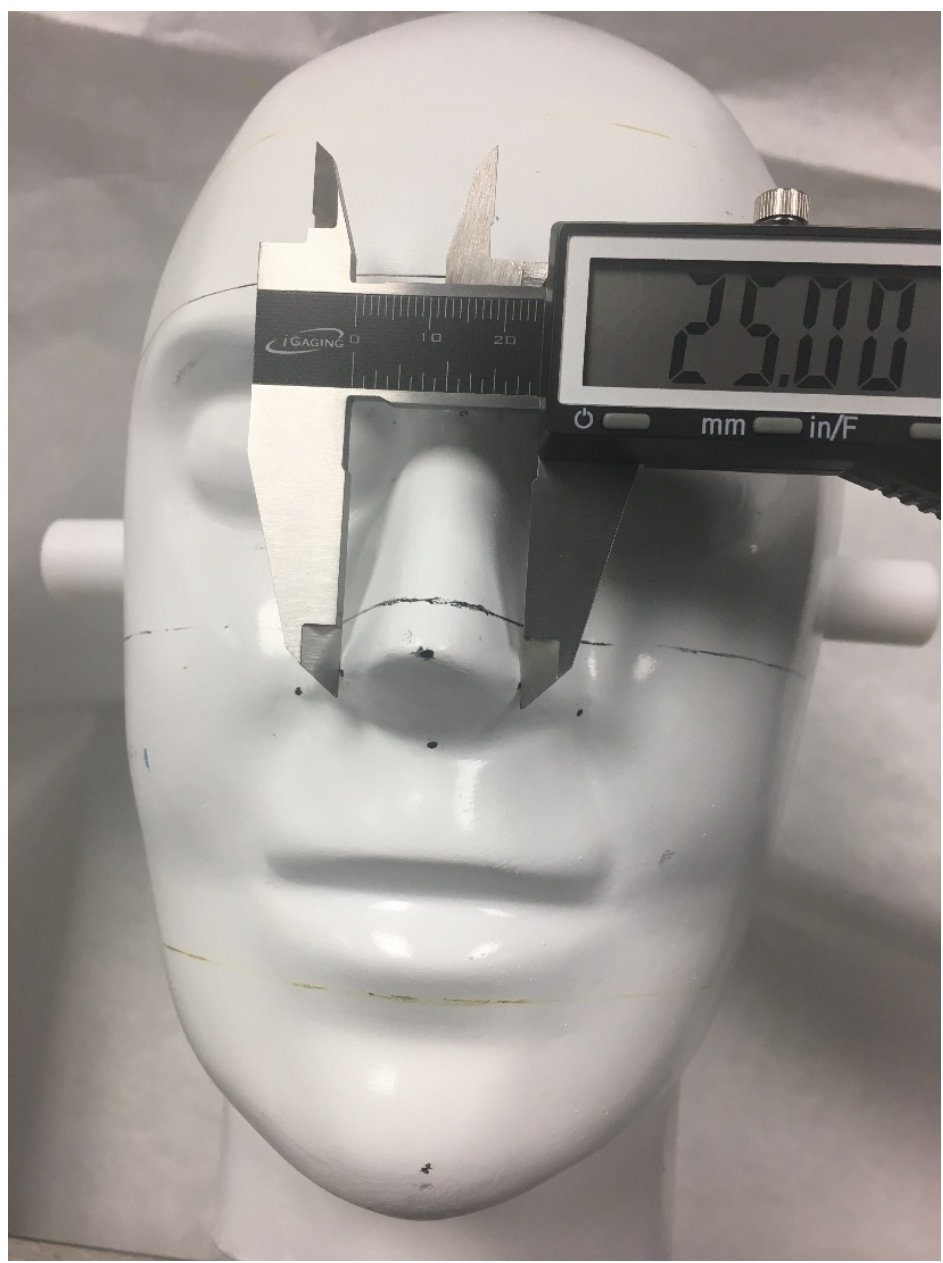

Figure 7-4: Nose measurement of most convex point- Points 4-5.

\begin{tabular}{|l|l|}
\hline $1-3$ & $27 \mathrm{~mm}$ \\
\hline $3-2$ & $27 \mathrm{~mm}$ \\
\hline $1-4$ & $18 \mathrm{~mm}$ \\
\hline $2-5$ & $18 \mathrm{~mm}$ \\
\hline $4-6$ & $20 \mathrm{~mm}$ \\
\hline $5-6$ & $20 \mathrm{~mm}$ \\
\hline $4-5$ & $25 \mathrm{~mm}$ \\
\hline $3-6$ & $22 \mathrm{~mm}$ \\
\hline
\end{tabular}

Table 7-2: Nose Landmark Measurements 


\subsection{Mouth}

Figure 4-5 shows anthropometric landmarks that are widely used for the mouth. A perimeter formed by connecting the points (1-2-3-4-5-1) defines the mouth. Any fluid or fluid residue that falls within this perimeter will be considered a "fail" for the mouth.

The perimeter will start at the left oral commissure or cheilion. This is where the lateral aspects of the vermilion of the upper and lower lips join. (Figure 6-5-point 1) From point 1 , the perimeter will travel along the contour of the line formed by the vermilion border of the upper lip. In a frontal view, this line resembles an archer's bow, which curves medially and superiorly from the commissures to the paramedian peaks located at the bases of the pillars of the philtrum (crista philtrae) (Figure 6-5points 2 and 3) with an inferior convexity lying between those peaks. The philtrum is the vertical groove in the midline of the upper lip bordered by these lateral pillars (ridges). From points $2-3$, the perimeter will travel to point 4 which resides as the right oral commissure or cheilion (Figure 6-5-point 4). From point 4, the perimeter will travel along the contour of the line formed by the vermilion border of the lower lip until it reaches the lowest apex of the lower lip, which will be point 5 . From point 5 the line will continue along the contour of the line formed by the vermillion border of the lower lip until it reconnects with point 1. 


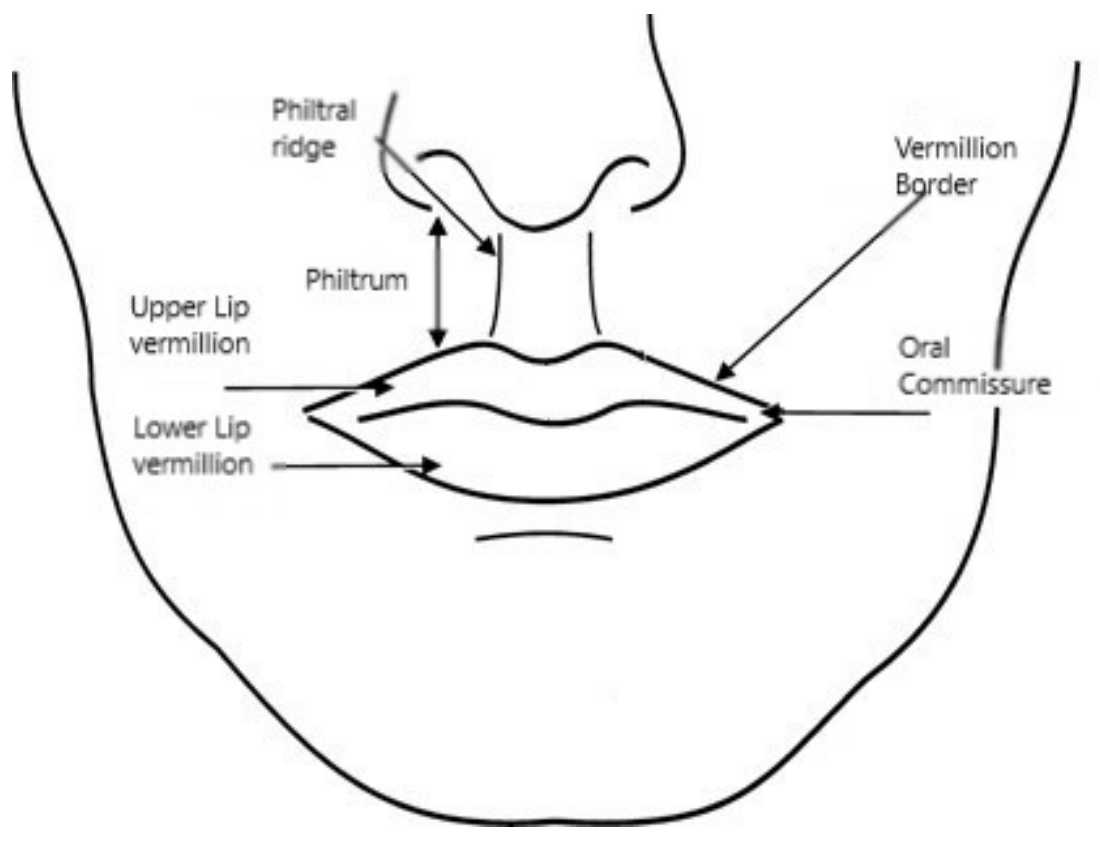

Source: (Raschke, et al., 2016)

Figure 7-5: Anthropometric Mouth Landmarks

The mouth perimeter measurements are defined in Figure 6-6 and Table 6-4 below for the European anthropometric headform. 


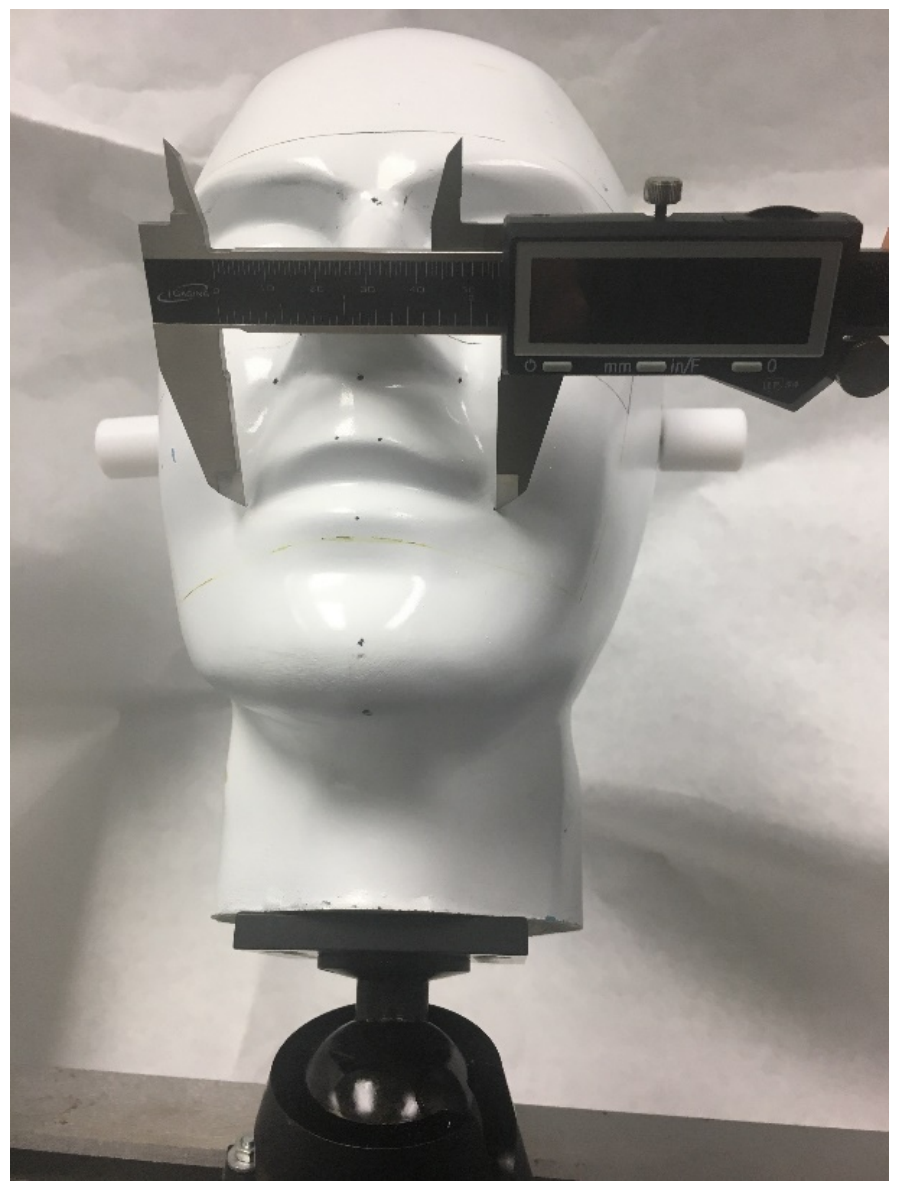

Figure 7-6: Mouth measurement between left and right oral commissure-Points 1-4.

\begin{tabular}{|l|l|}
\hline $1-2$ & $31 \mathrm{~mm}$ \\
\hline $2-3$ & $10 \mathrm{~mm}$ \\
\hline $3-4$ & $31 \mathrm{~mm}$ \\
\hline $4-5$ & $33.5 \mathrm{~mm}$ \\
\hline $5-1$ & $33.5 \mathrm{~mm}$ \\
\hline $1-4$ & $56.5 \mathrm{~mm}$ \\
\hline $2-5$ & $18 \mathrm{~mm}$ \\
\hline $3-5$ & $18 \mathrm{~mm}$ \\
\hline
\end{tabular}

Table 7-3: Mouth Landmark Measurements 


\section{PICTURES}

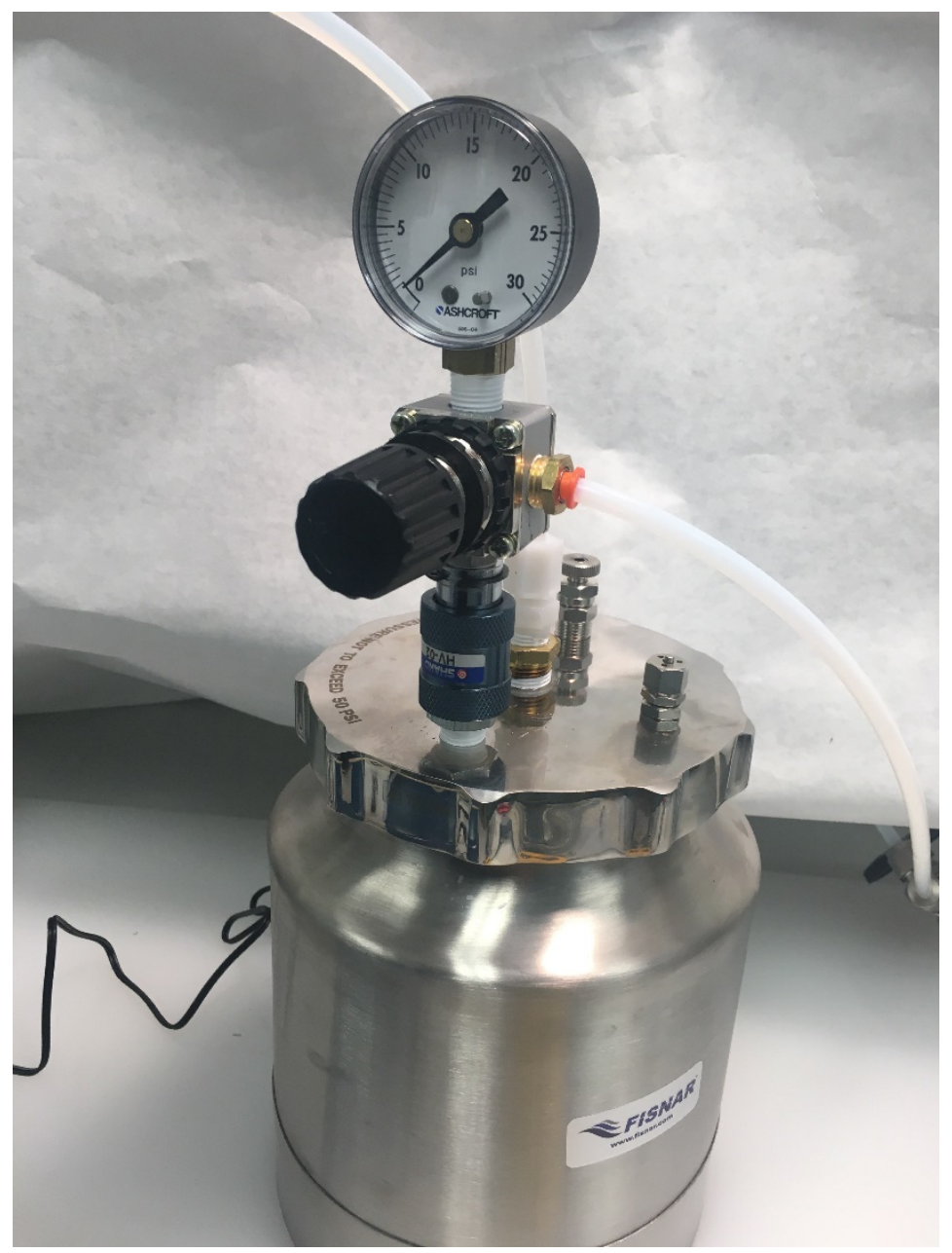

Figure 8-1. Pressure control gauge/reducer and Reservoir 


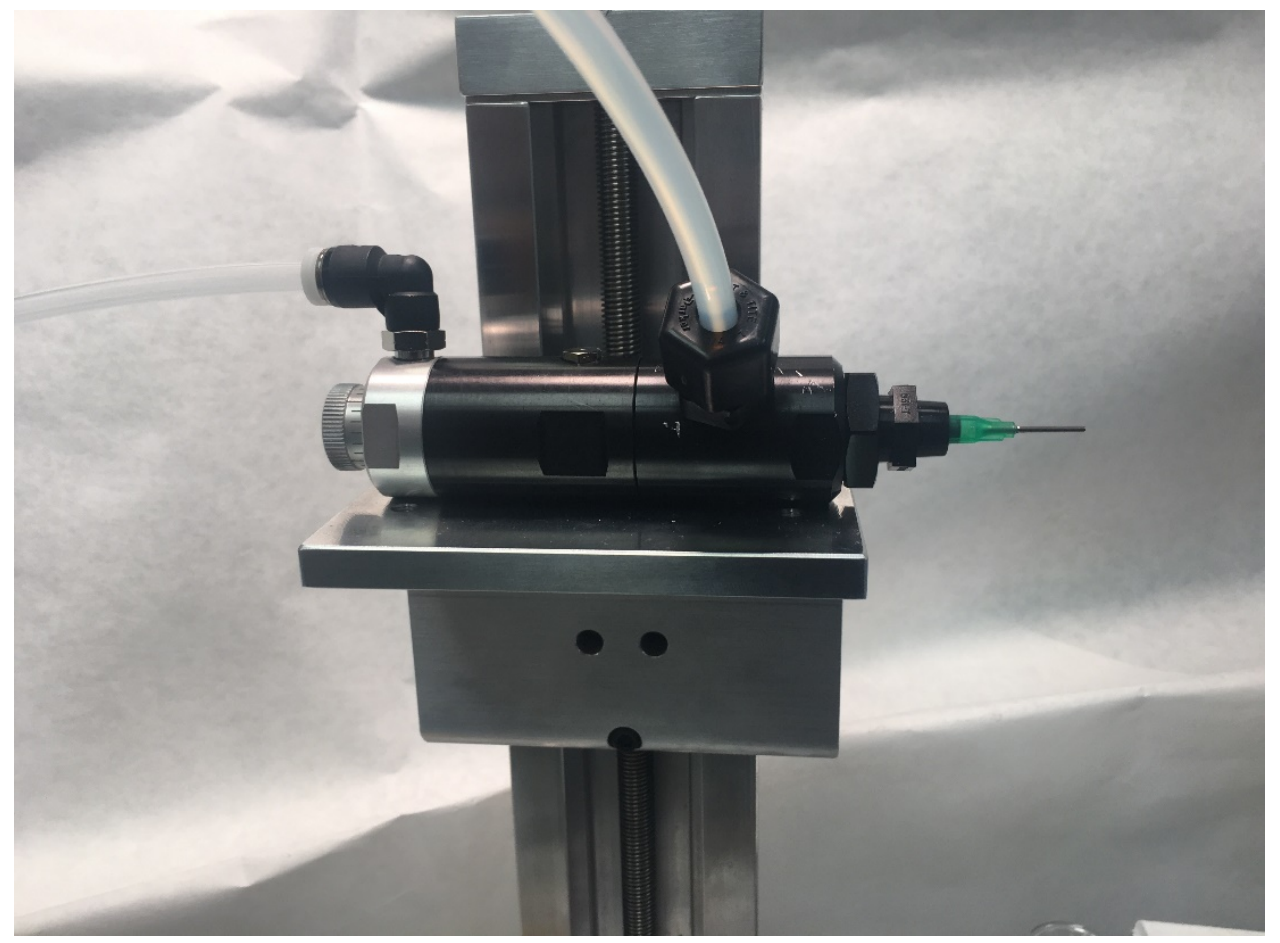

Figure 8-2. Cannula on the front of the pneumatic-controlled valve 


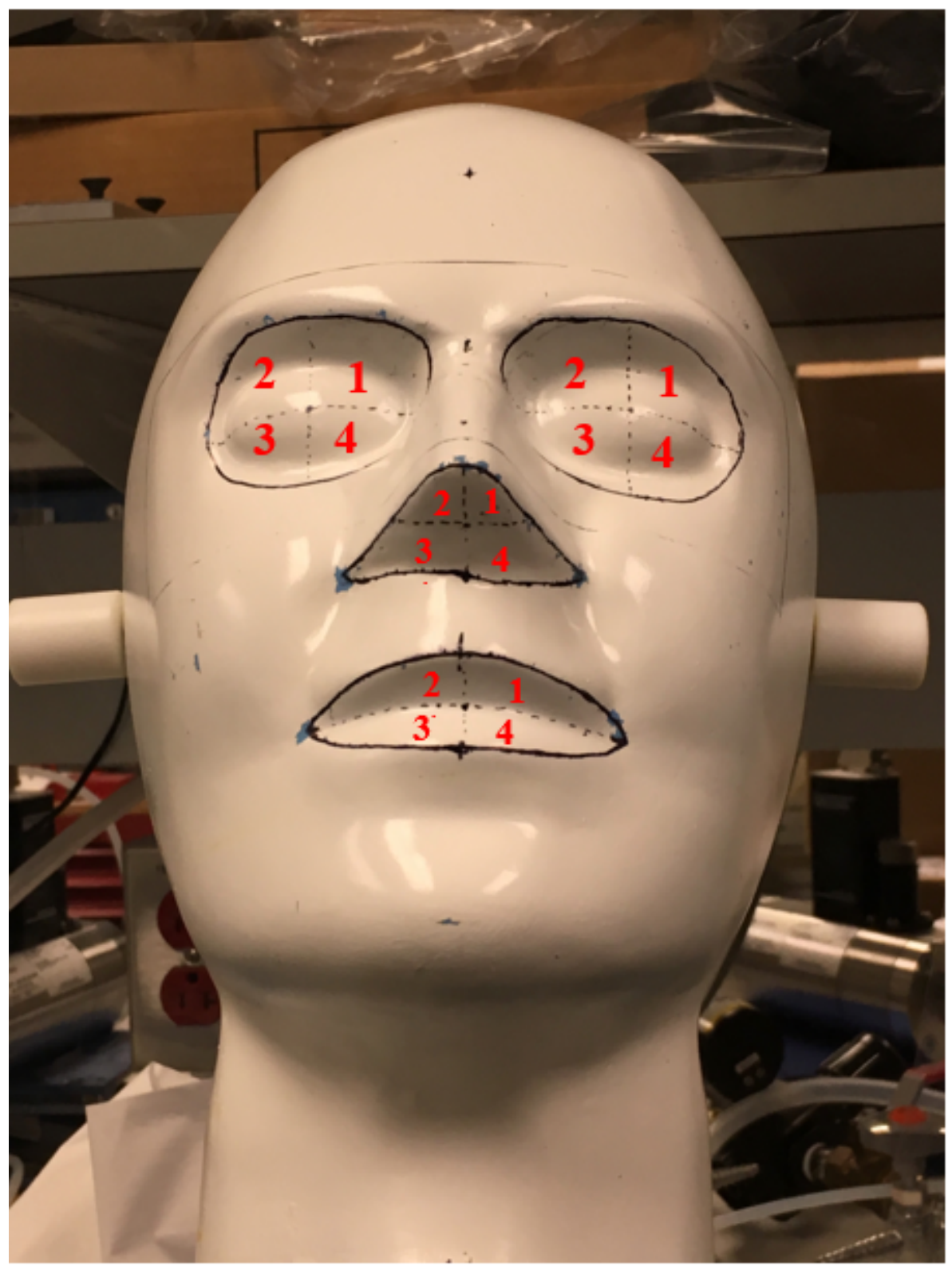

Figure 8-3. Anthropometric headform and grid with quadran 


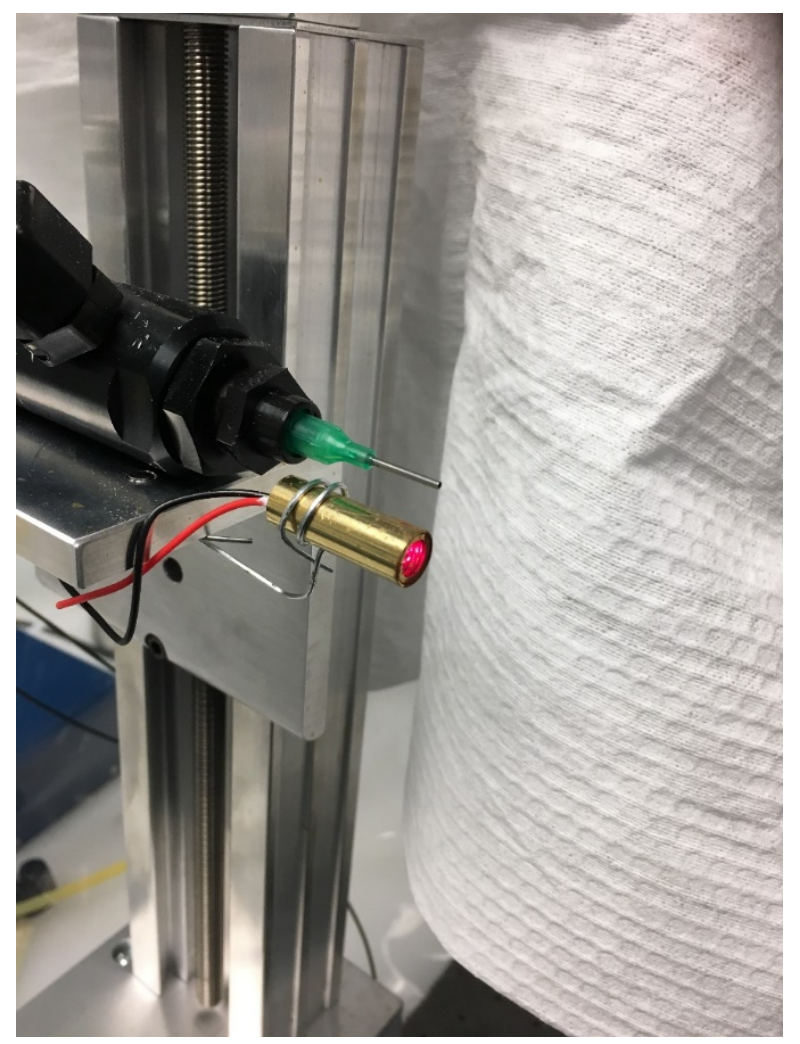

Figure 8-4. Cross Hair Laser on Platform

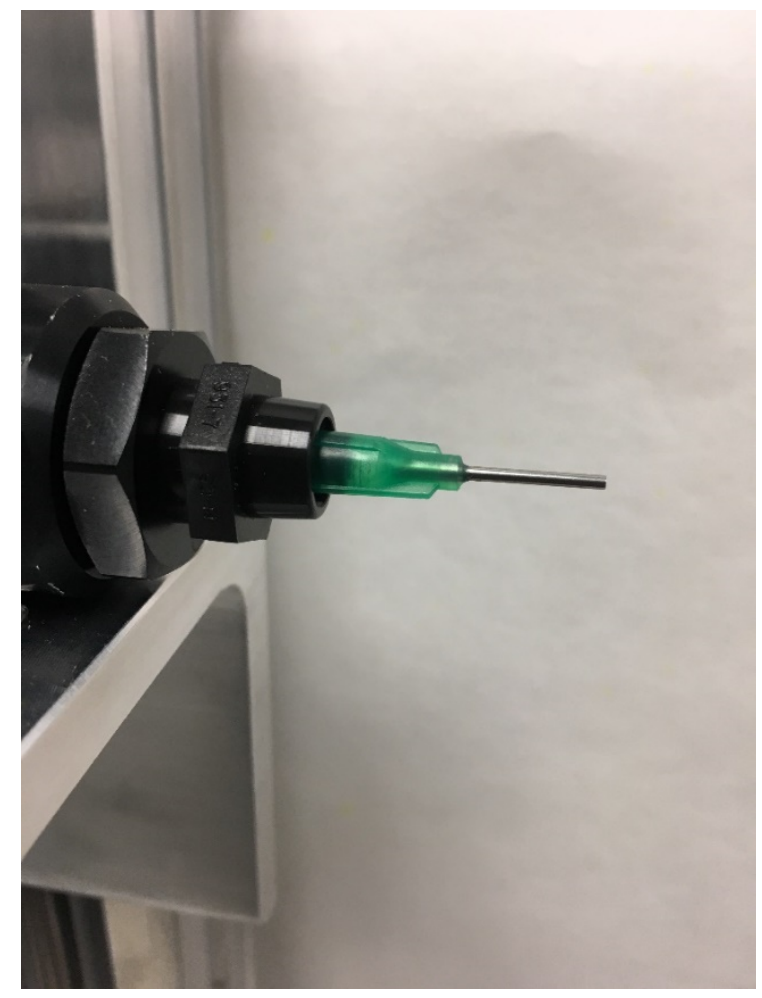

Figure 8-5. Spurt cannula 


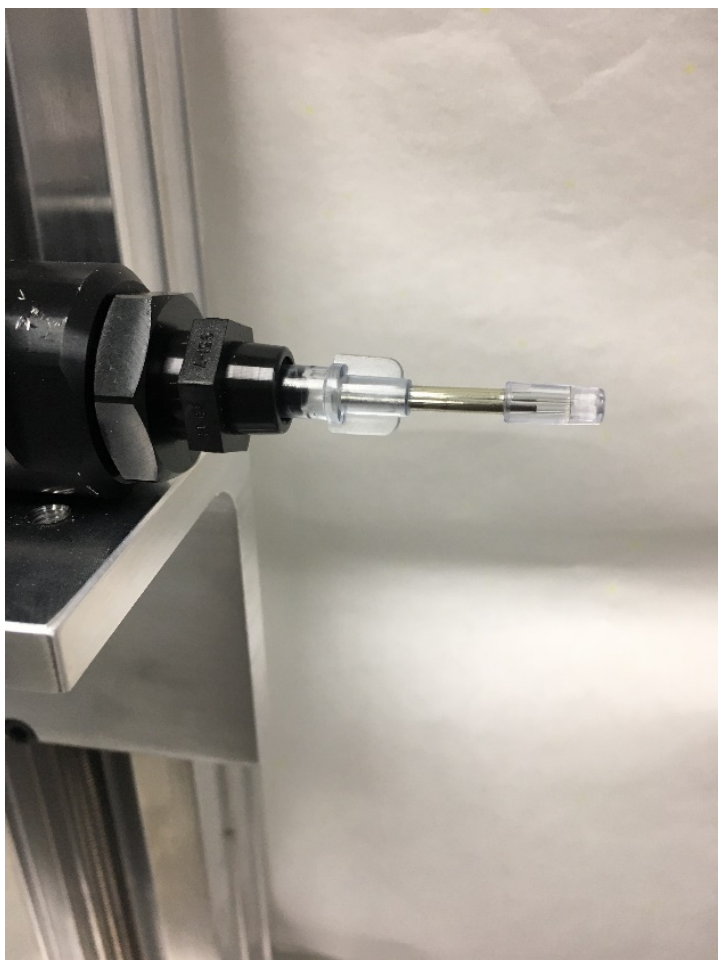

Figure 8-6. Spray cannula
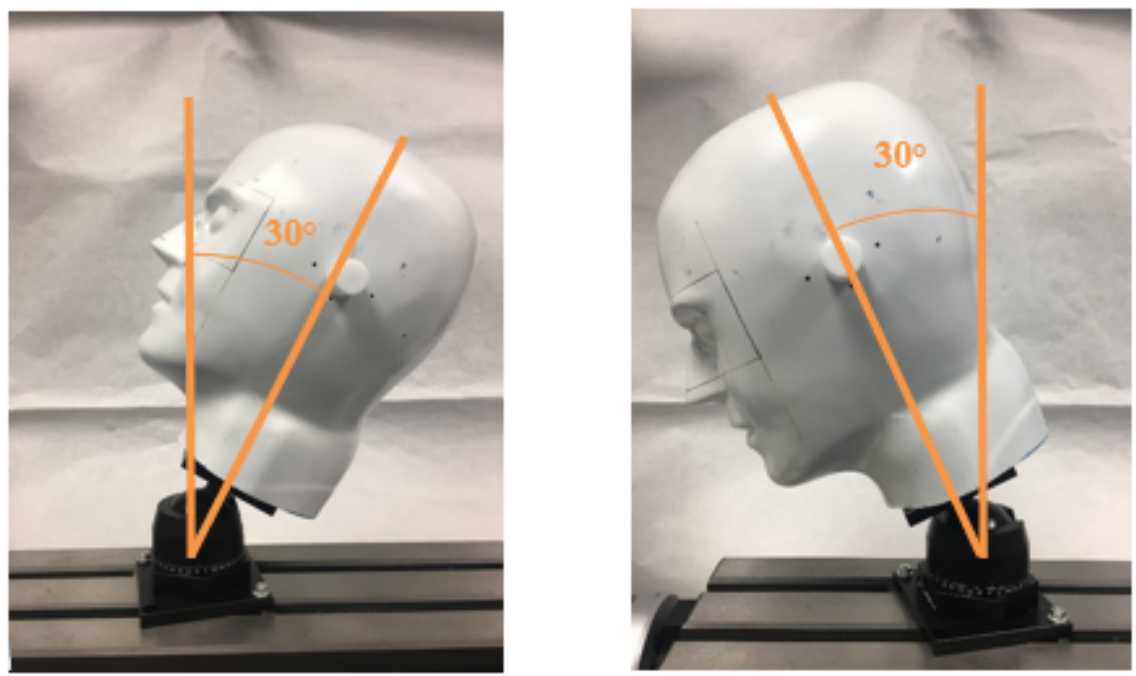

Figure 8-7: Posterior and Anterior head Manipulations 

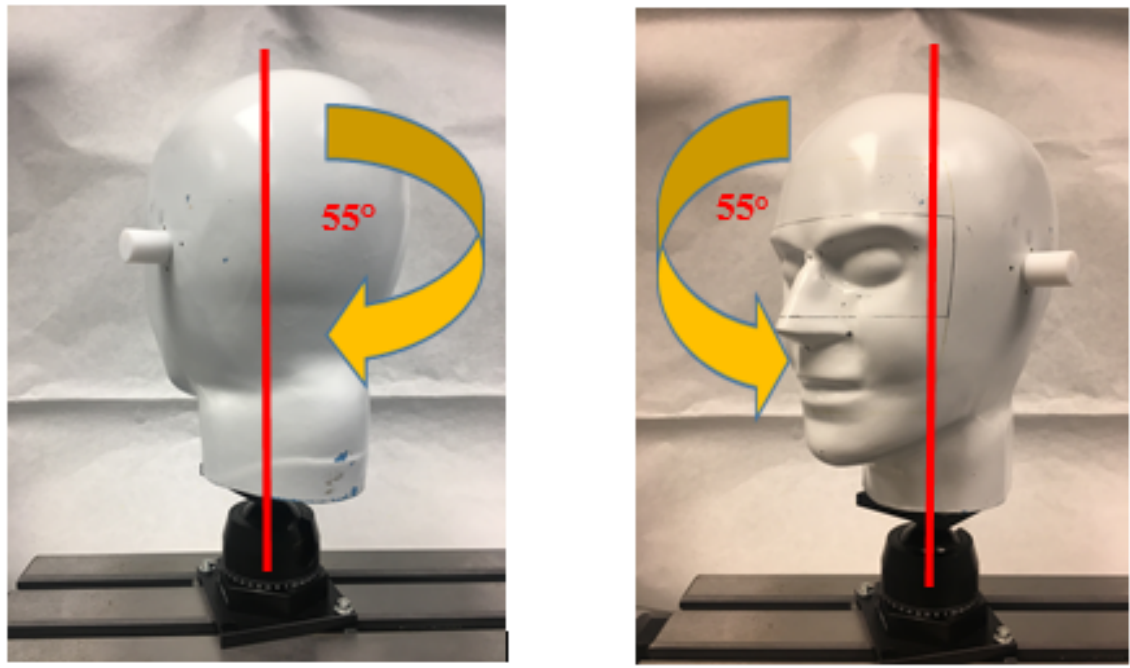

Figure 8-8: Left and Right head Manipulations

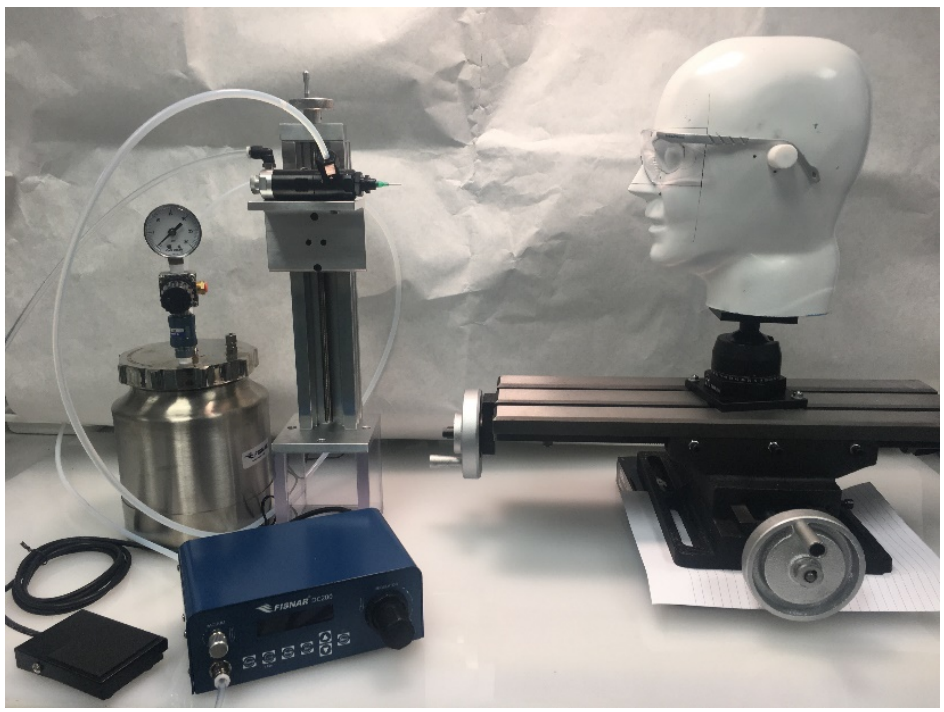

Figure 8-9. Overall Setup 


\title{
9. Fluid Preparation SOP
}

\section{Fluid Preparation SOP}

\author{
$($ saline + fluorescein + surfactant $):$ \\ $0.9 \%$ saline \\ $0.002 \mathrm{M}$ fluorescein \\ $0.1 \%$ surfynol $104 \mathrm{H}$ \\ For 1 Liter: \\ $9 \mathrm{~g} \mathrm{NaCl}$ \\ $0.752 \mathrm{~g}$ fluorescein \\ $1.0 \mathrm{~mL}$ surfynol $104 \mathrm{H}$ \\ $\mathrm{diH}_{2} \mathrm{O}$ to $1 \mathrm{~L}$
}

a. Place magnetic stir bar in $1 \mathrm{~L}$ Erlenmeyer flask and weigh both with triple beam balance to determine tare weight.

b. Add $1000 \mathrm{~g}$ auxiliary weight to opposite end of balance beam

c. Weigh $\mathrm{NaCl}$ on a scientific balance and add to flask, rinsing with $\mathrm{diH}_{2} \mathrm{O}$ as needed

d. Weigh fluorescein on a scientific balance and add to flask, rinsing with $\mathrm{diH}_{2} \mathrm{O}$ as needed

e. Add remaining volume of $\mathrm{diH}_{2} \mathrm{O}$ until indicator at the end of balance beam is level with the zero indicator on the balance base.

f. Transfer flask to magnetic stirrer and create a strong vortex.

g. Using an Eppendorf micropipettor device and disposable tip, carefully pipet the surfynol $104 \mathrm{H}$ into the solution, rinsing tip several times.

h. Allow solution to mix with a strong vortex for 30 minute. 


\section{APPENDIX B: APPARATUS BUILDING INSTRUCTIONS}


All materials listed below are what is recommended for building materials. These materials or materials of equivalence are to be used when constructing this apparatus.

The apparatus is to be mounted on a solid sheet of material rigid enough to hold each part in a stable and sturdy position. This was done by using a 24 " $\mathrm{x} 48$ " $\mathrm{x} 1 / 2$ " sheet of LDPE as shown below (Figure 1).

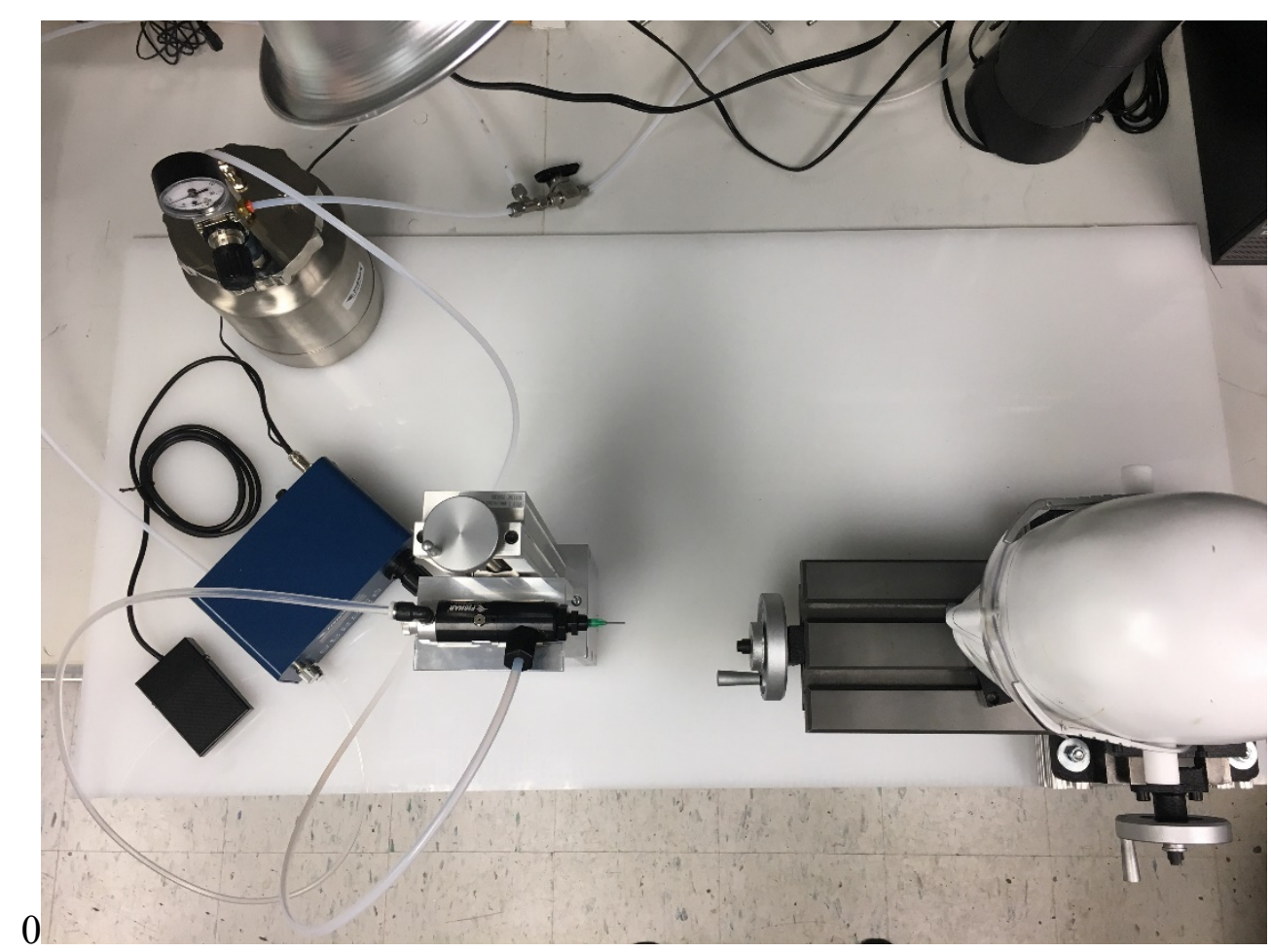

Figure 1: Top View of Apparatus

The next step is to mount the milling table to the LDPE sheet. The milling table used in this apparatus is a Grizzly 6" x 18.5" compound table (Figure 2). To mount the table it is necessary to raise the milling table 1.5" above the LDPE sheet. This was done by use two $1.5 \times 1.5 " 80 / 20$ stock bar that was cut into two 11 " long pieces. The 2 pieces then have a $1 / 2$ hole drilled through the center of the $80 / 20$ stock bar. Each hole is drilled at 1.5 " in from each end. Next, the milling tables anchor points are to be aligned with the holes in the $80 / 20$ stock bar and fitted to be squared with the corner of the LDPE sheet. The milling table is held down through the $80 / 20$ stock bar and the LDPE sheet by four 3/8"-2" hex bolts along 1-1/4" washers and corresponding nuts (Figure 3 and Figure 4). To be able to bolt the milling table down, the LDPE must have 4 aligned holes drilled at $1 / 2$ ". These 4 holes must also have a counter sunk hole to allow for the hex head of the bolt to sit beneath the bottom of the LDPE sheet (Figure 5). This counter sunk hole should be around 7/8" wide. 


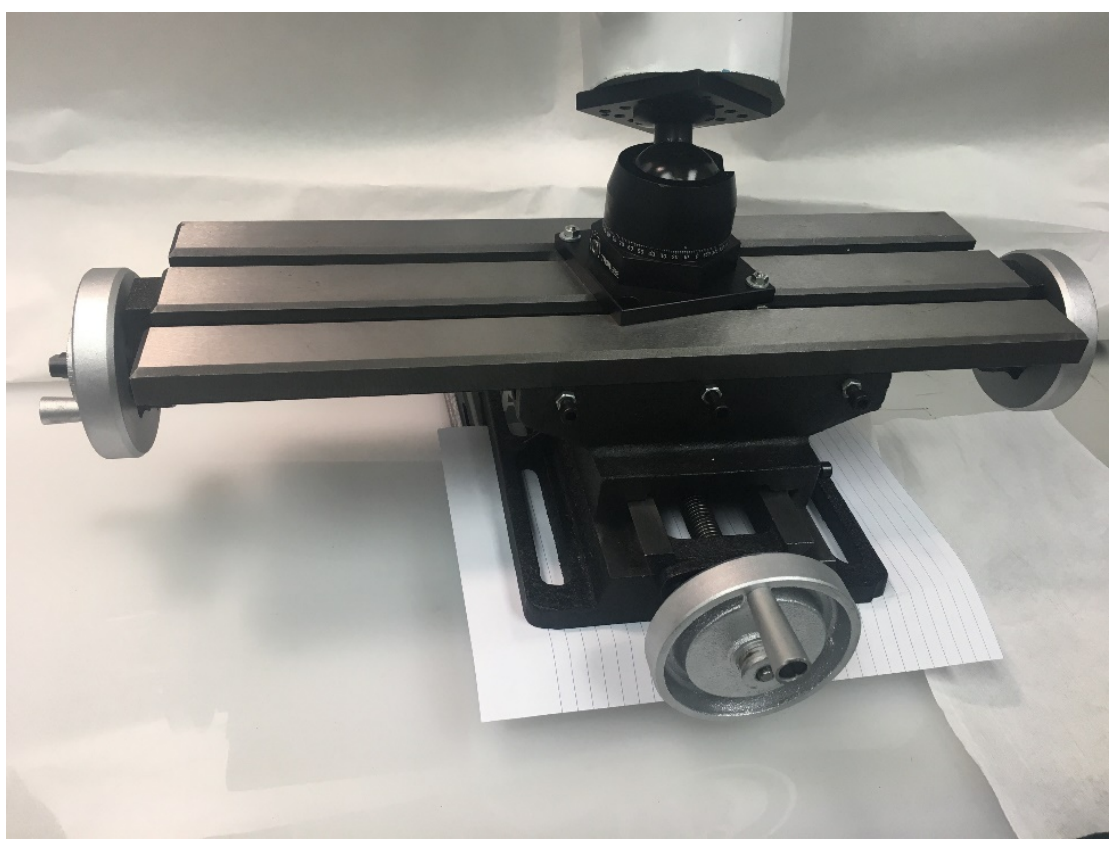

Figure 2: Milling Table

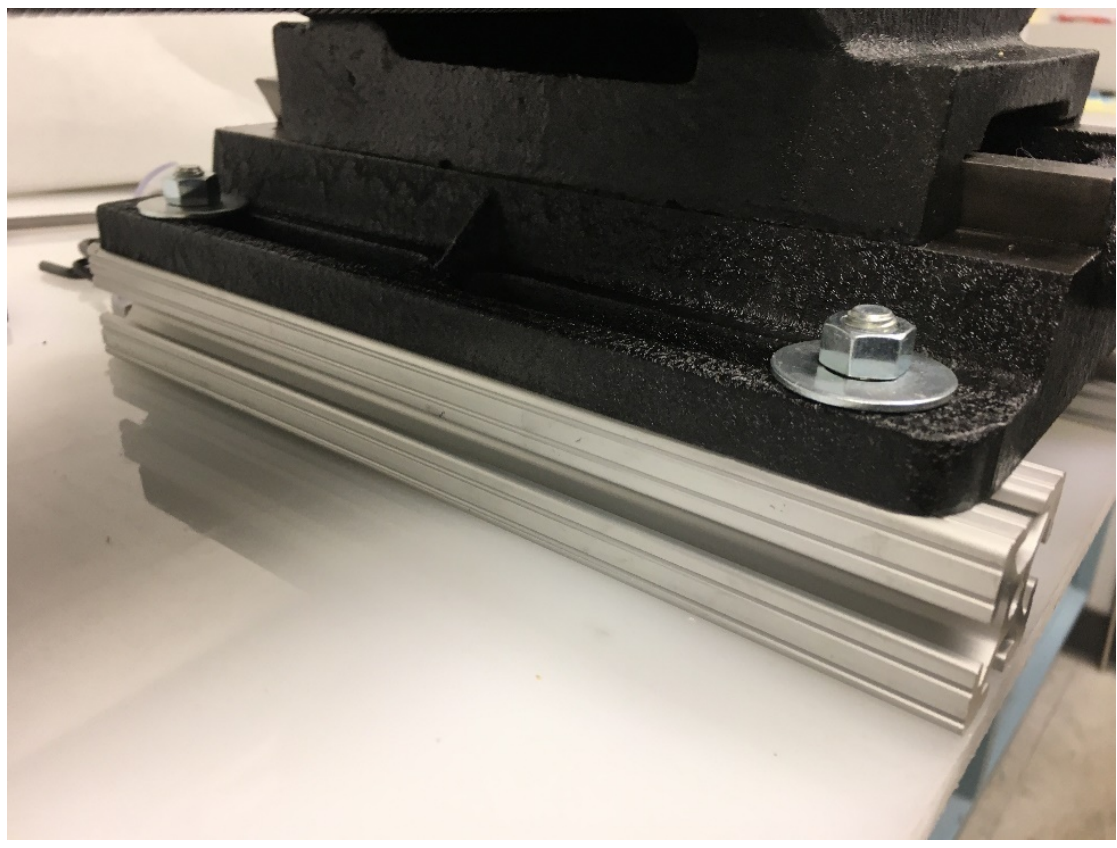

Figure 3: Inside View of Milling Table Anchored to LDPE Sheet 


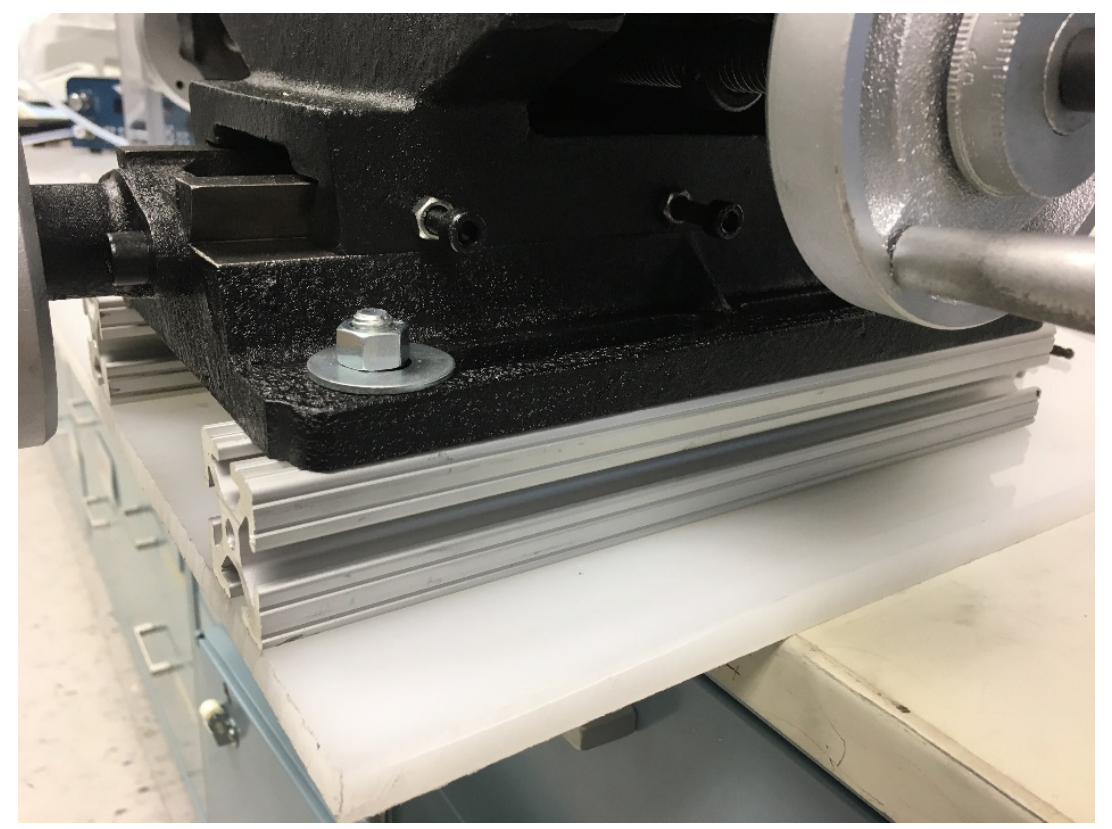

Figure 4: Outside View of Milling Table Anchored to LDPE Sheet

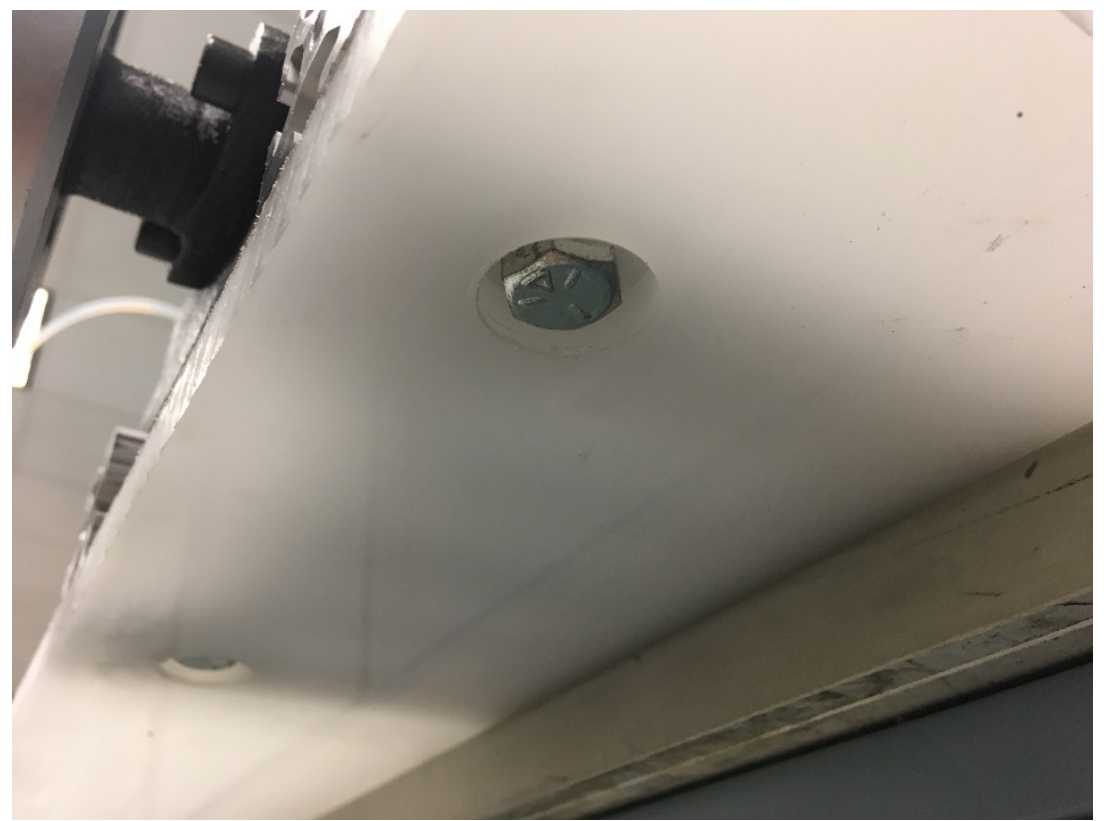

Figure 5: Counter Sunk Hole with Through Bolt

After getting the milling table attached to the LDPA platform sheet, the next step is to attach the headform to the articulating base. The articulating base is made from ThorLabs and is shown in the CAD file below (Figure 6). 


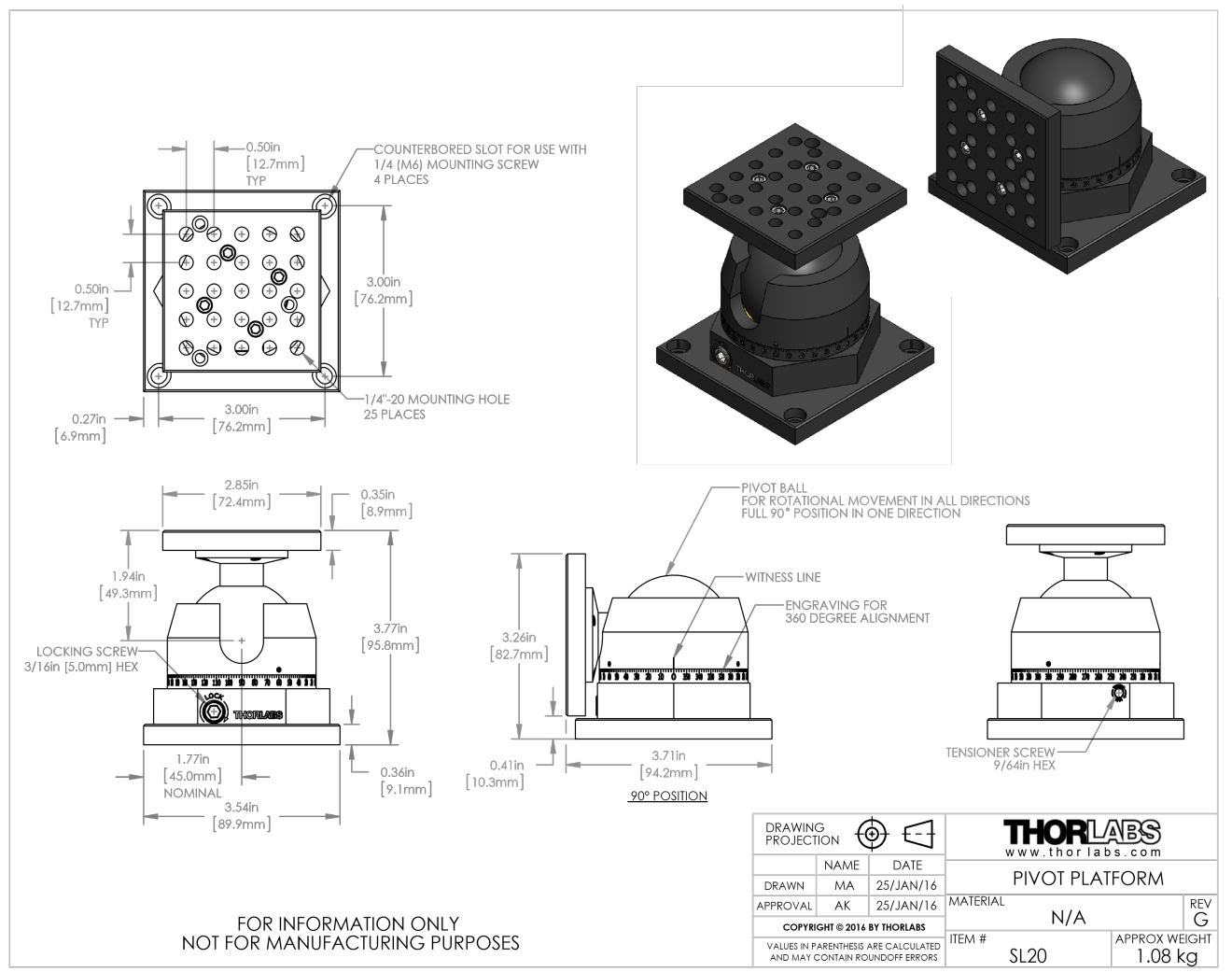

Figure 6: Articulating Base Layout

The UK Anthropometric headform is attached to the articulating base by using two 2" dry wall screws. Both of the headforms center ear holes must be aligned directly to the center of the articulating base. The wood screws can then be inserted in any appropriated hole of the articulating base and into the base of the neck of the headform. The optimal screw pattern would be 1 screw on either side of the pedestal (Figure 7). 


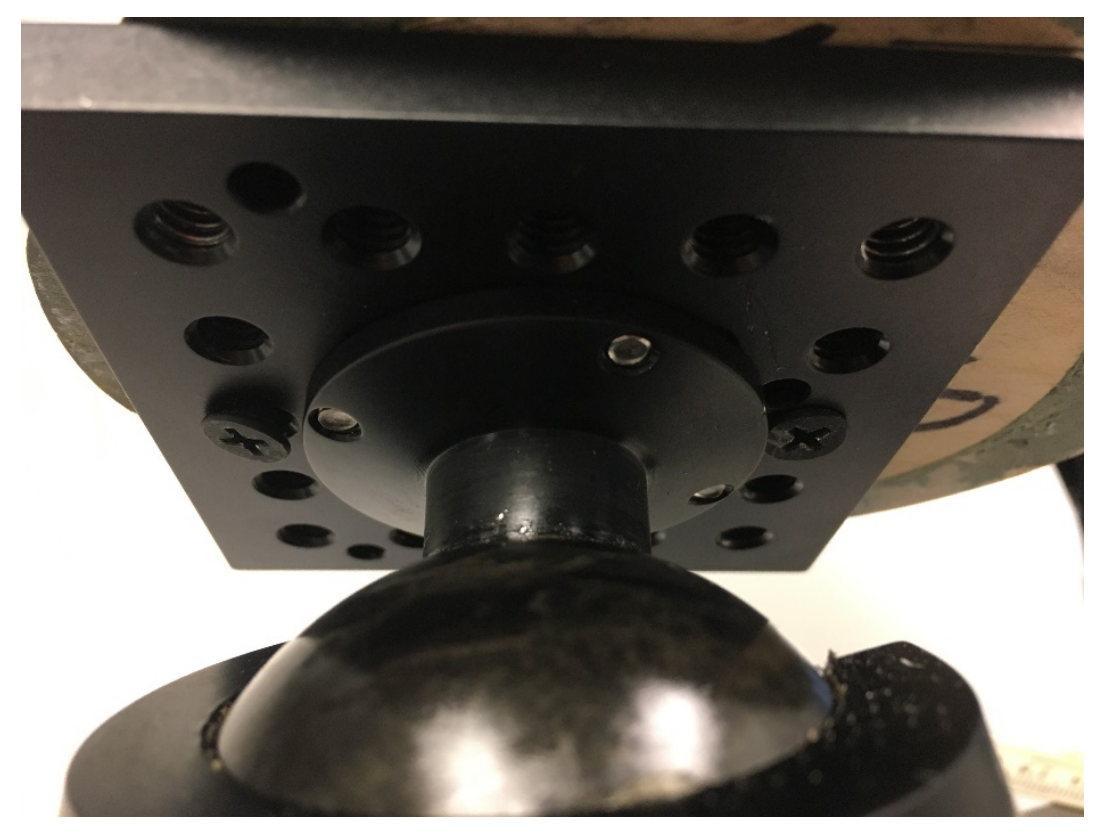

Figure 7: Articulating Base Screw Pattern

After attached the anthropometric head to the articulating base, the base then needs to be attached to the milling table. This is done using two 3/16" $-1-1 / 4$ " fully threaded bolts, corresponding nuts, and 1/2" washers (Figure 8, Figure 9, and Figure 10).

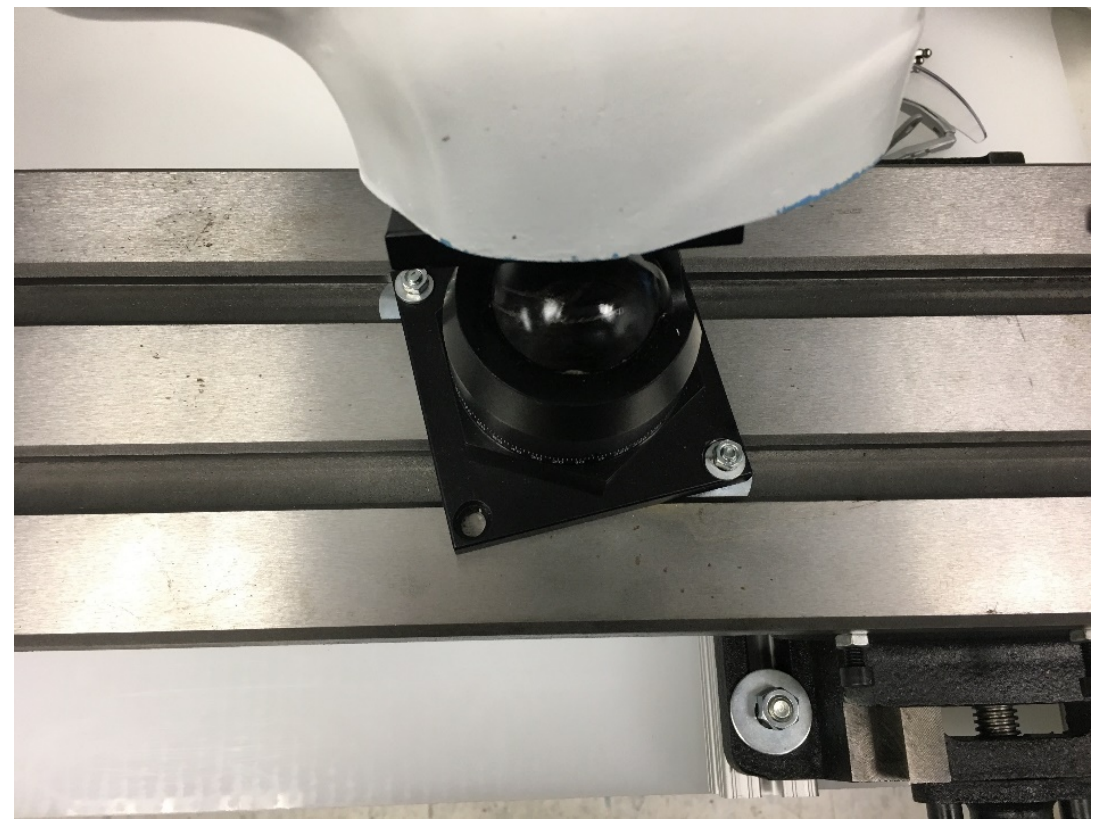

Figure 8: Top View of Articulating Base Attachment 


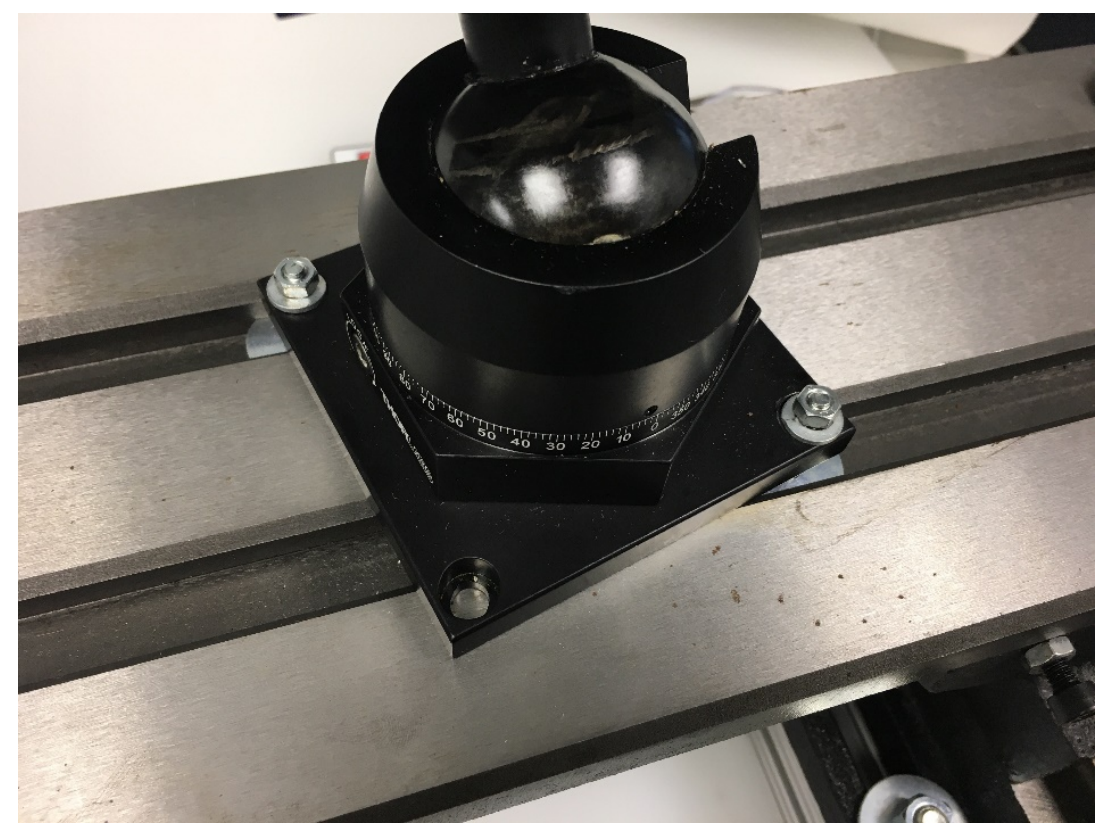

Figure 9: Side View of Articulating Base Attachment

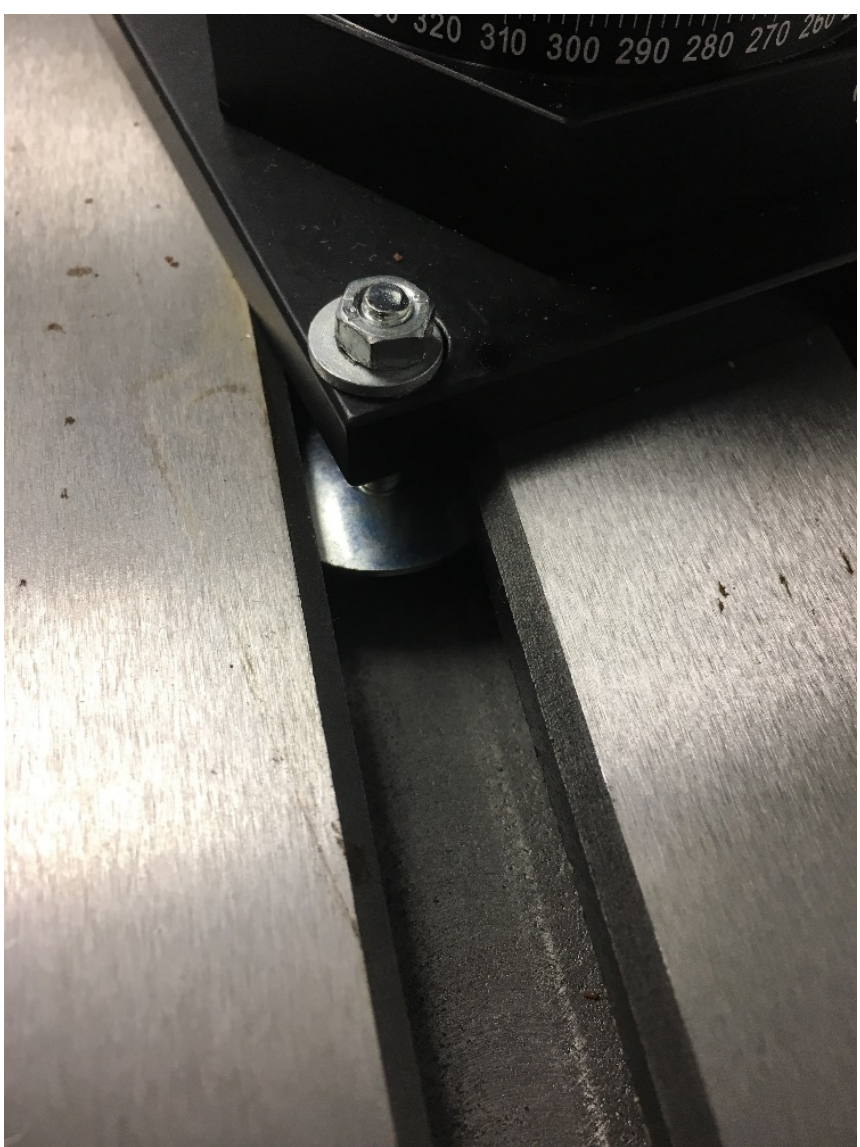

Figure 10: Close Up of Bolt on Articulating Base Attachment

The next piece of the apparatus that needs to be anchored to the LDPE sheet platform is the uni-slide stand. Given that the milling table is $6 \frac{1}{2}$ " tall, the uni-slide stand then needs to be 
raised on a platform itself to have matching heights for adequate nozzle projection (Figure 11). This platform can be built into a simple rectangular 4" $\mathrm{x} 4$ " box by using LDPE, polycarbonate, PTFE, or equivalent materials. This rectangular box can also be bought; either method is sufficient as long as the stand can remain stable and is raised at least $61 / 2$ ". The box used to raise the uni-slide in this apparatus was built out of PTFE sheets. Two pieces were cut into 3"x $6 \frac{1 / 2}{2}$ and two more 4 "x $6 \frac{1 / 2}{2}$. These four pieces were screwed together using $3 / 4$ " plastic screws (Figure 12). The box ends remain open. The uni slide will then sit atop the box and is screwed down into the top of the fabricated box through the uni slides pre drilled holes using four $3 / 4$ " plastic screws (Figure 13).

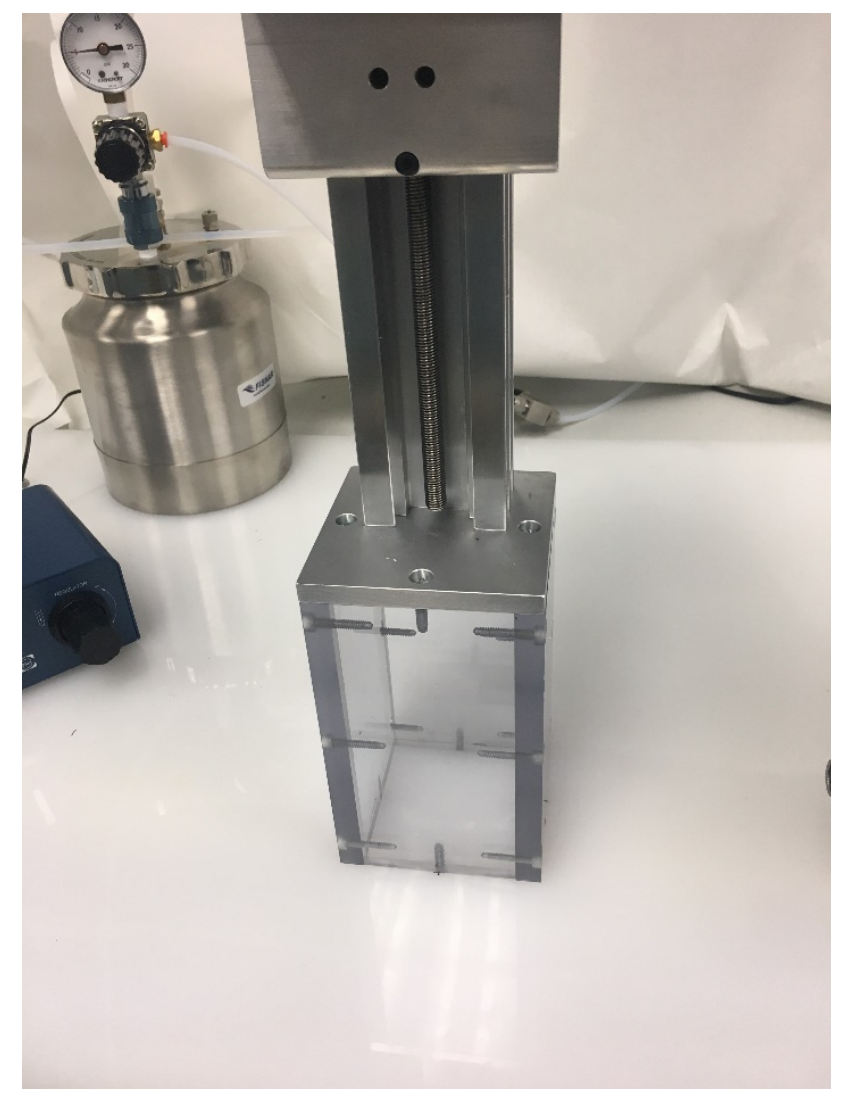

Figure 11: Uni-Slide Attached to Fabricated Box 


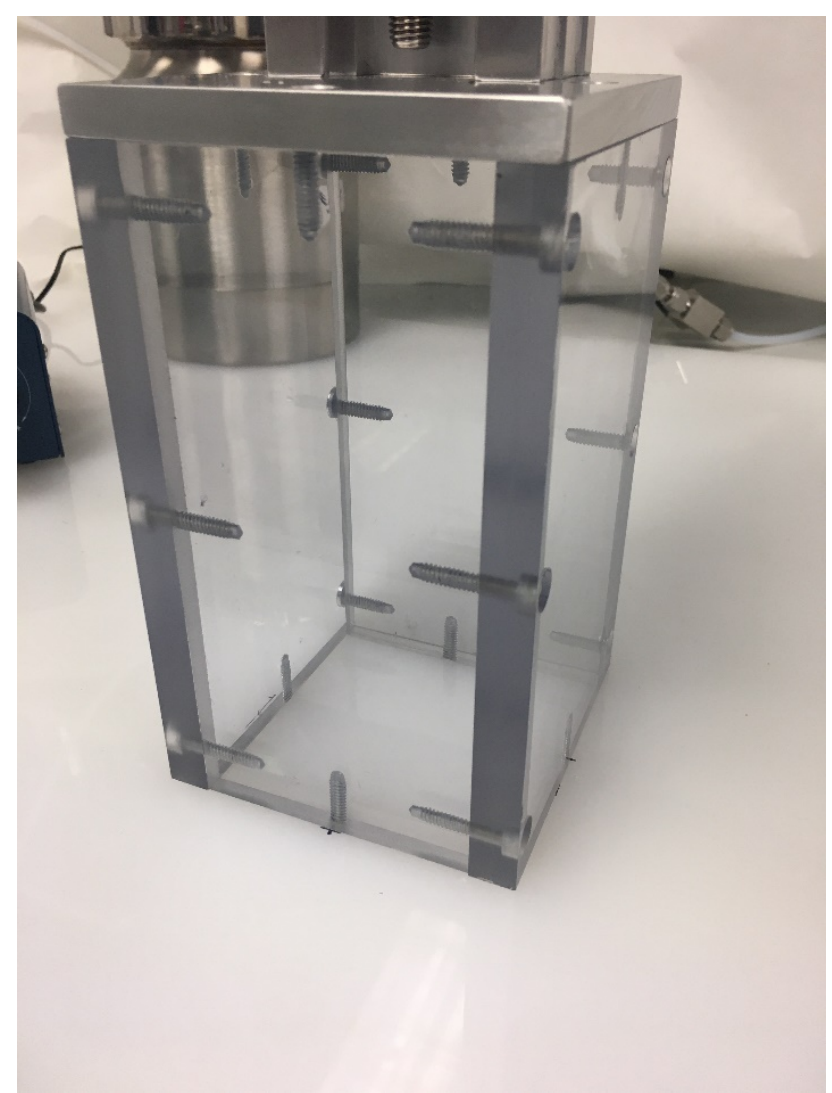

Figure 12: Fabricated Box

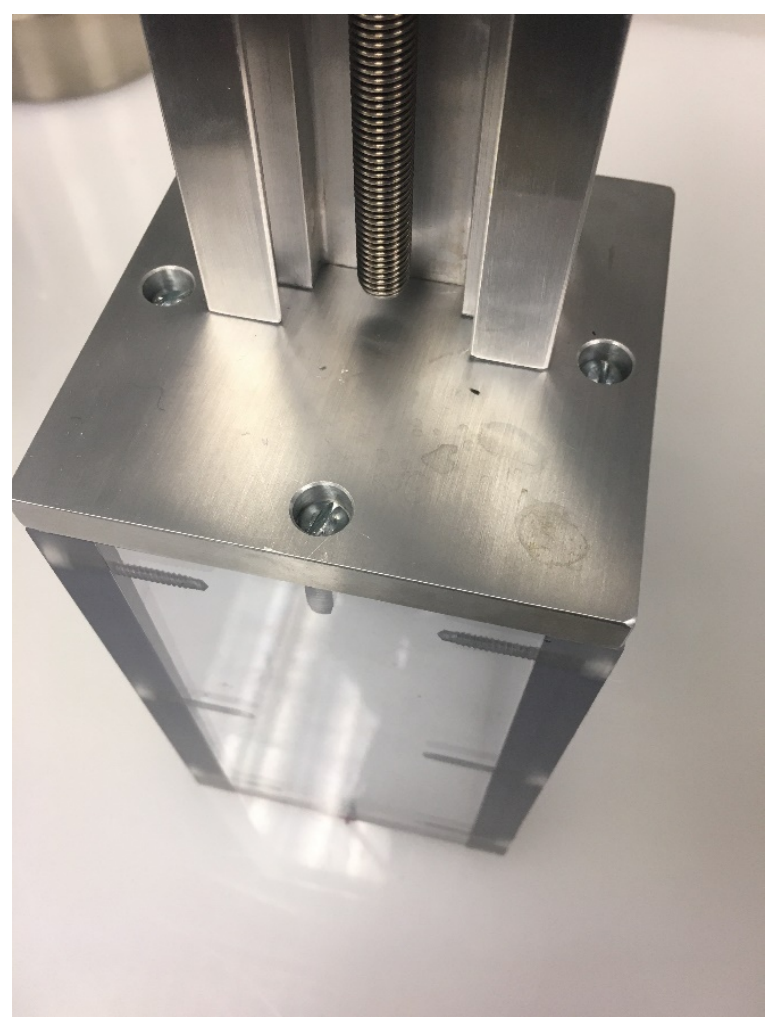

Figure 13: Uni-Slide Screwed to Box 
After securing the uni-slide stand to the fabricated box, the next step is to attach the nozzle to the uni-slides mounting bracket. The nozzle is secured to the mounting bracket by one 3/16"$1 / 2$ " fully threaded hex head bolt. The nozzle is held by using the M5 mounting hole (Figure 14). A locking washer is also needed between the bolt head and the bottom of the mounting bracket for tension purposes (Figure 15 and Figure 16).

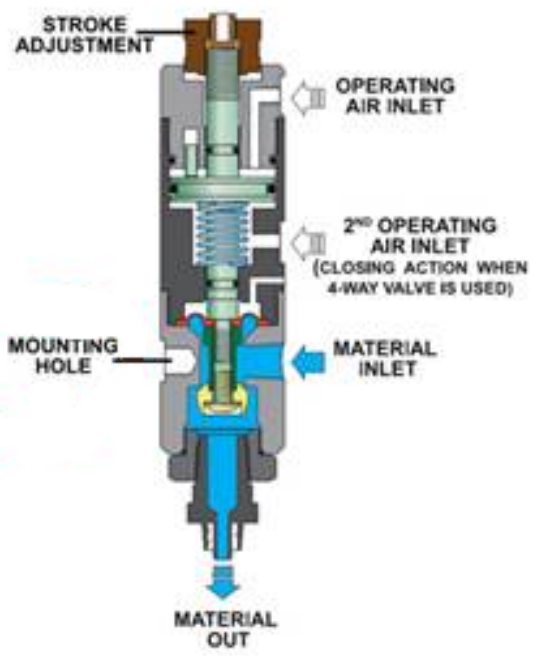

Figure 14: Nozzle Diagram

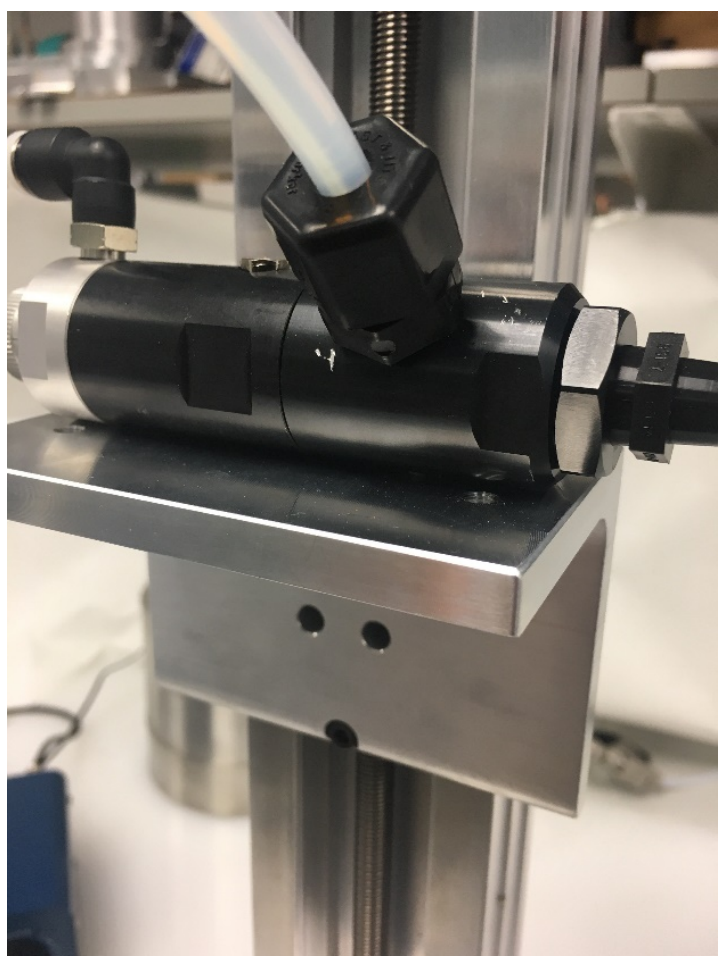


Figure 15: Mounted Nozzle on Bracket

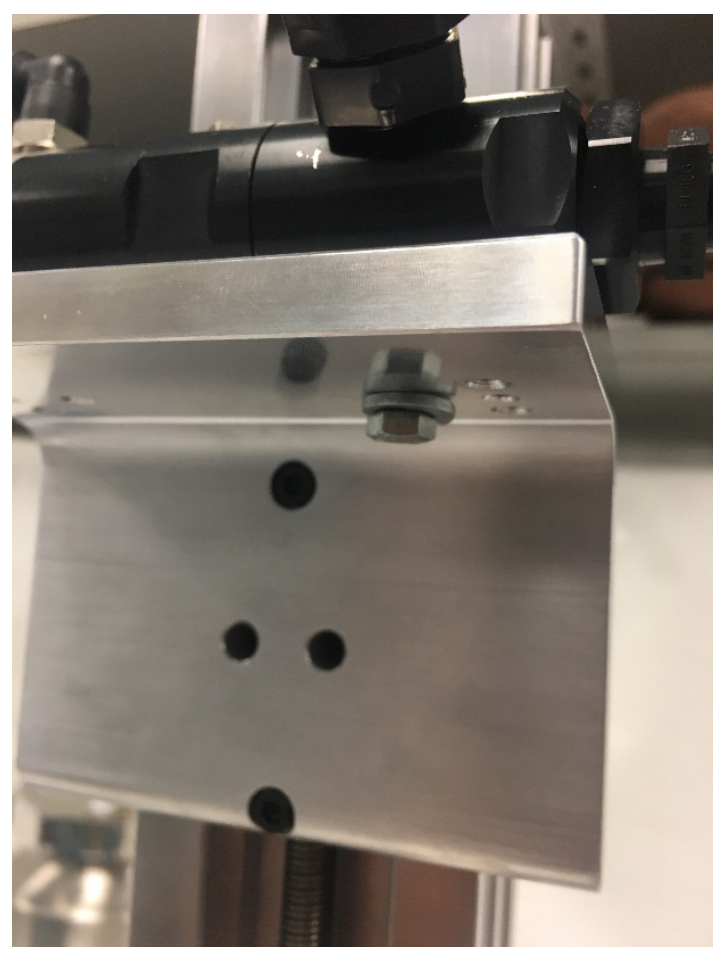

Figure 16: Bottom View of Mounting Bracket

After getting the nozzle mounted to the uni-slides mounting bracket, it is important to get the nozzle as square and in the center as possible on the bracket before completely tightening it down (Figure 17).

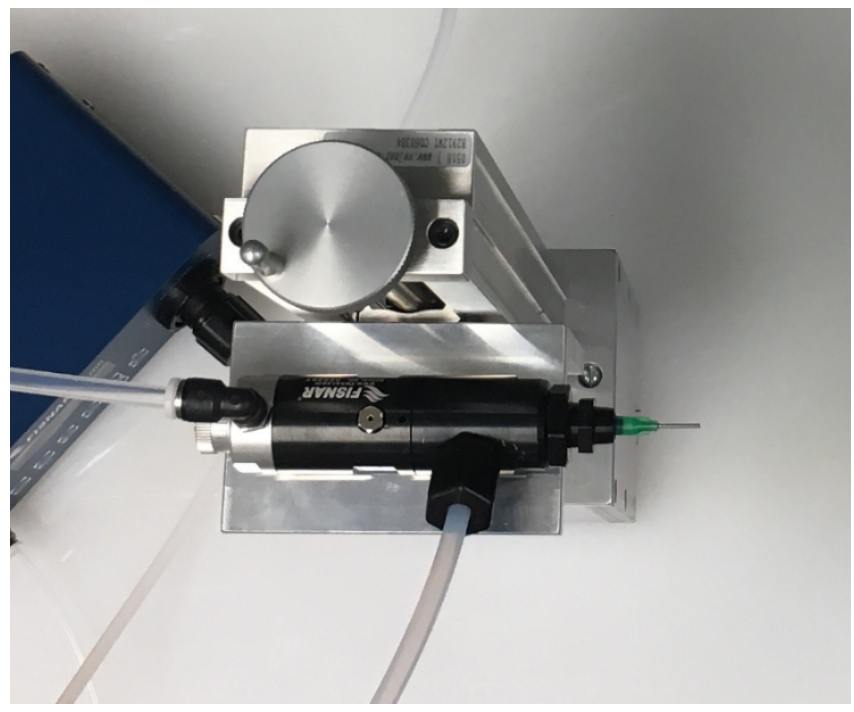

Figure 17: Top View of Nozzle Mounted 
The next step is securing the fabricated box to the LDPE sheet platform. (At this point the nozzle should already be attached to the uni-slide mount and the uni-slide should be attached to the fabricated box) The nozzle needs to the place in a manner so that when it is shot the fluid would pass directly through the center of the milling table or to the center of the anthropometric head (Figure 18). The edge of the fabricated box should also run parallel with the edge of the LDPE sheet platform (Figure 18).

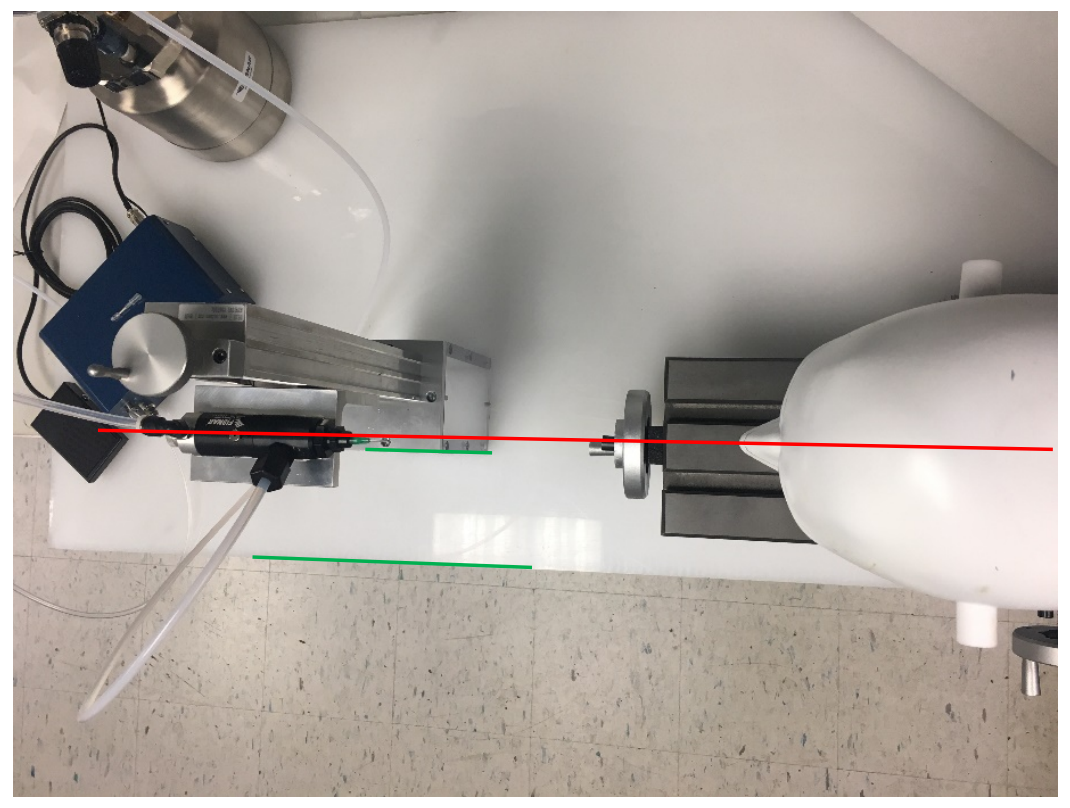

Figure 18: Orientation of Nozzle and Uni-Slide

After getting the orientation of the nozzle stand to that of the milling table and anthropometric head, it will then need to be anchored down. This can be achieved by the same method as the milling table. By using four 1-1/4" plastic screws that are drilled and countersunk from the bottom of the LDPE sheet platform (Figure 19 and Figure 20). 


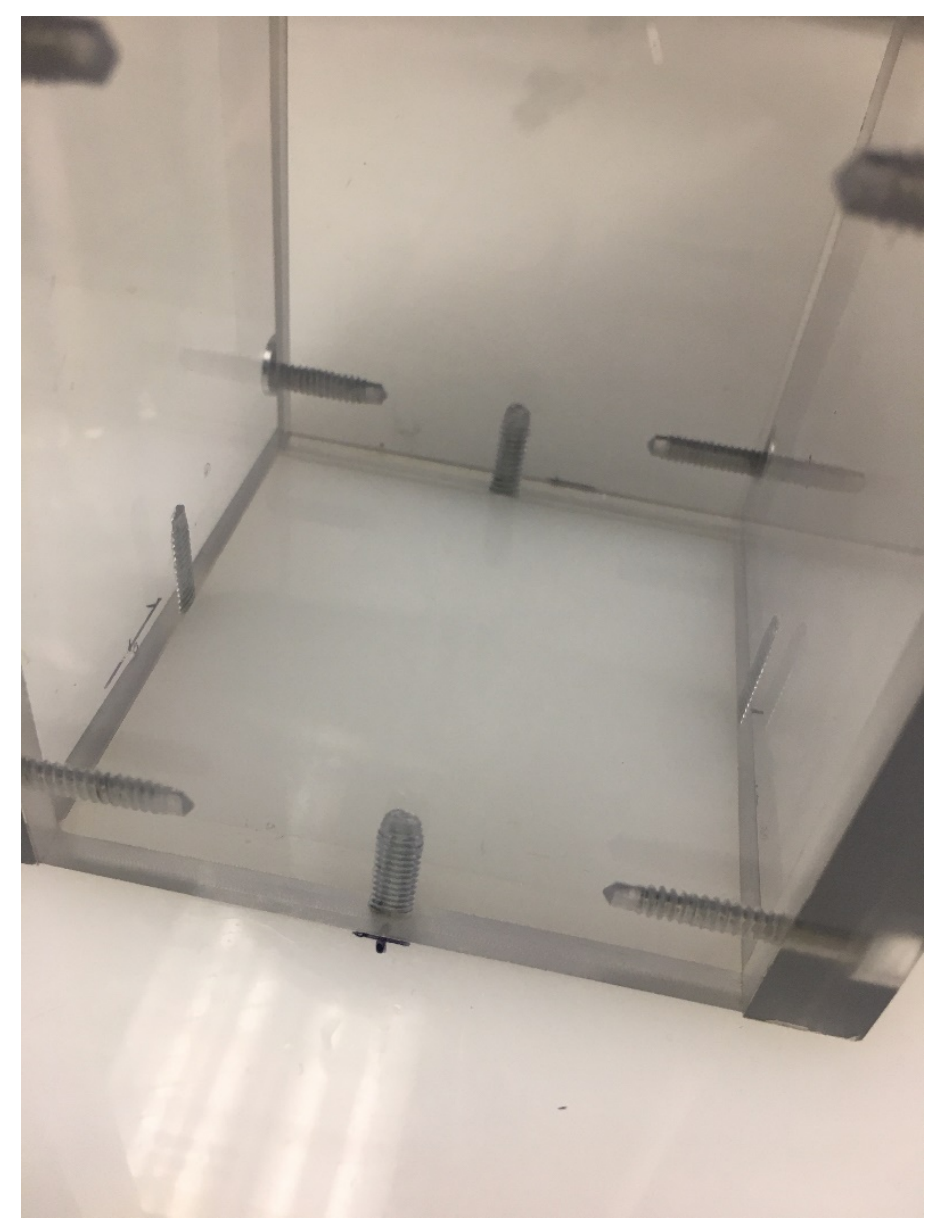

Figure 19: Fabricated Box Secured to LDPE Sheet

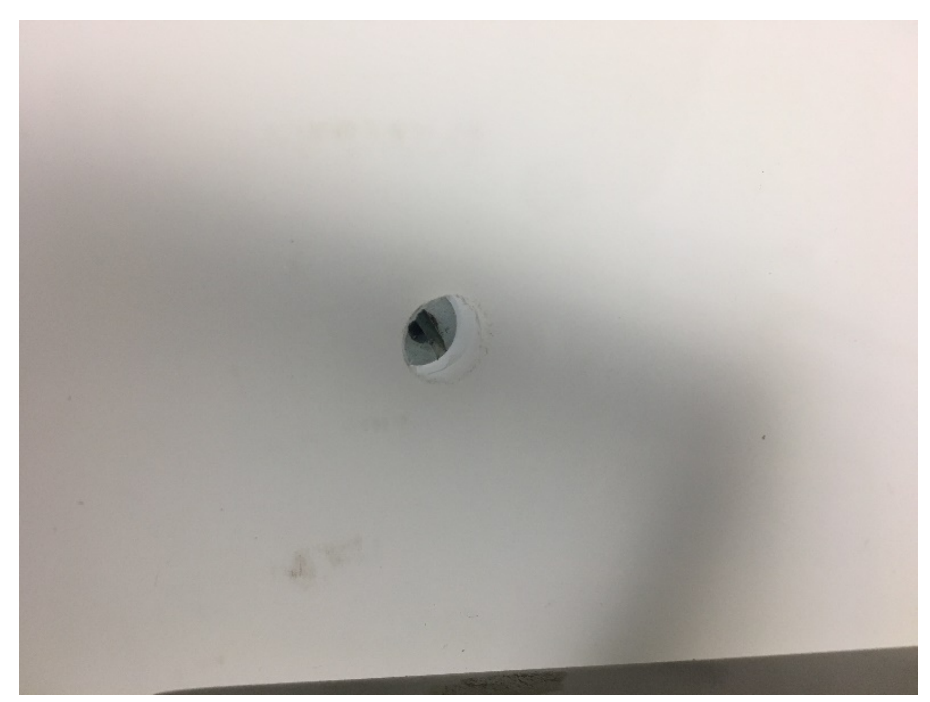

Figure 20: Countersunk Hole for Uni-Slide Box 
The next step is to connect air pressure to the pressurized container and dispensing unit with an airline capable of supply consistent pressure of at least 70 psi. These two air inlets are fed by a $1 / 4$ " push connection (Figure 21 and Figure 22). After running the airline to the container and dispensing unit, another $1 / 4$ " airline needs to be connected from the dispensing unit to the nozzle (Figure 23 and Figure 24). After connecting all of airlines to the container, dispenser, and nozzle; the next step is to connect the pressurized container reservoir to the nozzle (Figure 25 and Figure 26).

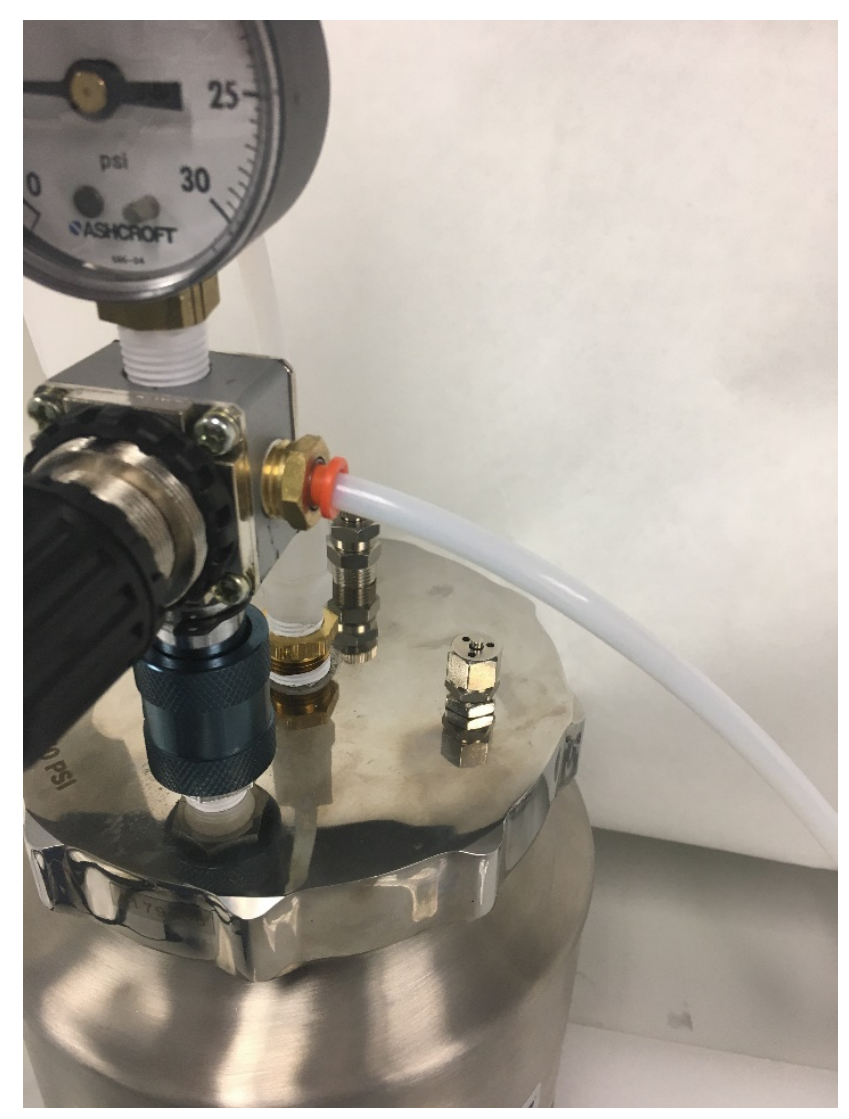

Figure 21: Supply Air Line Connection into Container

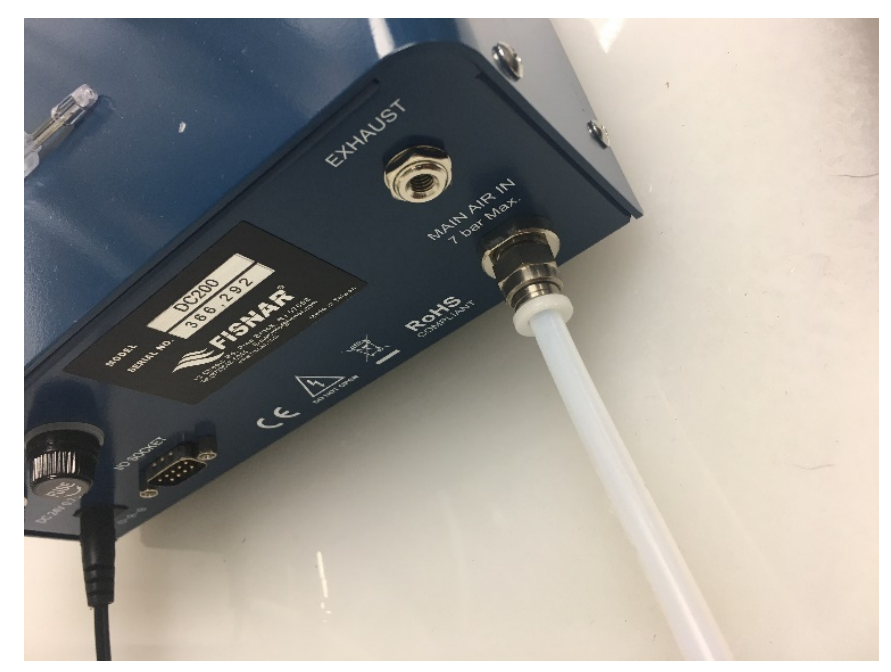


Figure 22: Supply Air Line Connection into Dispenser

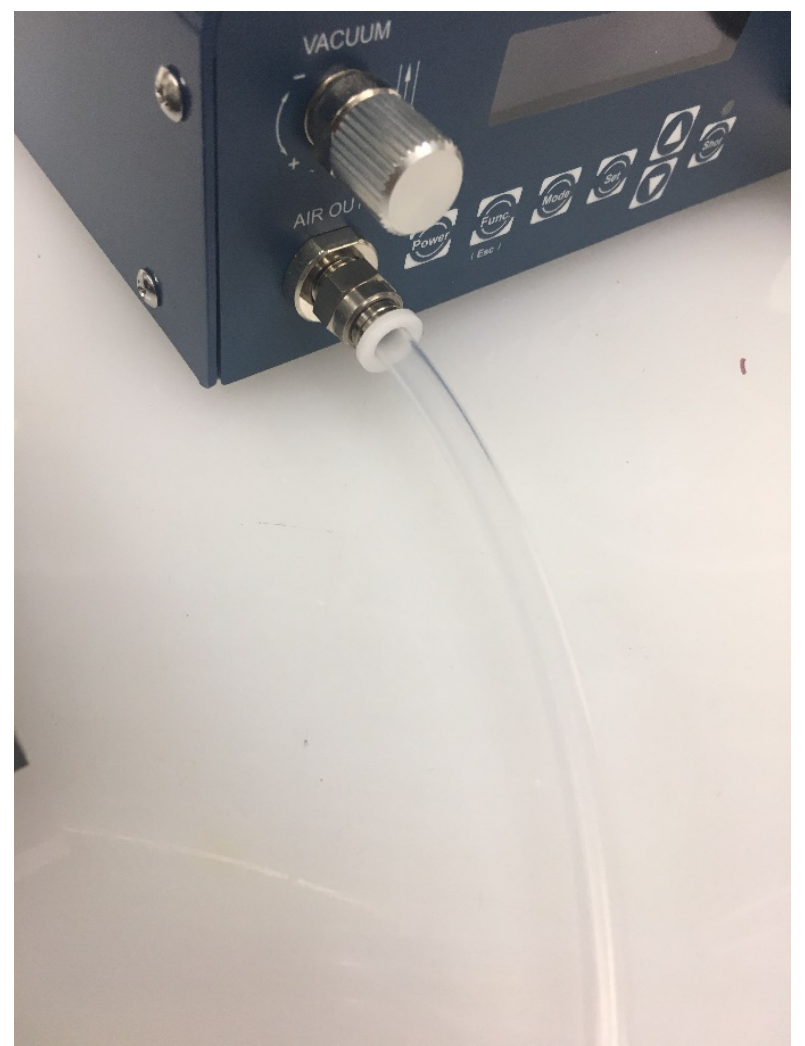

Figure 23: Air Line from Dispenser to Nozzle-Dispenser Output 


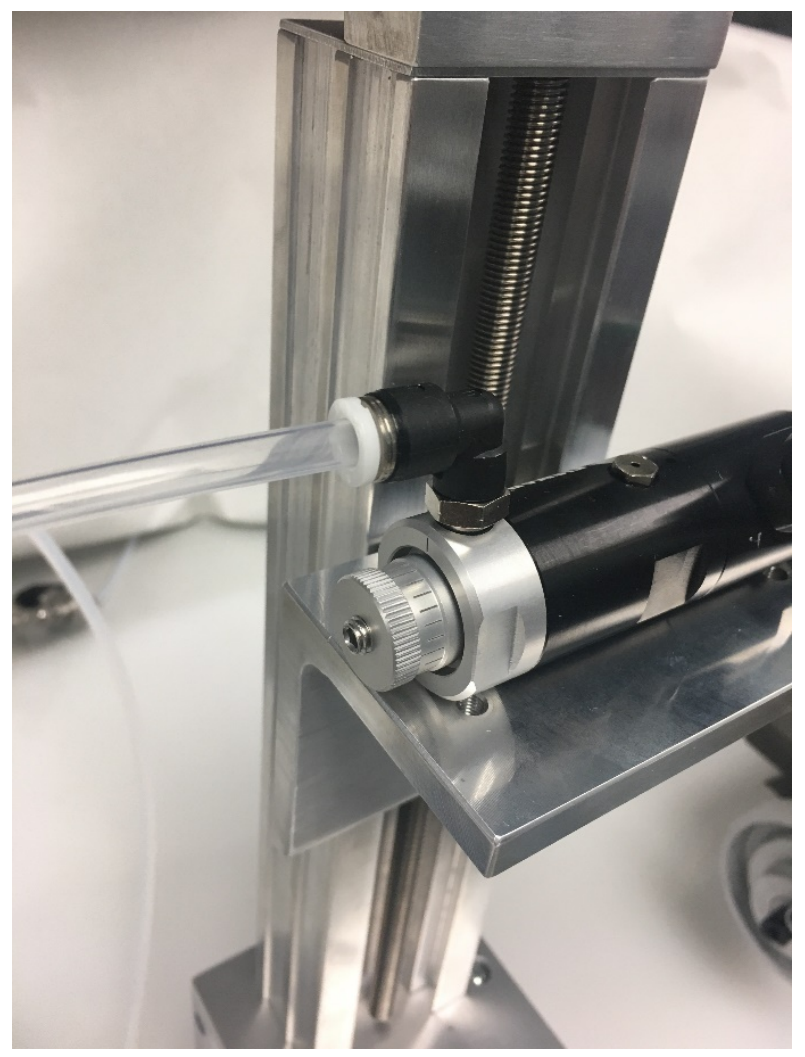

Figure 24: Air Line from Dispenser to Nozzle-Nozzle Input

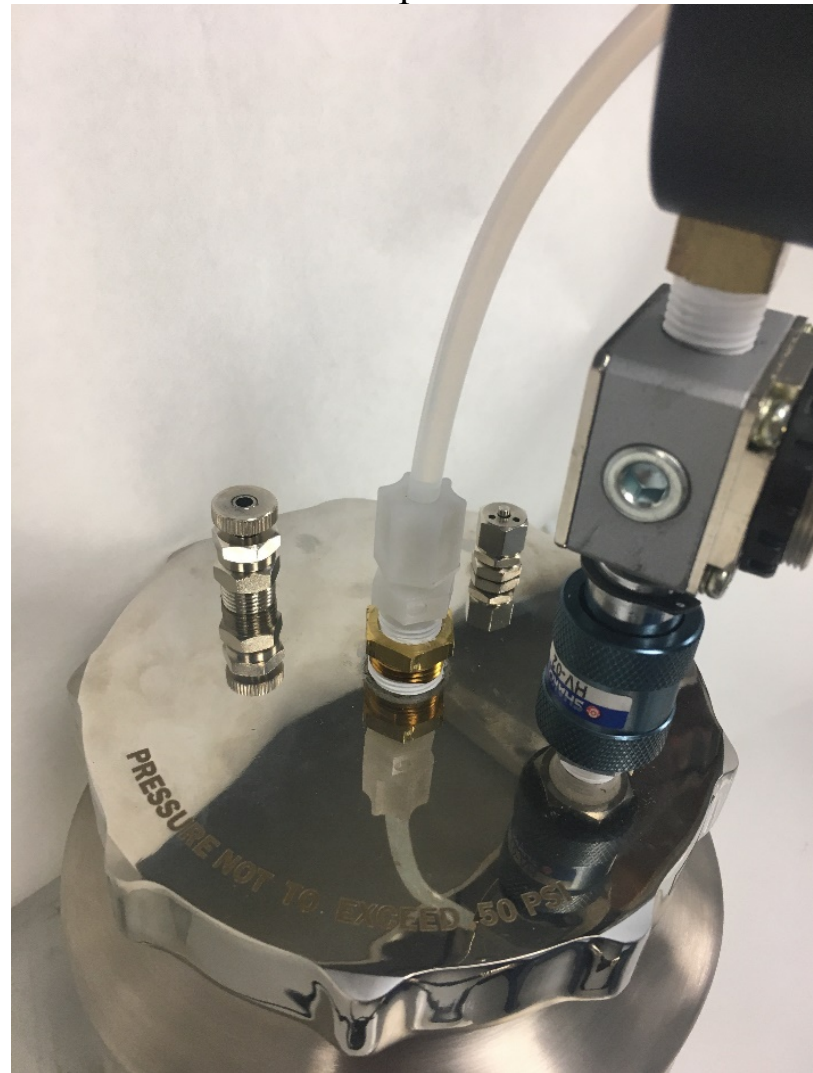

Figure 25: Fluid line from Pressurized Container Reservoir to Nozzle 


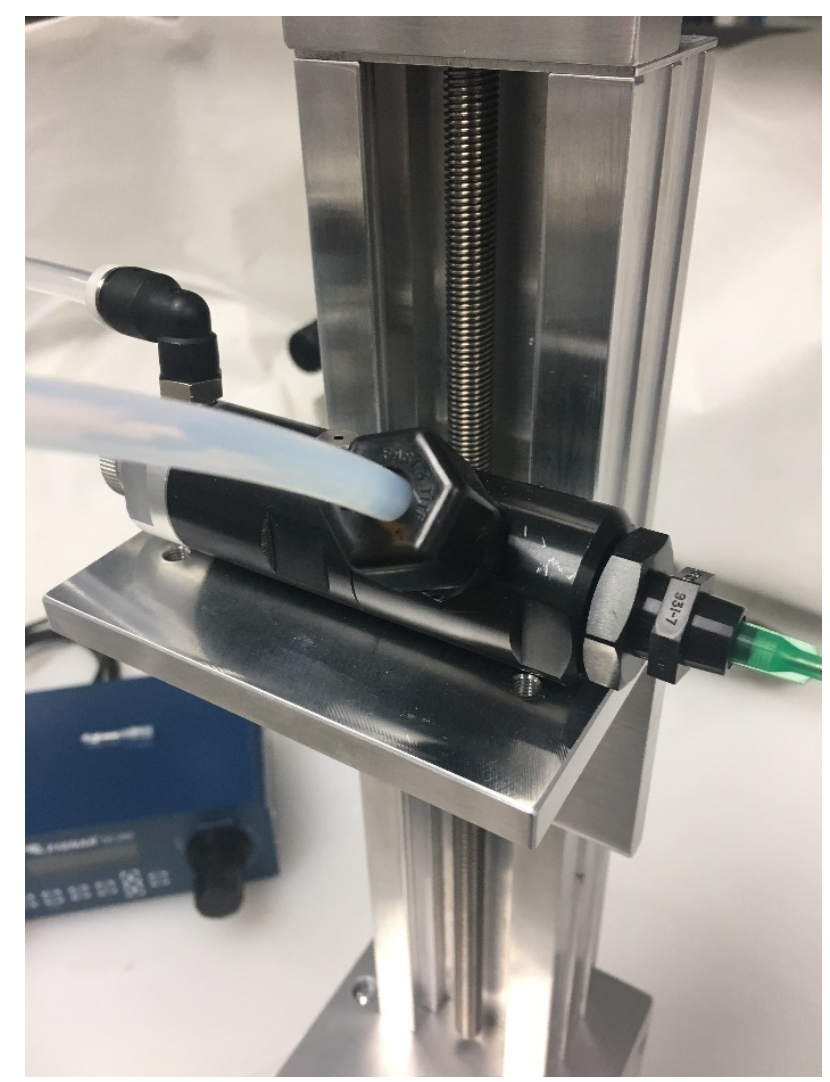

Figure 26: Fluid line Into Nozzle from Pressurized Container Reservoir to Nozzle After the airlines and fluid line is connected, the power cord and foot pedal must be connected to the dispensing unit. Both of these connections are made at the back of the dispensing unit (Figure 27 and Figure 28). 


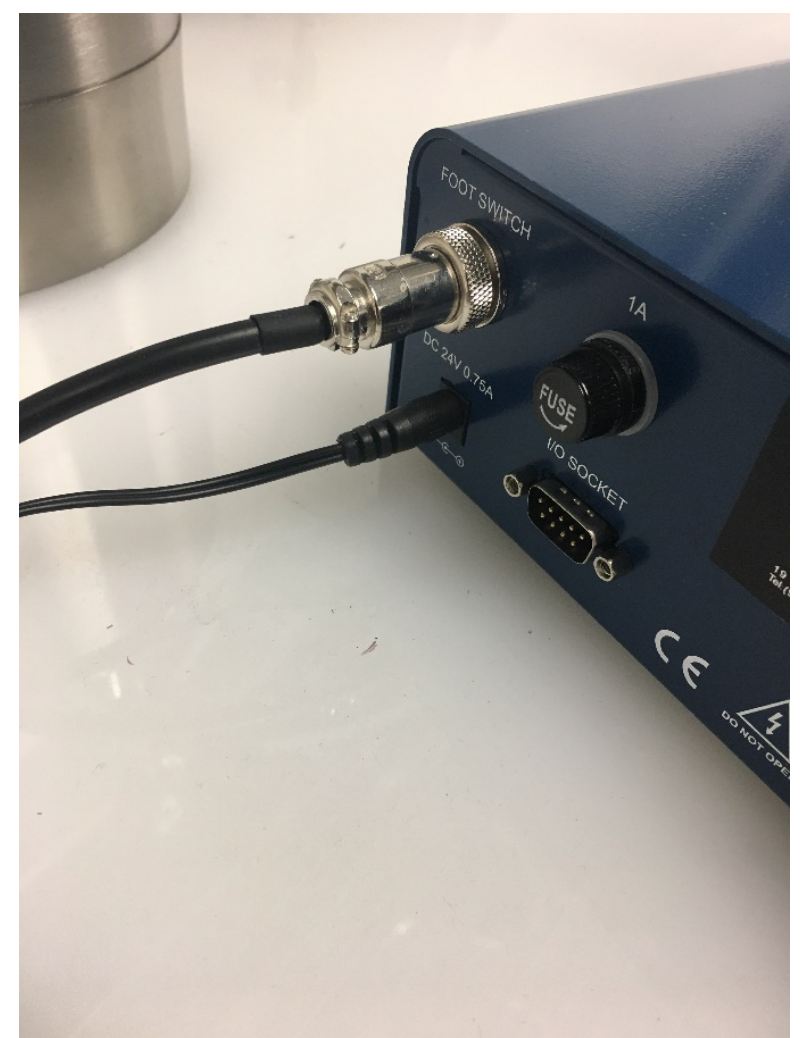

Figure 27: Connections at Back of Dispenser

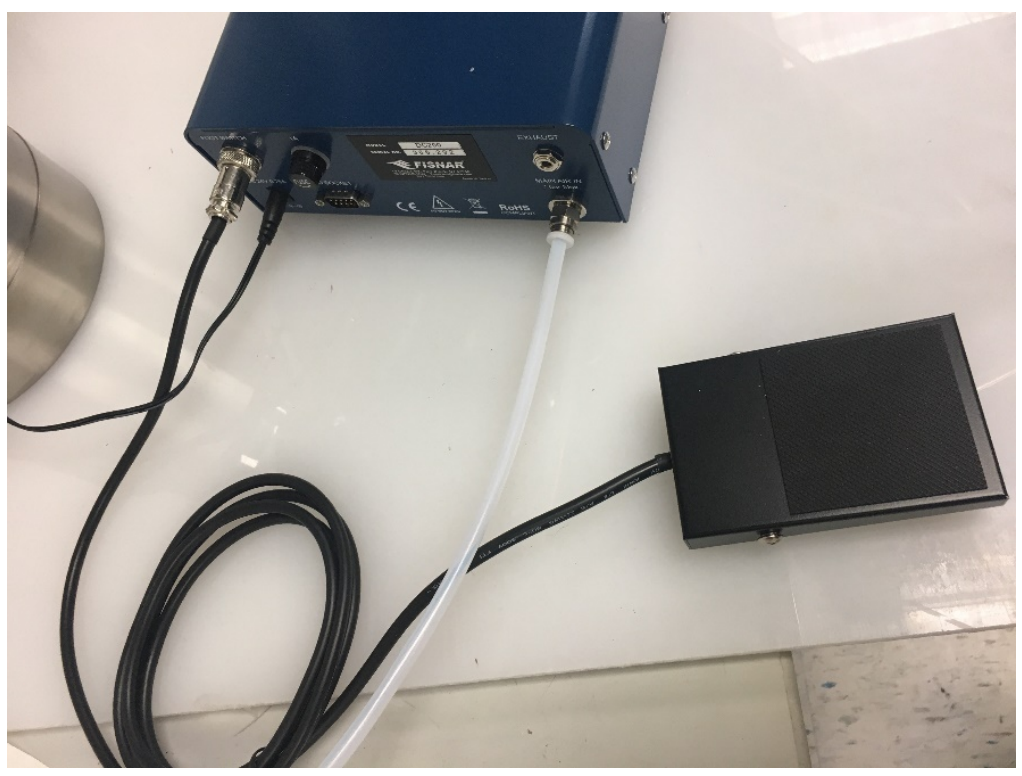

Figure 28: Foot Pedal and Connections for Dispenser 


\section{Parts List}

\section{McMaster-Carr}

(1) LDPE Sheet 24"x48"x1/2" Part\# 8657K616

(1) 80/20 1"x1"-24" 47065T101

(4) Hex bolt 3/8"-2" 91309A632

(4) Hex nuts 3/8"-16 95462A031

(4) 1-1/4" flat washer 90107A040

(2) Dry wall screws 90093A400

(2) 3/16 Hex bolts 91309A626

(2) $3 / 16$ Hex nuts

(3) $1.125 \%$ washers $91525 \mathrm{~A} 268$

(1) LDPE sheet 24"x24" 8657K416

(24) No.4 - 3/4"Screws 90380A120

(4) No. 8 1-1/4” Screws 92325A319

(1) 0-30 PSI Pressure Gauge 4089K61

\section{Grizzly}

(1) 6" x 18.5" compound Table - G8750

\section{ThorLabs}

(1) Articulation base - SL20

\section{Velmex}

(1) UniSlide Elevating Table-T=9.5" - B2912W1

\section{Ellsworth}

(1) Poppet Valve - VP300

(1) Pressure Tank Stainless Steel Special - IJ2601N-SS-SP

(1) Digital Dispenser-Valve Controlled - DC200 


\title{
Fluid Preparation SOP
}

\author{
(saline + fluorescein + surfactant): \\ $0.9 \%$ saline \\ $0.002 \mathrm{M}$ fluorescein \\ $0.1 \%$ surfynol $104 \mathrm{H}$
}

For 1 Liter:

$9 \mathrm{~g} \mathrm{NaCl}$

$0.752 \mathrm{~g}$ fluorescein

$1.0 \mathrm{~mL}$ surfynol $104 \mathrm{H}$

$\mathrm{diH}_{2} \mathrm{O}$ to $1 \mathrm{~L}$

i. Place magnetic stir bar in $1 \mathrm{~L}$ Erlenmeyer flask and weigh both with triple beam balance to determine tare weight.

j. Add $1000 \mathrm{~g}$ auxiliary weight to opposite end of balance beam

k. Weigh $\mathrm{NaCl}$ on a scientific balance and add to flask, rinsing with $\mathrm{diH}_{2} \mathrm{O}$ as needed

1. Weigh fluorescein on a scientific balance and add to flask, rinsing with $\operatorname{diH}_{2} \mathrm{O}$ as needed

m. Add remaining volume of $\mathrm{diH}_{2} \mathrm{O}$ until indicator at the end of balance beam is level with the zero indicator on the balance base.

n. Transfer flask to magnetic stirrer and create a strong vortex.

o. Using an Eppendorf micropipettor device and disposable tip, carefully pipet the surfynol $104 \mathrm{H}$ into the solution, rinsing tip several times.

p. Allow solution to mix with a strong vortex for 30 minute. 


\section{APPENDIX C: ENSEMBLE TEST DATA}




\begin{tabular}{|c|c|c|c|c|c|c|c|c|c|c|c|c|c|c|}
\hline position1 & type1 & type2 & type3 & position2 & passfaileyes & distance & quad1 & passfailnose & distance2 & quad2 & passfailmout & distance3 & quad3 & Ensemble \\
\hline 1 & Spurt & $635 \mathrm{~cm} / \mathrm{s}$ & $2 \mathrm{ml}$ & Up & Pass & 22.32 & - & Pass & 5.69 & - & Pass & 33.61 & - & A \\
\hline 2 & Spurt & $635 \mathrm{~cm} / \mathrm{s}$ & $2 \mathrm{ml}$ & Down & Fail & 1.26 & L Q2 & Fail & Ran Thru & Q3 & Fail & Ran Thru & Q2/Q3 & A \\
\hline 3 & Spurt & $635 \mathrm{~cm} / \mathrm{s}$ & $2 \mathrm{ml}$ & Right & Pass & 17.91 & - & Pass & 50.4 & - & Pass & 50.79 & - & A \\
\hline 4 & Spurt & $635 \mathrm{~cm} / \mathrm{s}$ & $2 \mathrm{ml}$ & Left & Pass & 20.49 & - & Pass & 50.14 & - & Pass & 36.14 & - & A \\
\hline 1 & Spray & $500 \mathrm{~cm} / \mathrm{s}$ & $1 \mathrm{ml}$ & Up & Pass & 26.32 & - & Pass & 74.45 & - & Pass & 78.26 & - & A \\
\hline 2 & Spray & $500 \mathrm{~cm} / \mathrm{s}$ & $1 \mathrm{ml}$ & Down & Pass & 17.19 & - & Pass & 71.22 & - & Pass & 93.4 & - & A \\
\hline 3 & Spray & $500 \mathrm{~cm} / \mathrm{s}$ & $1 \mathrm{ml}$ & Right & Pass & 13.29 & - & Pass & 48.26 & - & Pass & 37.58 & - & A \\
\hline 4 & Spray & $500 \mathrm{~cm} / \mathrm{s}$ & $1 \mathrm{ml}$ & Left & Pass & 15.13 & - & Pass & 41.94 & - & Pass & 33.5 & - & A \\
\hline 1 & Spurt & $635 \mathrm{~cm} / \mathrm{s}$ & $2 \mathrm{ml}$ & Up & Pass & 22.42 & - & Pass & 3.36 & - & Pass & 35.87 & - & A \\
\hline 2 & Spurt & $635 \mathrm{~cm} / \mathrm{s}$ & $2 \mathrm{ml}$ & Down & Fail & 18.42 & L Q3 & Fail & Ran Thru & Q4 & Fail & Ran Thru & Q2/Q4 & A \\
\hline 3 & Spurt & $635 \mathrm{~cm} / \mathrm{s}$ & $2 \mathrm{ml}$ & Right & Pass & 19.25 & - & Pass & 56.08 & - & Pass & 39.09 & - & A \\
\hline 4 & Spurt & $635 \mathrm{~cm} / \mathrm{s}$ & $2 \mathrm{ml}$ & Left & Pass & 18.28 & - & Pass & 38.59 & - & Pass & 34.9 & - & A \\
\hline 1 & Spray & $500 \mathrm{~cm} / \mathrm{s}$ & $1 \mathrm{ml}$ & Up & Pass & 22.52 & - & Pass & 70.68 & - & Pass & 77.54 & - & A \\
\hline 2 & Spray & $500 \mathrm{~cm} / \mathrm{s}$ & $1 \mathrm{ml}$ & Down & Pass & 17.63 & - & Pass & 67.83 & - & Pass & 92.19 & - & A \\
\hline 3 & Spray & $500 \mathrm{~cm} / \mathrm{s}$ & $1 \mathrm{ml}$ & Right & Pass & 17.37 & - & Pass & 43.96 & - & Pass & 32.53 & - & A \\
\hline 4 & Spray & $500 \mathrm{~cm} / \mathrm{s}$ & $1 \mathrm{ml}$ & Left & Pass & 23.04 & - & Pass & 43.2 & - & Pass & 38.16 & - & A \\
\hline 1 & Spurt & $635 \mathrm{~cm} / \mathrm{s}$ & $2 \mathrm{ml}$ & Up & Pass & 23.01 & - & Pass & 72.4 & - & Pass & 77.85 & - & A \\
\hline 2 & Spurt & $635 \mathrm{~cm} / \mathrm{s}$ & $2 \mathrm{ml}$ & Down & Fail & 17.35 & R Q4 & Fail & Ran Thru & Q2/Q3 & Pass & 5.84 & - & A \\
\hline 3 & Spurt & $635 \mathrm{~cm} / \mathrm{s}$ & $2 \mathrm{ml}$ & Right & Pass & 17.49 & - & Pass & 56.52 & - & Pass & 46.2 & - & A \\
\hline 4 & Spurt & $635 \mathrm{~cm} / \mathrm{s}$ & $2 \mathrm{ml}$ & Left & Pass & 21.89 & - & Pass & 50.84 & - & Pass & 48.19 & - & A \\
\hline 1 & Spray & $500 \mathrm{~cm} / \mathrm{s}$ & $1 \mathrm{ml}$ & Up & Pass & 26.57 & - & Pass & 76.23 & - & Pass & 78.35 & - & A \\
\hline 2 & Spray & $500 \mathrm{~cm} / \mathrm{s}$ & $1 \mathrm{ml}$ & Down & Pass & 16.87 & - & Pass & 68.08 & - & Pass & 92.44 & - & A \\
\hline 3 & Spray & $500 \mathrm{~cm} / \mathrm{s}$ & $1 \mathrm{ml}$ & Right & Pass & 19.95 & - & Pass & 46.05 & - & Pass & 36.8 & - & A \\
\hline 4 & Spray & $500 \mathrm{~cm} / \mathrm{s}$ & $1 \mathrm{ml}$ & Left & Pass & 23.96 & - & Pass & 41.56 & - & Pass & 33.65 & - & A \\
\hline 1 & Spurt & $635 \mathrm{~cm} / \mathrm{s}$ & $2 \mathrm{ml}$ & Up & Pass & 4.91 & - & Pass & 45.72 & - & Pass & 81.97 & - & A \\
\hline 2 & Spurt & $635 \mathrm{~cm} / \mathrm{s}$ & $2 \mathrm{ml}$ & Down & Fail & 21.6 & L Q2 & Fail & Ran Thru & Q4 & Fail & Ran Thru & Q1/Q4 & A \\
\hline 3 & Spurt & $635 \mathrm{~cm} / \mathrm{s}$ & $2 \mathrm{ml}$ & Right & Pass & 16.28 & - & Pass & 54.66 & - & Pass & 30.24 & - & A \\
\hline 4 & Spurt & $635 \mathrm{~cm} / \mathrm{s}$ & $2 \mathrm{ml}$ & Left & Pass & 20.46 & - & Pass & 62.82 & - & Pass & 43.66 & - & A \\
\hline 1 & Spray & $500 \mathrm{~cm} / \mathrm{s}$ & $1 \mathrm{ml}$ & Up & Pass & 23.4 & - & Pass & 73.51 & - & Pass & 74.55 & - & A \\
\hline 2 & Spray & $500 \mathrm{~cm} / \mathrm{s}$ & $1 \mathrm{ml}$ & Down & Pass & 15.75 & - & Pass & 71.99 & - & Pass & 97.16 & - & A \\
\hline 3 & Spray & $500 \mathrm{~cm} / \mathrm{s}$ & $1 \mathrm{ml}$ & Right & Pass & 18.23 & - & Pass & 45.84 & - & Pass & 37.59 & - & A \\
\hline 4 & Spray & $500 \mathrm{~cm} / \mathrm{s}$ & $1 \mathrm{ml}$ & Left & Pass & 16.84 & - & Pass & 44.11 & - & Pass & 36.48 & - & A \\
\hline 1 & Spurt & $635 \mathrm{~cm} / \mathrm{s}$ & $2 \mathrm{ml}$ & Up & Pass & 8.59 & - & Pass & 2.75 & - & Pass & 30.55 & - & A \\
\hline 2 & Spurt & $635 \mathrm{~cm} / \mathrm{s}$ & $2 \mathrm{ml}$ & Down & Fail & 11.5 & L Q3 & Fail & Ran Thru & Q3/Q4 & Fail & Ran Thru & Q1/Q4 & A \\
\hline 3 & Spurt & $635 \mathrm{~cm} / \mathrm{s}$ & $2 \mathrm{ml}$ & Right & Pass & 18.14 & - & Pass & 46.22 & - & Pass & 45.95 & - & A \\
\hline 4 & Spurt & $635 \mathrm{~cm} / \mathrm{s}$ & $2 \mathrm{ml}$ & Left & Pass & 18.11 & - & Pass & 49.46 & - & Pass & 52.76 & - & A \\
\hline 1 & Spray & $500 \mathrm{~cm} / \mathrm{s}$ & $1 \mathrm{ml}$ & Up & Pass & 23.37 & - & Pass & 74.6 & - & Pass & 76.1 & - & A \\
\hline 2 & Spray & $500 \mathrm{~cm} / \mathrm{s}$ & $1 \mathrm{ml}$ & Down & Pass & 18.16 & - & Pass & 68.29 & - & Pass & 97.22 & - & A \\
\hline 3 & Spray & $500 \mathrm{~cm} / \mathrm{s}$ & $1 \mathrm{ml}$ & Right & Pass & 19.03 & - & Pass & 44.56 & - & Pass & 37.52 & - & A \\
\hline 4 & Spray & $500 \mathrm{~cm} / \mathrm{s}$ & $1 \mathrm{ml}$ & Left & Pass & 15.21 & - & Pass & 41.46 & - & Pass & 39.12 & - & A \\
\hline 1 & Spurt & $635 \mathrm{~cm} / \mathrm{s}$ & $2 \mathrm{ml}$ & Up & Pass & 21.94 & - & Pass & 74.79 & - & Pass & 82.14 & - & A \\
\hline $\begin{array}{l}2 \\
3\end{array}$ & $\begin{array}{l}\text { Spurt } \\
\text { Spurt }\end{array}$ & $\begin{array}{l}635 \mathrm{~cm} / \mathrm{s} \\
635 \mathrm{~cm} / \mathrm{s}\end{array}$ & $\begin{array}{l}2 \mathrm{ml} \\
2 \mathrm{ml}\end{array}$ & $\begin{array}{l}\text { Down } \\
\text { Right }\end{array}$ & $\begin{array}{l}\text { Fail } \\
\text { Pass }\end{array}$ & $\begin{array}{l}22.43 \\
20.62\end{array}$ & R Q1 & $\begin{array}{l}\text { Fail } \\
\text { Pass }\end{array}$ & $\begin{array}{l}\text { Ran Thru } \\
31.47\end{array}$ & Q3 & $\begin{array}{l}\text { Fail } \\
\text { Pass }\end{array}$ & $\begin{array}{c}\text { Ran Thru } \\
34.26\end{array}$ & Q2/Q3 & A \\
\hline 4 & Spurt & $635 \mathrm{~cm} / \mathrm{s}$ & $2 \mathrm{ml}$ & Left & Pass & 22.14 & - & Pass & 52.44 & - & Pass & 45.33 & - & A \\
\hline 1 & Spray & $500 \mathrm{~cm} / \mathrm{s}$ & $1 \mathrm{ml}$ & Up & Pass & 25.79 & - & Pass & 75.05 & - & Pass & 75.93 & - & A \\
\hline 2 & Spray & $500 \mathrm{~cm} / \mathrm{s}$ & $1 \mathrm{ml}$ & Down & Pass & 16.51 & - & Pass & 71.97 & - & Pass & 92.85 & - & A \\
\hline 3 & Spray & $500 \mathrm{~cm} / \mathrm{s}$ & $1 \mathrm{ml}$ & Right & Pass & 14.68 & - & Pass & 43.07 & - & Pass & 29.09 & - & A \\
\hline 4 & Spray & $500 \mathrm{~cm} / \mathrm{s}$ & $1 \mathrm{ml}$ & Left & Pass & 19.71 & - & Pass & 44.55 & - & Pass & 31.82 & - & A \\
\hline 1 & Spurt & $635 \mathrm{~cm} / \mathrm{s}$ & $2 \mathrm{ml}$ & Up & Pass & 23.76 & - & Pass & 3.56 & - & Pass & 338.68 & - & A \\
\hline 2 & Spurt & $635 \mathrm{~cm} / \mathrm{s}$ & $2 \mathrm{ml}$ & Down & Fail & 17.24 & L Q3 & Pass & 1.82 & - & Pass & 2.54 & - & A \\
\hline 3 & Spurt & $635 \mathrm{~cm} / \mathrm{s}$ & $2 \mathrm{ml}$ & Right & Pass & 19.33 & - & Pass & 47.34 & - & Pass & 51.98 & & A \\
\hline 4 & Spurt & $635 \mathrm{~cm} / \mathrm{s}$ & $2 \mathrm{ml}$ & Left & Pass & 18.04 & - & Pass & 56.91 & - & Pass & 52.42 & & A \\
\hline 1 & Spray & $500 \mathrm{~cm} / \mathrm{s}$ & $1 \mathrm{ml}$ & Up & Pass & 24.35 & - & Pass & 74.52 & - & Pass & 74.71 & - & A \\
\hline
\end{tabular}




\begin{tabular}{|c|c|c|c|c|c|c|c|c|c|c|c|c|c|c|}
\hline 2 & Spray & $500 \mathrm{~cm} / \mathrm{s}$ & $1 \mathrm{ml}$ & Down & Pass & 15.12 & - & Pass & 70.67 & - & Pass & 96.91 & - & A \\
\hline 3 & Spray & $500 \mathrm{~cm} / \mathrm{s}$ & $1 \mathrm{ml}$ & Right & Pass & 21.03 & - & Pass & 40.79 & - & Pass & 34.5 & - & A \\
\hline 4 & Spray & $500 \mathrm{~cm} / \mathrm{s}$ & $1 \mathrm{ml}$ & Left & Pass & 20.81 & - & Pass & 51.61 & - & Pass & 33.21 & - & A \\
\hline 1 & Spurt & $635 \mathrm{~cm} / \mathrm{s}$ & $2 \mathrm{ml}$ & Up & Pass & 23.19 & - & Pass & 75.45 & - & Pass & 77.36 & - & A \\
\hline 2 & Spurt & $635 \mathrm{~cm} / \mathrm{s}$ & $2 \mathrm{ml}$ & Down & Fail & 16.25 & R Q1 & Fail & Ran Thru & Q3 & Fail & Ran Thru & Q2/Q3 & A \\
\hline 3 & Spurt & $635 \mathrm{~cm} / \mathrm{s}$ & $2 \mathrm{ml}$ & Right & Pass & 8.86 & - & Pass & 34.93 & - & Pass & 53.02 & - & A \\
\hline 4 & Spurt & $635 \mathrm{~cm} / \mathrm{s}$ & $2 \mathrm{ml}$ & Left & Pass & 21.16 & - & Pass & 50.55 & - & Pass & 52.5 & - & A \\
\hline 1 & Spray & $500 \mathrm{~cm} / \mathrm{s}$ & $1 \mathrm{ml}$ & Up & Pass & 25.58 & - & Pass & 73.83 & - & Pass & 80.39 & - & A \\
\hline 2 & Spray & $500 \mathrm{~cm} / \mathrm{s}$ & $1 \mathrm{ml}$ & Down & Pass & 17.21 & - & Pass & 70.16 & - & Pass & 93.54 & - & A \\
\hline 3 & Spray & $500 \mathrm{~cm} / \mathrm{s}$ & $1 \mathrm{ml}$ & Right & Pass & 18.3 & - & Pass & 42.84 & - & Pass & 38.54 & - & A \\
\hline 4 & Spray & $500 \mathrm{~cm} / \mathrm{s}$ & $1 \mathrm{ml}$ & Left & Pass & 18.94 & - & Pass & 43.61 & - & Pass & 37.62 & - & A \\
\hline 1 & Spurt & $635 \mathrm{~cm} / \mathrm{s}$ & $2 \mathrm{ml}$ & Up & Pass & 23.39 & - & Pass & 76.25 & - & Pass & 88.6 & - & A \\
\hline 2 & Spurt & $635 \mathrm{~cm} / \mathrm{s}$ & $2 \mathrm{ml}$ & Down & Fail & 18.19 & R Q4 & Fail & Ran Thru & Q3 & Pass & 4.86 & - & A \\
\hline 3 & Spurt & $635 \mathrm{~cm} / \mathrm{s}$ & $2 \mathrm{ml}$ & Right & Pass & 18.9 & - & Pass & 49.4 & - & Pass & 51.97 & - & A \\
\hline 4 & Spurt & $635 \mathrm{~cm} / \mathrm{s}$ & $2 \mathrm{ml}$ & Left & Pass & 19.49 & - & Pass & 48.41 & - & Pass & 35.14 & - & A \\
\hline 1 & Spray & $500 \mathrm{~cm} / \mathrm{s}$ & $1 \mathrm{ml}$ & Up & Pass & 23.93 & - & Pass & 74.95 & - & Pass & 79.12 & - & A \\
\hline 2 & Spray & $500 \mathrm{~cm} / \mathrm{s}$ & $1 \mathrm{ml}$ & Down & Pass & 15.84 & - & Pass & 71.56 & - & Pass & 94.63 & - & A \\
\hline 3 & Spray & $500 \mathrm{~cm} / \mathrm{s}$ & $1 \mathrm{ml}$ & Right & Pass & 19.23 & - & Pass & 44.51 & - & Pass & 35.26 & - & A \\
\hline 4 & Spray & $500 \mathrm{~cm} / \mathrm{s}$ & $1 \mathrm{ml}$ & Left & Pass & 19.66 & - & Pass & 49.26 & - & Pass & 34.12 & - & A \\
\hline 1 & Spurt & $635 \mathrm{~cm} / \mathrm{s}$ & $2 \mathrm{ml}$ & Up & Pass & 19.82 & - & Pass & 6.99 & - & Pass & 32.54 & - & A \\
\hline 2 & Spurt & $635 \mathrm{~cm} / \mathrm{s}$ & $2 \mathrm{ml}$ & Down & Fail & 19.23 & L Q2 & Pass & 3.12 & - & Pass & 2.45 & - & A \\
\hline 3 & Spurt & $635 \mathrm{~cm} / \mathrm{s}$ & $2 \mathrm{ml}$ & Right & Pass & 21.32 & - & Pass & 55.25 & - & Pass & 44.62 & - & A \\
\hline 4 & Spurt & $635 \mathrm{~cm} / \mathrm{s}$ & $2 \mathrm{ml}$ & Left & Pass & 22.48 & - & Pass & 51.28 & - & Pass & 47.81 & - & A \\
\hline 1 & Spray & $500 \mathrm{~cm} / \mathrm{s}$ & $1 \mathrm{ml}$ & Up & Pass & 23.09 & - & Pass & 74.44 & - & Pass & 75.32 & - & A \\
\hline 2 & Spray & $500 \mathrm{~cm} / \mathrm{s}$ & $1 \mathrm{ml}$ & Down & Pass & 16.47 & - & Pass & 72.95 & - & Pass & 93.11 & - & A \\
\hline 3 & Spray & $500 \mathrm{~cm} / \mathrm{s}$ & $1 \mathrm{ml}$ & Right & Pass & 18.75 & - & Pass & 44.65 & - & Pass & 37.72 & - & A \\
\hline 4 & Spray & $500 \mathrm{~cm} / \mathrm{s}$ & $1 \mathrm{ml}$ & Left & Pass & 17.45 & - & Pass & 41.36 & - & Pass & 39.24 & - & A \\
\hline 1 & Spurt & $635 \mathrm{~cm} / \mathrm{s}$ & $2 \mathrm{ml}$ & Up & Pass & 1.85 & - & Pass & 58.38 & - & Pass & 76.92 & - & B \\
\hline 2 & Spurt & $635 \mathrm{~cm} / \mathrm{s}$ & $2 \mathrm{ml}$ & Down & Pass & 55.55 & - & Pass & 105.58 & - & Pass & 125.68 & - & B \\
\hline 3 & Spurt & $635 \mathrm{~cm} / \mathrm{s}$ & $2 \mathrm{ml}$ & Right & Pass & 68.72 & - & Pass & 73.78 & - & Pass & 61.23 & - & B \\
\hline 4 & Spurt & $635 \mathrm{~cm} / \mathrm{s}$ & $2 \mathrm{ml}$ & Left & Pass & 49.42 & - & Pass & 67.71 & - & Pass & 62.45 & - & B \\
\hline 1 & Spray & $500 \mathrm{~cm} / \mathrm{s}$ & $1 \mathrm{ml}$ & Up & Pass & 68.46 & - & Pass & 115.63 & - & Pass & 134.9 & - & B \\
\hline 2 & Spray & $500 \mathrm{~cm} / \mathrm{s}$ & $1 \mathrm{ml}$ & Down & Pass & 30.8 & - & Pass & 81.68 & - & Pass & 100.62 & - & B \\
\hline 3 & Spray & $500 \mathrm{~cm} / \mathrm{s}$ & $1 \mathrm{ml}$ & Right & Pass & 39.95 & - & Pass & 70.72 & - & Pass & 45.65 & - & B \\
\hline 4 & Spray & $500 \mathrm{~cm} / \mathrm{s}$ & $1 \mathrm{ml}$ & Left & Pass & 39.41 & - & Pass & 39.76 & - & Pass & 33 & - & B \\
\hline 1 & Spurt & $635 \mathrm{~cm} / \mathrm{s}$ & $2 \mathrm{ml}$ & Up & Fail & 0.75 & L Q1 & Pass & 37.64 & - & Pass & 57.14 & - & B \\
\hline 2 & Spurt & $635 \mathrm{~cm} / \mathrm{s}$ & $2 \mathrm{ml}$ & Down & Pass & - & - & Pass & NA & - & Pass & NA & - & B \\
\hline 3 & Spurt & $635 \mathrm{~cm} / \mathrm{s}$ & $2 \mathrm{ml}$ & Right & Pass & 54.47 & - & Pass & 67.47 & - & Pass & 53.96 & - & B \\
\hline 4 & Spurt & $635 \mathrm{~cm} / \mathrm{s}$ & $2 \mathrm{ml}$ & Left & Pass & 56.54 & - & Pass & 72.23 & - & Pass & 61.46 & - & B \\
\hline 1 & Spray & $500 \mathrm{~cm} / \mathrm{s}$ & $1 \mathrm{ml}$ & Up & Pass & 48.42 & - & Pass & 65.66 & - & Pass & 59.87 & - & B \\
\hline 2 & Spray & $500 \mathrm{~cm} / \mathrm{s}$ & $1 \mathrm{ml}$ & Down & Pass & 70.21 & - & Pass & 120.23 & - & Pass & 110.15 & - & B \\
\hline 3 & Spray & $500 \mathrm{~cm} / \mathrm{s}$ & $1 \mathrm{ml}$ & Right & Pass & 29.23 & - & Pass & 79.73 & - & Pass & 102.3 & - & B \\
\hline 4 & Spray & $500 \mathrm{~cm} / \mathrm{s}$ & $1 \mathrm{ml}$ & Left & Pass & 37.55 & - & Pass & 68.26 & - & Pass & 41.39 & - & B \\
\hline 1 & Spurt & $635 \mathrm{~cm} / \mathrm{s}$ & $2 \mathrm{ml}$ & Up & Fail & 8.49 & L Q1 & Pass & 45.68 & - & Pass & 70.37 & - & B \\
\hline 2 & Spurt & $635 \mathrm{~cm} / \mathrm{s}$ & $2 \mathrm{ml}$ & Down & Pass & - & - & Pass & NA & - & Pass & NA & - & B \\
\hline 3 & Spurt & $635 \mathrm{~cm} / \mathrm{s}$ & $2 \mathrm{ml}$ & Right & Pass & 49.92 & - & Pass & 63.95 & - & Pass & 51.2 & - & B \\
\hline 4 & Spurt & $635 \mathrm{~cm} / \mathrm{s}$ & $2 \mathrm{ml}$ & Left & Pass & 37.46 & - & Pass & 47.01 & - & Pass & 41.54 & - & B \\
\hline 1 & Spray & $500 \mathrm{~cm} / \mathrm{s}$ & $1 \mathrm{ml}$ & Up & Pass & 59.78 & - & Pass & 97.79 & - & Pass & 123.16 & - & B \\
\hline 2 & Spray & $500 \mathrm{~cm} / \mathrm{s}$ & $1 \mathrm{ml}$ & Down & Pass & 38.99 & - & Pass & 87.95 & - & Pass & 113.45 & - & B \\
\hline 3 & Spray & $500 \mathrm{~cm} / \mathrm{s}$ & $1 \mathrm{ml}$ & Right & Pass & 47.63 & - & Pass & 52.27 & - & Pass & 37.12 & - & B \\
\hline 4 & Spray & $500 \mathrm{~cm} / \mathrm{s}$ & $1 \mathrm{ml}$ & Left & Pass & 47.47 & - & Pass & 55.62 & - & Pass & 33.67 & - & B \\
\hline 1 & Spurt & $635 \mathrm{~cm} / \mathrm{s}$ & $2 \mathrm{ml}$ & Up & Fail & 2.67 & R Q2 & Pass & 18.26 & - & Pass & 44.38 & - & B \\
\hline 2 & Spurt & $635 \mathrm{~cm} / \mathrm{s}$ & $2 \mathrm{ml}$ & Down & Pass & - & - & Pass & NA & - & Pass & NA & - & B \\
\hline 3 & Spurt & $635 \mathrm{~cm} / \mathrm{s}$ & $2 \mathrm{ml}$ & Right & Pass & 69.83 & - & Pass & 87.4 & - & Pass & 73.9 & - & B \\
\hline
\end{tabular}




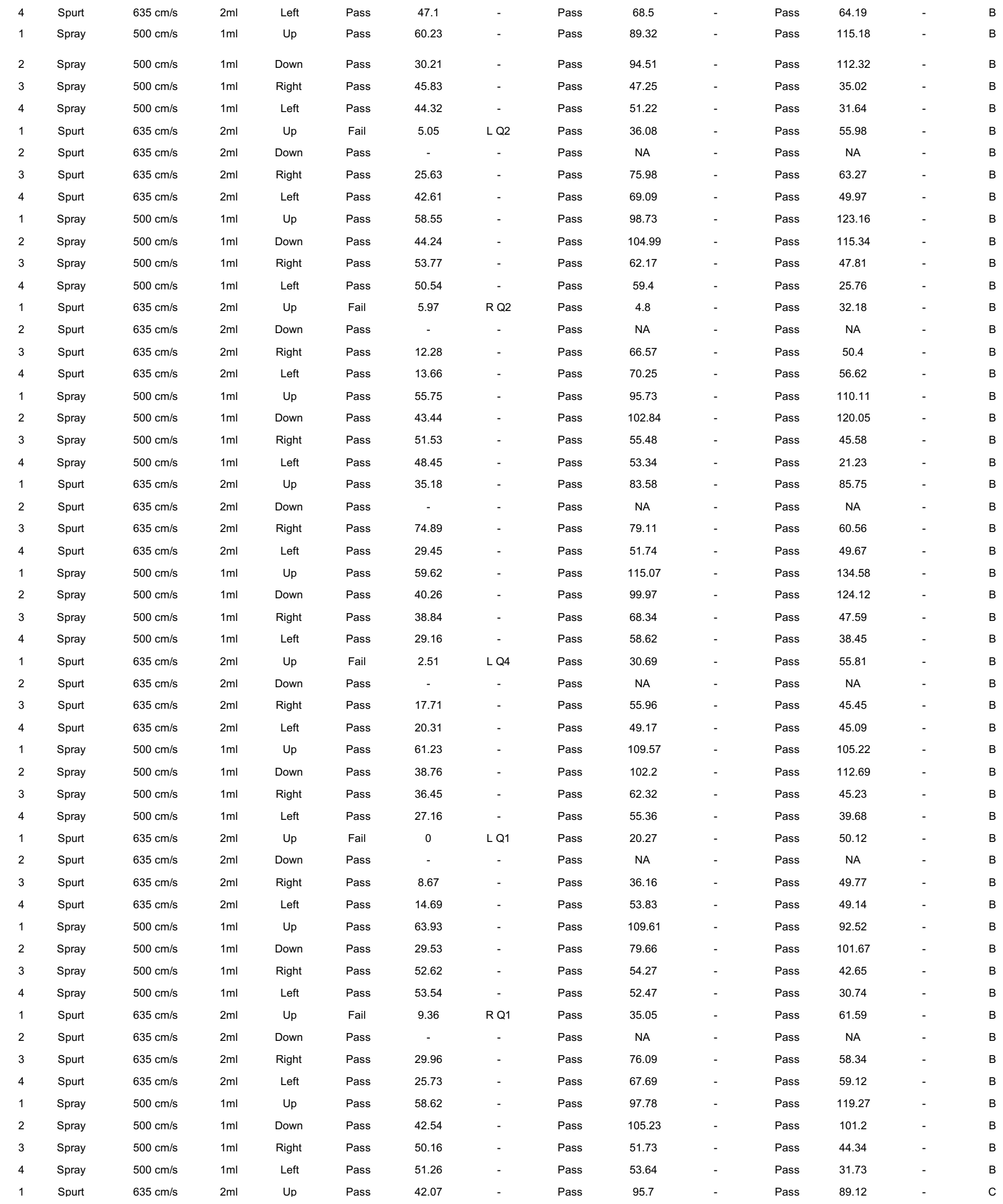




\begin{tabular}{|c|c|c|c|c|c|c|c|c|c|c|c|c|c|}
\hline 2 & Spurt & $635 \mathrm{~cm} / \mathrm{s}$ & $2 \mathrm{ml}$ & Down & Pass & 9.58 & - & Pass & 67.78 & - & Pass & 93.61 & - \\
\hline 3 & Spurt & $635 \mathrm{~cm} / \mathrm{s}$ & $2 \mathrm{ml}$ & Right & Pass & 51.13 & - & Pass & 64.38 & - & Pass & 77.87 & - \\
\hline 4 & Spurt & $635 \mathrm{~cm} / \mathrm{s}$ & $2 \mathrm{ml}$ & Left & Pass & 41.91 & - & Pass & 67.14 & - & Pass & 81.29 & - \\
\hline 1 & Spray & $500 \mathrm{~cm} / \mathrm{s}$ & $1 \mathrm{ml}$ & Up & Pass & 51.62 & - & Pass & 104.57 & - & Pass & 81.98 & - \\
\hline 2 & Spray & $500 \mathrm{~cm} / \mathrm{s}$ & $1 \mathrm{ml}$ & Down & Pass & 38.24 & - & Pass & 89.49 & - & Pass & 113.94 & - \\
\hline 3 & Spray & $500 \mathrm{~cm} / \mathrm{s}$ & $1 \mathrm{ml}$ & Right & Pass & 45.49 & - & Pass & 81.28 & - & Pass & 82.68 & - \\
\hline 4 & Spray & $500 \mathrm{~cm} / \mathrm{s}$ & $1 \mathrm{ml}$ & Left & Pass & 43.94 & - & Pass & 74.16 & - & Pass & 78.07 & - \\
\hline 1 & Spurt & $635 \mathrm{~cm} / \mathrm{s}$ & $2 \mathrm{ml}$ & Up & Pass & 39.25 & - & Pass & 91.25 & - & Pass & 87.01 & - \\
\hline 2 & Spurt & $635 \mathrm{~cm} / \mathrm{s}$ & $2 \mathrm{ml}$ & Down & Pass & 34.57 & - & Pass & 79.27 & - & Pass & 102.31 & - \\
\hline 3 & Spurt & $635 \mathrm{~cm} / \mathrm{s}$ & $2 \mathrm{ml}$ & Right & Pass & 53.19 & - & Pass & 67.68 & - & Pass & 51.04 & - \\
\hline 4 & Spurt & $635 \mathrm{~cm} / \mathrm{s}$ & $2 \mathrm{ml}$ & Left & Pass & 47.02 & - & Pass & 59.05 & - & Pass & 56.22 & - \\
\hline 1 & Spray & $500 \mathrm{~cm} / \mathrm{s}$ & $1 \mathrm{ml}$ & Up & Pass & 59.35 & - & Pass & 103.79 & - & Pass & 85.18 & - \\
\hline 2 & Spray & $500 \mathrm{~cm} / \mathrm{s}$ & $1 \mathrm{ml}$ & Down & Pass & 35.17 & - & Pass & 82.93 & - & Pass & 110.7 & - \\
\hline 3 & Spray & $500 \mathrm{~cm} / \mathrm{s}$ & $1 \mathrm{ml}$ & Right & Pass & 35.2 & - & Pass & 78.17 & - & Pass & 72.09 & - \\
\hline 4 & Spray & $500 \mathrm{~cm} / \mathrm{s}$ & $1 \mathrm{ml}$ & Left & Pass & 37.15 & - & Pass & 74.76 & & Pass & 69.13 & - \\
\hline 1 & Spurt & $635 \mathrm{~cm} / \mathrm{s}$ & $2 \mathrm{ml}$ & Up & Pass & 35.79 & - & Pass & 87.04 & - & Pass & 90.7 & - \\
\hline 2 & Spurt & $635 \mathrm{~cm} / \mathrm{s}$ & $2 \mathrm{ml}$ & Down & Pass & 40.21 & - & Pass & 88.31 & - & Pass & 109.42 & - \\
\hline 3 & Spurt & $635 \mathrm{~cm} / \mathrm{s}$ & $2 \mathrm{ml}$ & Right & Pass & 52.13 & - & Pass & 66.45 & - & Pass & 58.91 & - \\
\hline 4 & Spurt & $635 \mathrm{~cm} / \mathrm{s}$ & $2 \mathrm{ml}$ & Left & Pass & 45.86 & - & Pass & 58.12 & - & Pass & 57.42 & - \\
\hline 1 & Spray & $500 \mathrm{~cm} / \mathrm{s}$ & $1 \mathrm{ml}$ & Up & Pass & 44.02 & - & Pass & 93.27 & - & Pass & 81.51 & - \\
\hline 2 & Spray & $500 \mathrm{~cm} / \mathrm{s}$ & $1 \mathrm{ml}$ & Down & Pass & 34.57 & - & Pass & 84.85 & - & Pass & 111.31 & - \\
\hline 3 & Spray & $500 \mathrm{~cm} / \mathrm{s}$ & $1 \mathrm{ml}$ & Right & Pass & 42.45 & - & Pass & 60.36 & - & Pass & 62.65 & - \\
\hline 4 & Spray & $500 \mathrm{~cm} / \mathrm{s}$ & $1 \mathrm{ml}$ & Left & Pass & 39.09 & - & Pass & 67.69 & - & Pass & 56.5 & - \\
\hline 1 & Spurt & $635 \mathrm{~cm} / \mathrm{s}$ & $2 \mathrm{ml}$ & Up & Pass & 39.81 & - & Pass & 85.12 & - & Pass & 89.53 & - \\
\hline 2 & Spurt & $635 \mathrm{~cm} / \mathrm{s}$ & $2 \mathrm{ml}$ & Down & Pass & 30.82 & - & Pass & 79.5 & - & Pass & 103.63 & - \\
\hline 3 & Spurt & $635 \mathrm{~cm} / \mathrm{s}$ & $2 \mathrm{ml}$ & Right & Pass & 53.14 & - & Pass & 78.27 & - & Pass & 70.57 & - \\
\hline 4 & Spurt & $635 \mathrm{~cm} / \mathrm{s}$ & $2 \mathrm{ml}$ & Left & Pass & 55.92 & - & Pass & 75.13 & - & Pass & 73.69 & - \\
\hline 1 & Spray & $500 \mathrm{~cm} / \mathrm{s}$ & $1 \mathrm{ml}$ & Up & Pass & 46.05 & - & Pass & 99.24 & - & Pass & 72.65 & - \\
\hline 2 & Spray & $500 \mathrm{~cm} / \mathrm{s}$ & $1 \mathrm{ml}$ & Down & Pass & 31.93 & - & Pass & 87.75 & - & Pass & 109.27 & - \\
\hline 3 & Spray & $500 \mathrm{~cm} / \mathrm{s}$ & $1 \mathrm{ml}$ & Right & Pass & 42.85 & - & Pass & 81.06 & - & Pass & 61.68 & - \\
\hline 4 & Spray & $500 \mathrm{~cm} / \mathrm{s}$ & $1 \mathrm{ml}$ & Left & Pass & 40.93 & - & Pass & 80.27 & - & Pass & 58.36 & - \\
\hline 1 & Spurt & $635 \mathrm{~cm} / \mathrm{s}$ & $2 \mathrm{ml}$ & Up & Pass & 38.14 & - & Pass & 88.56 & - & Pass & 88.78 & - \\
\hline 2 & Spurt & $635 \mathrm{~cm} / \mathrm{s}$ & $2 \mathrm{ml}$ & Down & Pass & 31.26 & - & Pass & 80.54 & - & Pass & 105.46 & - \\
\hline 3 & Spurt & $635 \mathrm{~cm} / \mathrm{s}$ & $2 \mathrm{ml}$ & Right & Pass & 56.81 & - & Pass & 77.43 & - & Pass & 72.56 & - \\
\hline 4 & Spurt & $635 \mathrm{~cm} / \mathrm{s}$ & $2 \mathrm{ml}$ & Left & Pass & 54.62 & - & Pass & 81.23 & - & Pass & 70.45 & - \\
\hline 1 & Spray & $500 \mathrm{~cm} / \mathrm{s}$ & $1 \mathrm{ml}$ & Up & Pass & 56.78 & - & Pass & 103.92 & - & Pass & 80.06 & - \\
\hline 2 & Spray & $500 \mathrm{~cm} / \mathrm{s}$ & $1 \mathrm{ml}$ & Down & Pass & 35.04 & - & Pass & 87.38 & - & Pass & 111.25 & - \\
\hline 3 & Spray & $500 \mathrm{~cm} / \mathrm{s}$ & $1 \mathrm{ml}$ & Right & Pass & 35.83 & - & Pass & 74.43 & - & Pass & 70.49 & - \\
\hline 4 & Spray & $500 \mathrm{~cm} / \mathrm{s}$ & $1 \mathrm{ml}$ & Left & Pass & 36.02 & - & Pass & 81.52 & - & Pass & 73.01 & - \\
\hline 1 & Spurt & $635 \mathrm{~cm} / \mathrm{s}$ & $2 \mathrm{ml}$ & Up & Pass & 31.89 & - & Pass & 84.12 & - & Pass & 81.26 & - \\
\hline 2 & Spurt & $635 \mathrm{~cm} / \mathrm{s}$ & $2 \mathrm{ml}$ & Down & Pass & 29.89 & - & Pass & 78.92 & - & Pass & 101.61 & - \\
\hline 3 & Spurt & $635 \mathrm{~cm} / \mathrm{s}$ & $2 \mathrm{ml}$ & Right & Pass & 51.12 & - & Pass & 70.14 & - & Pass & 68.42 & - \\
\hline 4 & Spurt & $635 \mathrm{~cm} / \mathrm{s}$ & $2 \mathrm{ml}$ & Left & Pass & 55.69 & - & Pass & 73.26 & - & Pass & 69.87 & - \\
\hline 1 & Spray & $500 \mathrm{~cm} / \mathrm{s}$ & $1 \mathrm{ml}$ & Up & Pass & 52.96 & - & Pass & 101.8 & - & Pass & 77.68 & - \\
\hline 2 & Spray & $500 \mathrm{~cm} / \mathrm{s}$ & $1 \mathrm{ml}$ & Down & Pass & 33.16 & - & Pass & 85.62 & - & Pass & 112.43 & - \\
\hline 3 & Spray & $500 \mathrm{~cm} / \mathrm{s}$ & $1 \mathrm{ml}$ & Right & Pass & 43.45 & - & Pass & 31.36 & - & Pass & 62.34 & - \\
\hline 4 & Spray & $500 \mathrm{~cm} / \mathrm{s}$ & $1 \mathrm{ml}$ & Left & Pass & 38.11 & - & Pass & 67.26 & - & Pass & 56.25 & - \\
\hline 1 & Spurt & $635 \mathrm{~cm} / \mathrm{s}$ & $2 \mathrm{ml}$ & Up & Pass & 37.51 & - & Pass & 85.49 & - & Pass & 85.83 & - \\
\hline 2 & Spurt & $635 \mathrm{~cm} / \mathrm{s}$ & $2 \mathrm{ml}$ & Down & Pass & 42.81 & - & Pass & 91.25 & - & Pass & 113.44 & - \\
\hline 3 & Spurt & $635 \mathrm{~cm} / \mathrm{s}$ & $2 \mathrm{ml}$ & Right & Pass & 50.58 & - & Pass & 75.54 & - & Pass & 65.04 & - \\
\hline 4 & Spurt & $635 \mathrm{~cm} / \mathrm{s}$ & $2 \mathrm{ml}$ & Left & Pass & 48.26 & - & Pass & 80.81 & - & Pass & 69.35 & - \\
\hline 1 & Spray & $500 \mathrm{~cm} / \mathrm{s}$ & $1 \mathrm{ml}$ & Up & Pass & 53.84 & - & Pass & 102.31 & - & Pass & 79.15 & - \\
\hline 2 & Spray & $500 \mathrm{~cm} / \mathrm{s}$ & $1 \mathrm{ml}$ & Down & Pass & 34.65 & - & Pass & 84.16 & - & Pass & 110.38 & - \\
\hline 3 & Spray & $500 \mathrm{~cm} / \mathrm{s}$ & $1 \mathrm{ml}$ & Right & Pass & 43.45 & - & Pass & 61.63 & - & Pass & 63.24 & - \\
\hline
\end{tabular}




\begin{tabular}{|c|c|c|c|c|c|c|c|c|c|c|c|c|c|}
\hline 4 & Spray & $500 \mathrm{~cm} / \mathrm{s}$ & $1 \mathrm{ml}$ & Left & Pass & 38.98 & - & Pass & 68.69 & - & Pass & 55.12 & - \\
\hline 1 & Spurt & $635 \mathrm{~cm} / \mathrm{s}$ & $2 \mathrm{ml}$ & Up & Pass & 35.13 & - & Pass & 86.21 & - & Pass & 84.19 & - \\
\hline 2 & Spurt & $635 \mathrm{~cm} / \mathrm{s}$ & $2 \mathrm{ml}$ & Down & Pass & 40.23 & - & Pass & 85.12 & - & Pass & 110.26 & - \\
\hline 3 & Spurt & $635 \mathrm{~cm} / \mathrm{s}$ & $2 \mathrm{ml}$ & Right & Pass & 52.32 & - & Pass & 76.01 & - & Pass & 68.92 & - \\
\hline 4 & Spurt & $635 \mathrm{~cm} / \mathrm{s}$ & $2 \mathrm{ml}$ & Left & Pass & 51.69 & - & Pass & 75.48 & - & Pass & 66.13 & - \\
\hline 1 & Spray & $500 \mathrm{~cm} / \mathrm{s}$ & $1 \mathrm{ml}$ & Up & Pass & 48.62 & - & Pass & 105.78 & - & Pass & 83.47 & - \\
\hline 2 & Spray & $500 \mathrm{~cm} / \mathrm{s}$ & $1 \mathrm{ml}$ & Down & Pass & 36.33 & - & Pass & 87.19 & - & Pass & 113.41 & - \\
\hline 3 & Spray & $500 \mathrm{~cm} / \mathrm{s}$ & $1 \mathrm{ml}$ & Right & Pass & 43.58 & - & Pass & 80.06 & - & Pass & 62.86 & - \\
\hline 4 & Spray & $500 \mathrm{~cm} / \mathrm{s}$ & $1 \mathrm{ml}$ & Left & Pass & 41.91 & - & Pass & 79.89 & - & Pass & 59.36 & - \\
\hline 1 & Spurt & $635 \mathrm{~cm} / \mathrm{s}$ & $2 \mathrm{ml}$ & Up & Pass & 36.98 & - & Pass & 84.56 & - & Pass & 88.23 & - \\
\hline 2 & Spurt & $635 \mathrm{~cm} / \mathrm{s}$ & $2 \mathrm{ml}$ & Down & Pass & 39.72 & - & Pass & 84.95 & - & Pass & 102.68 & - \\
\hline 3 & Spurt & $635 \mathrm{~cm} / \mathrm{s}$ & $2 \mathrm{ml}$ & Right & Pass & 56 & - & Pass & 80.63 & - & Pass & 65.38 & - \\
\hline 4 & Spurt & $635 \mathrm{~cm} / \mathrm{s}$ & $2 \mathrm{ml}$ & Left & Pass & 54.99 & - & Pass & 76.32 & - & Pass & 62.91 & - \\
\hline 1 & Spray & $500 \mathrm{~cm} / \mathrm{s}$ & $1 \mathrm{ml}$ & Up & Pass & 51.48 & - & Pass & 101.69 & - & Pass & 77.14 & - \\
\hline 2 & Spray & $500 \mathrm{~cm} / \mathrm{s}$ & $1 \mathrm{ml}$ & Down & Pass & 32.15 & - & Pass & 83.46 & - & Pass & 110.9 & - \\
\hline 3 & Spray & $500 \mathrm{~cm} / \mathrm{s}$ & $1 \mathrm{ml}$ & Right & Pass & 35.83 & - & Pass & 75.34 & - & Pass & 70.33 & - \\
\hline 4 & Spray & $500 \mathrm{~cm} / \mathrm{s}$ & $1 \mathrm{ml}$ & Left & Pass & 36.28 & - & Pass & 82.51 & - & Pass & 72.94 & - \\
\hline 1 & Spurt & $635 \mathrm{~cm} / \mathrm{s}$ & $2 \mathrm{ml}$ & Up & Pass & 38.41 & - & Pass & 81.2 & - & Pass & 90.21 & - \\
\hline 2 & Spurt & $635 \mathrm{~cm} / \mathrm{s}$ & $2 \mathrm{ml}$ & Down & Pass & 41.2 & - & Pass & 82.56 & - & Pass & 105.36 & - \\
\hline 3 & Spurt & $635 \mathrm{~cm} / \mathrm{s}$ & $2 \mathrm{ml}$ & Right & Pass & 58.69 & - & Pass & 83.11 & - & Pass & 69.51 & - \\
\hline 4 & Spurt & $635 \mathrm{~cm} / \mathrm{s}$ & $2 \mathrm{ml}$ & Left & Pass & 55.62 & - & Pass & 84.22 & - & Pass & 71.21 & - \\
\hline 1 & Spray & $500 \mathrm{~cm} / \mathrm{s}$ & $1 \mathrm{ml}$ & Up & Pass & 48.12 & - & Pass & 106.23 & - & Pass & 76.35 & - \\
\hline 2 & Spray & $500 \mathrm{~cm} / \mathrm{s}$ & $1 \mathrm{ml}$ & Down & Pass & 33.41 & - & Pass & 86.53 & - & Pass & 112.57 & - \\
\hline 3 & Spray & $500 \mathrm{~cm} / \mathrm{s}$ & $1 \mathrm{ml}$ & Right & Pass & 60.26 & - & Pass & 71.75 & - & Pass & 62.11 & - \\
\hline 4 & Spray & $500 \mathrm{~cm} / \mathrm{s}$ & $1 \mathrm{ml}$ & Left & Pass & 55.75 & - & Pass & 67.82 & - & Pass & 65.89 & - \\
\hline 1 & Spurt & $635 \mathrm{~cm} / \mathrm{s}$ & $2 \mathrm{ml}$ & Up & Pass & 3.68 & - & Pass & 20.2 & - & Pass & 40.35 & - \\
\hline 2 & Spurt & $635 \mathrm{~cm} / \mathrm{s}$ & $2 \mathrm{ml}$ & Down & Fail & 11.6 & L Q3 & Fail & Ran Thru & Q2/Q3 & Fail & Ran Thru & Q2/Q3/Q4 \\
\hline 3 & Spurt & $635 \mathrm{~cm} / \mathrm{s}$ & $2 \mathrm{ml}$ & Right & Pass & 20.62 & - & Pass & 31.47 & - & Pass & 34.26 & - \\
\hline 4 & Spurt & $635 \mathrm{~cm} / \mathrm{s}$ & $2 \mathrm{ml}$ & Left & Pass & 22.14 & - & Pass & 62.44 & - & Pass & 50.3 & - \\
\hline 1 & Spray & $500 \mathrm{~cm} / \mathrm{s}$ & $1 \mathrm{ml}$ & Up & Fail & 3.96 & R Q1 & Pass & 37.69 & - & Pass & 48.63 & - \\
\hline 2 & Spray & $500 \mathrm{~cm} / \mathrm{s}$ & $1 \mathrm{ml}$ & Down & Pass & 1.44 & - & Pass & 40.62 & - & Pass & 61.4 & - \\
\hline 3 & Spray & $500 \mathrm{~cm} / \mathrm{s}$ & $1 \mathrm{ml}$ & Right & Pass & 13.43 & - & Pass & 33.11 & - & Pass & 26.06 & - \\
\hline 4 & Spray & $500 \mathrm{~cm} / \mathrm{s}$ & $1 \mathrm{ml}$ & Left & Pass & 15.25 & - & Pass & 36.05 & - & Pass & 34.18 & - \\
\hline 1 & Spurt & $635 \mathrm{~cm} / \mathrm{s}$ & $2 \mathrm{ml}$ & Up & Pass & 6.61 & - & Pass & 46.61 & - & Pass & 66.13 & - \\
\hline 2 & Spurt & $635 \mathrm{~cm} / \mathrm{s}$ & $2 \mathrm{ml}$ & Down & Fail & 17.84 & R Q4 & Pass & 2.05 & - & Pass & 2.1 & - \\
\hline 3 & Spurt & $635 \mathrm{~cm} / \mathrm{s}$ & $2 \mathrm{ml}$ & Right & Pass & 22.13 & - & Pass & 40.18 & - & Pass & 48.21 & - \\
\hline 4 & Spurt & $635 \mathrm{~cm} / \mathrm{s}$ & $2 \mathrm{ml}$ & Left & Pass & 20.7 & - & Pass & 54.6 & - & Pass & 43.04 & - \\
\hline 1 & Spray & $500 \mathrm{~cm} / \mathrm{s}$ & $1 \mathrm{ml}$ & Up & Fail & 9.11 & L Q4 & Pass & 28.92 & - & Pass & 44.82 & - \\
\hline 2 & Spray & $500 \mathrm{~cm} / \mathrm{s}$ & $1 \mathrm{ml}$ & Down & Pass & 19.7 & - & Pass & 75.15 & - & Pass & 97.43 & - \\
\hline 3 & Spray & $500 \mathrm{~cm} / \mathrm{s}$ & $1 \mathrm{ml}$ & Right & Pass & 12.65 & - & Pass & 38.29 & - & Pass & 34.06 & - \\
\hline 4 & Spray & $500 \mathrm{~cm} / \mathrm{s}$ & $1 \mathrm{ml}$ & Left & Pass & 8.82 & - & Pass & 34.21 & - & Pass & 33.07 & - \\
\hline 1 & Spurt & $635 \mathrm{~cm} / \mathrm{s}$ & $2 \mathrm{ml}$ & Up & Pass & 7.16 & - & Pass & 46.59 & - & Pass & 62.12 & - \\
\hline 2 & Spurt & $635 \mathrm{~cm} / \mathrm{s}$ & $2 \mathrm{ml}$ & Down & Fail & 19.19 & R Q4 & Pass & 29.34 & - & Pass & 52.36 & - \\
\hline 3 & Spurt & $635 \mathrm{~cm} / \mathrm{s}$ & $2 \mathrm{ml}$ & Right & Pass & 19.33 & - & Pass & 47.34 & - & Pass & 51.98 & - \\
\hline 4 & Spurt & $635 \mathrm{~cm} / \mathrm{s}$ & $2 \mathrm{ml}$ & Left & Pass & 18.04 & - & Pass & 56.91 & - & Pass & 52.42 & - \\
\hline 1 & Spray & $500 \mathrm{~cm} / \mathrm{s}$ & $1 \mathrm{ml}$ & Up & Fail & 1.45 & R Q1 & Pass & 32.22 & - & Pass & 43.01 & - \\
\hline 2 & Spray & $500 \mathrm{~cm} / \mathrm{s}$ & $1 \mathrm{ml}$ & Down & Pass & 1.36 & - & Pass & 25.81 & - & Pass & 49.92 & - \\
\hline 3 & Spray & $500 \mathrm{~cm} / \mathrm{s}$ & $1 \mathrm{ml}$ & Right & Pass & 5.61 & - & Pass & 34.51 & - & Pass & 31.28 & - \\
\hline 4 & Spray & $500 \mathrm{~cm} / \mathrm{s}$ & $1 \mathrm{ml}$ & Left & Pass & 10.38 & - & Pass & 32.84 & - & Pass & 32.97 & - \\
\hline 1 & Spurt & $635 \mathrm{~cm} / \mathrm{s}$ & $2 \mathrm{ml}$ & Up & Pass & 1.59 & - & Pass & 45.03 & - & Pass & 65.79 & - \\
\hline 2 & Spurt & $635 \mathrm{~cm} / \mathrm{s}$ & $2 \mathrm{ml}$ & Down & Fail & 18.6 & R Q4 & Pass & 24.21 & - & Pass & 47.55 & - \\
\hline 3 & Spurt & $635 \mathrm{~cm} / \mathrm{s}$ & $2 \mathrm{ml}$ & Right & Pass & 20.52 & - & Pass & 50.07 & - & Pass & 49.41 & - \\
\hline 4 & Spurt & $635 \mathrm{~cm} / \mathrm{s}$ & $2 \mathrm{ml}$ & Left & Pass & 22.39 & - & Pass & 51.09 & - & Pass & 57.01 & - \\
\hline 1 & Spray & $500 \mathrm{~cm} / \mathrm{s}$ & $1 \mathrm{ml}$ & Up & Fail & 7.25 & L Q4 & Pass & 38.71 & - & Pass & 52.98 & - \\
\hline
\end{tabular}




\begin{tabular}{|c|c|c|c|c|c|c|c|c|c|c|c|c|c|c|}
\hline 2 & Spray & $500 \mathrm{~cm} / \mathrm{s}$ & $1 \mathrm{ml}$ & Down & Pass & 12.58 & - & Pass & 61.61 & - & Pass & 85.46 & - & D \\
\hline 3 & Spray & $500 \mathrm{~cm} / \mathrm{s}$ & $1 \mathrm{ml}$ & Right & Pass & 11.11 & - & Pass & 36.79 & - & Pass & 33.06 & - & D \\
\hline 4 & Spray & $500 \mathrm{~cm} / \mathrm{s}$ & $1 \mathrm{ml}$ & Left & Pass & 14.1 & - & Pass & 36.02 & - & Pass & 32.32 & - & D \\
\hline 1 & Spurt & $635 \mathrm{~cm} / \mathrm{s}$ & $2 \mathrm{ml}$ & Up & Pass & 2.96 & - & Pass & 45.7 & - & Pass & 68.31 & - & D \\
\hline 2 & Spurt & $635 \mathrm{~cm} / \mathrm{s}$ & $2 \mathrm{ml}$ & Down & Fail & 11.63 & L Q3 & Pass & 38.27 & - & Pass & 53.54 & - & D \\
\hline 3 & Spurt & $635 \mathrm{~cm} / \mathrm{s}$ & $2 \mathrm{ml}$ & Right & Pass & 8.86 & - & Pass & 34.93 & - & Pass & 53.02 & - & $\mathrm{D}$ \\
\hline 4 & Spurt & $635 \mathrm{~cm} / \mathrm{s}$ & $2 \mathrm{ml}$ & Left & Pass & 21.16 & - & Pass & 50.55 & - & Pass & 52.5 & - & D \\
\hline 1 & Spray & $500 \mathrm{~cm} / \mathrm{s}$ & $1 \mathrm{ml}$ & Up & Fail & 10.06 & R Q3 & Pass & 25.9 & - & Pass & 50.53 & - & D \\
\hline 2 & Spray & $500 \mathrm{~cm} / \mathrm{s}$ & $1 \mathrm{ml}$ & Down & Pass & 29.55 & - & Pass & 74.81 & - & Pass & 96.87 & - & $\mathrm{D}$ \\
\hline 3 & Spray & $500 \mathrm{~cm} / \mathrm{s}$ & $1 \mathrm{ml}$ & Right & Pass & 9.33 & - & Pass & 36.29 & - & Pass & 37.07 & - & D \\
\hline 4 & Spray & $500 \mathrm{~cm} / \mathrm{s}$ & $1 \mathrm{ml}$ & Left & Pass & 15.65 & - & Pass & 37.64 & - & Pass & 35.06 & - & D \\
\hline 1 & Spurt & $635 \mathrm{~cm} / \mathrm{s}$ & $2 \mathrm{ml}$ & Up & Fail & 14.16 & R Q1 & Pass & 44.95 & - & Pass & 65.94 & - & D \\
\hline 2 & Spurt & $635 \mathrm{~cm} / \mathrm{s}$ & $2 \mathrm{ml}$ & Down & Fail & 23.29 & R Q1 & Pass & 47.29 & - & Pass & 67.1 & - & D \\
\hline 3 & Spurt & $635 \mathrm{~cm} / \mathrm{s}$ & $2 \mathrm{ml}$ & Right & Pass & 27.34 & - & Pass & 45.11 & - & Pass & 55.2 & - & D \\
\hline 4 & Spurt & $635 \mathrm{~cm} / \mathrm{s}$ & $2 \mathrm{ml}$ & Left & Pass & 22.49 & - & Pass & 55.84 & - & Pass & 62.62 & - & $\mathrm{D}$ \\
\hline 1 & Spray & $500 \mathrm{~cm} / \mathrm{s}$ & $1 \mathrm{ml}$ & Up & Fail & 6.67 & L Q4 & Pass & 33.06 & - & Pass & 48.02 & - & D \\
\hline 2 & Spray & $500 \mathrm{~cm} / \mathrm{s}$ & $1 \mathrm{ml}$ & Down & Pass & 25.76 & - & Pass & 75.49 & - & Pass & 94.97 & - & D \\
\hline 3 & Spray & $500 \mathrm{~cm} / \mathrm{s}$ & $1 \mathrm{ml}$ & Right & Pass & 13.21 & - & Pass & 34.71 & - & Pass & 31.63 & - & D \\
\hline 4 & Spray & $500 \mathrm{~cm} / \mathrm{s}$ & $1 \mathrm{ml}$ & Left & Pass & 12.77 & - & Pass & 36.31 & - & Pass & 32.85 & - & D \\
\hline 1 & Spurt & $635 \mathrm{~cm} / \mathrm{s}$ & $2 \mathrm{ml}$ & Up & Pass & 5.62 & - & Pass & 43.03 & - & Pass & 71.44 & - & D \\
\hline 2 & Spurt & $635 \mathrm{~cm} / \mathrm{s}$ & $2 \mathrm{ml}$ & Down & Fail & 16.77 & R Q1 & Pass & 2.95 & - & Pass & 26.82 & - & D \\
\hline 3 & Spurt & $635 \mathrm{~cm} / \mathrm{s}$ & $2 \mathrm{ml}$ & Right & Pass & 25.21 & - & Pass & 45.86 & - & Pass & 31.85 & - & D \\
\hline 4 & Spurt & $635 \mathrm{~cm} / \mathrm{s}$ & $2 \mathrm{ml}$ & Left & Pass & 19.19 & - & Pass & 44.92 & - & Pass & 35.4 & - & D \\
\hline 1 & Spray & $500 \mathrm{~cm} / \mathrm{s}$ & $1 \mathrm{ml}$ & Up & Fail & 21.21 & L Q1 & Pass & 39.31 & - & Pass & 50.19 & - & $\mathrm{D}$ \\
\hline 2 & Spray & $500 \mathrm{~cm} / \mathrm{s}$ & $1 \mathrm{ml}$ & Down & Pass & 29.01 & - & Pass & 76.93 & - & Pass & 101.91 & - & D \\
\hline 3 & Spray & $500 \mathrm{~cm} / \mathrm{s}$ & $1 \mathrm{ml}$ & Right & Pass & 14.82 & - & Pass & 40.26 & - & Pass & 30.41 & - & D \\
\hline 4 & Spray & $500 \mathrm{~cm} / \mathrm{s}$ & $1 \mathrm{ml}$ & Left & Pass & 16.79 & - & Pass & 41.22 & - & Pass & 34.74 & - & $\mathrm{D}$ \\
\hline 1 & Spurt & $635 \mathrm{~cm} / \mathrm{s}$ & $2 \mathrm{ml}$ & Up & Fail & 21.45 & R Q1 & Pass & 2.91 & - & Pass & 29.22 & - & D \\
\hline 2 & Spurt & $635 \mathrm{~cm} / \mathrm{s}$ & $2 \mathrm{ml}$ & Down & Fail & 17.22 & R Q4 & Pass & 38.33 & - & Pass & 59.73 & - & $\mathrm{D}$ \\
\hline 3 & Spurt & $635 \mathrm{~cm} / \mathrm{s}$ & $2 \mathrm{ml}$ & Right & Pass & 18.21 & - & Pass & 53.04 & - & Pass & 56.84 & - & D \\
\hline 4 & Spurt & $635 \mathrm{~cm} / \mathrm{s}$ & $2 \mathrm{ml}$ & Left & Pass & 14.2 & - & Pass & 54.09 & - & Pass & 42.51 & - & D \\
\hline 1 & Spray & $500 \mathrm{~cm} / \mathrm{s}$ & $1 \mathrm{ml}$ & Up & Fail & 11.99 & L Q1 & Pass & 53.55 & - & Pass & 43.01 & - & D \\
\hline 2 & Spray & $500 \mathrm{~cm} / \mathrm{s}$ & $1 \mathrm{ml}$ & Down & Pass & 30.91 & - & Pass & 76.93 & - & Pass & 98.54 & - & D \\
\hline 3 & Spray & $500 \mathrm{~cm} / \mathrm{s}$ & $1 \mathrm{ml}$ & Right & Pass & 12.32 & - & Pass & 41.61 & - & Pass & 38.57 & - & D \\
\hline 4 & Spray & $500 \mathrm{~cm} / \mathrm{s}$ & $1 \mathrm{ml}$ & Left & Pass & 10.29 & - & Pass & 32.9 & - & Pass & 30.21 & - & D \\
\hline 1 & Spurt & $635 \mathrm{~cm} / \mathrm{s}$ & $2 \mathrm{ml}$ & Up & Pass & 2.38 & - & Pass & 46.34 & - & Pass & 67.27 & - & D \\
\hline 2 & Spurt & $635 \mathrm{~cm} / \mathrm{s}$ & $2 \mathrm{ml}$ & Down & Fail & 13.05 & 13.05 & Pass & 13.82 & - & Pass & 34.57 & - & $\mathrm{D}$ \\
\hline 3 & Spurt & $635 \mathrm{~cm} / \mathrm{s}$ & $2 \mathrm{ml}$ & Right & Pass & 14.35 & - & Pass & 54.8 & - & Pass & 40.17 & - & D \\
\hline 4 & Spurt & $635 \mathrm{~cm} / \mathrm{s}$ & $2 \mathrm{ml}$ & Left & Pass & 22.47 & - & Pass & 60.66 & - & Pass & 47.84 & - & D \\
\hline 1 & Spray & $500 \mathrm{~cm} / \mathrm{s}$ & $1 \mathrm{ml}$ & Up & Fail & 16.06 & L Q4 & Pass & 34.64 & - & Pass & 48.02 & - & D \\
\hline 2 & Spray & $500 \mathrm{~cm} / \mathrm{s}$ & $1 \mathrm{ml}$ & Down & Pass & 27.31 & - & Pass & 77.88 & - & Pass & 97.48 & - & $\mathrm{D}$ \\
\hline 3 & Spray & $500 \mathrm{~cm} / \mathrm{s}$ & $1 \mathrm{ml}$ & Right & Pass & 17.39 & - & Pass & 35.11 & - & Pass & 33.64 & - & D \\
\hline 4 & Spray & $500 \mathrm{~cm} / \mathrm{s}$ & $1 \mathrm{ml}$ & Left & Pass & 13.55 & - & Pass & 37.6 & - & Pass & 35.23 & - & D \\
\hline 1 & Spurt & $635 \mathrm{~cm} / \mathrm{s}$ & $2 \mathrm{ml}$ & Up & Pass & 33.24 & - & Pass & 81.94 & - & Pass & 103.51 & - & D \\
\hline 2 & Spurt & $635 \mathrm{~cm} / \mathrm{s}$ & $2 \mathrm{ml}$ & Down & Fail & 23.03 & L Q3 & Fail & Ran Thru & Q3/Q4 & Fail & Ran Thru & Q1/Q4 & D \\
\hline 3 & Spurt & $635 \mathrm{~cm} / \mathrm{s}$ & $2 \mathrm{ml}$ & Right & Pass & 11.65 & - & Pass & 52.64 & - & Pass & 59.83 & - & D \\
\hline 4 & Spurt & $635 \mathrm{~cm} / \mathrm{s}$ & $2 \mathrm{ml}$ & Left & Pass & 26.69 & - & Pass & 60.15 & - & Pass & 60.21 & - & D \\
\hline 1 & Spray & $500 \mathrm{~cm} / \mathrm{s}$ & $1 \mathrm{ml}$ & Up & Fail & 5.29 & R Q4 & Pass & 39.83 & - & Pass & 54.78 & - & D \\
\hline 2 & Spray & $500 \mathrm{~cm} / \mathrm{s}$ & $1 \mathrm{ml}$ & Down & Pass & 28.11 & - & Pass & 70.83 & - & Pass & 93.19 & - & D \\
\hline 3 & Spray & $500 \mathrm{~cm} / \mathrm{s}$ & $1 \mathrm{ml}$ & Right & Pass & 8.37 & - & Pass & 35.05 & - & Pass & 30.06 & - & D \\
\hline 4 & Spray & $500 \mathrm{~cm} / \mathrm{s}$ & $1 \mathrm{ml}$ & Left & Pass & 14.2 & - & Pass & 34.98 & - & Pass & 36.93 & - & D \\
\hline 1 & Spurt & $635 \mathrm{~cm} / \mathrm{s}$ & $2 \mathrm{ml}$ & Up & Pass & 67.26 & - & Pass & 122.22 & - & Pass & 94.8 & - & $E$ \\
\hline 2 & Spurt & $635 \mathrm{~cm} / \mathrm{s}$ & $2 \mathrm{ml}$ & Down & Pass & - & - & Pass & NA & - & Pass & NA & - & $\mathrm{E}$ \\
\hline 3 & Spurt & $635 \mathrm{~cm} / \mathrm{s}$ & $2 \mathrm{ml}$ & Right & Pass & 47.15 & - & Pass & 65.2 & - & Pass & 46.98 & - & E \\
\hline
\end{tabular}




\begin{tabular}{|c|c|c|c|c|c|c|c|c|c|c|c|c|c|}
\hline 4 & Spurt & $635 \mathrm{~cm} / \mathrm{s}$ & $2 \mathrm{ml}$ & Left & Pass & 52.47 & - & Pass & 58.92 & - & Pass & 37.6 & - \\
\hline 1 & Spray & $500 \mathrm{~cm} / \mathrm{s}$ & $1 \mathrm{ml}$ & Up & Pass & 64.61 & - & Pass & 110.68 & - & Pass & 75.5 & - \\
\hline 2 & Spray & $500 \mathrm{~cm} / \mathrm{s}$ & $1 \mathrm{ml}$ & Down & Pass & 45.27 & - & Pass & 99.04 & - & Pass & 117.96 & - \\
\hline 3 & Spray & $500 \mathrm{~cm} / \mathrm{s}$ & $1 \mathrm{ml}$ & Right & Pass & 55.82 & - & Pass & 54.21 & - & Pass & 36.44 & - \\
\hline 4 & Spray & $500 \mathrm{~cm} / \mathrm{s}$ & $1 \mathrm{ml}$ & Left & Pass & 55.32 & - & Pass & 51.95 & - & Pass & 37.38 & - \\
\hline 1 & Spurt & $635 \mathrm{~cm} / \mathrm{s}$ & $2 \mathrm{ml}$ & Up & Fail & 5.69 & R Q2 & Pass & 1.45 & - & Pass & 32.36 & - \\
\hline 2 & Spurt & $635 \mathrm{~cm} / \mathrm{s}$ & $2 \mathrm{ml}$ & Down & Pass & - & - & Pass & NA & - & Pass & NA & - \\
\hline 3 & Spurt & $635 \mathrm{~cm} / \mathrm{s}$ & $2 \mathrm{ml}$ & Right & Pass & 49.2 & - & Pass & 64.89 & - & Pass & 48.15 & - \\
\hline 4 & Spurt & $635 \mathrm{~cm} / \mathrm{s}$ & $2 \mathrm{ml}$ & Left & Pass & 50.86 & - & Pass & 57.45 & - & Pass & 39.54 & - \\
\hline 1 & Spray & $500 \mathrm{~cm} / \mathrm{s}$ & $1 \mathrm{ml}$ & Up & Pass & 65.51 & - & Pass & 114.19 & - & Pass & 84.45 & - \\
\hline 2 & Spray & $500 \mathrm{~cm} / \mathrm{s}$ & $1 \mathrm{ml}$ & Down & Pass & 32.03 & - & Pass & 85.29 & - & Pass & 108.24 & - \\
\hline 3 & Spray & $500 \mathrm{~cm} / \mathrm{s}$ & $1 \mathrm{ml}$ & Right & Pass & 32.09 & - & Pass & 62.05 & - & Pass & 43.8 & - \\
\hline 4 & Spray & $500 \mathrm{~cm} / \mathrm{s}$ & $1 \mathrm{ml}$ & Left & Pass & 30.41 & - & Pass & 52.83 & - & Pass & 47.83 & - \\
\hline 1 & Spurt & $635 \mathrm{~cm} / \mathrm{s}$ & $2 \mathrm{ml}$ & Up & Pass & 1.64 & - & Pass & 4.18 & - & Pass & 33.28 & - \\
\hline 2 & Spurt & $635 \mathrm{~cm} / \mathrm{s}$ & $2 \mathrm{ml}$ & Down & Pass & 47.32 & - & Pass & 94.82 & - & Pass & 116.5 & - \\
\hline 3 & Spurt & $635 \mathrm{~cm} / \mathrm{s}$ & $2 \mathrm{ml}$ & Right & Pass & 45.87 & - & Pass & 67.45 & - & Pass & 38.1 & - \\
\hline 4 & Spurt & $635 \mathrm{~cm} / \mathrm{s}$ & $2 \mathrm{ml}$ & Left & Pass & 50.31 & - & Pass & 60.29 & - & Pass & 41.85 & - \\
\hline 1 & Spray & $500 \mathrm{~cm} / \mathrm{s}$ & $1 \mathrm{ml}$ & Up & Pass & 6.68 & - & Pass & 41.26 & - & Pass & 57.69 & - \\
\hline 2 & Spray & $500 \mathrm{~cm} / \mathrm{s}$ & $1 \mathrm{ml}$ & Down & Pass & 38.05 & - & Pass & 93.83 & - & Pass & 115.13 & - \\
\hline 3 & Spray & $500 \mathrm{~cm} / \mathrm{s}$ & $1 \mathrm{ml}$ & Right & Pass & 40.31 & - & Pass & 64.15 & - & Pass & 42.75 & - \\
\hline 4 & Spray & $500 \mathrm{~cm} / \mathrm{s}$ & $1 \mathrm{ml}$ & Left & Pass & 46.59 & - & Pass & 62.51 & - & Pass & 49.65 & - \\
\hline 1 & Spurt & $635 \mathrm{~cm} / \mathrm{s}$ & $2 \mathrm{ml}$ & Up & Pass & 28.41 & - & Pass & 5.02 & - & Pass & 35.35 & - \\
\hline 2 & Spurt & $635 \mathrm{~cm} / \mathrm{s}$ & $2 \mathrm{ml}$ & Down & Pass & - & - & Pass & NA & - & Pass & NA & - \\
\hline 3 & Spurt & $635 \mathrm{~cm} / \mathrm{s}$ & $2 \mathrm{ml}$ & Right & Pass & 48.17 & - & Pass & 66.32 & - & Pass & 36.51 & - \\
\hline 4 & Spurt & $635 \mathrm{~cm} / \mathrm{s}$ & $2 \mathrm{ml}$ & Left & Pass & 53.47 & - & Pass & 59.93 & - & Pass & 33.21 & - \\
\hline 1 & Spray & $500 \mathrm{~cm} / \mathrm{s}$ & $1 \mathrm{ml}$ & Up & Pass & 48.05 & - & Pass & 91.13 & - & Pass & 110.23 & - \\
\hline 2 & Spray & $500 \mathrm{~cm} / \mathrm{s}$ & $1 \mathrm{ml}$ & Down & Pass & 33.63 & - & Pass & 87.57 & - & Pass & 108.86 & - \\
\hline 3 & Spray & $500 \mathrm{~cm} / \mathrm{s}$ & $1 \mathrm{ml}$ & Right & Pass & 49.07 & - & Pass & 53.28 & - & Pass & 37.47 & - \\
\hline 4 & Spray & $500 \mathrm{~cm} / \mathrm{s}$ & $1 \mathrm{ml}$ & Left & Pass & 52.27 & - & Pass & 51.76 & - & Pass & 32.46 & - \\
\hline 1 & Spurt & $635 \mathrm{~cm} / \mathrm{s}$ & $2 \mathrm{ml}$ & Up & Pass & 51.86 & - & Pass & 98.1 & - & Pass & 74.85 & - \\
\hline 2 & Spurt & $635 \mathrm{~cm} / \mathrm{s}$ & $2 \mathrm{ml}$ & Down & Pass & - & - & Pass & NA & - & Pass & NA & - \\
\hline 3 & Spurt & $635 \mathrm{~cm} / \mathrm{s}$ & $2 \mathrm{ml}$ & Right & Pass & 45.12 & - & Pass & 60.21 & - & Pass & 48.56 & - \\
\hline 4 & Spurt & $635 \mathrm{~cm} / \mathrm{s}$ & $2 \mathrm{ml}$ & Left & Pass & 46.56 & - & Pass & 54.98 & - & Pass & 39.62 & - \\
\hline 1 & Spray & $500 \mathrm{~cm} / \mathrm{s}$ & $1 \mathrm{ml}$ & Up & Pass & 49.04 & - & Pass & 79.72 & - & Pass & 80.06 & - \\
\hline 2 & Spray & $500 \mathrm{~cm} / \mathrm{s}$ & $1 \mathrm{ml}$ & Down & Pass & 19.54 & - & Pass & 75.79 & - & Pass & 92.75 & - \\
\hline 3 & Spray & $500 \mathrm{~cm} / \mathrm{s}$ & $1 \mathrm{ml}$ & Right & Pass & 53.64 & - & Pass & 56.21 & - & Pass & 39.07 & - \\
\hline 4 & Spray & $500 \mathrm{~cm} / \mathrm{s}$ & $1 \mathrm{ml}$ & Left & Pass & 58.96 & - & Pass & 59.77 & - & Pass & 41.91 & - \\
\hline 1 & Spurt & $635 \mathrm{~cm} / \mathrm{s}$ & $2 \mathrm{ml}$ & Up & Pass & 4.37 & - & Pass & 33.23 & - & Pass & 55.23 & - \\
\hline 2 & Spurt & $635 \mathrm{~cm} / \mathrm{s}$ & $2 \mathrm{ml}$ & Down & Pass & - & - & Pass & NA & - & Pass & NA & - \\
\hline 3 & Spurt & $635 \mathrm{~cm} / \mathrm{s}$ & $2 \mathrm{ml}$ & Right & Pass & 40.45 & - & Pass & 64.74 & - & Pass & 46.2 & - \\
\hline 4 & Spurt & $635 \mathrm{~cm} / \mathrm{s}$ & $2 \mathrm{ml}$ & Left & Pass & 58.39 & - & Pass & 64.79 & & Pass & 51.38 & - \\
\hline 1 & Spray & $500 \mathrm{~cm} / \mathrm{s}$ & $1 \mathrm{ml}$ & Up & Pass & 65.78 & - & Pass & 114.02 & - & Pass & 84.52 & - \\
\hline 2 & Spray & $500 \mathrm{~cm} / \mathrm{s}$ & $1 \mathrm{ml}$ & Down & Pass & 20.75 & - & Pass & 74.46 & - & Pass & 94.5 & - \\
\hline 3 & Spray & $500 \mathrm{~cm} / \mathrm{s}$ & $1 \mathrm{ml}$ & Right & Pass & 38.29 & - & Pass & 61.17 & - & Pass & 40.86 & - \\
\hline 4 & Spray & $500 \mathrm{~cm} / \mathrm{s}$ & $1 \mathrm{ml}$ & Left & Pass & 63.56 & - & Pass & 72.06 & - & Pass & 54.67 & - \\
\hline 1 & Spurt & $635 \mathrm{~cm} / \mathrm{s}$ & $2 \mathrm{ml}$ & Up & Pass & 4.99 & - & Pass & 44.6 & - & Pass & 69.15 & - \\
\hline 2 & Spurt & $635 \mathrm{~cm} / \mathrm{s}$ & $2 \mathrm{ml}$ & Down & Pass & - & - & Pass & NA & - & Pass & NA & - \\
\hline 3 & Spurt & $635 \mathrm{~cm} / \mathrm{s}$ & $2 \mathrm{ml}$ & Right & Pass & 41.54 & - & Pass & 65.74 & - & Pass & 45.61 & - \\
\hline 4 & Spurt & $635 \mathrm{~cm} / \mathrm{s}$ & $2 \mathrm{ml}$ & Left & Pass & 41.39 & - & Pass & 63.73 & & Pass & 49.32 & - \\
\hline 1 & Spray & $500 \mathrm{~cm} / \mathrm{s}$ & $1 \mathrm{ml}$ & Up & Pass & 68.19 & - & Pass & 104.78 & - & Pass & 83.24 & - \\
\hline 2 & Spray & $500 \mathrm{~cm} / \mathrm{s}$ & $1 \mathrm{ml}$ & Down & Pass & 24.56 & - & Pass & 75.68 & - & Pass & 103.13 & - \\
\hline 3 & Spray & $500 \mathrm{~cm} / \mathrm{s}$ & $1 \mathrm{ml}$ & Right & Pass & 53.25 & - & Pass & 59.86 & - & Pass & 40.63 & - \\
\hline 4 & Spray & $500 \mathrm{~cm} / \mathrm{s}$ & $1 \mathrm{ml}$ & Left & Pass & 36.3 & - & Pass & 52.76 & - & Pass & 37.53 & - \\
\hline 1 & Spurt & $635 \mathrm{~cm} / \mathrm{s}$ & $2 \mathrm{ml}$ & Up & Pass & 40.93 & - & Pass & 83.26 & - & Pass & 104.8 & - \\
\hline
\end{tabular}




\begin{tabular}{|c|c|c|c|c|c|c|c|c|c|c|c|c|c|c|}
\hline 2 & Spurt & $635 \mathrm{~cm} / \mathrm{s}$ & $2 \mathrm{ml}$ & Down & Pass & 39.84 & - & Pass & 88.35 & - & Pass & 109.8 & - & $\mathrm{E}$ \\
\hline 3 & Spurt & $635 \mathrm{~cm} / \mathrm{s}$ & $2 \mathrm{ml}$ & Right & Pass & 40.04 & - & Pass & 64.74 & - & Pass & 46.2 & - & $E$ \\
\hline 4 & Spurt & $635 \mathrm{~cm} / \mathrm{s}$ & $2 \mathrm{ml}$ & Left & Pass & 39.56 & - & Pass & 69.79 & & Pass & 51.83 & - & $E$ \\
\hline 1 & Spray & $500 \mathrm{~cm} / \mathrm{s}$ & $1 \mathrm{ml}$ & Up & Pass & 51.66 & - & Pass & 103.24 & - & Pass & 83.04 & - & $\mathrm{E}$ \\
\hline 2 & Spray & $500 \mathrm{~cm} / \mathrm{s}$ & $1 \mathrm{ml}$ & Down & Pass & 32.16 & - & Pass & 84.81 & - & Pass & 106.97 & - & $E$ \\
\hline 3 & Spray & $500 \mathrm{~cm} / \mathrm{s}$ & $1 \mathrm{ml}$ & Right & Pass & 53.63 & - & Pass & 58.36 & - & Pass & 37.6 & - & $E$ \\
\hline 4 & Spray & $500 \mathrm{~cm} / \mathrm{s}$ & $1 \mathrm{ml}$ & Left & Pass & 55.14 & - & Pass & 68.15 & - & Pass & 52.28 & - & $E$ \\
\hline 1 & Spurt & $635 \mathrm{~cm} / \mathrm{s}$ & $2 \mathrm{ml}$ & Up & Pass & 26.62 & - & Pass & 75.59 & - & Pass & 40.31 & - & $E$ \\
\hline 2 & Spurt & $635 \mathrm{~cm} / \mathrm{s}$ & $2 \mathrm{ml}$ & Down & Pass & - & - & Pass & NA & - & Pass & NA & - & $\mathrm{E}$ \\
\hline 3 & Spurt & $635 \mathrm{~cm} / \mathrm{s}$ & $2 \mathrm{ml}$ & Right & Pass & 34.51 & - & Pass & 55.23 & - & Pass & 40.13 & - & $E$ \\
\hline 4 & Spurt & $635 \mathrm{~cm} / \mathrm{s}$ & $2 \mathrm{ml}$ & Left & Pass & 39.11 & - & Pass & 57.43 & & Pass & 52.21 & - & $\mathrm{E}$ \\
\hline 1 & Spray & $500 \mathrm{~cm} / \mathrm{s}$ & $1 \mathrm{ml}$ & Up & Pass & 54.72 & - & Pass & 100.82 & - & Pass & 82.61 & - & $E$ \\
\hline 2 & Spray & $500 \mathrm{~cm} / \mathrm{s}$ & $1 \mathrm{ml}$ & Down & Pass & 22.65 & - & Pass & 76.58 & - & Pass & 98.73 & - & $E$ \\
\hline 3 & Spray & $500 \mathrm{~cm} / \mathrm{s}$ & $1 \mathrm{ml}$ & Right & Pass & 44.61 & - & Pass & 62.18 & - & Pass & 42.13 & - & $\mathrm{E}$ \\
\hline 4 & Spray & $500 \mathrm{~cm} / \mathrm{s}$ & $1 \mathrm{ml}$ & Left & Pass & 42.96 & - & Pass & 57.54 & - & Pass & 37.84 & - & $E$ \\
\hline 1 & Spurt & $635 \mathrm{~cm} / \mathrm{s}$ & $2 \mathrm{ml}$ & Up & Pass & 13.53 & - & Pass & 47.91 & - & Pass & 75.32 & - & $E$ \\
\hline 2 & Spurt & $635 \mathrm{~cm} / \mathrm{s}$ & $2 \mathrm{ml}$ & Down & Pass & 43.35 & - & Pass & 96.45 & - & Pass & 114.15 & - & $E$ \\
\hline 3 & Spurt & $635 \mathrm{~cm} / \mathrm{s}$ & $2 \mathrm{ml}$ & Right & Pass & 36.23 & - & Pass & 49.23 & - & Pass & 37.54 & - & $E$ \\
\hline 4 & Spurt & $635 \mathrm{~cm} / \mathrm{s}$ & $2 \mathrm{ml}$ & Left & Pass & 41.26 & - & Pass & 50.87 & & Pass & 38.92 & - & $E$ \\
\hline 1 & Spray & $500 \mathrm{~cm} / \mathrm{s}$ & $1 \mathrm{ml}$ & Up & Pass & 53.17 & - & Pass & 105.44 & - & Pass & 76.91 & - & $E$ \\
\hline 2 & Spray & $500 \mathrm{~cm} / \mathrm{s}$ & $1 \mathrm{ml}$ & Down & Pass & 25.9 & - & Pass & 82.53 & - & Pass & 102.4 & - & $E$ \\
\hline 3 & Spray & $500 \mathrm{~cm} / \mathrm{s}$ & $1 \mathrm{ml}$ & Right & Pass & 52.54 & - & Pass & 59.89 & - & Pass & 45.82 & - & $E$ \\
\hline 4 & Spray & $500 \mathrm{~cm} / \mathrm{s}$ & $1 \mathrm{ml}$ & Left & Pass & 47.84 & - & Pass & 60.39 & - & Pass & 46.09 & - & $E$ \\
\hline 1 & Spurt & $635 \mathrm{~cm} / \mathrm{s}$ & $2 \mathrm{ml}$ & Up & Pass & 1.26 & - & Pass & 44.83 & - & Pass & 69.43 & - & $F$ \\
\hline $\begin{array}{l}2 \\
3\end{array}$ & $\begin{array}{l}\text { Spurt } \\
\text { Spurt }\end{array}$ & $\begin{array}{l}635 \mathrm{~cm} / \mathrm{s} \\
635 \mathrm{~cm} / \mathrm{s}\end{array}$ & $\begin{array}{l}2 \mathrm{ml} \\
2 \mathrm{ml}\end{array}$ & $\begin{array}{l}\text { Down } \\
\text { Right }\end{array}$ & $\begin{array}{l}\text { Pass } \\
\text { Pass }\end{array}$ & $\begin{array}{c}0.01 \\
15.93\end{array}$ & $\begin{array}{c}\text { L Q2 } \\
-\end{array}$ & $\begin{array}{r}\text { Fail } \\
\text { Pass }\end{array}$ & $\begin{array}{c}\text { Ran Thru } \\
40.77\end{array}$ & $\begin{array}{c}\text { Q3/Q4 } \\
-\end{array}$ & $\begin{array}{l}\text { Fail } \\
\text { Pass }\end{array}$ & $\begin{array}{c}\text { Ran Thru } \\
41.39\end{array}$ & $\begin{array}{c}\mathrm{Q1,Q2,Q3,Q4} \\
-\end{array}$ & $\begin{array}{l}F \\
F\end{array}$ \\
\hline 4 & Spurt & $635 \mathrm{~cm} / \mathrm{s}$ & $2 \mathrm{ml}$ & Left & Pass & 15.3 & - & Pass & 38.13 & - & Pass & 24.49 & - & $\mathrm{F}$ \\
\hline 1 & Spray & $500 \mathrm{~cm} / \mathrm{s}$ & $1 \mathrm{ml}$ & Up & Pass & 12.61 & - & Pass & 37.07 & - & Pass & 46.77 & - & $F$ \\
\hline 2 & Spray & $500 \mathrm{~cm} / \mathrm{s}$ & $1 \mathrm{ml}$ & Down & Pass & 6.76 & - & Pass & 58.7 & - & Pass & 71.9 & - & $F$ \\
\hline 3 & Spray & $500 \mathrm{~cm} / \mathrm{s}$ & $1 \mathrm{ml}$ & Right & Pass & 4.23 & - & Pass & 34.38 & - & Pass & 36.35 & - & $F$ \\
\hline 4 & Spray & $500 \mathrm{~cm} / \mathrm{s}$ & $1 \mathrm{ml}$ & Left & Pass & 9.56 & - & Pass & 38.45 & - & Pass & 33.21 & - & $\mathrm{F}$ \\
\hline 1 & Spurt & $635 \mathrm{~cm} / \mathrm{s}$ & $2 \mathrm{ml}$ & Up & Fail & 17.63 & L Q3 & Pass & 30.25 & - & Pass & 53.86 & - & $F$ \\
\hline 2 & Spurt & $635 \mathrm{~cm} / \mathrm{s}$ & $2 \mathrm{ml}$ & Down & Fail & 11.82 & L Q4 & Fail & Ran Thru & Q4 & Fail & Ran Thru & Q1/Q4 & $\mathrm{F}$ \\
\hline 3 & Spurt & $635 \mathrm{~cm} / \mathrm{s}$ & $2 \mathrm{ml}$ & Right & Pass & 7.76 & - & Pass & 38.54 & - & Pass & 37.26 & - & $\mathrm{F}$ \\
\hline 4 & Spurt & $635 \mathrm{~cm} / \mathrm{s}$ & $2 \mathrm{ml}$ & Left & Pass & 22.34 & - & Pass & 43.88 & - & Pass & 37.5 & - & $\mathrm{F}$ \\
\hline $\begin{array}{l}1 \\
2\end{array}$ & $\begin{array}{l}\text { Spray } \\
\text { Spray }\end{array}$ & $\begin{array}{l}500 \mathrm{~cm} / \mathrm{s} \\
500 \mathrm{~cm} / \mathrm{s}\end{array}$ & $\begin{array}{l}1 \mathrm{ml} \\
1 \mathrm{ml}\end{array}$ & $\begin{array}{l}\text { Up } \\
\text { Down }\end{array}$ & $\begin{array}{l}\text { Fail } \\
\text { Fail }\end{array}$ & $\begin{array}{c}6.2 \\
5.33\end{array}$ & $\begin{array}{l}\text { R Q4 } \\
\text { L Q1 }\end{array}$ & $\begin{array}{l}\text { Pass } \\
\text { Pass }\end{array}$ & $\begin{array}{l}36.09 \\
25.64\end{array}$ & - & $\begin{array}{l}\text { Pass } \\
\text { Pass }\end{array}$ & $\begin{array}{l}40.81 \\
45.86\end{array}$ & - & $\begin{array}{l}F \\
F\end{array}$ \\
\hline 3 & Spray & $500 \mathrm{~cm} / \mathrm{s}$ & $1 \mathrm{ml}$ & Right & Pass & 12.57 & - & Pass & 37.18 & - & Pass & 41.04 & - & $\mathrm{F}$ \\
\hline 4 & Spray & $500 \mathrm{~cm} / \mathrm{s}$ & $1 \mathrm{ml}$ & Left & Pass & 10.11 & - & Pass & 35.13 & - & Pass & 40.21 & - & $\mathrm{F}$ \\
\hline 1 & Spurt & $635 \mathrm{~cm} / \mathrm{s}$ & $2 \mathrm{ml}$ & Up & Fail & 7.72 & R Q1 & Pass & 40.72 & - & Pass & 38.12 & - & $\mathrm{F}$ \\
\hline 2 & Spurt & $635 \mathrm{~cm} / \mathrm{s}$ & $2 \mathrm{ml}$ & Down & Fail & 5.556 & L Q2 & Fail & Ran Thru & Q3/Q4 & Fail & Ran Thru & Q1,Q2,Q3,Q4 & $\mathrm{F}$ \\
\hline 3 & Spurt & $635 \mathrm{~cm} / \mathrm{s}$ & $2 \mathrm{ml}$ & Right & Pass & 15.24 & - & Pass & 42.88 & - & Pass & 36.09 & - & $\mathrm{F}$ \\
\hline 4 & Spurt & $635 \mathrm{~cm} / \mathrm{s}$ & $2 \mathrm{ml}$ & Left & Pass & 18.13 & - & Pass & 39.55 & - & Pass & 30.38 & - & $\mathrm{F}$ \\
\hline 1 & Spray & $500 \mathrm{~cm} / \mathrm{s}$ & $1 \mathrm{ml}$ & Up & Fail & 6.62 & R Q4 & Pass & 35.84 & - & Pass & 38.45 & - & $\mathrm{F}$ \\
\hline 2 & Spray & $500 \mathrm{~cm} / \mathrm{s}$ & $1 \mathrm{ml}$ & Down & Pass & 1.17 & - & Pass & 46.36 & - & Pass & 70.52 & - & $\mathrm{F}$ \\
\hline 3 & Spray & $500 \mathrm{~cm} / \mathrm{s}$ & $1 \mathrm{ml}$ & Right & Pass & 12.43 & - & Pass & 31.46 & - & Pass & 36.19 & - & $\mathrm{F}$ \\
\hline 4 & Spray & $500 \mathrm{~cm} / \mathrm{s}$ & $1 \mathrm{ml}$ & Left & Pass & 13.87 & - & Pass & 30.23 & - & Pass & 38.69 & - & $\mathrm{F}$ \\
\hline 1 & Spurt & $635 \mathrm{~cm} / \mathrm{s}$ & $2 \mathrm{ml}$ & Up & Fail & 8.09 & L Q3 & Pass & 32.49 & - & Pass & 36.84 & - & $\mathrm{F}$ \\
\hline 2 & Spurt & $635 \mathrm{~cm} / \mathrm{s}$ & $2 \mathrm{ml}$ & Down & Fail & 9.87 & L Q3 & Pass & On Line & Q3 & Fail & Ran Thru & Q2/Q3 & $\mathrm{F}$ \\
\hline 3 & Spurt & $635 \mathrm{~cm} / \mathrm{s}$ & $2 \mathrm{ml}$ & Right & Pass & 18.31 & - & Pass & 49.85 & - & Pass & 44.58 & - & $\mathrm{F}$ \\
\hline 4 & Spurt & $635 \mathrm{~cm} / \mathrm{s}$ & $2 \mathrm{ml}$ & Left & Pass & 15.86 & - & Pass & 38.31 & - & Pass & 38.02 & - & $\mathrm{F}$ \\
\hline 1 & Spray & $500 \mathrm{~cm} / \mathrm{s}$ & $1 \mathrm{ml}$ & Up & Pass & 20.27 & - & Pass & 34.4 & - & Pass & 46.91 & - & $F$ \\
\hline 2 & Spray & $500 \mathrm{~cm} / \mathrm{s}$ & $1 \mathrm{ml}$ & Down & Pass & 6.65 & - & Pass & 59.76 & - & Pass & 84.39 & - & $F$ \\
\hline 3 & Sprav & $500 \mathrm{~cm} / \mathrm{s}$ & $1 \mathrm{ml}$ & Riaht & Pass & 9.89 & - & Pass & 35.37 & - & Pass & 40.41 & - & $\mathrm{F}$ \\
\hline
\end{tabular}




\begin{tabular}{|c|c|c|c|c|c|c|c|c|c|c|c|c|c|c|}
\hline 4 & Spray & $500 \mathrm{~cm} / \mathrm{s}$ & $1 \mathrm{ml}$ & Left & Pass & 7.47 & - & Pass & 35.23 & - & Pass & 45.89 & - & $\mathrm{F}$ \\
\hline 1 & Spurt & $635 \mathrm{~cm} / \mathrm{s}$ & $2 \mathrm{ml}$ & Up & Pass & 4.12 & - & Pass & 45.41 & - & Pass & 46.81 & - & $\mathrm{F}$ \\
\hline 2 & Spurt & $635 \mathrm{~cm} / \mathrm{s}$ & $2 \mathrm{ml}$ & Down & Fail & 23.71 & R Q4 & Fail & Ran Thru & Q3/Q4 & Fail & Ran Thru & Q1,Q2,Q3,Q4 & $\mathrm{F}$ \\
\hline 3 & Spurt & $635 \mathrm{~cm} / \mathrm{s}$ & $2 \mathrm{ml}$ & Right & Pass & 16.07 & - & Pass & 33.95 & - & Pass & 27.8 & - & $\mathrm{F}$ \\
\hline 4 & Spurt & $635 \mathrm{~cm} / \mathrm{s}$ & $2 \mathrm{ml}$ & Left & Pass & 9.84 & - & Pass & 47.89 & - & Pass & 44.61 & - & $\mathrm{F}$ \\
\hline 1 & Spray & $500 \mathrm{~cm} / \mathrm{s}$ & $1 \mathrm{ml}$ & Up & Pass & 19.54 & - & Pass & 36.28 & - & Pass & 42.97 & - & $\mathrm{F}$ \\
\hline 2 & Spray & $500 \mathrm{~cm} / \mathrm{s}$ & $1 \mathrm{ml}$ & Down & Fail & 20.11 & L Q4 & Pass & 50.98 & - & Pass & 64.69 & - & $\mathrm{F}$ \\
\hline 3 & Spray & $500 \mathrm{~cm} / \mathrm{s}$ & $1 \mathrm{ml}$ & Right & Pass & 7.28 & - & Pass & 32.96 & - & Pass & 39.58 & - & $\mathrm{F}$ \\
\hline 4 & Spray & $500 \mathrm{~cm} / \mathrm{s}$ & $1 \mathrm{ml}$ & Left & Pass & 9.25 & - & Pass & 30.26 & - & Pass & 41.54 & - & $\mathrm{F}$ \\
\hline 1 & Spurt & $635 \mathrm{~cm} / \mathrm{s}$ & $2 \mathrm{ml}$ & Up & Fail & 11.24 & R Q2 & Pass & 44.15 & - & Pass & 43.15 & - & $\mathrm{F}$ \\
\hline 2 & Spurt & $635 \mathrm{~cm} / \mathrm{s}$ & $2 \mathrm{ml}$ & Down & Fail & 24.12 & R Q1 & Fail & Ran Thru & Q3 & Fail & Ran Thru & Q2/Q3 & $\mathrm{F}$ \\
\hline 3 & Spurt & $635 \mathrm{~cm} / \mathrm{s}$ & $2 \mathrm{ml}$ & Right & Pass & 15.73 & - & Pass & 42.74 & - & Pass & 37.9 & - & $\mathrm{F}$ \\
\hline 4 & Spurt & $635 \mathrm{~cm} / \mathrm{s}$ & $2 \mathrm{ml}$ & Left & Pass & 23.56 & - & Pass & 41.94 & - & Pass & 36.49 & - & $\mathrm{F}$ \\
\hline 1 & Spray & $500 \mathrm{~cm} / \mathrm{s}$ & $1 \mathrm{ml}$ & Up & Pass & 17.36 & - & Pass & 36.41 & - & Pass & 47.48 & - & $\mathrm{F}$ \\
\hline 2 & Spray & $500 \mathrm{~cm} / \mathrm{s}$ & $1 \mathrm{ml}$ & Down & Fail & 23.86 & L Q1 & Pass & 50.05 & - & Pass & 61.06 & - & $\mathrm{F}$ \\
\hline 3 & Spray & $500 \mathrm{~cm} / \mathrm{s}$ & $1 \mathrm{ml}$ & Right & Pass & 5.21 & - & Pass & 31.69 & - & Pass & 33.95 & - & $\mathrm{F}$ \\
\hline 4 & Spray & $500 \mathrm{~cm} / \mathrm{s}$ & $1 \mathrm{ml}$ & Left & Pass & 8.63 & - & Pass & 29.51 & - & Pass & 34.12 & - & $\mathrm{F}$ \\
\hline 1 & Spurt & $635 \mathrm{~cm} / \mathrm{s}$ & $2 \mathrm{ml}$ & Up & Fail & 8.24 & L Q3 & Pass & 44.26 & - & Pass & 39.63 & - & $\mathrm{F}$ \\
\hline 2 & Spurt & $635 \mathrm{~cm} / \mathrm{s}$ & $2 \mathrm{ml}$ & Down & Fail & 7.63 & $\mathrm{R}$ Q2 & Fail & Ran Thru & Q3 & Fail & Ran Thru & Q2/Q3 & $\mathrm{F}$ \\
\hline 3 & Spurt & $635 \mathrm{~cm} / \mathrm{s}$ & $2 \mathrm{ml}$ & Right & Pass & 17.13 & - & Pass & 46.31 & - & Pass & 40.13 & - & $\mathrm{F}$ \\
\hline 4 & Spurt & $635 \mathrm{~cm} / \mathrm{s}$ & $2 \mathrm{ml}$ & Left & Pass & 12.35 & - & Pass & 36.13 & - & Pass & 23.49 & - & $\mathrm{F}$ \\
\hline 1 & Spray & $500 \mathrm{~cm} / \mathrm{s}$ & $1 \mathrm{ml}$ & Up & Fail & 13.25 & $\mathrm{R}$ Q2 & Pass & 31.03 & - & Pass & 38.47 & - & $\mathrm{F}$ \\
\hline 2 & Spray & $500 \mathrm{~cm} / \mathrm{s}$ & $1 \mathrm{ml}$ & Down & Fail & 15.97 & R Q4 & Pass & 25.53 & - & Pass & 48.67 & - & $\mathrm{F}$ \\
\hline 3 & Spray & $500 \mathrm{~cm} / \mathrm{s}$ & $1 \mathrm{ml}$ & Right & Pass & 13.99 & - & Pass & 40.67 & - & Pass & 45.9 & - & $\mathrm{F}$ \\
\hline 4 & Spray & $500 \mathrm{~cm} / \mathrm{s}$ & $1 \mathrm{ml}$ & Left & Pass & 12.46 & - & Pass & 39.16 & - & Pass & 43.15 & - & $\mathrm{F}$ \\
\hline 1 & Spurt & $635 \mathrm{~cm} / \mathrm{s}$ & $2 \mathrm{ml}$ & Up & Pass & 4.95 & - & Pass & 47.86 & - & Pass & 41.7 & - & $\mathrm{F}$ \\
\hline 2 & Spurt & $635 \mathrm{~cm} / \mathrm{s}$ & $2 \mathrm{ml}$ & Down & Fail & 9.05 & R Q4 & Fail & Ran Thru & Q3 & Fail & Ran Thru & Q2/Q3 & $\mathrm{F}$ \\
\hline 3 & Spurt & $635 \mathrm{~cm} / \mathrm{s}$ & $2 \mathrm{ml}$ & Right & Pass & 16.11 & - & Pass & 41.17 & - & Pass & 39.42 & - & $\mathrm{F}$ \\
\hline 4 & Spurt & $635 \mathrm{~cm} / \mathrm{s}$ & $2 \mathrm{ml}$ & Left & Pass & 19.23 & - & Pass & 38.55 & - & Pass & 31.48 & - & $\mathrm{F}$ \\
\hline 1 & Spray & $500 \mathrm{~cm} / \mathrm{s}$ & $1 \mathrm{ml}$ & Up & Pass & 10.9 & - & Pass & 35.24 & - & Pass & 48.03 & - & $\mathrm{F}$ \\
\hline 2 & Spray & $500 \mathrm{~cm} / \mathrm{s}$ & $1 \mathrm{ml}$ & Down & Fail & 24.49 & R Q2 & Pass & 40.14 & - & Pass & 61.25 & - & $\mathrm{F}$ \\
\hline 3 & Spray & $500 \mathrm{~cm} / \mathrm{s}$ & $1 \mathrm{ml}$ & Right & Pass & 10.17 & - & Pass & 42.37 & - & Pass & 45.78 & - & $\mathrm{F}$ \\
\hline 4 & Spray & $500 \mathrm{~cm} / \mathrm{s}$ & $1 \mathrm{ml}$ & Left & Pass & 11.98 & - & Pass & 45.61 & - & Pass & 44.78 & - & $\mathrm{F}$ \\
\hline 1 & Spurt & $635 \mathrm{~cm} / \mathrm{s}$ & $2 \mathrm{ml}$ & Up & Fail & 12.92 & L Q4 & Pass & 43.64 & - & Pass & 33.76 & - & $\mathrm{F}$ \\
\hline 2 & Spurt & $635 \mathrm{~cm} / \mathrm{s}$ & $2 \mathrm{ml}$ & Down & Fail & 17.35 & L Q3 & Fail & Ran Thru & Q3/Q4 & Fail & Ran Thru & Q1,Q2,Q3,Q4 & $\mathrm{F}$ \\
\hline 3 & Spurt & $635 \mathrm{~cm} / \mathrm{s}$ & $2 \mathrm{ml}$ & Right & Pass & 14.58 & - & Pass & 39.44 & - & Pass & 37.47 & - & $\mathrm{F}$ \\
\hline 4 & Spurt & $635 \mathrm{~cm} / \mathrm{s}$ & $2 \mathrm{ml}$ & Left & Pass & 16.73 & - & Pass & 45.61 & - & Pass & 41.24 & - & $\mathrm{F}$ \\
\hline 1 & Spray & $500 \mathrm{~cm} / \mathrm{s}$ & $1 \mathrm{ml}$ & Up & Fail & 13.98 & L Q4 & Pass & 37.74 & - & Pass & 46.99 & - & $\mathrm{F}$ \\
\hline 2 & Spray & $500 \mathrm{~cm} / \mathrm{s}$ & $1 \mathrm{ml}$ & Down & Fail & 23.93 & L Q4 & Pass & 47.02 & - & Pass & 59.95 & - & $\mathrm{F}$ \\
\hline 3 & Spray & $500 \mathrm{~cm} / \mathrm{s}$ & $1 \mathrm{ml}$ & Right & Pass & 14.72 & - & Pass & 42.51 & - & Pass & 45.64 & - & $\mathrm{F}$ \\
\hline 4 & Spray & $500 \mathrm{~cm} / \mathrm{s}$ & $1 \mathrm{ml}$ & Left & Pass & 12.23 & - & Pass & 46.78 & - & Pass & 47.26 & - & $\mathrm{F}$ \\
\hline 1 & Spurt & $635 \mathrm{~cm} / \mathrm{s}$ & $2 \mathrm{ml}$ & Up & Fail & 4.94 & R Q4 & Pass & 40.7 & - & Pass & 39.47 & - & $\mathrm{F}$ \\
\hline 2 & Spurt & $635 \mathrm{~cm} / \mathrm{s}$ & $2 \mathrm{ml}$ & Down & Fail & 24.64 & L Q2 & Fail & Ran Thru & Q4 & Fail & Ran Thru & Q1/Q4 & $\mathrm{F}$ \\
\hline 3 & Spurt & $635 \mathrm{~cm} / \mathrm{s}$ & $2 \mathrm{ml}$ & Right & Pass & 15.33 & - & Pass & 41.49 & - & Pass & 40.73 & - & $\mathrm{F}$ \\
\hline 4 & Spurt & $635 \mathrm{~cm} / \mathrm{s}$ & $2 \mathrm{ml}$ & Left & Pass & 8.74 & - & Pass & 39.56 & - & Pass & 36.62 & - & $\mathrm{F}$ \\
\hline 1 & Spray & $500 \mathrm{~cm} / \mathrm{s}$ & $1 \mathrm{ml}$ & Up & Fail & 14.3 & R Q3 & Pass & 32.84 & - & Pass & 42.2 & - & $\mathrm{F}$ \\
\hline 2 & Spray & $500 \mathrm{~cm} / \mathrm{s}$ & $1 \mathrm{ml}$ & Down & Pass & 5.76 & - & Pass & 58.67 & - & Pass & 71.1 & - & $\mathrm{F}$ \\
\hline 3 & Spray & $500 \mathrm{~cm} / \mathrm{s}$ & $1 \mathrm{ml}$ & Right & Pass & 19.43 & - & Pass & 35.7 & - & Pass & 43.15 & - & $\mathrm{F}$ \\
\hline 4 & Spray & $500 \mathrm{~cm} / \mathrm{s}$ & $1 \mathrm{ml}$ & Left & Pass & 10.56 & - & Pass & 32.13 & - & Pass & 36.84 & - & $\mathrm{F}$ \\
\hline 1 & Spurt & $635 \mathrm{~cm} / \mathrm{s}$ & $2 \mathrm{ml}$ & Up & Fail & 11.19 & R Q4 & Pass & 1.09 & - & Fail & Ran Thru & Q1/Q4 & G \\
\hline 2 & Spurt & $635 \mathrm{~cm} / \mathrm{s}$ & $2 \mathrm{ml}$ & Down & Fail & 19.22 & R Q4 & Fail & Ran Thru & Q2/Q3 & Pass & 5.46 & - & G \\
\hline 3 & Spurt & $635 \mathrm{~cm} / \mathrm{s}$ & $2 \mathrm{ml}$ & Right & Pass & 14.63 & - & Pass & 42.94 & - & Pass & 51.36 & - & G \\
\hline 4 & Spurt & $635 \mathrm{~cm} / \mathrm{s}$ & $2 \mathrm{ml}$ & Left & Pass & 23.12 & - & Pass & 45.08 & - & Pass & 50.02 & - & G \\
\hline 1 & Spray & $500 \mathrm{~cm} / \mathrm{s}$ & $1 \mathrm{ml}$ & Up & Fail & 10.86 & R Q3 & Pass & 36.87 & - & Pass & 53.33 & - & G \\
\hline
\end{tabular}




\begin{tabular}{|c|c|c|c|c|c|c|c|c|c|c|c|c|c|c|}
\hline 2 & Spray & $500 \mathrm{~cm} / \mathrm{s}$ & $1 \mathrm{ml}$ & Down & Pass & 4.82 & - & Pass & 31.63 & - & Pass & 53.17 & - & G \\
\hline 3 & Spray & $500 \mathrm{~cm} / \mathrm{s}$ & $1 \mathrm{ml}$ & Right & Fail & 20.82 & L Q4 & Pass & 40.63 & - & Pass & 40.21 & - & G \\
\hline 4 & Spray & $500 \mathrm{~cm} / \mathrm{s}$ & $1 \mathrm{ml}$ & Left & Fail & 14.51 & R Q3 & Pass & 35.46 & - & Pass & 36.55 & - & G \\
\hline 1 & Spurt & $635 \mathrm{~cm} / \mathrm{s}$ & $2 \mathrm{ml}$ & Up & Fail & 3.34 & L Q3 & Fail & Ran Thru & Q3 & Fail & Ran Thru & Q2/Q3 & G \\
\hline $\begin{array}{l}2 \\
3\end{array}$ & $\begin{array}{l}\text { Spurt } \\
\text { Spurt }\end{array}$ & $\begin{array}{l}635 \mathrm{~cm} / \mathrm{s} \\
635 \mathrm{~cm} / \mathrm{s}\end{array}$ & $\begin{array}{l}2 \mathrm{ml} \\
2 \mathrm{ml}\end{array}$ & $\begin{array}{l}\text { Down } \\
\text { Right }\end{array}$ & $\begin{array}{l}\text { Fail } \\
\text { Pass }\end{array}$ & $\begin{array}{c}6.61 \\
18.42\end{array}$ & L Q3 & $\begin{array}{l}\text { Fail } \\
\text { Pass }\end{array}$ & $\begin{array}{c}\text { Ran Thru } \\
47.02\end{array}$ & $\begin{array}{c}\text { Q1/Q4 } \\
-\end{array}$ & $\begin{array}{l}\text { Pass } \\
\text { Pass }\end{array}$ & $\begin{array}{c}9.91 \\
46.85\end{array}$ & - & $\begin{array}{l}\mathrm{G} \\
\mathrm{G}\end{array}$ \\
\hline 4 & Spurt & $635 \mathrm{~cm} / \mathrm{s}$ & $2 \mathrm{ml}$ & Left & Pass & 20 & - & Pass & 47.16 & - & Pass & 51.44 & - & G \\
\hline 1 & Spray & $500 \mathrm{~cm} / \mathrm{s}$ & $1 \mathrm{ml}$ & Up & Fail & 14.44 & R Q4 & Pass & 41.42 & - & Pass & 56.61 & - & G \\
\hline 2 & Spray & $500 \mathrm{~cm} / \mathrm{s}$ & $1 \mathrm{ml}$ & Down & Fail & 16.56 & $\mathrm{R}$ Q2 & Pass & 37.56 & - & Pass & 61.07 & - & G \\
\hline 3 & Spray & $500 \mathrm{~cm} / \mathrm{s}$ & $1 \mathrm{ml}$ & Right & Fail & 24.52 & L Q1 & Pass & 35.81 & - & Pass & 34.89 & - & G \\
\hline 4 & Spray & $500 \mathrm{~cm} / \mathrm{s}$ & $1 \mathrm{ml}$ & Left & Fail & 8.38 & $\mathrm{R} Q 3$ & Pass & 28.35 & - & Pass & 37.76 & - & G \\
\hline 1 & Spurt & $635 \mathrm{~cm} / \mathrm{s}$ & $2 \mathrm{ml}$ & Up & Fail & 1.07 & L Q3 & Pass & 1.01 & - & Pass & 34.6 & - & G \\
\hline 2 & Spurt & $635 \mathrm{~cm} / \mathrm{s}$ & $2 \mathrm{ml}$ & Down & Fail & 20.72 & R Q2 & Fail & 5.33 & Q2 & Pass & 25.32 & - & G \\
\hline 3 & Spurt & $635 \mathrm{~cm} / \mathrm{s}$ & $2 \mathrm{ml}$ & Right & Pass & 13.03 & - & Pass & 45.28 & - & Pass & 31.22 & - & G \\
\hline 4 & Spurt & $635 \mathrm{~cm} / \mathrm{s}$ & $2 \mathrm{ml}$ & Left & Pass & 26.96 & - & Pass & 46.36 & - & Pass & 57.62 & - & G \\
\hline 1 & Spray & $500 \mathrm{~cm} / \mathrm{s}$ & $1 \mathrm{ml}$ & Up & Fail & 3.12 & L Q3 & Pass & 35.8 & - & Pass & 55.39 & - & G \\
\hline 2 & Spray & $500 \mathrm{~cm} / \mathrm{s}$ & $1 \mathrm{ml}$ & Down & Pass & 3.68 & - & Pass & 43.91 & - & Pass & 64.05 & - & G \\
\hline 3 & Spray & $500 \mathrm{~cm} / \mathrm{s}$ & $1 \mathrm{ml}$ & Right & Fail & 15.98 & L Q4 & Pass & 31.64 & - & Pass & 34.42 & - & G \\
\hline 4 & Spray & $500 \mathrm{~cm} / \mathrm{s}$ & $1 \mathrm{ml}$ & Left & Fail & 14.52 & R Q3 & Pass & 31.2 & - & Pass & 41.15 & - & G \\
\hline 1 & Spurt & $635 \mathrm{~cm} / \mathrm{s}$ & $2 \mathrm{ml}$ & Up & Fail & 0.66 & L Q4 & Pass & On Line & Q1/Q2 & Pass & 27.6 & - & G \\
\hline 2 & Spurt & $635 \mathrm{~cm} / \mathrm{s}$ & $2 \mathrm{ml}$ & Down & Fail & 16.33 & L Q2 & Fail & Ran Thru & Q2/Q3 & Fail & Ran Thru & Q2/Q3 & G \\
\hline 3 & Spurt & $635 \mathrm{~cm} / \mathrm{s}$ & $2 \mathrm{ml}$ & Right & Pass & 10.02 & - & Pass & 48.2 & - & Pass & 49.98 & - & G \\
\hline 4 & Spurt & $635 \mathrm{~cm} / \mathrm{s}$ & $2 \mathrm{ml}$ & Left & Pass & 13.5 & - & Pass & 46.4 & - & Pass & 41.96 & - & G \\
\hline 1 & Spray & $500 \mathrm{~cm} / \mathrm{s}$ & $1 \mathrm{ml}$ & Up & Fail & 1.49 & L Q4 & Pass & 34.49 & - & Pass & 51.35 & - & G \\
\hline 2 & Spray & $500 \mathrm{~cm} / \mathrm{s}$ & $1 \mathrm{ml}$ & Down & Pass & 3.06 & - & Pass & 39.05 & - & Pass & 58.56 & - & G \\
\hline 3 & Spray & $500 \mathrm{~cm} / \mathrm{s}$ & $1 \mathrm{ml}$ & Right & Pass & 0.081 & - & Pass & 38.62 & - & Pass & 38.83 & - & G \\
\hline 4 & Spray & $500 \mathrm{~cm} / \mathrm{s}$ & $1 \mathrm{ml}$ & Left & Fail & 16.27 & R Q3 & Pass & 25.34 & - & Pass & 37.13 & - & G \\
\hline 1 & Spurt & $635 \mathrm{~cm} / \mathrm{s}$ & $2 \mathrm{ml}$ & Up & Fail & 2.86 & L Q3 & Pass & 1.54 & - & Pass & 31.31 & - & G \\
\hline 2 & Spurt & $635 \mathrm{~cm} / \mathrm{s}$ & $2 \mathrm{ml}$ & Down & Fail & 11.64 & LQ1 & Fail & 5.64 & Q1 & Pass & 15.83 & - & G \\
\hline 3 & Spurt & $635 \mathrm{~cm} / \mathrm{s}$ & $2 \mathrm{ml}$ & Right & Pass & 12.06 & - & Pass & 47.72 & - & Pass & 39.25 & - & G \\
\hline 4 & Spurt & $635 \mathrm{~cm} / \mathrm{s}$ & $2 \mathrm{ml}$ & Left & Pass & 11.86 & - & Pass & 49.92 & - & Pass & 40.91 & - & G \\
\hline 1 & Spray & $500 \mathrm{~cm} / \mathrm{s}$ & $1 \mathrm{ml}$ & Up & Fail & 6.24 & $\mathrm{R} Q 4$ & Pass & 31.12 & - & Pass & 52.83 & - & G \\
\hline 2 & Spray & $500 \mathrm{~cm} / \mathrm{s}$ & $1 \mathrm{ml}$ & Down & Pass & 2.03 & - & Pass & 41.03 & - & Pass & 59.87 & - & G \\
\hline 3 & Spray & $500 \mathrm{~cm} / \mathrm{s}$ & $1 \mathrm{ml}$ & Right & Fail & 14.48 & L Q4 & Pass & 29.76 & - & Pass & 36.26 & - & G \\
\hline 4 & Spray & $500 \mathrm{~cm} / \mathrm{s}$ & $1 \mathrm{ml}$ & Left & Fail & 16.97 & $\mathrm{R} Q 3$ & Pass & 34.72 & - & Pass & 37.23 & - & G \\
\hline 1 & Spurt & $635 \mathrm{~cm} / \mathrm{s}$ & $2 \mathrm{ml}$ & Up & Fail & 1.29 & $\mathrm{R} Q 2$ & Pass & 1.98 & - & Pass & 23.31 & - & G \\
\hline 2 & Spurt & $635 \mathrm{~cm} / \mathrm{s}$ & $2 \mathrm{ml}$ & Down & Fail & 9.76 & R Q1 & Fail & Ran Thru & Q1/Q2/Q3 & Pass & 5.09 & - & G \\
\hline 3 & Spurt & $635 \mathrm{~cm} / \mathrm{s}$ & $2 \mathrm{ml}$ & Right & Pass & 14.32 & - & Pass & 47.19 & - & Pass & 34.46 & - & G \\
\hline 4 & Spurt & $635 \mathrm{~cm} / \mathrm{s}$ & $2 \mathrm{ml}$ & Left & Pass & 17.7 & - & Pass & 49.4 & - & Pass & 53.92 & - & G \\
\hline 1 & Spray & $500 \mathrm{~cm} / \mathrm{s}$ & $1 \mathrm{ml}$ & Up & Fail & 12.44 & L Q4 & Pass & 35.25 & - & Pass & 54.78 & - & G \\
\hline 2 & Spray & $500 \mathrm{~cm} / \mathrm{s}$ & $1 \mathrm{ml}$ & Down & Fail & 16.83 & L Q4 & Pass & 31.06 & - & Pass & 51.1 & - & G \\
\hline 3 & Spray & $500 \mathrm{~cm} / \mathrm{s}$ & $1 \mathrm{ml}$ & Right & Fail & 17.69 & L Q4 & Pass & 35.38 & - & Pass & 34.55 & - & G \\
\hline 4 & Spray & $500 \mathrm{~cm} / \mathrm{s}$ & $1 \mathrm{ml}$ & Left & Fail & 13.5 & $\mathrm{R} Q 3$ & Pass & 31.27 & - & Pass & 32.45 & - & G \\
\hline 1 & Spurt & $635 \mathrm{~cm} / \mathrm{s}$ & $2 \mathrm{ml}$ & Up & Fail & 3.86 & L Q3 & Pass & 1.81 & - & Pass & 27.45 & - & G \\
\hline 2 & Spurt & $635 \mathrm{~cm} / \mathrm{s}$ & $2 \mathrm{ml}$ & Down & Fail & 13.42 & R Q4 & Fail & 6.94 & Q2 & Pass & 24.37 & - & G \\
\hline 3 & Spurt & $635 \mathrm{~cm} / \mathrm{s}$ & $2 \mathrm{ml}$ & Right & Pass & 12.36 & - & Pass & 43.69 & - & Pass & 50.64 & - & G \\
\hline 4 & Spurt & $635 \mathrm{~cm} / \mathrm{s}$ & $2 \mathrm{ml}$ & Left & Pass & 22.12 & - & Pass & 44.8 & - & Pass & 49.48 & - & G \\
\hline 1 & Spray & $500 \mathrm{~cm} / \mathrm{s}$ & $1 \mathrm{ml}$ & Up & Fail & 5.44 & $\mathrm{R}$ Q4 & Pass & 31.42 & - & Pass & 51.9 & - & G \\
\hline 2 & Spray & $500 \mathrm{~cm} / \mathrm{s}$ & $1 \mathrm{ml}$ & Down & Pass & 3.01 & - & Pass & 46.27 & - & Pass & 65.81 & - & G \\
\hline 3 & Spray & $500 \mathrm{~cm} / \mathrm{s}$ & $1 \mathrm{ml}$ & Right & Fail & 14.61 & L Q4 & Pass & 33.51 & - & Pass & 32.78 & - & G \\
\hline 4 & Spray & $500 \mathrm{~cm} / \mathrm{s}$ & $1 \mathrm{ml}$ & Left & Fail & 16.01 & $\mathrm{R} Q 3$ & Pass & 33.98 & - & Pass & 31.47 & - & G \\
\hline 1 & Spurt & $635 \mathrm{~cm} / \mathrm{s}$ & $2 \mathrm{ml}$ & Up & Fail & 1.98 & $\mathrm{R}$ Q2 & Pass & 0.55 & - & Pass & 21.76 & - & G \\
\hline
\end{tabular}




\begin{tabular}{|c|c|c|c|c|c|c|c|c|c|c|c|c|c|c|}
\hline $\begin{array}{l}2 \\
3\end{array}$ & $\begin{array}{l}\text { Spurt } \\
\text { Spurt }\end{array}$ & $\begin{array}{l}635 \mathrm{~cm} / \mathrm{s} \\
635 \mathrm{~cm} / \mathrm{s}\end{array}$ & $\begin{array}{l}2 \mathrm{ml} \\
2 \mathrm{ml}\end{array}$ & $\begin{array}{l}\text { Down } \\
\text { Right }\end{array}$ & $\begin{array}{l}\text { Fail } \\
\text { Pass }\end{array}$ & $\begin{array}{l}7.69 \\
11.2\end{array}$ & L Q3 & $\begin{array}{l}\text { Fail } \\
\text { Pass }\end{array}$ & $\begin{array}{c}\text { Ran Thru } \\
49.23\end{array}$ & Q1/Q4 & $\begin{array}{l}\text { Fail } \\
\text { Pass }\end{array}$ & $\begin{array}{c}\text { Ran Thru } \\
47.68\end{array}$ & Q1/Q4 & $\begin{array}{l}G \\
G\end{array}$ \\
\hline 4 & Spurt & $635 \mathrm{~cm} / \mathrm{s}$ & $2 \mathrm{ml}$ & Left & Pass & 12.25 & - & Pass & 45.62 & - & Pass & 40.39 & - & G \\
\hline 1 & Spray & $500 \mathrm{~cm} / \mathrm{s}$ & $1 \mathrm{ml}$ & Up & Fail & 12.33 & LQ3 & Pass & 33.09 & - & Pass & 53.8 & - & G \\
\hline 2 & Spray & $500 \mathrm{~cm} / \mathrm{s}$ & $1 \mathrm{ml}$ & Down & Fail & 2.44 & L Q4 & Pass & 18.6 & - & Pass & 44.38 & - & G \\
\hline 3 & Spray & $500 \mathrm{~cm} / \mathrm{s}$ & $1 \mathrm{ml}$ & Right & Fail & 14.82 & L Q4 & Pass & 33.4 & - & Pass & 34.92 & - & G \\
\hline 4 & Spray & $500 \mathrm{~cm} / \mathrm{s}$ & $1 \mathrm{ml}$ & Left & Fail & 12.87 & $\mathrm{R} Q 3$ & Pass & 28.91 & - & Pass & 32.55 & - & G \\
\hline 1 & Spurt & $635 \mathrm{~cm} / \mathrm{s}$ & $2 \mathrm{ml}$ & Up & Fail & 0.77 & R Q1 & Fail & Ran Thru & Q1/Q4 & Pass & 14.2 & - & G \\
\hline 2 & Spurt & $635 \mathrm{~cm} / \mathrm{s}$ & $2 \mathrm{ml}$ & Down & Fail & 12.53 & L Q3 & Fail & Ran Thru & Q4 & Fail & Q1/Q2/Q3 & - & G \\
\hline 3 & Spurt & $635 \mathrm{~cm} / \mathrm{s}$ & $2 \mathrm{ml}$ & Right & Pass & 12.67 & - & Pass & 54.45 & - & Pass & 48.11 & - & G \\
\hline 4 & Spurt & $635 \mathrm{~cm} / \mathrm{s}$ & $2 \mathrm{ml}$ & Left & Pass & 15.86 & - & Pass & 59.26 & - & Pass & 44.98 & - & G \\
\hline 1 & Spray & $500 \mathrm{~cm} / \mathrm{s}$ & $1 \mathrm{ml}$ & Up & Fail & 9.68 & R Q4 & Pass & 35.68 & - & Pass & 51.23 & - & G \\
\hline 2 & Spray & $500 \mathrm{~cm} / \mathrm{s}$ & $1 \mathrm{ml}$ & Down & Pass & 3.11 & - & Pass & 37.56 & - & Pass & 55.41 & - & G \\
\hline 3 & Spray & $500 \mathrm{~cm} / \mathrm{s}$ & $1 \mathrm{ml}$ & Right & Fail & 14.52 & L Q4 & Pass & 30.64 & - & Pass & 38.56 & - & G \\
\hline 4 & Spray & $500 \mathrm{~cm} / \mathrm{s}$ & $1 \mathrm{ml}$ & Left & Fail & 15.69 & R Q3 & Pass & 32.33 & - & Pass & 40.21 & - & G \\
\hline 1 & Spurt & $635 \mathrm{~cm} / \mathrm{s}$ & $2 \mathrm{ml}$ & Up & Fail & 12.27 & LQ2 & Pass & 2.36 & - & Pass & 16.13 & - & G \\
\hline 2 & Spurt & $635 \mathrm{~cm} / \mathrm{s}$ & $2 \mathrm{ml}$ & Down & Fail & 4.27 & R Q4 & Fail & 4.27 & Q1 & Pass & 24.55 & - & G \\
\hline 3 & Spurt & $635 \mathrm{~cm} / \mathrm{s}$ & $2 \mathrm{ml}$ & Right & Pass & 10.72 & - & Pass & 51.26 & - & Pass & 45.62 & - & G \\
\hline 4 & Spurt & $635 \mathrm{~cm} / \mathrm{s}$ & $2 \mathrm{ml}$ & Left & Pass & 8.56 & - & Pass & 47.26 & v & Pass & 41.23 & - & G \\
\hline 1 & Spray & $500 \mathrm{~cm} / \mathrm{s}$ & $1 \mathrm{ml}$ & Up & Fail & 11.22 & L Q3 & Pass & 33.25 & - & Pass & 50.36 & - & G \\
\hline 2 & Spray & $500 \mathrm{~cm} / \mathrm{s}$ & $1 \mathrm{ml}$ & Down & Pass & 2.75 & - & Pass & 36.12 & - & Pass & 49.51 & - & G \\
\hline 3 & Spray & $500 \mathrm{~cm} / \mathrm{s}$ & $1 \mathrm{ml}$ & Right & Fail & 12.23 & L Q4 & Pass & 30.23 & - & Pass & 33.26 & - & G \\
\hline 4 & Spray & $500 \mathrm{~cm} / \mathrm{s}$ & $1 \mathrm{ml}$ & Left & Fail & 14.78 & R Q3 & Pass & 31.74 & - & Pass & 34.51 & - & G \\
\hline 1 & Spurt & $635 \mathrm{~cm} / \mathrm{s}$ & $2 \mathrm{ml}$ & Up & Fail & 14.45 & L Q3 & Pass & 3.01 & - & Pass & 33.09 & - & $\mathrm{H}$ \\
\hline 2 & Spurt & $635 \mathrm{~cm} / \mathrm{s}$ & $2 \mathrm{ml}$ & Down & Pass & 0.91 & - & Pass & 44.73 & - & Pass & 66.37 & - & $\mathrm{H}$ \\
\hline 3 & Spurt & $635 \mathrm{~cm} / \mathrm{s}$ & $2 \mathrm{ml}$ & Right & Pass & 15.23 & - & Pass & 45.38 & - & Pass & 35.42 & - & $\mathrm{H}$ \\
\hline 4 & Spurt & $635 \mathrm{~cm} / \mathrm{s}$ & $2 \mathrm{ml}$ & Left & Pass & 16.48 & - & Pass & 44.72 & - & Pass & 33.64 & - & $\mathrm{H}$ \\
\hline 1 & Spray & $500 \mathrm{~cm} / \mathrm{s}$ & $1 \mathrm{ml}$ & Up & Fail & 7.03 & L Q2 & Pass & 34.28 & - & Pass & 58.75 & - & $\mathrm{H}$ \\
\hline 2 & Spray & $500 \mathrm{~cm} / \mathrm{s}$ & $1 \mathrm{ml}$ & Down & Pass & 5.78 & - & Pass & 44.97 & - & Pass & 76.8 & - & $\mathrm{H}$ \\
\hline 3 & Spray & $500 \mathrm{~cm} / \mathrm{s}$ & $1 \mathrm{ml}$ & Right & Pass & 9.54 & - & Pass & 48.39 & - & Pass & 33.47 & - & $\mathrm{H}$ \\
\hline 4 & Spray & $500 \mathrm{~cm} / \mathrm{s}$ & $1 \mathrm{ml}$ & Left & Pass & 10.62 & - & Pass & 45.98 & - & Pass & 29.17 & - & $\mathrm{H}$ \\
\hline 1 & Spurt & $635 \mathrm{~cm} / \mathrm{s}$ & $2 \mathrm{ml}$ & Up & Pass & 12.97 & - & Pass & 2.95 & - & Pass & 31.32 & - & $\mathrm{H}$ \\
\hline 2 & Spurt & $635 \mathrm{~cm} / \mathrm{s}$ & $2 \mathrm{ml}$ & Down & Fail & 17.76 & R Q1 & Pass & 2.26 & - & Fail & Ran Thru & Q2/Q3 & $\mathrm{H}$ \\
\hline 3 & Spurt & $635 \mathrm{~cm} / \mathrm{s}$ & $2 \mathrm{ml}$ & Right & Pass & 12.02 & - & Pass & 45.52 & - & Pass & 36.63 & - & $\mathrm{H}$ \\
\hline 4 & Spurt & $635 \mathrm{~cm} / \mathrm{s}$ & $2 \mathrm{ml}$ & Left & Pass & 15.22 & - & Pass & 44.54 & - & Pass & 39.52 & - & $\mathrm{H}$ \\
\hline 1 & Spray & $500 \mathrm{~cm} / \mathrm{s}$ & $1 \mathrm{ml}$ & Up & Fail & 4.55 & R Q4 & Pass & 44.7 & - & Pass & 67.76 & - & $\mathrm{H}$ \\
\hline 2 & Spray & $500 \mathrm{~cm} / \mathrm{s}$ & $1 \mathrm{ml}$ & Down & Pass & 6.53 & - & Pass & 48.76 & - & Pass & 69.43 & - & $\mathrm{H}$ \\
\hline 3 & Spray & $500 \mathrm{~cm} / \mathrm{s}$ & $1 \mathrm{ml}$ & Right & Pass & 13.96 & - & Pass & 50.1 & - & Pass & 32.81 & - & $\mathrm{H}$ \\
\hline 4 & Spray & $500 \mathrm{~cm} / \mathrm{s}$ & $1 \mathrm{ml}$ & Left & Pass & 10.52 & - & Pass & 39.03 & - & Pass & 21.28 & - & $\mathrm{H}$ \\
\hline 1 & Spurt & $635 \mathrm{~cm} / \mathrm{s}$ & $2 \mathrm{ml}$ & Up & Fail & 9.22 & L Q2 & Pass & 6.8 & - & Pass & 36.73 & - & $\mathrm{H}$ \\
\hline 2 & Spurt & $635 \mathrm{~cm} / \mathrm{s}$ & $2 \mathrm{ml}$ & Down & Fail & 4.53 & R Q2 & Pass & 35.05 & - & Pass & 59.81 & - & $\mathrm{H}$ \\
\hline 3 & Spurt & $635 \mathrm{~cm} / \mathrm{s}$ & $2 \mathrm{ml}$ & Right & Pass & 16.04 & - & Pass & 53.63 & - & Pass & 39.48 & - & $\mathrm{H}$ \\
\hline 4 & Spurt & $635 \mathrm{~cm} / \mathrm{s}$ & $2 \mathrm{ml}$ & Left & Pass & 15.27 & - & Pass & 48.52 & - & Pass & 38.39 & - & $\mathrm{H}$ \\
\hline 1 & Spray & $500 \mathrm{~cm} / \mathrm{s}$ & $1 \mathrm{ml}$ & Up & Fail & 15.26 & L Q2 & Pass & 36.46 & - & Pass & 60.74 & - & $\mathrm{H}$ \\
\hline 2 & Spray & $500 \mathrm{~cm} / \mathrm{s}$ & $1 \mathrm{ml}$ & Down & Pass & 7.01 & - & Pass & 56.56 & - & Pass & 82.25 & - & $\mathrm{H}$ \\
\hline 3 & Spray & $500 \mathrm{~cm} / \mathrm{s}$ & $1 \mathrm{ml}$ & Right & Pass & 15.48 & - & Pass & 53.85 & - & Pass & 40.23 & - & $\mathrm{H}$ \\
\hline 4 & Spray & $500 \mathrm{~cm} / \mathrm{s}$ & $1 \mathrm{ml}$ & Left & Pass & 6.76 & - & Pass & 37.79 & - & Pass & 22.29 & - & $\mathrm{H}$ \\
\hline 1 & Spurt & $635 \mathrm{~cm} / \mathrm{s}$ & $2 \mathrm{ml}$ & Up & Pass & 9.45 & - & Pass & 7.26 & - & Pass & 35.79 & - & $\mathrm{H}$ \\
\hline 2 & Spurt & $635 \mathrm{~cm} / \mathrm{s}$ & $2 \mathrm{ml}$ & Down & Fail & 13.88 & R Q4 & Fail & Ran Thru & Q2/Q3 & Fail & Ran Thru & Q2/Q3 & $\mathrm{H}$ \\
\hline 3 & Spurt & $635 \mathrm{~cm} / \mathrm{s}$ & $2 \mathrm{ml}$ & Right & Pass & 8.82 & - & Pass & 54.96 & - & Pass & 41.88 & - & $\mathrm{H}$ \\
\hline 4 & Spurt & $635 \mathrm{~cm} / \mathrm{s}$ & $2 \mathrm{ml}$ & Left & Pass & 12.54 & - & Pass & 52.49 & - & Pass & 53.23 & - & $\mathrm{H}$ \\
\hline 1 & Spray & $500 \mathrm{~cm} / \mathrm{s}$ & $1 \mathrm{ml}$ & Up & Fail & 9.6 & LQ2 & Pass & 39.85 & - & Pass & 60.2 & - & $\mathrm{H}$ \\
\hline 2 & Spray & $500 \mathrm{~cm} / \mathrm{s}$ & $1 \mathrm{ml}$ & Down & Pass & 5.03 & - & Pass & 47.3 & - & Pass & 70.37 & - & $\mathrm{H}$ \\
\hline 3 & Spray & $500 \mathrm{~cm} / \mathrm{s}$ & $1 \mathrm{ml}$ & Right & Pass & 8.11 & - & Pass & 50.64 & - & Pass & 38.77 & - & $\mathrm{H}$ \\
\hline 4 & Spray & $500 \mathrm{~cm} / \mathrm{s}$ & $1 \mathrm{ml}$ & Left & Pass & 9.43 & - & Pass & 39.72 & - & Pass & 23.62 & - & $\mathrm{H}$ \\
\hline 1 & Spurt & $635 \mathrm{~cm} / \mathrm{s}$ & $2 \mathrm{ml}$ & Up & Pass & 4.5 & - & Pass & 8.56 & - & Pass & 36.59 & - & $\mathrm{H}$ \\
\hline
\end{tabular}




\begin{tabular}{|c|c|c|c|c|c|c|c|c|c|c|c|c|c|c|}
\hline 2 & Spurt & $635 \mathrm{~cm} / \mathrm{s}$ & $2 \mathrm{ml}$ & Down & Fail & 2.45 & L Q4 & Fail & Ran Thru & Q4 & Fail & Ran Thru & Q1/Q4 & $\mathrm{H}$ \\
\hline 3 & Spurt & $635 \mathrm{~cm} / \mathrm{s}$ & $2 \mathrm{ml}$ & Right & Pass & 9.58 & - & Pass & 50.23 & - & Pass & 42.21 & - & $\mathrm{H}$ \\
\hline 4 & Spurt & $635 \mathrm{~cm} / \mathrm{s}$ & $2 \mathrm{ml}$ & Left & Pass & 11.21 & - & Pass & 48.27 & - & Pass & 40.54 & - & $\mathrm{H}$ \\
\hline 1 & Spray & $500 \mathrm{~cm} / \mathrm{s}$ & $1 \mathrm{ml}$ & Up & Fail & 5.96 & R Q3 & Pass & 31.24 & - & Pass & 56.15 & - & $\mathrm{H}$ \\
\hline 2 & Spray & $500 \mathrm{~cm} / \mathrm{s}$ & $1 \mathrm{ml}$ & Down & Pass & 6.04 & - & Pass & 56.17 & - & Pass & 79.7 & - & $\mathrm{H}$ \\
\hline 3 & Spray & $500 \mathrm{~cm} / \mathrm{s}$ & $1 \mathrm{ml}$ & Right & Pass & 10.13 & - & Pass & 45.19 & - & Pass & 31.1 & - & $\mathrm{H}$ \\
\hline 4 & Spray & $500 \mathrm{~cm} / \mathrm{s}$ & $1 \mathrm{ml}$ & Left & Pass & 8.69 & - & Pass & 38.56 & - & Pass & 23.37 & - & $\mathrm{H}$ \\
\hline 1 & Spurt & $635 \mathrm{~cm} / \mathrm{s}$ & $2 \mathrm{ml}$ & Up & Fail & 14.71 & R Q1 & Pass & 45.65 & - & Pass & 67.83 & - & $\mathrm{H}$ \\
\hline 2 & Spurt & $635 \mathrm{~cm} / \mathrm{s}$ & $2 \mathrm{ml}$ & Down & Fail & 15.25 & L Q4 & Fail & Ran Thru & Q1/Q4 & Fail & Q2/Q3 & & $\mathrm{H}$ \\
\hline 3 & Spurt & $635 \mathrm{~cm} / \mathrm{s}$ & $2 \mathrm{ml}$ & Right & Pass & 11.37 & - & Pass & 54.36 & - & Pass & 42.61 & - & $\mathrm{H}$ \\
\hline 4 & Spurt & $635 \mathrm{~cm} / \mathrm{s}$ & $2 \mathrm{ml}$ & Left & Pass & 7.25 & - & Pass & 47.46 & - & Pass & 44 & - & $\mathrm{H}$ \\
\hline 1 & Spray & $500 \mathrm{~cm} / \mathrm{s}$ & $1 \mathrm{ml}$ & Up & Fail & 7.91 & L Q2 & Pass & 33.38 & - & Pass & 56.97 & - & $\mathrm{H}$ \\
\hline 2 & Spray & $500 \mathrm{~cm} / \mathrm{s}$ & $1 \mathrm{ml}$ & Down & Pass & 5.13 & - & Pass & 41.79 & - & Pass & 60.91 & - & $\mathrm{H}$ \\
\hline 3 & Spray & $500 \mathrm{~cm} / \mathrm{s}$ & $1 \mathrm{ml}$ & Right & Pass & 14.39 & - & Pass & 51.03 & - & Pass & 38.56 & - & $\mathrm{H}$ \\
\hline 4 & Spray & $500 \mathrm{~cm} / \mathrm{s}$ & $1 \mathrm{ml}$ & Left & Pass & 5.64 & - & Pass & 34.34 & - & Pass & 27.18 & - & $\mathrm{H}$ \\
\hline 1 & Spurt & $635 \mathrm{~cm} / \mathrm{s}$ & $2 \mathrm{ml}$ & Up & Fail & 5.31 & R Q1 & Pass & 2.54 & - & Pass & 31.72 & - & $\mathrm{H}$ \\
\hline 2 & Spurt & $635 \mathrm{~cm} / \mathrm{s}$ & $2 \mathrm{ml}$ & Down & Fail & 11.13 & L Q4 & Fail & Ran Thru & Q1/Q4 & Fail & Ran Thru & Q1/Q4 & $\mathrm{H}$ \\
\hline 3 & Spurt & $635 \mathrm{~cm} / \mathrm{s}$ & $2 \mathrm{ml}$ & Right & Pass & 5.16 & - & Pass & 47.14 & - & Pass & 41.13 & - & $\mathrm{H}$ \\
\hline 4 & Spurt & $635 \mathrm{~cm} / \mathrm{s}$ & $2 \mathrm{ml}$ & Left & Pass & 20.58 & - & Pass & 48.24 & - & Pass & 46.94 & - & $\mathrm{H}$ \\
\hline 1 & Spray & $500 \mathrm{~cm} / \mathrm{s}$ & $1 \mathrm{ml}$ & Up & Fail & 8.45 & L Q4 & Pass & 28.69 & - & Pass & 58.5 & - & $\mathrm{H}$ \\
\hline 2 & Spray & $500 \mathrm{~cm} / \mathrm{s}$ & $1 \mathrm{ml}$ & Down & Pass & 5.27 & - & Pass & 51.83 & - & Pass & 73.93 & - & $\mathrm{H}$ \\
\hline 3 & Spray & $500 \mathrm{~cm} / \mathrm{s}$ & $1 \mathrm{ml}$ & Right & Pass & 14.09 & - & Pass & 39.21 & - & Pass & 31.52 & - & $\mathrm{H}$ \\
\hline 4 & Spray & $500 \mathrm{~cm} / \mathrm{s}$ & $1 \mathrm{ml}$ & Left & Pass & 2.59 & - & Pass & 45.4 & - & Pass & 31.47 & - & $\mathrm{H}$ \\
\hline 1 & Spurt & $635 \mathrm{~cm} / \mathrm{s}$ & $2 \mathrm{ml}$ & Up & Pass & 8.66 & - & Pass & 3.26 & - & Pass & 30.19 & - & $\mathrm{H}$ \\
\hline 2 & Spurt & $635 \mathrm{~cm} / \mathrm{s}$ & $2 \mathrm{ml}$ & Down & Pass & 1.91 & - & Fail & Ran Thu & Q1/Q4 & Pass & 11.18 & - & $\mathrm{H}$ \\
\hline 3 & Spurt & $635 \mathrm{~cm} / \mathrm{s}$ & $2 \mathrm{ml}$ & Right & Pass & 19.47 & - & Pass & 35.23 & - & Pass & 48.92 & - & $\mathrm{H}$ \\
\hline 4 & Spurt & $635 \mathrm{~cm} / \mathrm{s}$ & $2 \mathrm{ml}$ & Left & Pass & 19.83 & - & Pass & 47.48 & - & Pass & 44.59 & - & $\mathrm{H}$ \\
\hline 1 & Spray & $500 \mathrm{~cm} / \mathrm{s}$ & $1 \mathrm{ml}$ & Up & Pass & 6.37 & - & Pass & 45.27 & - & Pass & 66.03 & - & $\mathrm{H}$ \\
\hline 2 & Spray & $500 \mathrm{~cm} / \mathrm{s}$ & $1 \mathrm{ml}$ & Down & Pass & 9.45 & - & Pass & 52.21 & - & Pass & 72.05 & - & $\mathrm{H}$ \\
\hline 3 & Spray & $500 \mathrm{~cm} / \mathrm{s}$ & $1 \mathrm{ml}$ & Right & Pass & 8.38 & - & Pass & 50.64 & - & Pass & 37.85 & - & $\mathrm{H}$ \\
\hline 4 & Spray & $500 \mathrm{~cm} / \mathrm{s}$ & $1 \mathrm{ml}$ & Left & Pass & 11.21 & - & Pass & 41.63 & - & Pass & 23.52 & - & $\mathrm{H}$ \\
\hline 1 & Spurt & $635 \mathrm{~cm} / \mathrm{s}$ & $2 \mathrm{ml}$ & Up & Fail & 12.75 & L Q2 & Pass & 65.63 & - & Pass & 97.7 & - & $\mathrm{H}$ \\
\hline 2 & Spurt & $635 \mathrm{~cm} / \mathrm{s}$ & $2 \mathrm{ml}$ & Down & Fail & 14.32 & L Q2 & Fail & Ran Thru & Q1/Q4 & Fail & Ran Thur & Q1/Q4 & $\mathrm{H}$ \\
\hline 3 & Spurt & $635 \mathrm{~cm} / \mathrm{s}$ & $2 \mathrm{ml}$ & Right & Pass & 12.46 & - & Pass & 58.46 & - & Pass & 25.91 & - & $\mathrm{H}$ \\
\hline 4 & Spurt & $635 \mathrm{~cm} / \mathrm{s}$ & $2 \mathrm{ml}$ & Left & Pass & 8.26 & - & Pass & 43.69 & - & Pass & 49.38 & - & $\mathrm{H}$ \\
\hline 1 & Spray & $500 \mathrm{~cm} / \mathrm{s}$ & $1 \mathrm{ml}$ & Up & Fail & 14.95 & R Q1 & Pass & 50.2 & - & Pass & 69.44 & - & $\mathrm{H}$ \\
\hline 2 & Spray & $500 \mathrm{~cm} / \mathrm{s}$ & $1 \mathrm{ml}$ & Down & Pass & 6.68 & - & Pass & 57.64 & - & Pass & 79.43 & - & $\mathrm{H}$ \\
\hline 3 & Spray & $500 \mathrm{~cm} / \mathrm{s}$ & $1 \mathrm{ml}$ & Right & Pass & 8.42 & - & Pass & 51.94 & - & Pass & 40.3 & - & $\mathrm{H}$ \\
\hline 4 & Spray & $500 \mathrm{~cm} / \mathrm{s}$ & $1 \mathrm{ml}$ & Left & Pass & 7.78 & - & Pass & 35.42 & - & Pass & 32.84 & - & $\mathrm{H}$ \\
\hline 1 & Spurt & $635 \mathrm{~cm} / \mathrm{s}$ & $2 \mathrm{ml}$ & Up & Fail & 15.23 & L Q2 & Pass & 8 & - & Pass & 35.94 & - & $\mathrm{H}$ \\
\hline 2 & Spurt & $635 \mathrm{~cm} / \mathrm{s}$ & $2 \mathrm{ml}$ & Down & Fail & 21.6 & R Q4 & Fail & Ran Thru & Q2/Q3 & Fail & Ran Thru & Q2/Q3 & $\mathrm{H}$ \\
\hline 3 & Spurt & $635 \mathrm{~cm} / \mathrm{s}$ & $2 \mathrm{ml}$ & Right & Pass & 13.52 & - & Pass & 54.63 & - & Pass & 29.24 & - & $\mathrm{H}$ \\
\hline 4 & Spurt & $635 \mathrm{~cm} / \mathrm{s}$ & $2 \mathrm{ml}$ & Left & Pass & 5.26 & - & Pass & 48.59 & - & Pass & 45.01 & - & $\mathrm{H}$ \\
\hline 1 & Spray & $500 \mathrm{~cm} / \mathrm{s}$ & $1 \mathrm{ml}$ & Up & Fail & 2.28 & L Q2 & Pass & 37.93 & - & Pass & 63.29 & - & $\mathrm{H}$ \\
\hline 2 & Spray & $500 \mathrm{~cm} / \mathrm{s}$ & $1 \mathrm{ml}$ & Down & Pass & 6.93 & - & Pass & 59.09 & - & Pass & 82.28 & - & $\mathrm{H}$ \\
\hline 3 & Spray & $500 \mathrm{~cm} / \mathrm{s}$ & $1 \mathrm{ml}$ & Right & Pass & 11.11 & - & Pass & 50.26 & - & Pass & 38.37 & - & $\mathrm{H}$ \\
\hline 4 & Spray & $500 \mathrm{~cm} / \mathrm{s}$ & $1 \mathrm{ml}$ & Left & Pass & 7.67 & - & Pass & 44.9 & - & Pass & 29.96 & - & $\mathrm{H}$ \\
\hline 1 & Spurt & $635 \mathrm{~cm} / \mathrm{s}$ & $2 \mathrm{ml}$ & Up & Fail & 19.02 & L Q4 & Pass & 39.57 & - & Pass & 61.21 & - & I \\
\hline $\begin{array}{l}2 \\
3\end{array}$ & $\begin{array}{l}\text { Spurt } \\
\text { Spurt }\end{array}$ & $\begin{array}{l}635 \mathrm{~cm} / \mathrm{s} \\
635 \mathrm{~cm} / \mathrm{s}\end{array}$ & $\begin{array}{l}2 \mathrm{ml} \\
2 \mathrm{ml}\end{array}$ & $\begin{array}{l}\text { Down } \\
\text { Right }\end{array}$ & $\begin{array}{l}\text { Fail } \\
\text { Pass }\end{array}$ & $\begin{array}{l}19.51 \\
19.59\end{array}$ & $\begin{array}{c}\text { R Q4 } \\
-\end{array}$ & $\begin{array}{l}\text { Pass } \\
\text { Pass }\end{array}$ & $\begin{array}{c}2.75 \\
39.55\end{array}$ & - & $\begin{array}{l}\text { Pass } \\
\text { Pass }\end{array}$ & $\begin{array}{c}3.26 \\
29.07\end{array}$ & - & I \\
\hline 4 & Spurt & $635 \mathrm{~cm} / \mathrm{s}$ & $2 \mathrm{ml}$ & Left & Pass & 15.69 & - & Pass & 56.74 & - & Pass & 31.52 & - & I \\
\hline 1 & Spray & $500 \mathrm{~cm} / \mathrm{s}$ & $1 \mathrm{ml}$ & Up & Fail & 6.91 & L Q1 & Pass & 31.2 & - & Pass & 61.46 & - & I \\
\hline 2 & Spray & $500 \mathrm{~cm} / \mathrm{s}$ & $1 \mathrm{ml}$ & Down & Pass & 3.84 & - & Pass & 34.74 & - & Pass & 59.91 & - & I \\
\hline 3 & Spray & $500 \mathrm{~cm} / \mathrm{s}$ & $1 \mathrm{ml}$ & Right & Fail & 18.24 & L Q4 & Pass & 33.98 & - & Pass & 49.41 & - & I \\
\hline
\end{tabular}




\begin{tabular}{|c|c|c|c|c|c|c|c|c|c|c|c|c|c|}
\hline 4 & Spray & $500 \mathrm{~cm} / \mathrm{s}$ & $1 \mathrm{ml}$ & Left & Pass & 1.43 & - & Pass & 35.38 & - & Pass & 39.97 & - \\
\hline 1 & Spurt & $635 \mathrm{~cm} / \mathrm{s}$ & $2 \mathrm{ml}$ & Up & Fail & 11.95 & L Q1 & Fail & Ran Thru & Q4 & Fail & Ran Thru & Q1/Q4 \\
\hline 2 & Spurt & $635 \mathrm{~cm} / \mathrm{s}$ & $2 \mathrm{ml}$ & Down & Fail & 14.73 & R Q4 & Pass & 2.15 & - & Pass & 4.67 & - \\
\hline 3 & Spurt & $635 \mathrm{~cm} / \mathrm{s}$ & $2 \mathrm{ml}$ & Right & Pass & 13.27 & - & Pass & 40.46 & - & Pass & 30.6 & - \\
\hline 4 & Spurt & $635 \mathrm{~cm} / \mathrm{s}$ & $2 \mathrm{ml}$ & Left & Pass & 18.37 & - & Pass & 51.49 & - & Pass & 49.08 & - \\
\hline 1 & Spray & $500 \mathrm{~cm} / \mathrm{s}$ & $1 \mathrm{ml}$ & Up & Fail & 5.67 & L Q4 & Pass & 32.77 & - & Pass & 62.06 & - \\
\hline 2 & Spray & $500 \mathrm{~cm} / \mathrm{s}$ & $1 \mathrm{ml}$ & Down & Pass & 3.33 & - & Pass & 34.73 & - & Pass & 57.07 & - \\
\hline 3 & Spray & $500 \mathrm{~cm} / \mathrm{s}$ & $1 \mathrm{ml}$ & Right & Pass & 2.95 & - & Pass & 34.3 & - & Pass & 45.09 & - \\
\hline 4 & Spray & $500 \mathrm{~cm} / \mathrm{s}$ & $1 \mathrm{ml}$ & Left & Pass & 2.95 & - & Pass & 34.38 & - & Pass & 34.93 & - \\
\hline 1 & Spurt & $635 \mathrm{~cm} / \mathrm{s}$ & $2 \mathrm{ml}$ & Up & Fail & 15.61 & R Q1 & Fail & Ran Thru & Q2/Q3 & Fail & Ran Thru & Q2/Q3 \\
\hline 2 & Spurt & $635 \mathrm{~cm} / \mathrm{s}$ & $2 \mathrm{ml}$ & Down & Fail & 11.37 & $\mathrm{~L} q 3$ & Fail & Ran Thru & Q4 & Fail & Ran Thru & Q2/Q3 \\
\hline 3 & Spurt & $635 \mathrm{~cm} / \mathrm{s}$ & $2 \mathrm{ml}$ & Right & Pass & 14.02 & - & Pass & 48.97 & - & Pass & 25.89 & - \\
\hline 4 & Spurt & $635 \mathrm{~cm} / \mathrm{s}$ & $2 \mathrm{ml}$ & Left & Pass & 14.14 & - & Pass & 47.12 & - & Pass & 37.21 & - \\
\hline 1 & Spray & $500 \mathrm{~cm} / \mathrm{s}$ & $1 \mathrm{ml}$ & Up & Fail & 3.24 & R Q4 & Pass & 37.89 & - & Pass & 57.56 & - \\
\hline 2 & Spray & $500 \mathrm{~cm} / \mathrm{s}$ & $1 \mathrm{ml}$ & Down & Pass & 4.59 & - & Pass & 33.83 & - & Pass & 58.71 & - \\
\hline 3 & Spray & $500 \mathrm{~cm} / \mathrm{s}$ & $1 \mathrm{ml}$ & Right & Fail & 22.98 & L Q4 & Pass & 42.81 & - & Pass & 40.65 & - \\
\hline 4 & Spray & $500 \mathrm{~cm} / \mathrm{s}$ & $1 \mathrm{ml}$ & Left & Fail & 21.36 & R Q3 & Pass & 34.76 & - & Pass & 40.95 & - \\
\hline 1 & Spurt & $635 \mathrm{~cm} / \mathrm{s}$ & $2 \mathrm{ml}$ & Up & Fail & 19.77 & L Q2 & Fail & Ran Thru & Q3 & Fail & Ran Thru & Q2/Q3 \\
\hline $\begin{array}{l}2 \\
3\end{array}$ & $\begin{array}{l}\text { Spurt } \\
\text { Spurt }\end{array}$ & $\begin{array}{l}635 \mathrm{~cm} / \mathrm{s} \\
635 \mathrm{~cm} / \mathrm{s}\end{array}$ & $\begin{array}{l}2 \mathrm{ml} \\
2 \mathrm{ml}\end{array}$ & $\begin{array}{l}\text { Down } \\
\text { Right }\end{array}$ & $\begin{array}{l}\text { Fail } \\
\text { Pass }\end{array}$ & $\begin{array}{l}16.47 \\
12.98\end{array}$ & R Q3 & $\begin{array}{l}\text { Fail } \\
\text { Pass }\end{array}$ & $\begin{array}{c}\text { Ran Thru } \\
41.46\end{array}$ & Q2/Q3 & $\begin{array}{l}\text { Fail } \\
\text { Pass }\end{array}$ & $\begin{array}{c}\text { Ran Thru } \\
45.08\end{array}$ & Q2/Q3 \\
\hline 4 & Spurt & $635 \mathrm{~cm} / \mathrm{s}$ & $2 \mathrm{ml}$ & Left & Pass & 24.78 & - & Pass & 41.12 & - & Pass & 37.58 & - \\
\hline 1 & Spray & $500 \mathrm{~cm} / \mathrm{s}$ & $1 \mathrm{ml}$ & Up & Fail & 17.02 & R Q1 & Pass & 33.66 & - & Pass & 54.69 & - \\
\hline 2 & Spray & $500 \mathrm{~cm} / \mathrm{s}$ & $1 \mathrm{ml}$ & Down & Pass & 4.02 & - & Pass & 37.21 & - & Pass & 62.57 & - \\
\hline 3 & Spray & $500 \mathrm{~cm} / \mathrm{s}$ & $1 \mathrm{ml}$ & Right & Pass & 2.33 & - & Pass & 34.49 & - & Pass & 30.21 & - \\
\hline 4 & Spray & $500 \mathrm{~cm} / \mathrm{s}$ & $1 \mathrm{ml}$ & Left & Pass & 2.51 & - & Pass & 35.38 & - & Pass & 44.6 & - \\
\hline 1 & Spurt & $635 \mathrm{~cm} / \mathrm{s}$ & $2 \mathrm{ml}$ & Up & Fail & 15.34 & R Q4 & Fail & Ran Thru & Q1 & Fail & Ran Thru & Q1/Q4 \\
\hline $\begin{array}{l}2 \\
3\end{array}$ & $\begin{array}{l}\text { Spurt } \\
\text { Spurt }\end{array}$ & $\begin{array}{l}635 \mathrm{~cm} / \mathrm{s} \\
635 \mathrm{~cm} / \mathrm{s}\end{array}$ & $\begin{array}{l}2 \mathrm{ml} \\
2 \mathrm{ml}\end{array}$ & $\begin{array}{l}\text { Down } \\
\text { Right }\end{array}$ & $\begin{array}{l}\text { Fail } \\
\text { Pass }\end{array}$ & $\begin{array}{l}15.71 \\
11.97\end{array}$ & R Q4 & $\begin{array}{r}\text { Fail } \\
\text { Pass }\end{array}$ & $\begin{array}{c}\text { Ran Thru } \\
49.09\end{array}$ & Q3/Q4 & $\begin{array}{c}\text { Fail } \\
\text { Pass }\end{array}$ & $\begin{array}{c}\text { Ran Thru } \\
38.49\end{array}$ & Q2/Q3 \\
\hline 4 & Spurt & $635 \mathrm{~cm} / \mathrm{s}$ & $2 \mathrm{ml}$ & Left & Pass & 15.9 & - & Pass & 50.52 & - & Pass & 37.47 & - \\
\hline 1 & Spray & $500 \mathrm{~cm} / \mathrm{s}$ & $1 \mathrm{ml}$ & Up & Fail & 18.46 & R Q4 & Pass & 38.47 & - & Pass & 59.52 & - \\
\hline 2 & Spray & $500 \mathrm{~cm} / \mathrm{s}$ & $1 \mathrm{ml}$ & Down & Pass & 2.25 & - & Pass & 31.69 & - & Pass & 55.65 & - \\
\hline 3 & Spray & $500 \mathrm{~cm} / \mathrm{s}$ & $1 \mathrm{ml}$ & Right & Pass & 7.55 & - & Pass & 50.37 & - & Pass & 44.24 & - \\
\hline 4 & Spray & $500 \mathrm{~cm} / \mathrm{s}$ & $1 \mathrm{ml}$ & Left & Pass & 2.74 & - & Pass & 38.57 & - & Pass & 42.01 & - \\
\hline 1 & Spurt & $635 \mathrm{~cm} / \mathrm{s}$ & $2 \mathrm{ml}$ & Up & Fail & 17.39 & L Q3 & Fail & Ran Thru & Q2/Q3 & Fail & Ran Thru & Q2/Q3 \\
\hline 2 & Spurt & $635 \mathrm{~cm} / \mathrm{s}$ & $2 \mathrm{ml}$ & Down & Fail & 7.09 & R Q4 & Fail & Ran Thru & Q3 & Fail & Ran Thru & Q1/Q4 \\
\hline 3 & Spurt & $635 \mathrm{~cm} / \mathrm{s}$ & $2 \mathrm{ml}$ & Right & Pass & 22.25 & - & Pass & 40.72 & - & Pass & 26.62 & - \\
\hline 4 & Spurt & $635 \mathrm{~cm} / \mathrm{s}$ & $2 \mathrm{ml}$ & Left & Pass & 18.56 & - & Pass & 34.12 & - & Pass & 31.56 & - \\
\hline 1 & Spray & $500 \mathrm{~cm} / \mathrm{s}$ & $1 \mathrm{ml}$ & Up & Fail & 3.35 & R Q4 & Pass & 38.66 & - & Pass & 59.47 & - \\
\hline 2 & Spray & $500 \mathrm{~cm} / \mathrm{s}$ & $1 \mathrm{ml}$ & Down & Pass & 1.88 & - & Pass & 33.68 & - & Pass & 55.43 & - \\
\hline 3 & Spray & $500 \mathrm{~cm} / \mathrm{s}$ & $1 \mathrm{ml}$ & Right & Pass & 3.21 & - & Pass & 36.45 & - & Pass & 49.12 & - \\
\hline 4 & Spray & $500 \mathrm{~cm} / \mathrm{s}$ & $1 \mathrm{ml}$ & Left & Pass & 2.74 & - & Pass & 40.23 & - & Pass & 51.02 & - \\
\hline 1 & Spurt & $635 \mathrm{~cm} / \mathrm{s}$ & $2 \mathrm{ml}$ & Up & Fail & 16.03 & R Q4 & Fail & Ran Thru & Q3 & Fail & Ran Thru & Q2/Q3 \\
\hline $\begin{array}{l}2 \\
3\end{array}$ & $\begin{array}{l}\text { Spurt } \\
\text { Spurt }\end{array}$ & $\begin{array}{l}635 \mathrm{~cm} / \mathrm{s} \\
635 \mathrm{~cm} / \mathrm{s}\end{array}$ & $\begin{array}{l}2 \mathrm{ml} \\
2 \mathrm{ml}\end{array}$ & $\begin{array}{l}\text { Down } \\
\text { Right }\end{array}$ & $\begin{array}{l}\text { Fail } \\
\text { Pass }\end{array}$ & $\begin{array}{l}8.64 \\
16.1\end{array}$ & L Q3 & $\begin{array}{r}\text { Fail } \\
\text { Pass }\end{array}$ & $\begin{array}{c}\text { Ran Thru } \\
55.16\end{array}$ & Q4 & $\begin{array}{c}\text { Fail } \\
\text { Pass }\end{array}$ & $\begin{array}{c}\text { Ran Thru } \\
41.28\end{array}$ & Q1/Q4 \\
\hline 4 & Spurt & $635 \mathrm{~cm} / \mathrm{s}$ & $2 \mathrm{ml}$ & Left & Pass & 12.31 & - & Pass & 51.26 & - & Pass & 35.78 & - \\
\hline 1 & Spray & $500 \mathrm{~cm} / \mathrm{s}$ & $1 \mathrm{ml}$ & Up & Fail & 9.24 & L Q4 & Pass & 34.68 & - & Pass & 55.26 & - \\
\hline 2 & Spray & $500 \mathrm{~cm} / \mathrm{s}$ & $1 \mathrm{ml}$ & Down & Pass & 0.68 & - & Pass & 30.48 & - & Pass & 51.03 & - \\
\hline 3 & Spray & $500 \mathrm{~cm} / \mathrm{s}$ & $1 \mathrm{ml}$ & Right & Pass & 1.56 & - & Pass & 31.21 & - & Pass & 48.75 & - \\
\hline 4 & Spray & $500 \mathrm{~cm} / \mathrm{s}$ & $1 \mathrm{ml}$ & Left & Fail & 19.23 & R Q3 & Pass & 33.61 & - & Pass & 47.89 & - \\
\hline 1 & Spurt & $635 \mathrm{~cm} / \mathrm{s}$ & $2 \mathrm{ml}$ & Up & Fail & 5.23 & L Q3 & Pass & 3.42 & - & Fail & Ran Thru & Q1/Q4 \\
\hline 2 & Spurt & $635 \mathrm{~cm} / \mathrm{s}$ & $2 \mathrm{ml}$ & Down & Fail & 14.69 & L Q4 & Pass & 2.51 & - & Pass & 1.54 & - \\
\hline 3 & Spurt & $635 \mathrm{~cm} / \mathrm{s}$ & $2 \mathrm{ml}$ & Right & Pass & 20.19 & - & Pass & 37.45 & - & Pass & 29.7 & - \\
\hline 4 & Spurt & $635 \mathrm{~cm} / \mathrm{s}$ & $2 \mathrm{ml}$ & Left & Pass & 16.87 & - & Pass & 52.36 & - & Pass & 31.25 & - \\
\hline 1 & Sprav & $500 \mathrm{~cm} / \mathrm{s}$ & $1 \mathrm{ml}$ & Up & Fail & 20.48 & R Q1 & Pass & 36.43 & - & Pass & 56.96 & - \\
\hline
\end{tabular}




\begin{tabular}{|c|c|c|c|c|c|c|c|c|c|c|c|c|c|}
\hline 2 & Spray & $500 \mathrm{~cm} / \mathrm{s}$ & $1 \mathrm{ml}$ & Down & Pass & 1.45 & - & Pass & 36.47 & - & Pass & 57.05 & - \\
\hline 3 & Spray & $500 \mathrm{~cm} / \mathrm{s}$ & $1 \mathrm{ml}$ & Right & Pass & 3.65 & - & Pass & 35.26 & - & Pass & 54.23 & - \\
\hline 4 & Spray & $500 \mathrm{~cm} / \mathrm{s}$ & $1 \mathrm{ml}$ & Left & Pass & 3.12 & - & Pass & 33.59 & - & Pass & 51.24 & - \\
\hline 1 & Spurt & $635 \mathrm{~cm} / \mathrm{s}$ & $2 \mathrm{ml}$ & Up & Fail & 14.25 & R Q4 & Fail & Ran Thru & Q2/Q3 & Fail & Ran Thru & Q2/Q3 \\
\hline 2 & Spurt & $635 \mathrm{~cm} / \mathrm{s}$ & $2 \mathrm{ml}$ & Down & Fail & 12.1 & LQ3 & Fail & Ran Thru & Q3 & Fail & Ran Thru & Q2/Q3 \\
\hline 3 & Spurt & $635 \mathrm{~cm} / \mathrm{s}$ & $2 \mathrm{ml}$ & Right & Pass & 12.27 & - & Pass & 41.64 & - & Pass & 31.06 & - \\
\hline 4 & Spurt & $635 \mathrm{~cm} / \mathrm{s}$ & $2 \mathrm{ml}$ & Left & Pass & 17.48 & - & Pass & 50.49 & - & Pass & 49.28 & - \\
\hline 1 & Spray & $500 \mathrm{~cm} / \mathrm{s}$ & $1 \mathrm{ml}$ & Up & Fail & 22.31 & LQ1 & Pass & 38.04 & - & Pass & 61.37 & - \\
\hline 2 & Spray & $500 \mathrm{~cm} / \mathrm{s}$ & $1 \mathrm{ml}$ & Down & Pass & 1.72 & - & Pass & 26.83 & - & Pass & 52.74 & - \\
\hline 3 & Spray & $500 \mathrm{~cm} / \mathrm{s}$ & $1 \mathrm{ml}$ & Right & Fail & 20.26 & LQ4 & Pass & 19.54 & - & Pass & 48.51 & - \\
\hline 4 & Spray & $500 \mathrm{~cm} / \mathrm{s}$ & $1 \mathrm{ml}$ & Left & Fail & 17.54 & R Q3 & Pass & 29.65 & - & Pass & 49.21 & - \\
\hline 1 & Spurt & $635 \mathrm{~cm} / \mathrm{s}$ & $2 \mathrm{ml}$ & Up & Fail & 12.01 & LQ2 & Fail & Ran Thru & Q4 & Fail & Ran Thru & Q1/Q4 \\
\hline 2 & Spurt & $635 \mathrm{~cm} / \mathrm{s}$ & $2 \mathrm{ml}$ & Down & Fail & 13.4 & LQ3 & Fail & Ran Thru & Q1/Q2/Q3/Q4 & Fail & Ran Thru & $\mathrm{Q} 1 / \mathrm{Q} 2 / \mathrm{Q} 3 / \mathrm{Q} 4$ \\
\hline 3 & Spurt & $635 \mathrm{~cm} / \mathrm{s}$ & $2 \mathrm{ml}$ & Right & Pass & 12.28 & - & Pass & 41.46 & - & Pass & 46.08 & - \\
\hline 4 & Spurt & $635 \mathrm{~cm} / \mathrm{s}$ & $2 \mathrm{ml}$ & Left & Pass & 18.32 & - & Pass & 40.21 & - & Pass & 35.48 & - \\
\hline 1 & Spray & $500 \mathrm{~cm} / \mathrm{s}$ & $1 \mathrm{ml}$ & Up & Fail & 8.69 & L Q4 & Pass & 35.98 & - & Pass & 55.53 & - \\
\hline 2 & Spray & $500 \mathrm{~cm} / \mathrm{s}$ & $1 \mathrm{ml}$ & Down & Pass & 3.34 & - & Pass & 34.11 & - & Pass & 55.11 & - \\
\hline 3 & Spray & $500 \mathrm{~cm} / \mathrm{s}$ & $1 \mathrm{ml}$ & Right & Pass & 4.51 & - & Pass & 33.67 & - & Pass & 48.56 & - \\
\hline 4 & Spray & $500 \mathrm{~cm} / \mathrm{s}$ & $1 \mathrm{ml}$ & Left & Pass & 1.98 & - & Pass & 30.48 & - & Pass & 45.22 & - \\
\hline 1 & Spurt & $635 \mathrm{~cm} / \mathrm{s}$ & $2 \mathrm{ml}$ & Up & Fail & 6 & LQ2 & Pass & 3.56 & - & Pass & 6.46 & - \\
\hline 2 & Spurt & $635 \mathrm{~cm} / \mathrm{s}$ & $2 \mathrm{ml}$ & Down & Fail & 7.5 & R Q4 & Fail & Ran Thru & Q4 & Fail & Ran Thru & Q1/Q4 \\
\hline 3 & Spurt & $635 \mathrm{~cm} / \mathrm{s}$ & $2 \mathrm{ml}$ & Right & Pass & 15.5 & - & Pass & 38.56 & - & Pass & 32.35 & - \\
\hline 4 & Spurt & $635 \mathrm{~cm} / \mathrm{s}$ & $2 \mathrm{ml}$ & Left & Pass & 26.08 & - & Pass & 59.23 & - & Pass & 57.84 & - \\
\hline 1 & Spray & $500 \mathrm{~cm} / \mathrm{s}$ & $1 \mathrm{ml}$ & Up & Fail & 14.62 & L Q4 & Pass & 36.3 & - & Pass & 47.6 & - \\
\hline 2 & Spray & $500 \mathrm{~cm} / \mathrm{s}$ & $1 \mathrm{ml}$ & Down & Fail & 2.52 & L Q4 & Pass & 34.24 & - & Pass & 51.02 & - \\
\hline 3 & Spray & $500 \mathrm{~cm} / \mathrm{s}$ & $1 \mathrm{ml}$ & Right & Fail & 15.24 & L Q1 & Pass & 36.64 & - & Pass & 36.33 & - \\
\hline 4 & Spray & $500 \mathrm{~cm} / \mathrm{s}$ & $1 \mathrm{ml}$ & Left & Fail & 16.31 & $\mathrm{R} Q 3$ & Pass & 27.33 & - & Pass & 34.13 & - \\
\hline 1 & Spurt & $635 \mathrm{~cm} / \mathrm{s}$ & $2 \mathrm{ml}$ & Up & Fail & 9 & L Q1 & Pass & 2.75 & - & Pass & 3.25 & - \\
\hline 2 & Spurt & $635 \mathrm{~cm} / \mathrm{s}$ & $2 \mathrm{ml}$ & Down & Fail & 16.5 & L Q1 & Fail & Ran Thru & Q4 & Fail & Ran Thru & Q1/Q4 \\
\hline 3 & Spurt & $635 \mathrm{~cm} / \mathrm{s}$ & $2 \mathrm{ml}$ & Right & Pass & 23.75 & - & Pass & 45.49 & - & Pass & 35.38 & - \\
\hline 4 & Spurt & $635 \mathrm{~cm} / \mathrm{s}$ & $2 \mathrm{ml}$ & Left & Pass & 25.89 & - & Pass & 60.82 & - & Pass & 61.41 & - \\
\hline 1 & Spray & $500 \mathrm{~cm} / \mathrm{s}$ & $1 \mathrm{ml}$ & Up & Fail & 4.22 & R Q3 & Pass & 38.09 & - & Pass & 53.89 & - \\
\hline 2 & Spray & $500 \mathrm{~cm} / \mathrm{s}$ & $1 \mathrm{ml}$ & Down & Fail & 0.5 & L Q2 & Pass & 19.79 & - & Pass & 41.87 & - \\
\hline 3 & Spray & $500 \mathrm{~cm} / \mathrm{s}$ & $1 \mathrm{ml}$ & Right & Pass & 4.33 & - & Pass & 35.07 & - & Pass & 38.34 & - \\
\hline 4 & Spray & $500 \mathrm{~cm} / \mathrm{s}$ & $1 \mathrm{ml}$ & Left & Fail & 22.34 & R Q2 & Pass & 38.56 & - & Pass & 30.8 & - \\
\hline 1 & Spurt & $635 \mathrm{~cm} / \mathrm{s}$ & $2 \mathrm{ml}$ & Up & Fail & 4.29 & $\mathrm{R}$ Q4 & Pass & 56.47 & - & Pass & 33.78 & - \\
\hline 2 & Spurt & $635 \mathrm{~cm} / \mathrm{s}$ & $2 \mathrm{ml}$ & Down & Fail & 24 & LQ1 & Fail & Ran Thru & Q4 & Fail & Ran Thru & Q1/Q4 \\
\hline 3 & Spurt & $635 \mathrm{~cm} / \mathrm{s}$ & $2 \mathrm{ml}$ & Right & Pass & 14.56 & - & Pass & 36.32 & - & Pass & 28.89 & - \\
\hline 4 & Spurt & $635 \mathrm{~cm} / \mathrm{s}$ & $2 \mathrm{ml}$ & Left & Pass & 23.6 & - & Pass & 55.45 & - & Pass & 47.65 & - \\
\hline 1 & Spray & $500 \mathrm{~cm} / \mathrm{s}$ & $1 \mathrm{ml}$ & Up & Fail & 11 & R Q3 & Pass & 37.5 & - & Pass & 58.74 & - \\
\hline 2 & Spray & $500 \mathrm{~cm} / \mathrm{s}$ & $1 \mathrm{ml}$ & Down & Fail & 0.25 & L Q1 & Pass & 18.68 & - & Pass & 48.08 & - \\
\hline 3 & Spray & $500 \mathrm{~cm} / \mathrm{s}$ & $1 \mathrm{ml}$ & Right & Fail & 17.03 & LQ1 & Pass & 36.27 & - & Pass & 36.54 & - \\
\hline 4 & Spray & $500 \mathrm{~cm} / \mathrm{s}$ & $1 \mathrm{ml}$ & Left & Fail & 22.86 & $\mathrm{R} Q 2$ & Pass & 31.07 & - & Pass & 33.62 & - \\
\hline 1 & Spurt & $635 \mathrm{~cm} / \mathrm{s}$ & $2 \mathrm{ml}$ & Up & Fail & 7.5 & R Q4 & Pass & 27.94 & - & Pass & 31.53 & - \\
\hline 2 & Spurt & $635 \mathrm{~cm} / \mathrm{s}$ & $2 \mathrm{ml}$ & Down & Fail & 22.75 & R Q4 & Fail & ran thru & Q3 & Fail & ran thru & Q2/Q3 \\
\hline 3 & Spurt & $635 \mathrm{~cm} / \mathrm{s}$ & $2 \mathrm{ml}$ & Right & Pass & 23.06 & - & Pass & 44.93 & - & Pass & 32.87 & - \\
\hline 4 & Spurt & $635 \mathrm{~cm} / \mathrm{s}$ & $2 \mathrm{ml}$ & Left & Pass & 22.22 & - & Pass & 52.83 & - & Pass & 50.12 & - \\
\hline 1 & Spray & $500 \mathrm{~cm} / \mathrm{s}$ & $1 \mathrm{ml}$ & Up & Fail & 8 & LQ1 & Pass & 28.54 & - & Pass & 48.77 & - \\
\hline 2 & Spray & $500 \mathrm{~cm} / \mathrm{s}$ & $1 \mathrm{ml}$ & Down & Fail & 0.46 & R Q4 & Pass & 13.25 & - & Pass & 39.48 & - \\
\hline
\end{tabular}




\begin{tabular}{|c|c|c|c|c|c|c|c|c|c|c|c|c|c|}
\hline Spray & $500 \mathrm{~cm} / \mathrm{s}$ & $1 \mathrm{ml}$ & Right & Fail & 16.43 & LQ1 & Pass & 36.63 & - & Pass & 37.25 & - & $\mathrm{J}$ \\
\hline Spray & $500 \mathrm{~cm} / \mathrm{s}$ & $1 \mathrm{ml}$ & Left & Fail & 24.79 & R Q1 & Pass & 26.47 & - & Pass & 31.12 & - & $\mathrm{J}$ \\
\hline Spurt & $635 \mathrm{~cm} / \mathrm{s}$ & $2 \mathrm{ml}$ & Up & Fail & 2.43 & R Q1 & Pass & 19.87 & - & Pass & 34.84 & - & $J$ \\
\hline Spurt & $635 \mathrm{~cm} / \mathrm{s}$ & $2 \mathrm{ml}$ & Down & Fail & 16.46 & LQ3 & Fail & ran thur & Q4 & Fail & ran thru & Q1/Q4 & $\mathrm{J}$ \\
\hline Spurt & $635 \mathrm{~cm} / \mathrm{s}$ & $2 \mathrm{ml}$ & Right & Pass & 22 & - & Pass & 52.37 & - & Pass & 45.67 & - & J \\
\hline Spurt & $635 \mathrm{~cm} / \mathrm{s}$ & $2 \mathrm{ml}$ & Left & Pass & 18.17 & - & Pass & 56.51 & - & Pass & 47.2 & - & J \\
\hline Spray & $500 \mathrm{~cm} / \mathrm{s}$ & $1 \mathrm{ml}$ & Up & Fail & 0.33 & LQ1 & Pass & 14.53 & - & Pass & 41.42 & - & J \\
\hline Spray & $500 \mathrm{~cm} / \mathrm{s}$ & $1 \mathrm{ml}$ & Down & Fail & 14.78 & R Q3 & Pass & 30.88 & - & Pass & 45.58 & - & $\mathrm{J}$ \\
\hline Spray & $500 \mathrm{~cm} / \mathrm{s}$ & $1 \mathrm{ml}$ & Right & Fail & 23 & LQ4 & Pass & 38.92 & - & Pass & 37.04 & - & $J$ \\
\hline Spray & $500 \mathrm{~cm} / \mathrm{s}$ & $1 \mathrm{ml}$ & Left & Fail & 15.64 & R Q3 & Pass & 22.79 & - & Pass & 33.78 & - & $\mathrm{J}$ \\
\hline Spurt & $635 \mathrm{~cm} / \mathrm{s}$ & $2 \mathrm{ml}$ & Up & Fail & 2.58 & LQ1 & Pass & 2 & - & Fail & ran thru & Q1/Q4 & $J$ \\
\hline Spurt & $635 \mathrm{~cm} / \mathrm{s}$ & $2 \mathrm{ml}$ & Down & Fail & 3.28 & LQ1 & fail & ran thru & Q3 & Fail & ran thru & Q2/Q3 & $\mathrm{J}$ \\
\hline Spurt & $635 \mathrm{~cm} / \mathrm{s}$ & $2 \mathrm{ml}$ & Right & Pass & 25.14 & - & Pass & 52.47 & - & Pass & 44.56 & - & $\mathrm{J}$ \\
\hline Spurt & $635 \mathrm{~cm} / \mathrm{s}$ & $2 \mathrm{ml}$ & Left & Pass & 14.4 & - & Pass & 52.74 & - & Pass & 41.31 & - & $\mathrm{J}$ \\
\hline Spray & $500 \mathrm{~cm} / \mathrm{s}$ & $1 \mathrm{ml}$ & Up & Fail & 5.23 & R Q2 & Pass & 37.05 & - & Pass & 49.48 & - & J \\
\hline Spray & $500 \mathrm{~cm} / \mathrm{s}$ & $1 \mathrm{ml}$ & Down & Fail & 1.2 & R Q4 & Pass & 7.45 & - & Pass & 29.2 & - & J \\
\hline Spray & $500 \mathrm{~cm} / \mathrm{s}$ & $1 \mathrm{ml}$ & Right & Pass & 3.4 & - & Pass & 29.02 & - & Pass & 31.11 & - & $\mathrm{J}$ \\
\hline Spray & $500 \mathrm{~cm} / \mathrm{s}$ & $1 \mathrm{ml}$ & Left & Fail & 23.3 & R Q3 & Pass & 34.97 & - & Pass & 36.01 & - & $J$ \\
\hline Spurt & $635 \mathrm{~cm} / \mathrm{s}$ & $2 \mathrm{ml}$ & Up & Fail & 1.33 & L Q2 & Pass & 3.64 & - & Fail & ran thru & Q1/Q4 & $J$ \\
\hline Spurt & $635 \mathrm{~cm} / \mathrm{s}$ & $2 \mathrm{ml}$ & Down & Fail & 11.13 & LQ2 & Fail & ran thru & Q4 & Fail & ran thru & Q1/Q4 & J \\
\hline Spurt & $635 \mathrm{~cm} / \mathrm{s}$ & $2 \mathrm{ml}$ & Right & Pass & 19.76 & - & Pass & 58.07 & - & Pass & 43.47 & - & $J$ \\
\hline Spurt & $635 \mathrm{~cm} / \mathrm{s}$ & $2 \mathrm{ml}$ & Left & Pass & 24.46 & - & Pass & 36.96 & - & Pass & 53.26 & - & J \\
\hline Spray & $500 \mathrm{~cm} / \mathrm{s}$ & $1 \mathrm{ml}$ & Up & Fail & 10.18 & R Q3 & Pass & 33.65 & - & Pass & 50.99 & - & $\mathrm{J}$ \\
\hline Spray & $500 \mathrm{~cm} / \mathrm{s}$ & $1 \mathrm{ml}$ & Down & Fail & 1.87 & LQ3 & Pass & 22.02 & - & Pass & 43.96 & - & J \\
\hline Spray & $500 \mathrm{~cm} / \mathrm{s}$ & $1 \mathrm{ml}$ & Right & Fail & 24.31 & L Q4 & Pass & 29.85 & - & Pass & 35.19 & - & $\mathrm{J}$ \\
\hline Spray & $500 \mathrm{~cm} / \mathrm{s}$ & $1 \mathrm{ml}$ & Left & Fail & 16.88 & R Q1 & Pass & 27.88 & - & Pass & 33.92 & - & $\mathrm{J}$ \\
\hline Spurt & $635 \mathrm{~cm} / \mathrm{s}$ & $2 \mathrm{ml}$ & Up & Fail & 11.18 & R Q1 & Pass & 14 & - & Pass & 28.71 & - & $J$ \\
\hline Spurt & $635 \mathrm{~cm} / \mathrm{s}$ & $2 \mathrm{ml}$ & Down & Fail & 17.6 & LQ2 & Fail & Ran Thru & Q4 & Fail & ran thru & Q1/Q4 & $J$ \\
\hline Spurt & $635 \mathrm{~cm} / \mathrm{s}$ & $2 \mathrm{ml}$ & Right & Pass & 19.01 & - & Pass & 45.56 & - & Pass & 28.09 & - & $\mathrm{J}$ \\
\hline Spurt & $635 \mathrm{~cm} / \mathrm{s}$ & $2 \mathrm{ml}$ & Left & Pass & 25.78 & - & Pass & 40.53 & - & Pass & 26.34 & - & $J$ \\
\hline Spray & $500 \mathrm{~cm} / \mathrm{s}$ & $1 \mathrm{ml}$ & Up & Fail & 17.81 & LQ1 & Pass & 40.36 & - & Pass & 50.81 & - & J \\
\hline Spray & $500 \mathrm{~cm} / \mathrm{s}$ & $1 \mathrm{ml}$ & Down & Fail & 0.91 & R Q3 & Pass & 28.74 & - & Pass & 45.82 & - & $J$ \\
\hline Spray & $500 \mathrm{~cm} / \mathrm{s}$ & $1 \mathrm{ml}$ & Right & Fail & 1.15 & L Q4 & Pass & 36.45 & - & Pass & 39.24 & - & $J$ \\
\hline Spray & $500 \mathrm{~cm} / \mathrm{s}$ & $1 \mathrm{ml}$ & Left & Fail & 18.52 & R Q4 & Pass & 34.37 & - & Pass & 35.36 & - & $\mathrm{J}$ \\
\hline Spurt & $635 \mathrm{~cm} / \mathrm{s}$ & $2 \mathrm{ml}$ & Up & Fail & 10.32 & LQ2 & Pass & 20.29 & - & Pass & 39.87 & - & $J$ \\
\hline Spurt & $635 \mathrm{~cm} / \mathrm{s}$ & $2 \mathrm{ml}$ & Down & Fail & 2.87 & LQ2 & Fail & Ran Thru & Q3 & Fail & Ran thru & Q2/Q3 & $\mathrm{J}$ \\
\hline Spurt & $635 \mathrm{~cm} / \mathrm{s}$ & $2 \mathrm{ml}$ & Right & Pass & 15.11 & - & Pass & 41.9 & - & Pass & 29.02 & - & $J$ \\
\hline Spurt & $635 \mathrm{~cm} / \mathrm{s}$ & $2 \mathrm{ml}$ & Left & Pass & 17.09 & - & Pass & 40.01 & - & Pass & 30.7 & - & $J$ \\
\hline Spray & $500 \mathrm{~cm} / \mathrm{s}$ & $1 \mathrm{ml}$ & Up & Fail & 17.18 & R Q2 & Pass & 37.69 & - & Pass & 50.84 & - & $\mathrm{J}$ \\
\hline Spray & $500 \mathrm{~cm} / \mathrm{s}$ & $1 \mathrm{ml}$ & Down & Fail & 1.17 & R Q3 & Pass & 17.06 & - & Pass & 46.92 & - & $J$ \\
\hline Spray & $500 \mathrm{~cm} / \mathrm{s}$ & $1 \mathrm{ml}$ & Right & Fail & 21.25 & LQ3 & Pass & 33.45 & - & Pass & 35.28 & - & $\mathrm{J}$ \\
\hline Spray & $500 \mathrm{~cm} / \mathrm{s}$ & $1 \mathrm{ml}$ & Left & Fail & 7.08 & R Q4 & Pass & 30.36 & - & Pass & 34.24 & - & J \\
\hline Spurt & $635 \mathrm{~cm} / \mathrm{s}$ & $2 \mathrm{ml}$ & Up & Fail & 4.47 & L Q2 & Fail & Ran Thru & Q3 & Fail & Ran Thru & Q2/Q3 & $\mathrm{J}$ \\
\hline Spurt & $635 \mathrm{~cm} / \mathrm{s}$ & $2 \mathrm{ml}$ & Down & Fail & 12.59 & LQ3 & Pass & 1.75 & - & Fail & Ran Thru & Q1/Q4 & $J$ \\
\hline Spurt & $635 \mathrm{~cm} / \mathrm{s}$ & $2 \mathrm{ml}$ & Right & Pass & 14.41 & - & Pass & 42.83 & - & Pass & 33.39 & - & $J$ \\
\hline Spurt & $635 \mathrm{~cm} / \mathrm{s}$ & $2 \mathrm{ml}$ & Left & Pass & 14.52 & - & Pass & 43.08 & - & Pass & 32.25 & - & $J$ \\
\hline Spray & $500 \mathrm{~cm} / \mathrm{s}$ & $1 \mathrm{ml}$ & Up & Fail & 21.51 & L Q1 & Pass & 29.13 & - & Pass & 49.26 & - & $J$ \\
\hline Spray & $500 \mathrm{~cm} / \mathrm{s}$ & $1 \mathrm{ml}$ & Down & Fail & 3.2 & LQ1 & Pass & 22.95 & - & Pass & 44.24 & - & $J$ \\
\hline Spray & $500 \mathrm{~cm} / \mathrm{s}$ & $1 \mathrm{ml}$ & Right & Fail & 19.02 & L Q4 & Pass & 34.32 & - & Pass & 37.47 & - & $J$ \\
\hline Spray & $500 \mathrm{~cm} / \mathrm{s}$ & $1 \mathrm{ml}$ & Left & Fail & 15.93 & $\mathrm{R}$ Q2 & Pass & 25.72 & - & Pass & 33.1 & - & $\mathrm{J}$ \\
\hline
\end{tabular}


APPENDIX D: SAS DATA OUTPUT 
The LOGISTIC Procedure

\begin{tabular}{|l|l|}
\hline \multicolumn{2}{|c|}{ Model Information } \\
\hline Data Set & WORK.A \\
\hline Response Variable & eyespf \\
\hline Number of Response Levels & 2 \\
\hline Model & binary logit \\
\hline Optimization Technique & Fisher's scoring \\
\hline
\end{tabular}

\begin{tabular}{|l|l|}
\hline Number of Observations Read & 800 \\
\hline Number of Observations Used & 800 \\
\hline
\end{tabular}

\begin{tabular}{|r|l|r|}
\hline \multicolumn{3}{|c|}{ Response Profile } \\
\hline $\begin{array}{r}\text { Ordered } \\
\text { Value }\end{array}$ & eyespf & $\begin{array}{r}\text { Total } \\
\text { Frequency }\end{array}$ \\
\hline $\mathbf{1}$ & 0 & 563 \\
\hline $\mathbf{2}$ & 1 & 237 \\
\hline
\end{tabular}

Probability modeled is eyespf $=0$.

\begin{tabular}{|l|l|l|l|l|l|l|l|l|l|l|}
\hline \multicolumn{7}{|c|}{ Class Level Information } \\
\hline Class & Value & \multicolumn{7}{|c|}{ Design Variables } \\
\hline position1 & 1 & 1 & 0 & 0 & & & & & & \\
\hline & 2 & 0 & 1 & 0 & & & & & & \\
\hline & 3 & 0 & 0 & 1 & & & & & & \\
\hline & 4 & -1 & -1 & -1 & & & & & & \\
\hline type1 & Spray & 1 & & & & & & & & \\
\hline & Spurt & -1 & & & & & & & & \\
\hline Ensemble & A & 1 & 0 & 0 & 0 & 0 & 0 & 0 & 0 & 0 \\
\hline & B & 0 & 1 & 0 & 0 & 0 & 0 & 0 & 0 & 0 \\
\hline & C & 0 & 0 & 1 & 0 & 0 & 0 & 0 & 0 & 0 \\
\hline & D & 0 & 0 & 0 & 1 & 0 & 0 & 0 & 0 & 0 \\
\hline & E & 0 & 0 & 0 & 0 & 1 & 0 & 0 & 0 & 0 \\
\hline & F & 0 & 0 & 0 & 0 & 0 & 1 & 0 & 0 & 0 \\
\hline
\end{tabular}




\begin{tabular}{|l|l|l|l|l|l|l|l|l|l|l|}
\hline \multicolumn{10}{|c|}{ Class Level Information } \\
\hline Class & Value & \multicolumn{7}{|c|}{ Design Variables } \\
\hline & G & 0 & 0 & 0 & 0 & 0 & 0 & 1 & 0 & 0 \\
\hline & H & 0 & 0 & 0 & 0 & 0 & 0 & 0 & 1 & 0 \\
\hline & I & 0 & 0 & 0 & 0 & 0 & 0 & 0 & 0 & 1 \\
\hline & J & -1 & -1 & -1 & -1 & -1 & -1 & -1 & -1 & -1 \\
\hline
\end{tabular}

Model Convergence Status

Quasi-complete separation of data points detected.

Warning: The maximum likelihood estimate may not exist.

Warning: The LOGISTIC procedure continues in spite of the above warning. Results shown are based on the last maximum likelihood iteration. Validity of the model fit is questionable.

\begin{tabular}{|l|r|r|}
\hline \multicolumn{3}{|c|}{ Model Fit Statistics } \\
\hline Criterion & Intercept Only & $\begin{array}{r}\text { Intercept and } \\
\text { Covariates }\end{array}$ \\
\hline AIC & 974.245 & 524.657 \\
\hline SC & 978.930 & 590.241 \\
\hline $\mathbf{- 2}$ Log L & 972.245 & 496.657 \\
\hline
\end{tabular}

\begin{tabular}{|l|r|r|r|}
\hline \multicolumn{4}{|c|}{ Testing Global Null Hypothesis: BETA=0 } \\
\hline Test & Chi-Square & DF & Pr $>$ ChiSq \\
\hline Likelihood Ratio & 475.5886 & 13 & $<.0001$ \\
\hline Score & 361.8529 & 13 & $<.0001$ \\
\hline Wald & 157.3174 & 13 & $<.0001$ \\
\hline
\end{tabular}

\begin{tabular}{|l|r|r|r|}
\hline \multicolumn{4}{|c|}{ Type 3 Analysis of Effects } \\
\hline Effect & DF & $\begin{array}{r}\text { Wald } \\
\text { Chi-Square }\end{array}$ & Pr ChiSq \\
\hline position1 & 3 & 122.5091 & $<.0001$ \\
\hline type1 & 1 & 0.3130 & 0.5758 \\
\hline Ensemble & 9 & 128.1231 & $<.0001$ \\
\hline
\end{tabular}




\begin{tabular}{|l|l|r|r|r|r|r|}
\hline \multicolumn{7}{|c|}{ Analysis of Maximum Likelihood Estimates } \\
\hline Parameter & & DF & Estimate & $\begin{array}{r}\text { Standard } \\
\text { Error }\end{array}$ & $\begin{array}{r}\text { Wald } \\
\text { Chi-Square }\end{array}$ & Pr > ChiSq \\
\hline Intercept & & 1 & 3.0071 & 21.7286 & 0.0192 & 0.8899 \\
\hline position1 & $\mathbf{1}$ & 1 & -2.1815 & 0.2230 & 95.7103 & $<.0001$ \\
\hline position1 & $\mathbf{2}$ & 1 & -1.3424 & 0.2066 & 42.2004 & $<.0001$ \\
\hline position1 & $\mathbf{3}$ & 1 & 1.8694 & 0.2547 & 53.8631 & $<.0001$ \\
\hline type1 & Spray & 1 & 0.0627 & 0.1120 & 0.3130 & 0.5758 \\
\hline Ensemble & A & 1 & -0.0517 & 21.7311 & 0.0000 & 0.9981 \\
\hline Ensemble & B & 1 & 0.2385 & 21.7315 & 0.0001 & 0.9912 \\
\hline Ensemble & C & 1 & 13.3205 & 195.6 & 0.0046 & 0.9457 \\
\hline Ensemble & D & 1 & -1.3241 & 21.7302 & 0.0037 & 0.9514 \\
\hline Ensemble & E & 1 & 2.5303 & 21.7476 & 0.0135 & 0.9074 \\
\hline Ensemble & F & 1 & -1.7854 & 21.7302 & 0.0068 & 0.9345 \\
\hline Ensemble & G & 1 & -4.1692 & 21.7309 & 0.0368 & 0.8479 \\
\hline Ensemble & H & 1 & -1.4167 & 21.7302 & 0.0043 & 0.9480 \\
\hline Ensemble & I & 1 & -2.6410 & 21.7303 & 0.0148 & 0.9033 \\
\hline
\end{tabular}

\begin{tabular}{|l|r|r|r|}
\hline \multicolumn{4}{|c|}{ Odds Ratio Estimates } \\
\hline Effect & Point Estimate & \multicolumn{2}{|c|}{$\begin{array}{c}95 \% \text { Wald } \\
\text { Confidence Limits }\end{array}$} \\
\hline position1 1 vs 4 & 0.022 & 0.010 & 0.048 \\
\hline position1 2 vs 4 & 0.050 & 0.023 & 0.106 \\
\hline position1 3 vs 4 & 1.240 & 0.590 & 2.606 \\
\hline type1 Spray vs Spurt & 1.134 & 0.731 & 1.758 \\
\hline Ensemble A vs J & 104.534 & 35.706 & 306.037 \\
\hline Ensemble B vs J & 139.734 & 45.680 & 427.444 \\
\hline Ensemble C vs J & $>999.999$ & $<0.001$ & $>999.999$ \\
\hline Ensemble D vs J & 29.287 & 11.091 & 77.334 \\
\hline Ensemble E vs J & $>999.999$ & 161.369 & $>999.999$ \\
\hline Ensemble F vs J & 18.464 & 7.135 & 47.783 \\
\hline Ensemble G vs J & 1.702 & 0.743 & 3.901 \\
\hline Ensemble H vs J & 26.695 & 10.153 & 70.188 \\
\hline
\end{tabular}




\begin{tabular}{|l|r|r|r|}
\hline \multicolumn{3}{|c|}{ Odds Ratio Estimates } \\
\hline Effect & Point Estimate & \multicolumn{1}{|c|}{$\begin{array}{c}\text { 95\% Wald } \\
\text { Confidence Limits }\end{array}$} \\
\hline Ensemble I vs J & 7.848 & 3.164 & 19.462 \\
\hline
\end{tabular}

\begin{tabular}{|l|r|l|l|}
\hline \multicolumn{4}{|c|}{$\begin{array}{c}\text { Association of Predicted Probabilities and } \\
\text { Observed Responses }\end{array}$} \\
\hline Percent Concordant & 92.3 & Somers' D & 0.848 \\
\hline Percent Discordant & 7.5 & Gamma & 0.850 \\
\hline Percent Tied & 0.2 & Tau-a & 0.354 \\
\hline Pairs & 133431 & c & 0.924 \\
\hline
\end{tabular}


The SAS System

The LOGISTIC Procedure

\begin{tabular}{|l|l|}
\hline \multicolumn{2}{|c|}{ Model Information } \\
\hline Data Set & WORK.A \\
\hline Response Variable & nosepf \\
\hline Number of Response Levels & 2 \\
\hline Model & binary logit \\
\hline Optimization Technique & Fisher's scoring \\
\hline
\end{tabular}

\begin{tabular}{|l|l|}
\hline Number of Observations Read & 800 \\
\hline Number of Observations Used & 800 \\
\hline
\end{tabular}

\begin{tabular}{|r|l|r|}
\hline \multicolumn{3}{|c|}{ Response Profile } \\
\hline $\begin{array}{r}\text { Ordered } \\
\text { Value }\end{array}$ & nosepf & $\begin{array}{r}\text { Total } \\
\text { Frequency }\end{array}$ \\
\hline $\mathbf{1}$ & 0 & 737 \\
\hline $\mathbf{2}$ & 1 & 63 \\
\hline
\end{tabular}

Probability modeled is nosep $\mathrm{f}=0$.

\begin{tabular}{|l|l|l|l|l|l|l|l|l|l|l|}
\hline \multicolumn{7}{|c|}{ Class Level Information } \\
\hline Class & Value & \multicolumn{7}{|c|}{ Design Variables } \\
\hline position1 & 1 & 1 & 0 & 0 & & & & & & \\
\hline & 2 & 0 & 1 & 0 & & & & & & \\
\hline & 3 & 0 & 0 & 1 & & & & & & \\
\hline & 4 & -1 & -1 & -1 & & & & & & \\
\hline type1 & Spray & 1 & & & & & & & & \\
\hline & Spurt & -1 & & & & & & & & \\
\hline Ensemble & A & 1 & 0 & 0 & 0 & 0 & 0 & 0 & 0 & 0 \\
\hline & B & 0 & 1 & 0 & 0 & 0 & 0 & 0 & 0 & 0 \\
\hline & C & 0 & 0 & 1 & 0 & 0 & 0 & 0 & 0 & 0 \\
\hline & D & 0 & 0 & 0 & 1 & 0 & 0 & 0 & 0 & 0 \\
\hline & E & 0 & 0 & 0 & 0 & 1 & 0 & 0 & 0 & 0 \\
\hline & F & 0 & 0 & 0 & 0 & 0 & 1 & 0 & 0 & 0 \\
\hline
\end{tabular}




\begin{tabular}{|l|l|l|l|l|l|l|l|l|l|l|}
\hline \multicolumn{10}{|c|}{ Class Level Information } \\
\hline Class & Value & \multicolumn{7}{|c|}{ Design Variables } \\
\hline & G & 0 & 0 & 0 & 0 & 0 & 0 & 1 & 0 & 0 \\
\hline & H & 0 & 0 & 0 & 0 & 0 & 0 & 0 & 1 & 0 \\
\hline & I & 0 & 0 & 0 & 0 & 0 & 0 & 0 & 0 & 1 \\
\hline & J & -1 & -1 & -1 & -1 & -1 & -1 & -1 & -1 & -1 \\
\hline
\end{tabular}

Model Convergence Status

Quasi-complete separation of data points detected.

Warning: The maximum likelihood estimate may not exist.

Warning: The LOGISTIC procedure continues in spite of the above warning. Results shown are based on the last maximum likelihood iteration. Validity of the model fit is questionable.

\begin{tabular}{|l|r|r|}
\hline \multicolumn{3}{|c|}{ Model Fit Statistics } \\
\hline Criterion & Intercept Only & $\begin{array}{r}\text { Intercept and } \\
\text { Covariates }\end{array}$ \\
\hline AIC & 443.129 & 133.337 \\
\hline SC & 447.814 & 198.922 \\
\hline $\mathbf{- 2}$ Log L & 441.129 & 105.337 \\
\hline
\end{tabular}

\begin{tabular}{|l|r|r|r|}
\hline \multicolumn{4}{|c|}{ Testing Global Null Hypothesis: BETA=0 } \\
\hline Test & Chi-Square & DF & Pr $>$ ChiSq \\
\hline Likelihood Ratio & 335.7918 & 13 & $<.0001$ \\
\hline Score & 241.2354 & 13 & $<.0001$ \\
\hline Wald & 41.0603 & 13 & $<.0001$ \\
\hline
\end{tabular}

\begin{tabular}{|l|r|r|r|}
\hline \multicolumn{4}{|c|}{ Type 3 Analysis of Effects } \\
\hline Effect & DF & $\begin{array}{r}\text { Wald } \\
\text { Chi-Square }\end{array}$ & Pr ChiSq \\
\hline position1 & 3 & 36.6243 & $<.0001$ \\
\hline type1 & 1 & 0.0203 & 0.8868 \\
\hline Ensemble & 9 & 23.4097 & 0.0053 \\
\hline
\end{tabular}




\begin{tabular}{|l|l|r|r|r|r|r|}
\hline \multicolumn{7}{|c|}{ Analysis of Maximum Likelihood Estimates } \\
\hline Parameter & & DF & Estimate & $\begin{array}{r}\text { Standard } \\
\text { Error }\end{array}$ & $\begin{array}{r}\text { Wald } \\
\text { Chi-Square }\end{array}$ & Pr > ChiSq \\
\hline Intercept & & 1 & 20.6033 & 96.9257 & 0.0452 & 0.8317 \\
\hline position1 & $\mathbf{1}$ & 1 & -5.6956 & 64.6752 & 0.0078 & 0.9298 \\
\hline position1 & $\mathbf{2}$ & 1 & -9.5151 & 64.6761 & 0.0216 & 0.8830 \\
\hline position1 & $\mathbf{3}$ & 1 & 7.6053 & 144.6 & 0.0028 & 0.9581 \\
\hline type1 & Spray & 1 & 8.0958 & 56.8641 & 0.0203 & 0.8868 \\
\hline Ensemble & A & 1 & -4.0433 & 44.4794 & 0.0083 & 0.9276 \\
\hline Ensemble & B & 1 & 10.4283 & 233.9 & 0.0020 & 0.9644 \\
\hline Ensemble & C & 1 & 10.4283 & 233.9 & 0.0020 & 0.9644 \\
\hline Ensemble & D & 1 & -1.5728 & 44.4816 & 0.0013 & 0.9718 \\
\hline Ensemble & E & 1 & 10.4283 & 233.9 & 0.0020 & 0.9644 \\
\hline Ensemble & F & 1 & -4.4617 & 44.4796 & 0.0101 & 0.9201 \\
\hline Ensemble & G & 1 & -5.7610 & 44.4803 & 0.0168 & 0.8969 \\
\hline Ensemble & H & 1 & -3.6525 & 44.4792 & 0.0067 & 0.9346 \\
\hline Ensemble & I & 1 & -6.8914 & 44.4808 & 0.0240 & 0.8769 \\
\hline
\end{tabular}

\begin{tabular}{|l|r|r|r|}
\hline \multicolumn{4}{|c|}{ Odds Ratio Estimates } \\
\hline Effect & Point Estimate & \multicolumn{2}{|c|}{$\begin{array}{c}95 \% \text { Wald } \\
\text { Confidence Limits }\end{array}$} \\
\hline position1 1 vs 4 & $<0.001$ & $<0.001$ & $>999.999$ \\
\hline position1 2 vs 4 & $<0.001$ & $<0.001$ & $>999.999$ \\
\hline position1 3 vs 4 & 1.000 & $<0.001$ & $>999.999$ \\
\hline type1 Spray vs Spurt & $>999.999$ & $<0.001$ & $>999.999$ \\
\hline Ensemble A vs J & 2.360 & 0.376 & 14.830 \\
\hline Ensemble B vs J & $>999.999$ & $<0.001$ & $>999.999$ \\
\hline Ensemble C vs J & $>999.999$ & $<0.001$ & $>999.999$ \\
\hline Ensemble D vs J & 27.921 & 3.415 & 228.254 \\
\hline Ensemble E vs J & $>999.999$ & $<0.001$ & $>999.999$ \\
\hline Ensemble F vs J & 1.553 & 0.245 & 9.836 \\
\hline Ensemble G vs J & 0.424 & 0.067 & 2.662 \\
\hline Ensemble H vs J & 3.489 & 0.559 & 21.792 \\
\hline
\end{tabular}




\begin{tabular}{|l|r|r|r|}
\hline \multicolumn{3}{|c|}{ Odds Ratio Estimates } \\
\hline Effect & Point Estimate & \multicolumn{2}{|c|}{$\begin{array}{c}\text { 95\% Wald } \\
\text { Confidence Limits }\end{array}$} \\
\hline Ensemble I vs J & 0.137 & 0.022 & 0.869 \\
\hline
\end{tabular}

\begin{tabular}{|l|r|l|r|}
\hline \multicolumn{4}{|c|}{$\begin{array}{c}\text { Association of Predicted Probabilities and } \\
\text { Observed Responses }\end{array}$} \\
\hline Percent Concordant & 99.0 & Somers' D & 0.982 \\
\hline Percent Discordant & 0.8 & Gamma & 0.985 \\
\hline Percent Tied & 0.3 & Tau-a & 0.143 \\
\hline Pairs & 46431 & c & 0.991 \\
\hline
\end{tabular}


The SAS System

The LOGISTIC Procedure

\begin{tabular}{|l|l|}
\hline \multicolumn{2}{|c|}{ Model Information } \\
\hline Data Set & WORK.A \\
\hline Response Variable & mouthpf \\
\hline Number of Response Levels & 2 \\
\hline Model & binary logit \\
\hline Optimization Technique & Fisher's scoring \\
\hline
\end{tabular}

\begin{tabular}{|l|l|}
\hline Number of Observations Read & 800 \\
\hline Number of Observations Used & 800 \\
\hline
\end{tabular}

\begin{tabular}{|r|l|r|}
\hline \multicolumn{3}{|c|}{ Response Profile } \\
\hline $\begin{array}{r}\text { Ordered } \\
\text { Value }\end{array}$ & mouthpf & $\begin{array}{r}\text { Total } \\
\text { Frequency }\end{array}$ \\
\hline $\mathbf{1}$ & 0 & 741 \\
\hline $\mathbf{2}$ & 1 & 59 \\
\hline
\end{tabular}

Probability modeled is mouth $\mathrm{f}=0$.

\begin{tabular}{|l|l|l|l|l|l|l|l|l|l|l|}
\hline \multicolumn{7}{|c|}{ Class Level Information } \\
\hline Class & Value & \multicolumn{7}{|c|}{ Design Variables } \\
\hline position1 & 1 & 1 & 0 & 0 & & & & & & \\
\hline & 2 & 0 & 1 & 0 & & & & & & \\
\hline & 3 & 0 & 0 & 1 & & & & & & \\
\hline & 4 & -1 & -1 & -1 & & & & & & \\
\hline type1 & Spray & 1 & & & & & & & & \\
\hline & Spurt & -1 & & & & & & & & \\
\hline Ensemble & A & 1 & 0 & 0 & 0 & 0 & 0 & 0 & 0 & 0 \\
\hline & B & 0 & 1 & 0 & 0 & 0 & 0 & 0 & 0 & 0 \\
\hline & C & 0 & 0 & 1 & 0 & 0 & 0 & 0 & 0 & 0 \\
\hline & D & 0 & 0 & 0 & 1 & 0 & 0 & 0 & 0 & 0 \\
\hline & E & 0 & 0 & 0 & 0 & 1 & 0 & 0 & 0 & 0 \\
\hline & F & 0 & 0 & 0 & 0 & 0 & 1 & 0 & 0 & 0 \\
\hline
\end{tabular}




\begin{tabular}{|l|l|l|l|l|l|l|l|l|l|l|}
\hline \multicolumn{10}{|c|}{ Class Level Information } \\
\hline Class & Value & \multicolumn{7}{|c|}{ Design Variables } \\
\hline & G & 0 & 0 & 0 & 0 & 0 & 0 & 1 & 0 & 0 \\
\hline & H & 0 & 0 & 0 & 0 & 0 & 0 & 0 & 1 & 0 \\
\hline & I & 0 & 0 & 0 & 0 & 0 & 0 & 0 & 0 & 1 \\
\hline & J & -1 & -1 & -1 & -1 & -1 & -1 & -1 & -1 & -1 \\
\hline
\end{tabular}

Model Convergence Status

Quasi-complete separation of data points detected.

Warning: The maximum likelihood estimate may not exist.

Warning: The LOGISTIC procedure continues in spite of the above warning. Results shown are based on the last maximum likelihood iteration. Validity of the model fit is questionable.

\begin{tabular}{|l|r|r|}
\hline \multicolumn{3}{|c|}{ Model Fit Statistics } \\
\hline Criterion & Intercept Only & $\begin{array}{r}\text { Intercept and } \\
\text { Covariates }\end{array}$ \\
\hline AIC & 423.172 & 147.969 \\
\hline SC & 427.857 & 213.554 \\
\hline $\mathbf{- 2}$ Log L & 421.172 & 119.969 \\
\hline
\end{tabular}

\begin{tabular}{|l|r|r|r|}
\hline \multicolumn{4}{|c|}{ Testing Global Null Hypothesis: BETA=0 } \\
\hline Test & Chi-Square & DF & Pr $>$ ChiSq \\
\hline Likelihood Ratio & 301.2031 & 13 & $<.0001$ \\
\hline Score & 215.7963 & 13 & $<.0001$ \\
\hline Wald & 34.0715 & 13 & 0.0012 \\
\hline
\end{tabular}

\begin{tabular}{|l|r|r|r|}
\hline \multicolumn{4}{|c|}{ Type 3 Analysis of Effects } \\
\hline Effect & DF & $\begin{array}{r}\text { Wald } \\
\text { Chi-Square }\end{array}$ & Pr $>$ ChiSq \\
\hline position1 & 3 & 26.2271 & $<.0001$ \\
\hline type1 & 1 & 0.0173 & 0.8954 \\
\hline Ensemble & 9 & 26.6381 & 0.0016 \\
\hline
\end{tabular}




\begin{tabular}{|l|l|r|r|r|r|r|}
\hline \multicolumn{7}{|c|}{ Analysis of Maximum Likelihood Estimates } \\
\hline Parameter & & DF & Estimate & $\begin{array}{r}\text { Standard } \\
\text { Error }\end{array}$ & $\begin{array}{r}\text { Wald } \\
\text { Chi-Square }\end{array}$ & Pr > ChiSq \\
\hline Intercept & & 1 & 20.4299 & 100.6 & 0.0413 & 0.8390 \\
\hline position1 & $\mathbf{1}$ & 1 & -6.1559 & 65.4768 & 0.0088 & 0.9251 \\
\hline position1 & $\mathbf{2}$ & 1 & -9.0621 & 65.4775 & 0.0192 & 0.8899 \\
\hline position1 & $\mathbf{3}$ & 1 & 7.6090 & 146.4 & 0.0027 & 0.9586 \\
\hline type1 & Spray & 1 & 7.9343 & 60.3654 & 0.0173 & 0.8954 \\
\hline Ensemble & A & 1 & -3.5928 & 46.7437 & 0.0059 & 0.9387 \\
\hline Ensemble & B & 1 & 10.1180 & 245.9 & 0.0017 & 0.9672 \\
\hline Ensemble & C & 1 & 10.1180 & 245.9 & 0.0017 & 0.9672 \\
\hline Ensemble & D & 1 & -1.9675 & 46.7463 & 0.0018 & 0.9664 \\
\hline Ensemble & E & 1 & 10.1180 & 245.9 & 0.0017 & 0.9672 \\
\hline Ensemble & F & 1 & -4.8867 & 46.7438 & 0.0109 & 0.9167 \\
\hline Ensemble & G & 1 & -3.2577 & 46.7439 & 0.0049 & 0.9444 \\
\hline Ensemble & H & 1 & -3.9170 & 46.7437 & 0.0070 & 0.9332 \\
\hline Ensemble & I & 1 & -6.8762 & 46.7454 & 0.0216 & 0.8831 \\
\hline
\end{tabular}

\begin{tabular}{|l|r|r|r|}
\hline \multicolumn{4}{|c|}{ Odds Ratio Estimates } \\
\hline Effect & Point Estimate & \multicolumn{2}{|c|}{$\begin{array}{c}95 \% \text { Wald } \\
\text { Confidence Limits }\end{array}$} \\
\hline position1 1 vs 4 & $<0.001$ & $<0.001$ & $>999.999$ \\
\hline position1 2 vs 4 & $<0.001$ & $<0.001$ & $>999.999$ \\
\hline position1 3 vs 4 & 1.000 & $<0.001$ & $>999.999$ \\
\hline type1 Spray vs Spurt & $>999.999$ & $<0.001$ & $>999.999$ \\
\hline Ensemble A vs J & 9.617 & 1.750 & 52.837 \\
\hline Ensemble B vs J & $>999.999$ & $<0.001$ & $>999.999$ \\
\hline Ensemble C vs J & $>999.999$ & $<0.001$ & $>999.999$ \\
\hline Ensemble D vs J & 48.857 & 6.373 & 374.556 \\
\hline Ensemble E vs J & $>999.999$ & $<0.001$ & $>999.999$ \\
\hline Ensemble F vs J & 2.637 & 0.531 & 13.102 \\
\hline Ensemble G vs J & 13.446 & 2.359 & 76.620 \\
\hline Ensemble H vs J & 6.955 & 1.303 & 37.122 \\
\hline
\end{tabular}




\begin{tabular}{|l|r|r|r|}
\hline \multicolumn{3}{|c|}{ Odds Ratio Estimates } \\
\hline Effect & Point Estimate & \multicolumn{1}{|c|}{$\begin{array}{c}\text { 95\% Wald } \\
\text { Confidence Limits }\end{array}$} \\
\hline Ensemble I vs J & 0.361 & 0.069 & 1.875 \\
\hline
\end{tabular}

\begin{tabular}{|l|r|l|r|}
\hline \multicolumn{4}{|c|}{$\begin{array}{c}\text { Association of Predicted Probabilities and } \\
\text { Observed Responses }\end{array}$} \\
\hline Percent Concordant & 98.7 & Somers' D & 0.976 \\
\hline Percent Discordant & 1.0 & Gamma & 0.980 \\
\hline Percent Tied & 0.3 & Tau-a & 0.134 \\
\hline Pairs & 43719 & c & 0.988 \\
\hline
\end{tabular}




\section{APPENDIX E: Curriculum Vitae}




\title{
CURRICULUM VITAE
}

\author{
Jeremy R. Gouzd \\ Laboratory Technician Level II \\ $\mathrm{NIOSH}$ \\ Evaluation and Testing Branch \\ Phone: 304.285.6031 \\ Email:Ltv5@cdc.gov \\ JGouzd2@gmail.com
}

\section{Education:}

B.S. - Mechanical Engineering, Fairmont State University, 11/2013, High

Honors Scholar graduate

M.S. - Education-Professional Studies, Fairmont State University, 5/2015

\section{Certifications:}

IS-00100.b - Introduction to Incident Command System ICS-100

IS-00200.b - Single Resources and Initial Action Incident, ICS-200

IS-00700.b - National Incident Management System (NIMS), ICS-700

IS-00800.b - National Response Framework, ICS-800

AWR-130 - Incident Response to Terrorist Bombing - Awareness

\section{Work Experience:}

Laboratory Technician Level II at NIOSH in the Evaluation and Testing Branch

Major project responsibilities and leadership roles:

\footnotetext{
Conduct Laboratory Experiments Related To Analytical Research For Stockpile Investigation And Research. I use industry-accepted standards to test and evaluate a variety of personal protective equipment (PPE) such as respirators and isolation gowns worn by healthcare workers. Duties include ensuring the equipment meets manufacturer specifications to successfully perform testing. Operate TSI 8130 Filter Testers for Salt $(\mathrm{NaCl})$ to determination of particulate Filter Efficiency Level for N95, N99, N100 Filters against solid particles. Including the determination of Inhalation Resistance Test, Exhalation Resistance Test, and Exhalation Valve Leakage Test.
} 


\section{Work With Senior Project Officers To Implement Complex Sampling}

Plans. Operate And Maintain All Industrial Equipment For Field Readiness for preparation of field samples from occupationally-exposed workers. Field samples include fire fighter turnout gear and respirators that were involved in a fatality and evaluated as part of NIOSH's Fire Fighter Fatality Investigation Prevention Program (FFFIPP). The equipment must be prepped and ready at all times to prepare for turnout gear and respirator investigations, which are often high-profile and confidential. Regularly follow a chain of custody with evidence and all paperwork in a sensitive manner. All chain of custody evidence must be thoroughly documented upon arrival, signed in and out of the evidence cage, and documentation of its departure. Photo and written documentation is recorded as the package arrives, during the opening of package, and very specific details of the PPE as the visual inspection is completed. Respond to Requests for Information from senior project officers for the PPE evaluation results from the NIOSH FFFIPP. Designed and built new test equipment that allows more efficient and accurate tests to be conducted. Gained competency of laboratory equipment and standard test procedures used for investigations in the FFFIPP including Air Flow test, Rated service time test, positive pressure test, static pressure test, Gas flow test, Remaining service life indicator test (mechanical and electronic), and Exhalation resistance test.

\section{Calibrate Wide-Range Of Industrial Equipment To Ensure Valid}

Measurement Of Data. Calibrate and maintain equipment prior to use of all test devices used for these bench tests. I Follow Property Procedures To Track Laboratory Equipment by keeping detailed logs for each laboratory device and coordinate with manufacturers when calibration is needed by obtaining quotes, preparing appropriate forms, and shipping the equipment. Set up numerous quotes and estimates for purchasing of equipment and testing devices, which involves keeping track of laboratory equipment and its statuses.

Conduct Laboratory Experiments Related To Analytical Research. I use industry-accepted standards to test and evaluate a variety of personal protective equipment (PPE) such as respirators and isolation gowns worn by healthcare workers. Duties include ensuring the equipment meets manufacturer specifications to successfully perform testing. Gained competency in the PPE testing equipment such as Frazier Differential Pressure Air Permeability Tester, Instron Tensile Tester. I have also gained knowledge and experience related to testing according to industry standards for various types of respirators for penetration by synthetic blood according, including calibration of instrument and conditioning of samples.

Follow Established Decontamination Procedures Of Field Samples. As part of the FFFIPP program, I must maintain good safety hygiene practices and follow decontamination and clean up guidelines after testing. I ensure 
appropriate PPE and sufficient ventilation is always used during the visual inspection and testing of PPE. I use procedures of maintaining a clean decontamination process with contaminated units. Having the knowledge of correct PPE is vital in testing contaminated field samples.

Document And Prepare Analyses And Reports Of Study Findings And Test Results. Documenting fire fighter PPE investigations includes taking detailed records on appropriate data sheets, in putting the records into the electronic reports, and taking photographs. After the testing and evaluations are complete, I use the analyses and reports of the findings from the bench tests results and prepare a final report. These reports contain detailed information on the PPE investigations, equipment used, and the findings. I enter the reports into the computer and file the hard copies in appropriate locations. 